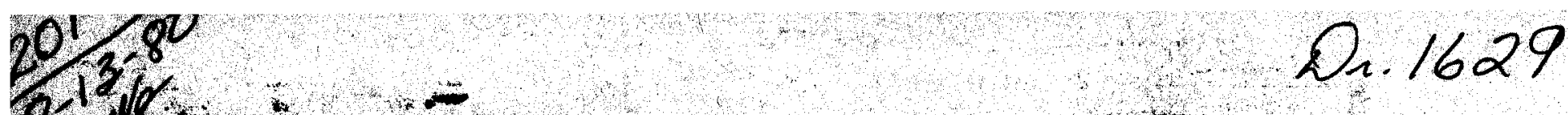

SALE: A SImplifled ALE Computer Program for Fluid Flow dif All Speeds

$\frac{\text { 응 }}{9}$

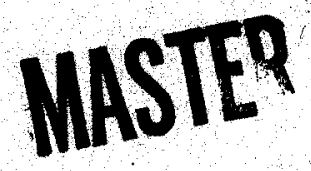

๘

$\geq$

क

$\sum$

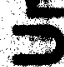




\section{DISCLAIMER}

This report was prepared as an account of work sponsored by an agency of the United States Government. Neither the United States Government nor any agency Thereof, nor any of their employees, makes any warranty, express or implied, or assumes any legal liability or responsibility for the accuracy, completeness, or usefulness of any information, apparatus, product, or process disclosed, or represents that its use would not infringe privately owned rights. Reference herein to any specific commercial product, process, or service by trade name, trademark, manufacturer, or otherwise does not necessarily constitute or imply its endorsement, recommendation, or favoring by the United States Government or any agency thereof. The views and opinions of authors expressed herein do not necessarily state or reflect those of the United States Government or any agency thereof. 


\section{DISCLAIMER}

Portions of this document may be illegible in electronic image products. Images are produced from the best available original document. 


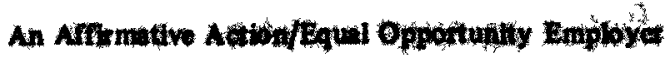

Edited by Karyn Ames

Photocomposition by JoAnn Painter and Joni Powell

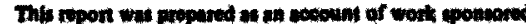

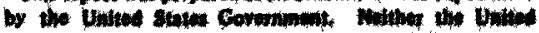

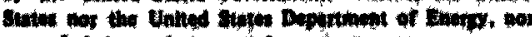

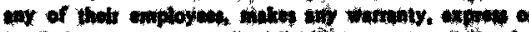

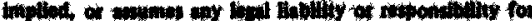

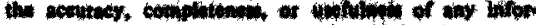

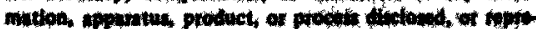

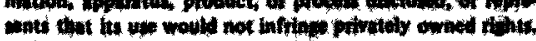

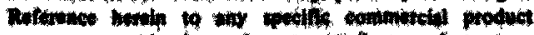

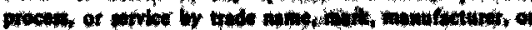

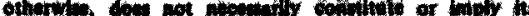

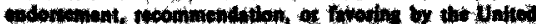

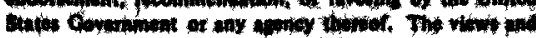

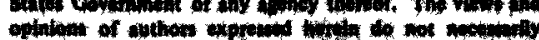

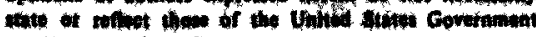
or way gancy thowof

vethen otwat

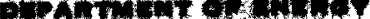

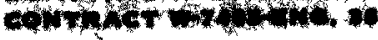




\title{
SALE: A Simplified ALE Computer Program for Fluid Flow at All Speeds
}

\author{
A. A. Amsden \\ H. M. Ruppel \\ C. W. Hirt
}
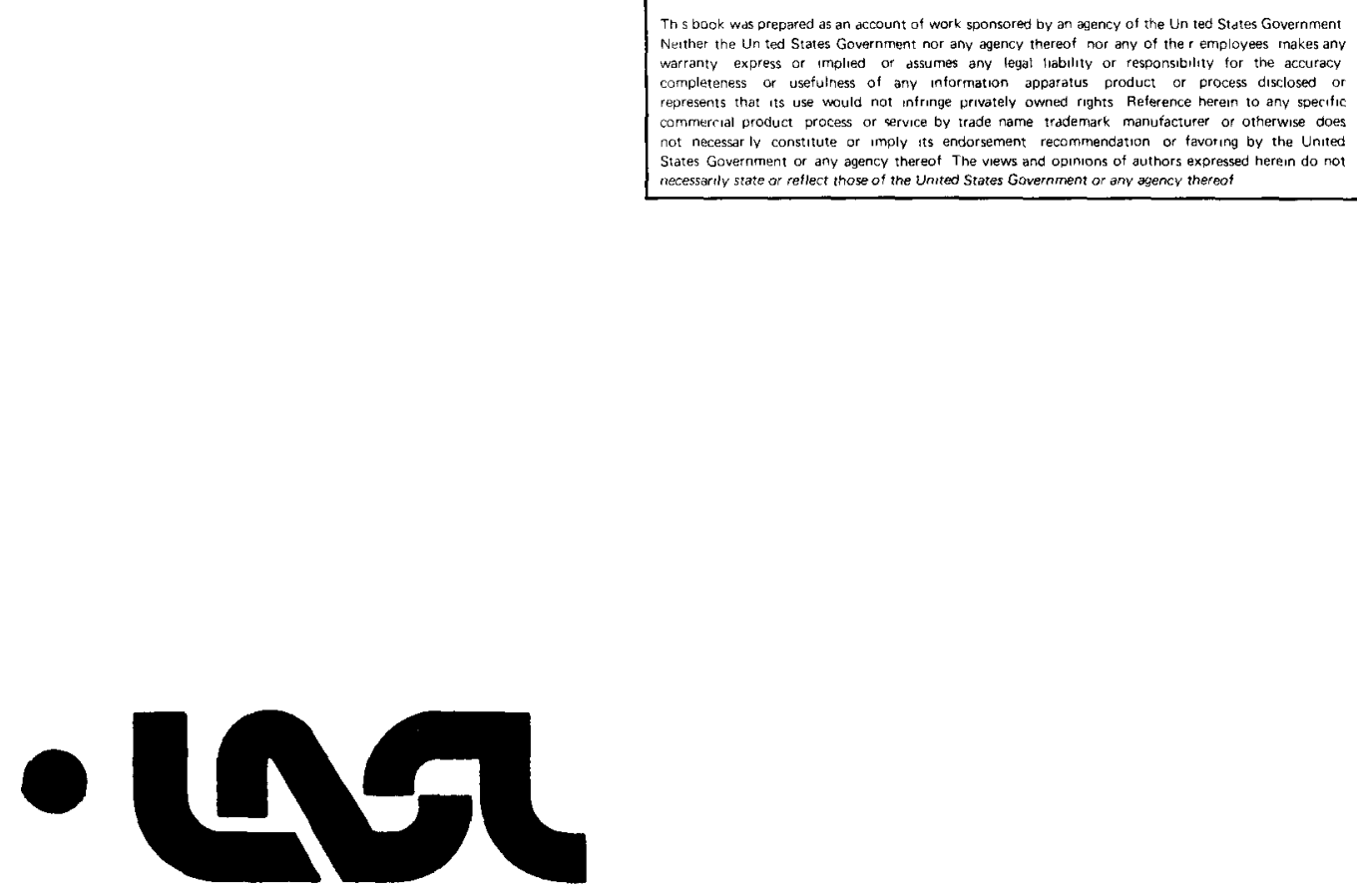


\section{CONTENTS}

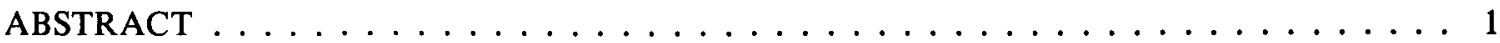

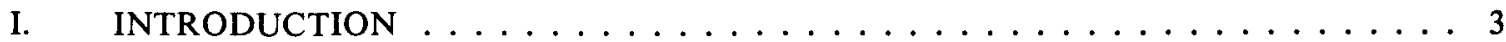

II. THE SALE SOLUTION ALGORITHM $\ldots \ldots \ldots \ldots \ldots \ldots \ldots \ldots$

A. The Three-Phase ICEd-ALE Approach $\ldots \ldots \ldots \ldots \ldots \ldots \ldots \ldots$

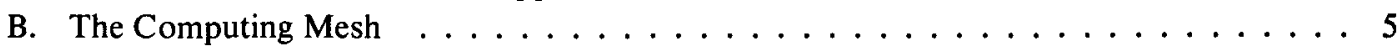

C. Initial Conditions and Preliminary Calculations $\ldots \ldots \ldots \ldots \ldots \ldots \ldots$

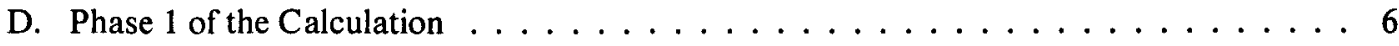

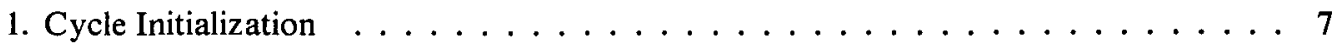

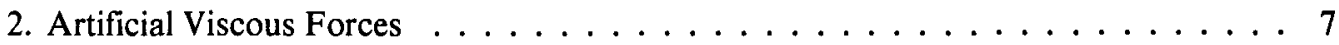

3. Stress Deviator Forces $\ldots \ldots \ldots \ldots \ldots \ldots$

4. Pressure Force Contributions . . . . . . . . . . . . . . . . 10

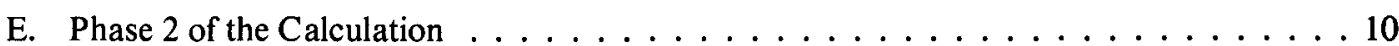

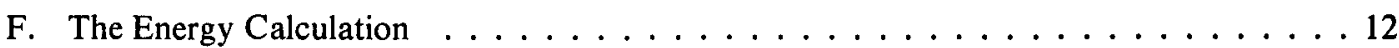

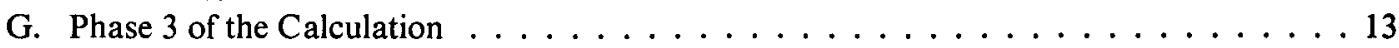

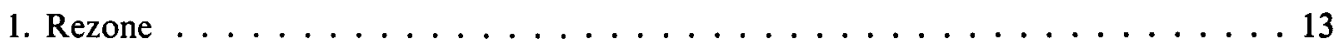

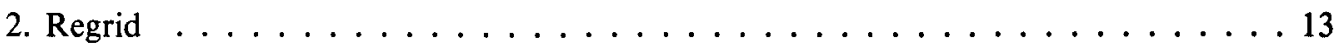

3. Advective Flux of Mass, Energy, and Momentum . . . . . . . . . 13

4. Updating the Vertex Quantities . . . . . . . . . . . . . . . . . . . . 16

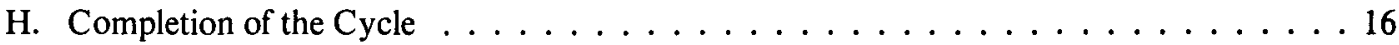

I. Summary of Solution Algorithm $\ldots \ldots \ldots \ldots \ldots$

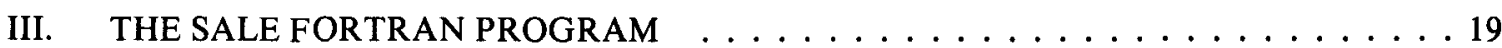

A. General Structure . . . . . . . . . . . . . . . . . . . . 19

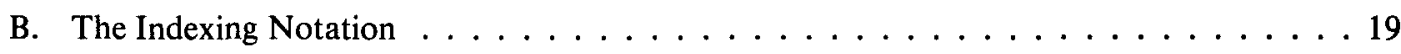

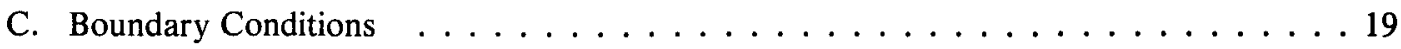

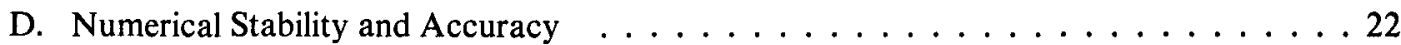

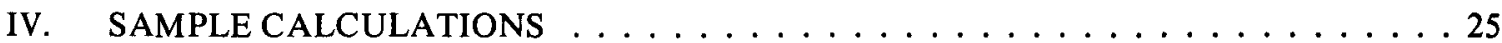

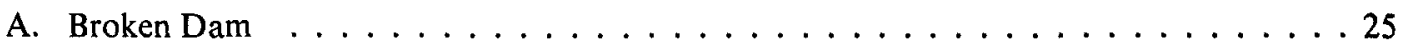

B. One-Dimensional Shock Tube . . . . . . . . . . . . . . . . 27

C. Supersonic Flow Through a Curved Duct $\ldots \ldots \ldots \ldots \ldots \ldots \ldots \ldots \ldots$

D. von Karman Vortex Street . . . . . . . . . . . . . . . . . 30

E. Strong Shock Passing Over a Mercury Drop in Water $\ldots \ldots \ldots \ldots . \ldots . \ldots 33$

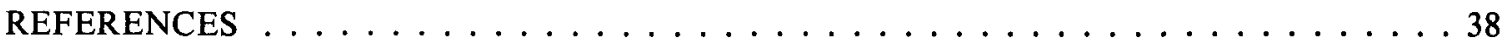

APPENDIX A. FORTRAN LISTING OF THE SALE PROGRAM $\ldots \ldots \ldots \ldots \ldots$

APPENDIX B. SYSTEM SUBROUTINE CALLS IN SALE $\ldots \ldots \ldots \ldots$

APPENDIX C. SAMPLE OUTPUT FROM BROKEN DAM CALCULATION $\ldots \ldots \ldots 1$ 


\title{
SALE: A SIMPLIFIED ALE COMPUTER PROGRAM FOR FLUID FLOW AT ALL SPEEDS
}

\author{
by
}

\author{
A. A. Amsden, H. M. Ruppel, and C. W. Hirt
}

\begin{abstract}
A simplified numerical fluid-dynamics computing technique is presented for calculating two-dimensional fluid flows at all speeds. It combines an implicit treatment of the pressure equation similar to that in the Implicit Continuous-fluid Eulerian (ICE) technique with the grid rezoning philosophy of the Arbitrary Lagrangian-Eulerian (ALE) method. As a result, it can handle flow speeds from supersonic to the incompressible limit in a grid that may be moved with the fluid in typical Lagrangian fashion, or held fixed in an Eulerian manner, or moved in some arbitrary way to give a continuous rezoning capability. The report describes the combined (ICEd-ALE) technique in the framework of the SALE (Simplified ALE) computer program, for which a general flow diagram and complete FORTRAN listing are included. A set of sample problems show how to use or modify the basic code for a variety of applications. Numerical listings are provided for a sample problem run with the SALE program.
\end{abstract}


0 


\section{INTRODUCTION}

Over the past decade, we have witnessed an increasing acceptance of and reliance upon numerical solutions for transient fluid flow problems. In many cases, experimental studies are prohibitively expensive, whereas high-speed computers are comparatively economical and allow a wide range of parameter variations to be examined in a short time. As a result, numerical solution techniques have become more sophisticated and the applications correspondingly more complex.

This report presents a simplified computer program to calculate two-dimensional fluid flows at all speeds, from the incompressible limit to highly supersonic. An implicit treatment of the pressure calculation similar to that in the Implicit Continuous-fluid Eulerian (ICE) technique ${ }^{1}$ provides this flow-speed versatility. In addition, the computing mesh may move with the fluid in a typical Lagrangian fashion, be held fixed in an Eulerian manner, or move in some arbitrarily specified way to provide a continuous rezoning capability. This latitude results from the use of an Arbitrary LagrangianEulerian (ALE) treatment ${ }^{2}$ of the computing mesh. The program is named SALE, for Simplified ALE. The essential features of the ICEd-ALE combination are presented here to make this report a self-contained guide. SALE bears a strong resemblance to YAQUI, the original but more complex ICEd-ALE program. ${ }^{3}$

The partial differential equations solved by the SALE program are the Navier-Stokes equations,

$$
\begin{aligned}
\frac{\partial \rho u}{\partial t} & +\frac{1}{r} \frac{\partial r \rho u^{2}}{\partial x}+\frac{\partial \rho u v}{\partial y} \\
& =-\frac{\partial(p+q)}{\partial x}+\frac{1}{r} \frac{\partial r \pi_{x x}}{\partial x}+\frac{\partial \pi_{x y}}{\partial y}-\frac{\pi_{\theta}}{r}+\rho g_{x}
\end{aligned}
$$$$
\frac{\partial \rho v}{\partial t}+\frac{1}{r} \frac{\partial r \rho u v}{\partial x}+\frac{\partial \rho v^{2}}{\partial y}
$$$$
=-\frac{\partial(p+q)}{\partial y}+\frac{1}{r} \frac{\partial r \pi}{\partial x}+\frac{\partial \pi_{y y}}{\partial y}+\rho g_{y} \text {, }
$$

and the mass and internal energy equations,

$\frac{\partial \rho}{\partial t}+\frac{1}{r} \frac{\partial r \rho u}{\partial x}+\frac{\partial \rho v}{\partial y}=0$,

and

$$
\begin{aligned}
\frac{\partial \rho I}{\partial t}+\frac{1}{r} \frac{\partial r \rho I u}{\partial x}+\frac{\partial \rho I v}{\partial y}= & -(p+q) D+\pi_{x x} \frac{\partial u}{\partial x}+\pi_{x y} \frac{\partial u}{\partial y} \\
& +\frac{u \pi_{\theta}}{I}+\pi_{x y} \frac{\partial v}{\partial x}+\pi_{y y} \frac{\partial v}{\partial y},
\end{aligned}
$$

where $\mathrm{D}$ is the velocity divergence,

$D=\frac{1}{r} \frac{\partial r u}{\partial x}+\frac{\partial v}{\partial y}$

Velocity components $(\mathrm{u}, \mathrm{v})$ are in the Cartesian coordinate directions $(x, y)$ or the cylindrical coordinate directions $(r, z)$. When Cartesian coordinates are desired, all radii $r$, which appear in these equations, are set to unity. The fluid pressure $p$ is determined from an equation of state $p=p(\rho, I)$ and supplemented with an artificial viscous pressure $q$ for the computation of shock waves, where

$q=\lambda_{0} \rho$ Area $D \min (0, D)$.

Artificial pressures are only used in regions of compression $(\mathrm{D}<0)$ and are scaled proportional to the area (Area) of each computational cell, with the constant of proportionality $\lambda_{0}$.

The stress deviator is defined according to

$$
\begin{aligned}
& \pi_{x x}=2 \mu \frac{\partial u}{\partial x}+\lambda D, \\
& \pi_{y y}=2 \mu \frac{\partial v}{\partial y}+\lambda D, \\
& \pi_{\theta}=\operatorname{Cy} 1\left[2 \mu \frac{u}{r}+\lambda D\right],
\end{aligned}
$$


and

$\pi_{x y}=\mu\left(\frac{\partial u}{\partial y}+\frac{\partial v}{\partial x}\right)$,

in which $\mu$ is the coefficient of viscosity and $\lambda$ is the coefficient of dilatational viscosity. The coefficient $\mathrm{Cyl}$ is zero for Cartesian coordinates and unity for cylindrical coordinates.

To facilitate its use by persons with modest experience in numerical fluid dynamics, the SALE program was written in modular form with extensive annotation and input options that provide a wide range of capabilities. In addition, SALE includes several improvements to the original YAQUI scheme that have been made since its publication. We intend that the SALE program serve not only as a useful tool for many applications, but also as a teaching aid and foundation for the development of new programs with expanded capabilities.

The basic solution algorithm for SALE appears in Sec. II of this report. Section III describes the FORTRAN program. We include a general flow diagram showing the logical partitioning of the code into a set of subroutines, each responsible for a clearly definable task. Section IV presents the results of several SALE calculations chosen to illustrate the versatility of the program.

Appendix A contains a FORTRAN listing of SALE that has been liberally annotated with comment cards, beginning with a description of the input parameters, to make it as self-explanatory as possible. Appendix B describes the functions performed by operating system CALLs appearing in SALE. For users who wish to check their results with ours, App. C presents selected plots and prints from the first calculation described in Sec. IV. 


\section{THE SALE SOLUTION ALGORITHM}

\section{A. The Three-Phase ICEd-ALE Approach}

The basic hydrodynamic part of each cycle of SALE is divided into three phases:

(1) Phase 1 is a typical, explicit Lagrangian calculation, in which the velocity field is updated by the effects of all forces.

(2) Phase 2 is a Newton-Raphson iteration that provides time-advanced pressures and velocities. The purpose of Phase 2 is to allow calculations in the low-speed and even completely incompressible regimes. The implicit, iterative scheme makes this possible with greater efficiency than a purely explicit calculation with reduced time step, as it offers a numerically stable means by which pressure signals can traverse more than one cell in a time step.

(3) Phase 3 performs all the advective flux calculations. This phase is required for runs that are Eulerian or contain some other form of mesh rezoning.

A powerful feature of SALE is the ease with which different phases can be combined in various ways to suit the requirements of individual problems. For example, in high-speed applications, an explicit calculation is acceptable, allowing the Phase 2 iteration to be bypassed. For an explicit Lagrangian calculation, only Phase 1 is required. For an implicit Lagrangian calculation, only the first two phases are used. In neither of these two cases are advective flux calculations necessary, and the Phase 1 or 2 results are final results for the cycle. All these options may be selected by appropriately defining the input data (see beginning of code in App. A).

\section{B. The Computing Mesh}

The computing mesh consists of a two-dimensional network of quadrilateral cells for either cylindrical or plane (Cartesian) coordinates. Calculations in cylindrical coordinates are scaled to unit azimuthal angle, which allows the equations to be written without any $\pi$ factors. The radial coordinate is denoted by $\mathbf{r}$ or $\mathbf{x}$, and the axial coordinate by $y$, with the origin located at the lower left corner of the mesh. The coordinate names in the equations are $x$ and $y$. The quantity $r$ is used to determine the geometry: $r$ is set equal to $x$ for cylindrical coordinates, but the expressions automatically reduce to Cartesian form if all $r$ 's are set to unity.

The vertices of the cells are labeled with the indices $i$ and $\mathrm{j}$, which increase in the radial and axial directions, respectively. Cell centers are denoted by half-integer indices $i+1 / 2$ and $j+1 / 2$. The mesh of cells is $N_{x}$ cells wide by $N_{y}$ cells high.

The mesh illustrated in Fig. 1 is in cylindrical coordinates, where the cells are sections of toroids of revolution about the cylindrical axis.

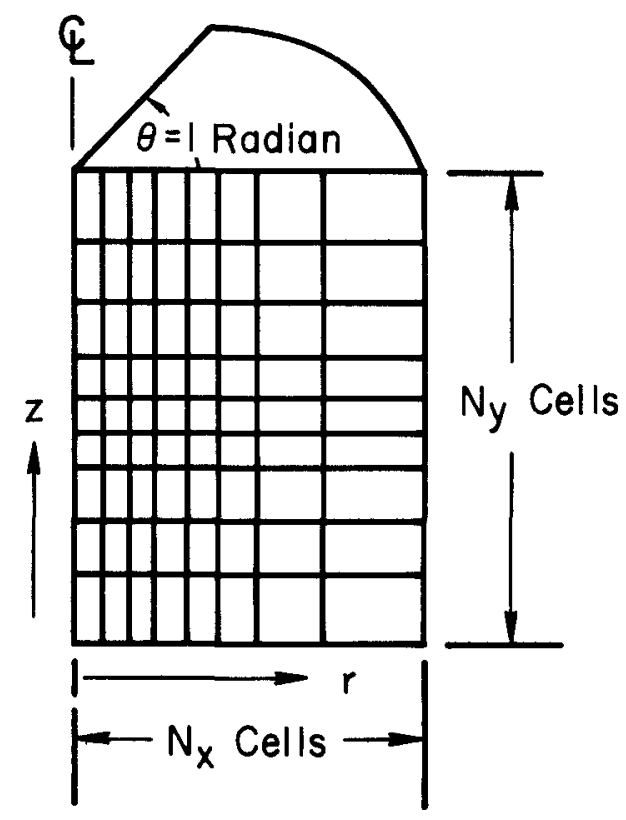

Fig. 1.

A typical SALE mesh in cylindrical coordinates. 


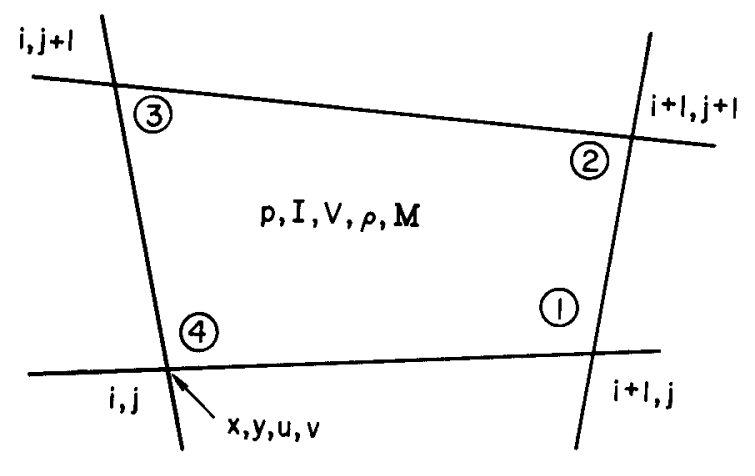

Fig. 2.

The assignment of variables about cell $(i+1 / 2$, $j+1 / 2)$.

The variables in an ICEd-ALE grid are of two types: those defined at vertices and those defined at cell centers. The principal variables are shown in Fig. 2, where coordinates ( $\mathrm{x}$ and $\mathrm{y}$ ) and corresponding velocity components ( $u$ and $v$ ) are defined at vertices. Pressures ( $p$ ), specific internal energies (I), cell volumes $(\mathrm{V})$, densities $(\rho)$, and masses $(M)$ are all assigned at cell centers.

In the equations that follow, the superscript $n$ refers to the beginning-of-cycle values. The advancement of the solution through a time step, of duration $\delta$ t, provides values at the beginning of the next $(n+1)$ cycle. Intermediate values are typically labeled with a subscript $\mathbf{L}$ for the results of Phases 1 or 2.

\section{Initial Conditions and Preliminary Calculations}

The input data supply the initial values of $x, y, u$, and $v$ at the vertices and $\rho$ and $I$ for the cells.

(1) The radius $r$ is calculated as $r=x$ in cylindrical coordinates, or $r=1$ in plane coordinates. The coordinate system is determined by the input parameter CYL, which is equal to 1 for cylindrical coordinates and is equal to zero for plane coordinates. Thus, we write

$r_{i}^{j}=\left(x_{i}^{j}\right) C Y L+1-C Y L \quad$.

(2) Cell volumes per unit azimuthal angle are given by the exact expression $v_{1+\frac{1}{2}}^{j+\frac{1}{2}}=\frac{1}{3}\left[\left(r_{1}+r_{2}+r_{3}\right) A T R+\left(r_{3}+r_{4}+r_{1}\right) A B L\right]$

where

$\operatorname{ATR}=\frac{1}{2}\left[\left(x_{3}-x_{2}\right)\left(y_{1}-y_{2}\right)-\left(x_{1}-x_{2}\right)\left(y_{3}-y_{2}\right)\right]$

and

$A B L=\frac{1}{2}\left[\left(x_{1}-x_{4}\right)\left(y_{3}-y_{4}\right)-\left(x_{3}-x_{4}\right)\left(y_{1}-y_{4}\right)\right]$.

The numerical subscript notation for vertex quantities associated with a given cell is simplified to that shown in Fig. 2. It is used throughout this report and in the SALE code.

(3) With the cell volumes defined, the masses at cell centers can be obtained from the product

$M_{i+\frac{1}{2}}^{j+\frac{1}{2}}=\rho_{i+\frac{1}{2}}^{j+\frac{1}{2}} V_{i+\frac{1}{2}}^{j+\frac{1}{2}}$

but it is also necessary to assign a mass to each vertex to obtain the time-advanced velocities. In SALE, we assume that the mass in each cell is shared equally between its four corner vertices, so vertex 4 in Fig. 2, for example, is given the mass

$M_{4}=\frac{1}{4}\left(M_{1+\frac{1}{2}}^{j+\frac{1}{2}}+M_{1-\frac{1}{2}}^{j+\frac{1}{2}}+M_{i-\frac{1}{2}}^{j-\frac{1}{2}}+M_{1+\frac{1}{2}}^{j-\frac{1}{2}}\right)$.

\section{Phase 1 of the Calculation}

In this phase, velocities are advanced explicitly in time in a purely Lagrangian fashion. If viscous, elastic, or other stresses are desired, they are included in this phase as well. The updating of the specific internal energies is delayed until after the optional implicit pressure calculation of Phase 2. This delay permits time-advanced pressures to be used in computing the pdV work and ensures consistency with the velocities coming out of Phase 2.

The ve'ocities resulting from this Lagrangian calculation phase are denoted by $\left(u_{L}, v_{L}\right)$. Pressure, viscous, and other force contributions are computed in separate subroutines, so that in each case the $\left(u_{L}, v_{L}\right)$ values are progressively updated with each contribution. This updating is started with the beginning-of-cycle values $(u, v)$. 
In the actual code, the order of updating is performed in the following sequence.

1. Cycle Initialization. This routine initializes the $\left(\mathrm{u}_{\mathrm{L}}\right.$, $v_{L}$ ) velocities with the beginning-of-cycle values $(u, v)$. In addition, cell densities $\rho$ and $\rho_{L}$ are calculated as the ratio of the cell mass to cell volume. Cell pressures (p) are calculated using an equation of state $p=f(p, I)$, although the equation of state is bypassed after the setup for implicit calculations, because the pressures resulting from the previous Phase 2 implicit solution generally prove to be a better initial guess for the next cycle iteration than the equation-of-state pressure. In the incompressible limit, we also bypass the equation of state in the setup and set zero pressures at time $t=0$.

2. Artificial Viscous Forces. Here the $\left(u_{L}, v_{L}\right)$ velocities are adjusted for contributions arising from a bulk artificial viscosity and from a coupling between alternate nodes.

a. Artificial Bulk Viscosity. For problems involving shock waves, an artificial pressure $\mathrm{Q}$ must be used to ensure mesh-resolvable shocks. This addition is required because mean kinetic energy is not conserved across a shock wave. Without dissipation, spurious velocity oscillations develop behind the shock to account for an excess of kinetic energy. We include the dissipation as a pressure addition, which models the fact that the pressure change across a shock is more than a simple adiabatic compression.

The viscous pressure used in SALE is quadratic in the velocity divergence, and is only added to cells undergoing compression,

$$
\left.Q_{i}^{j}=\min \left(0, D_{i}^{j}\right)\left[\lambda_{0} \rho_{i}^{j} D_{i}^{j} \text { (Area) }\right)\right] .
$$

In this expression, (Area) is the area of cell $(\mathrm{i}, \mathrm{j})$, so that

$$
\begin{aligned}
(\text { Area }) & =\frac{1}{2}\left[\left(x_{2}-x_{4}\right)\left(y_{3}-y_{1}\right)\right. \\
& \left.-\left(x_{1}-x_{3}\right)\left(y_{4}-y_{2}\right)\right],
\end{aligned}
$$

and $D_{i}^{\prime}$ is its velocity divergence $\nabla \cdot \vec{u}$ defined as

$$
\begin{aligned}
D_{1}^{j} & =\frac{1}{2(\text { Area })}\left[\left(u_{2}-u_{4}\right)\left(y_{3}-y_{1}\right)\right. \\
& -\left(u_{1}-u_{3}\right)\left(y_{4}-y_{2}\right)+\left(v_{4}-v_{2}\right)\left(x_{3}-x_{1}\right) \\
& \left.-\left(v_{1}-v_{3}\right)\left(x_{2}-x_{4}\right)\right]+\frac{u}{r},
\end{aligned}
$$

where

$\frac{u}{r}=\operatorname{cYL}\left(\frac{u_{1}+u_{2}+u_{3}+u_{4}}{r_{1}+r_{2}+r_{3}+r_{4}}\right)$.

The parameter $\lambda_{0}$ in the above expression for $Q_{i}^{j}$ is denoted by ARTVIS in the input data list, and should be less than 0.25 to avoid excessive viscous damping. A value of ARTVIS $=0.1$ has been satisfactory for many applications.

With $Q_{i}^{j}$ calculated, the appropriate contributions to the four vertices of cell $(i, j)$ are

$$
\begin{aligned}
& \left(u_{L}\right)_{1}=u_{1}+\frac{\delta t Q_{1}^{j}}{2 M_{1}} r_{1}\left(y_{2}-y_{4}\right), \\
& \left(u_{L}\right)_{2}=u_{2}+\frac{\delta t Q_{1}^{j}}{2 M_{2}} r_{2}\left(y_{3}-y_{1}\right), \\
& \left(u_{L}\right)_{3}=u_{3}-\frac{\delta t Q_{1}^{j}}{2 M_{3}} r_{3}\left(y_{2}-y_{4}\right), \\
& \left(u_{L}\right)_{4}=u_{4}-\frac{\delta t Q_{1}^{j}}{2 M_{4}} r_{4}\left(y_{3}-y_{1}\right), \\
& \left(v_{L}\right)_{1}=v_{1}-\frac{\delta t Q_{i}^{j}}{4 M_{1}}\left(r_{2}+r_{4}\right)\left(x_{2}-x_{4}\right), \\
& \left(v_{L}\right)_{2}=v_{2}-\frac{\delta t Q_{1}^{j}}{4 M_{2}}\left(r_{1}+r_{3}\right)\left(x_{3}-x_{1}\right), \\
& \left(v_{L}\right)_{3}=v_{3}+\frac{\delta t Q_{1}^{j}}{4 M_{3}}\left(r_{2}+r_{4}\right)\left(x_{2}-x_{4}\right),
\end{aligned}
$$

and

$$
\left(v_{L}\right)_{4}=v_{4}+\frac{\delta t Q_{i}^{j}}{4 M_{4}}\left(r_{1}+r_{3}\right)\left(x_{3}-x_{1}\right) .
$$


The asymmetry in the geometric factors in the above expressions, which also appears in other equations for pressure accelerations, arises from the difference in the effect of the boundary of the control volume on the two directions. Accelerations in the radial direction must include the forces on the ends of the one-radian section of the torus. These contributions do not enter in the axial direction.

b. Alternate Node Coupler. In a Lagrangian calculation using quadrilateral mesh cells, there are certain degenerate mesh deformations that do not result in net pressure or viscous forces. Typically, these deformations are associated with the shortest resolvable wavelengths $(2 \delta x)$ in the mesh. For example, Fig. 3 illustrates two such short-wavelength deformations. Figure 3a shows the bowtie pattern and Fig. 3b shows the herringbone pattern. In each case, the deforming cells undergo no change in volume so that no pressure variations are generated. Also, it is easily verified that no net viscous or elastic strain forces are generated at vertices embedded in the bowtie type of deformation.

Thus, to prevent such deformations from slowly degrading a solution, it is sometimes necessary to couple alternate mesh nodes with a small artificial restoring force. Ideally, this force should affect flows only at the $2 \delta x$ wavelength level, but have no influence on the larger, better resolved flow variations. We introduce small accelerations at each vertex, which are based on the surrounding velocity field and tend to keep the vertex velocities from deviating too strongly from their neighbors.

A fourth-order coupling scheme is effective for the bowtie mode, but a more diffusive second-order scheme must be used for the herringbone pattern. The fourthorder form is given by

$$
\begin{aligned}
u_{1}^{j} & =u_{i}^{j}+\frac{a}{4}\left[2\left(u_{i+1}^{j}+u_{i}^{j+1}+u_{i-1}^{j}+u_{i}^{j-1}\right)\right. \\
& -u_{i+1}^{j+1}-u_{1-1}^{j+1}-u_{i-1}^{j-1} \\
& \left.-u_{1+1}^{j-1}-4 u_{i}^{j}\right],
\end{aligned}
$$

in which $a_{n c}$ is a coefficient that governs the amount of coupling and implies a relaxation time of $\mathrm{a}_{\mathrm{nc}}^{-1}$ time steps.

The second-order form is given by

$u_{i}^{j}=u_{i}^{j}+\frac{a_{n c}}{4}\left[\left(u_{i+1}^{j}+u_{1}^{j+1}+u_{i-1}^{j}+u_{1}^{j-1}\right)-4 u_{1}^{j}\right]$.

In SALE, we combine both of these forms in the following set of expressions, in which $\xi=1$ results in the fourth-order form and $\xi=0$ results in the second-order form. Also, rather than sweeping vertices to make the contributions, we may equivalently sweep over cells and adjust the four vertices of each cell, such that

$$
\begin{aligned}
& \left(u_{L}\right)_{1}=\left(u_{L}\right)_{1}+\frac{a_{n c}}{4}\left[\left(\frac{1+\xi}{2}\right)\left(u_{2}+u_{4}\right)-\xi u_{3}-u_{1}\right], \\
& \left(u_{L}\right)_{2}=\left(u_{L}\right)_{2}+\frac{a n c}{4}\left[\left(\frac{1+\xi}{2}\right)\left(u_{3}+u_{1}\right)-\xi u_{4}-u_{2}\right], \\
& \left(u_{L}\right)_{3}=\left(u_{L}\right)_{3}+\frac{a n c}{4}\left[\left(\frac{1+\xi}{2}\right)\left(u_{4}+u_{2}\right)-\xi u_{1}-u_{3}\right],
\end{aligned}
$$

and

$\left(u_{L}\right)_{4}=\left(u_{L}\right)_{4}+\frac{a_{n c}}{4}\left[\left(\frac{1+\xi}{2}\right)\left(u_{1}+u_{3}\right)-\xi u_{2}-u_{4}\right]$.

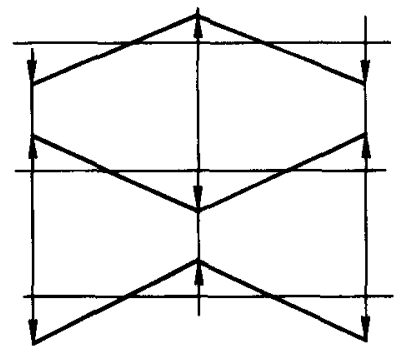

(a)

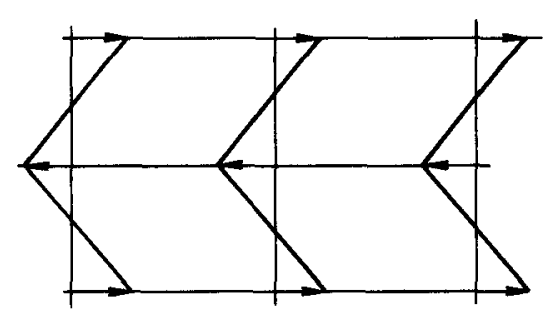

(b)
Fig. 3.

Two types of instabilities between adjacent nodes: (a) bowtie, (b) herringbone. 
Corresponding expressions are used for the y direction, with every $u$ or $u_{L}$ replaced by $v$ or $v_{L}$. Note that contributions at vertices on reflective boundaries must be doubled to obtain the correct value. This is necessary here because these artificial accelerations have been defined without reference to vertex masses. In the case of all other forces, no corrections are needed for boundary vertices, because the omission of force contributions from cells on the outside of a boundary is compensated for by a corresponding omission in vertex mass.

We emphasize that node coupling is diffusive and nonphysical and should be used with discretion. In a spherical expansion, for example, the smoothing effect of too much node coupling adversely affects the sphericity. To avoid its unintentional use, we require the SALE user to supply values for $\xi$ and $a_{n c}$ in the input data. Rarely should $a_{n c}$ exceed 0.05 .

3. Stress Deviator Forces. At this point, the shear viscosity $(\mu)$ and bulk viscosity $(\lambda)$ contributions are added, if either is specified, in terms of a stress deviator force. (This would also be the appropriate place to add material strength effects. These effects, however, have not been included in this version of SALE.)

For each cell, we define the divergence $D=\nabla \cdot \vec{u}$ as in step 1 above, and the four components of the viscous stress tensor as

$$
\begin{aligned}
& \Pi_{x x}=2 \mu \frac{\partial u}{\partial x}+\lambda \nabla \cdot \vec{u}, \\
& \pi_{y y}=2 \mu \frac{\partial v}{\partial y}+\lambda \nabla \cdot \vec{u}, \\
& \Pi_{x y}=\mu\left(\frac{\partial u}{\partial y}+\frac{\partial v}{\partial x}\right),
\end{aligned}
$$

and

$$
\Pi_{\theta}=\operatorname{crL}\left[2 \mu\left(\frac{u}{r}\right)+\lambda \nabla \cdot \vec{u}\right],
$$

where $u / r$ is defined as in Eq. (6). The finite difference expressions to compute these quantities are

$$
\begin{aligned}
\frac{\partial u}{\partial x} & =\frac{1}{2(\text { Area })}\left[\left(u_{2}-u_{4}\right)\left(y_{3}-y_{1}\right)\right. \\
& \left.-\left(u_{3}-u_{1}\right)\left(y_{2}-y_{4}\right)\right],
\end{aligned}
$$

$$
\begin{aligned}
\frac{\partial v}{\partial x} & =\frac{1}{2 \text { (Area) }}\left[\left(v_{2}-v_{4}\right)\left(y_{3}-y_{1}\right)\right. \\
& \left.-\left(v_{3}-v_{1}\right)\left(y_{2}-y_{4}\right)\right], \\
\frac{\partial u}{\partial y} & =\frac{1}{2(\text { Area })}\left[\left(u_{3}-u_{1}\right)\left(x_{2}-x_{4}\right)\right. \\
& \left.-\left(u_{2}-u_{4}\right)\left(x_{3}-x_{1}\right)\right],
\end{aligned}
$$

and

$$
\begin{aligned}
\frac{\partial v}{\partial y} & =\frac{1}{2(\text { Area })}\left[\left(v_{3}-v_{1}\right)\left(x_{2}-x_{4}\right)\right. \\
& \left.-\left(v_{2}-v_{4}\right)\left(x_{3}-x_{1}\right)\right]
\end{aligned}
$$

Stress deviator contributions to the vertex velocities are

$$
\begin{aligned}
\left(u_{L}\right)_{1} & =\left(u_{L}\right)_{1}+\frac{\delta t}{4 M_{1}}\left(r_{2}+r_{4}\right)\left[\pi_{x y}\left(x_{2}-x_{4}\right)\right. \\
& \left.-\pi_{x x}\left(y_{2}-y_{4}\right)-\frac{\text { Area }}{2} \Pi_{\theta}\right],
\end{aligned}
$$$$
\left(u_{L}\right)_{2}=\left(u_{L}\right)_{2}+\frac{\delta t}{4 M_{2}}\left(r_{1}+r_{3}\right)\left[\Pi_{x y}\left(x_{3}-x_{1}\right)\right.
$$$$
\left.-\Pi_{x x}\left(y_{3}-y_{1}\right)-\frac{\text { Area }}{2} \Gamma_{\theta}\right] \text {, }
$$$$
\left(u_{L}\right)_{3}=\left(u_{L}\right)_{3}-\frac{\delta t}{4 M_{3}}\left(r_{2}+r_{4}\right)\left[\Pi_{x y}\left(x_{2}-x_{4}\right)\right.
$$$$
\left.-I_{x x}\left(y_{2}-y_{4}\right)+\frac{\text { Area }}{2} \Pi_{\theta}\right] \text {, }
$$$$
\left(u_{L}\right)_{4}=\left(u_{L}\right)_{4}-\frac{\delta t}{4 M_{4}}\left(r_{1}+r_{3}\right)\left[\Pi_{x y}\left(x_{3}-x_{1}\right)\right.
$$$$
\left.-\pi_{x x}\left(y_{3}-y_{1}\right)+\frac{\text { Area }}{2} \pi_{\theta}\right] \text {, }
$$

$\left(v_{L}\right)_{1}=\left(v_{L}\right)_{1}+\frac{\delta t}{4 M_{1}}\left(x_{2}+r_{4}\right)\left[\pi_{y y}\left(x_{2}-x_{4}\right)\right.$

$$
\left.-\pi_{x y}\left(y_{2}-y_{4}\right)\right],
$$




$$
\begin{aligned}
\left(v_{L}\right)_{2} & =\left(v_{L}\right)_{2}+\frac{\delta t}{4 M_{2}}\left(r_{1}+r_{3}\right)\left[\pi_{y y}\left(x_{3}-x_{1}\right)\right. \\
& \left.-\pi_{x y}\left(y_{3}-y_{1}\right)\right], \\
\left(v_{L}\right)_{3} & =\left(v_{L}\right)_{3}-\frac{\delta t}{4 M_{3}}\left(r_{2}+r_{4}\right)\left[\pi_{y y}\left(x_{2}-x_{4}\right)\right. \\
& \left.-\Pi_{x y}\left(y_{2}-y_{4}\right)\right],
\end{aligned}
$$

and

$$
\begin{aligned}
\left(v_{L}\right)_{4} & =\left(v_{L}\right)_{4}-\frac{\delta t}{4 M_{4}}\left(r_{1}+r_{3}\right)\left[\pi_{y y}\left(x_{3}-x_{1}\right)\right. \\
& \left.-\pi_{x y}\left(y_{3}-y_{1}\right)\right] .
\end{aligned}
$$

The $\Pi$ terms are stored for later inclusion in the internal energy.

4. Pressure Force Contributions. The principal contribution to the velocities in Phase 1 comes from the pressure forces and body forces acting on the vertices.

a. Pressure Accelerations. The difference approximations used for the pressure accelerations are

$$
\begin{aligned}
& \left(u_{L}\right)_{1}=\left(u_{L}\right)_{1}+\frac{\delta t}{2 M_{1}} p_{i}^{j} r_{1}\left(y_{2}-y_{4}\right), \\
& \left(u_{L}\right)_{2}=\left(u_{L}\right)_{2}+\frac{\delta t}{2 M_{2}} p_{i}^{j} r_{2}\left(y_{3}-y_{1}\right), \\
& \left(u_{L}\right)_{3}=\left(u_{L}\right)_{3}-\frac{\delta t}{2 M_{3}} p_{i}^{j} r_{3}\left(y_{2}-y_{4}\right), \\
& \left(u_{L}\right)_{4}=\left(u_{L}\right)_{4}-\frac{\delta t}{2 M_{4}} p_{i}^{j} r_{4}\left(y_{3}-y_{1}\right), \\
& \left(v_{L}\right)_{1}=\left(v_{L}\right)_{1}-\frac{\delta t}{4 M_{1}} p_{1}^{j}\left(r_{2}+r_{4}\right)\left(x_{2}-x_{4}\right), \\
& \left(v_{L}\right)_{2}=\left(v_{L}\right)_{2}-\frac{\delta t}{4 M_{2}} p_{1}^{j}\left(r_{1}+r_{3}\right)\left(x_{3}-x_{1}\right), \\
& \left(v_{L}\right)_{3}=\left(v_{L}\right)_{3}+\frac{\delta t}{4 M_{3}} p_{1}^{j}\left(r_{2}+r_{4}\right)\left(x_{2}-x_{4}\right),
\end{aligned}
$$

and
$\left(v_{L}\right)_{4}=\left(v_{L}\right)_{4}+\frac{\delta t}{4 M_{4}} p_{i}^{j}\left(r_{1}+r_{3}\right)\left(x_{3}-x_{1}\right)$.

b. Body Accelerations. Finally, any desired body accelerations, such as those arising from gravitational effects, are added to the velocities. For example,

$\left(u_{L}\right)_{i}^{j}=\left(u_{L}\right)_{i}^{j}+\delta g_{x}$

and

$\left(v_{L}\right)_{i}^{j}=\left(v_{L}\right)_{i}^{j}+\delta t_{y}$

\section{E. Phase 2 of the Calculation}

Phase 2 provides an implicit treatment required to eliminate Courant-like time step restrictions that would otherwise be required to ensure computational stability in low-speed or incompressible flows. This phase can be bypassed entirely when an explicit calculation will suffice. The purpose of the implicit treatment in Phase 2 is to obtain a velocity field that has been accelerated by time-advanced pressure gradients. The time-advanced pressures, in turn, depend upon the densities and energies obtained when vertices are moved with these new velocities, but because these are functions of the new pressures, the pressures are by definition implicit and are in general best determined by iteration. Our implicit approach is formulated as follows. With the subscript $L$ again denoting time-advanced values, the desired pressure $p_{L}$ of cell $(i, j)$ will be the solution of

$\left(P_{L}\right)_{i}^{j}=f\left[\left(\rho_{L}\right)_{i}^{j},\left(I_{L}\right)_{i}^{j}\right]$,

where the new cell density and energy are approximated in terms of their initial values as

$$
\left(\rho_{L}\right)_{i}^{j}=\rho_{i}^{j}(v / V *)_{i}^{j}
$$

and

$\left(I_{L}\right)_{1}^{j}=I_{1}^{j}+\left(P_{L}\right)_{1}^{j}(1-V * / V) /\left(\rho_{L}\right)_{1}^{j}$. 
$\mathrm{V}$ is the volume of the cell at time $\mathrm{n}$, and $\mathrm{V}^{*}$ is the volume the cell would have if its vertices were moved according to the current Lagrangian velocity field,

$$
x_{i}^{*}=x_{1}+\left(u_{L}\right)_{1} \delta t, y_{1}^{*}=y_{1}+\left(v_{L}\right)_{1} \delta t, \ldots
$$

A solution for $\mathrm{p}_{\mathrm{L}}$ is obtained by applying a NewtonRaphson iteration, for which the Phase 1 velocities $\left(\mathrm{u}_{\mathrm{L}}, \mathrm{v}_{\mathrm{L}}\right)$ are used as initial guesses. The iteration consists of sweeping through the mesh and applying the following adjustments to each cell, once each sweep:

(1) Compute $V^{*}$ using the most updated values for $\left(\mathrm{u}_{\mathrm{L}}, \mathrm{v}_{\mathrm{L}}\right)$

(2) Compute new guesses for $\rho_{L}, I_{L}$, and $p_{L}$ from the above equations; and

(3) Compute a pressure change $\delta p$, according to

$$
\delta p=-\frac{p_{L}-f\left(\rho_{L}, I_{L}\right)}{S},
$$

where the most updated values are used for $p_{L}, \rho_{L}$, and $I_{L}$, and $S^{-1}$ is a relaxation factor to be described below.

(4) Adjust the current guess for $p_{L}$ by adding $\delta p$ to it;

(5) Adjust the velocities at the vertices of the cell to include this pressure change:

$$
\begin{aligned}
& \left(u_{L}\right)_{1}=\left(u_{L}\right)_{1}+\frac{\delta t \delta p}{2 M_{1}} r_{1}\left(y_{2}-y_{4}\right), \\
& \left(u_{L}\right)_{2}=\left(u_{L}\right)_{2}+\frac{\delta t \delta p}{2 M_{2}} r_{2}\left(y_{3}-y_{1}\right), \\
& \left(u_{L}\right)_{3}=\left(u_{L}\right)_{3}-\frac{\delta t \delta p}{2 M_{3}} r_{3}\left(y_{2}-y_{4}\right), \\
& \left(u_{L}\right)_{4}=\left(u_{L}\right)_{4}-\frac{\delta t \delta p}{2 M_{4}} r_{4}\left(y_{3}-y_{1}\right), \\
& \left(v_{L}\right)_{1}=\left(v_{L}\right)_{1}-\frac{\delta t \delta p}{4 M_{1}}\left(r_{2}+r_{4}\right)\left(x_{2}-x_{4}\right), \\
& \left(v_{L}\right)_{2}=\left(v_{L}\right)_{2}-\frac{\delta t \delta p}{4 M_{2}}\left(r_{1}+r_{3}\right)\left(x_{3}-x_{1}\right), \\
& \left(v_{L}\right)_{3}=\left(v_{L}\right)_{3}+\frac{\delta t \delta p}{4 M_{3}}\left(r_{2}+r_{4}\right)\left(x_{2}-x_{4}\right),
\end{aligned}
$$

and

$$
\left(v_{L}\right)_{4}=\left(v_{L}\right)_{4}+\frac{\delta t \delta p}{4 M_{4}}\left(r_{1}+r_{3}\right)\left(x_{3}-x_{1}\right) .
$$

The mesh is repeatedly swept and steps (1) through (5) are preformed once for each cell each sweep, until no cell exhibits a pressure change violating the inequality

$\frac{|\delta p|}{\left|P_{\max }\right|}<\varepsilon \quad$,

where $p_{\max }$ is the actual or an estimated maximum pressure in the mesh and $\varepsilon$ is an input number (EPS), typically of order $10^{-4}$.

The quantity $S$ used in step (3) must be chosen to keep the pressure changes bounded and progressing in the right direction. In the Newton-Raphson procedure, $\mathrm{S}$ is the derivative of the function whose root is sought with respect to $p$, the iteration variable. Here, $S$ is the rate at which the quantity $p-f(p, I)$ changes as the variable $p$ changes, and is computed numerically using the same relations outlined above. For this purpose, a small pressure change $\Delta p$ is chosen, scaled to the calculation;

$\Delta p=\frac{1}{\delta t^{2}}\left[\frac{p_{\varepsilon} \rho}{2\left(\frac{1}{\delta x^{2}}+\frac{1}{\delta y^{2}}\right)}\right]$.

Here, $\rho$ is a typical fluid density at time $t=0$, and $p_{\varepsilon}$ is an input quantity (PEPS), typically $10^{-4}$. The velocity changes that would be induced by $\Delta p$ are used to compute the corresponding volume, energy, and density changes, and from them a new pressure. Finally, $S$ is determined from the difference between $p-f(p, I)$, evaluated before and after the small change in pressure, and divided by $\Delta \mathrm{p}$. The resulting values for $\mathrm{S}^{-1}$ are multiplied by an optional over-relaxation coefficient, input as $\mathrm{OM}$, and stored for each cell before the iteration is begun. These quantities are not recomputed during the iteration.

The above procedure works well across a broad range of low-speed flow applications, but in the incompressible limit, the procedure is modified. The reason for this is that the method is then excessively sensitive to volume changes. In this case, we replace $p=f(p, I)$ with

$p=p_{L}+\frac{p_{L}}{\rho}-1$ 
which effectively holds the densities constant and results in much faster iteration convergence. Corresponding expressions are used for the evaluation of $S$.

It should be noted that the densities and internal energies calculated in the pressure iteration are temporary quantities used only to update the pressure. To ensure exact mass conservation, the final new densities are computed in Phase 3 after the cell masses and volumes have been calculated. The internal energy is also recalculated with time-centered volume changes, which conserves internal energy, and viscous contributions are then included.

In some cases, when the pressure iteration does not converge within several hundred iterations, it is still possible to continue a calculation without serious error. Usually this only happens when the incompressible option is used. For example, a poor initial guess for velocities or pressures may require a high number of iterations to relax to an acceptable solution. In such cases, the code automatically terminates the iteration, continues the cycle, and then proceeds on to the next cycle and repeats this process up to 10 times. The code aborts if the pressure iteration still has not converged after 10 cycles.

The Phase 1 and 2 calculations as outlined above comprise an implicit Lagrangian method stable for any Courant number, and allow calculations at all values of sound speed vs fluid speed.

\section{F. The Energy Calculation}

The pressure work and viscous dissipation contributions to internal energy are calculated next. The pressures used in the work expression are those resulting from the Phase 2 iteration when the implicit option is used. In the case of explicit calculations, the pressures used are those coming from the equation of state at the beginning of each cycle.

The equation for the change in internal energy in a cycle is

$I_{i}^{j}=I_{i}^{j}-\frac{\delta t}{2 M_{i}^{j}}\left[\left(P_{i}^{j}+Q_{i}^{j}\right) \frac{d V}{d t}+\frac{d V I S}{d t}\right]$.

Both the $d V / d t$ and $d V I S / d t$ quantities are in timecentered form, using averages of beginning-of-cycle and current velocities, for example
$\left(u_{T C}\right)_{1}=\frac{1}{2}\left[u_{1}+\left(u_{L}\right)_{1}\right]$

and

$\left(v_{T C}\right)_{1}=\frac{1}{2}\left[v_{1}+\left(v_{L}\right)_{1}\right], \ldots$

With this definition,

$$
\begin{aligned}
\frac{d V}{d t} & =\left(y_{2}-y_{4}\right)\left[r_{1}\left(u_{T C}\right)_{1}-r_{3}\left(u_{T C}\right)_{3}\right] \\
& +\left(y_{3}-y_{1}\right)\left[r_{2}\left(u_{T C}\right)_{2}-r_{4}\left(u_{T C}\right)_{4}\right] \\
& -\frac{1}{2}\left(r_{2}+r_{4}\right)\left(x_{2}-x_{4}\right)\left[\left(v_{T C}\right)_{1}-\left(v_{T C}\right)_{3}\right] \\
& -\frac{1}{2}\left(r_{1}+r_{3}\right)\left(x_{3}-x_{1}\right)\left[\left(v_{T C}\right)_{2}-\left(v_{T C}\right)_{4}\right]
\end{aligned}
$$

and

$$
\begin{aligned}
& \frac{d V I S}{d t}=\frac{1}{2}\left(x_{2}+r_{4}\right)\left[\pi_{x y}\left(x_{2}-x_{4}\right)\right. \\
& \left.-\Pi_{x x}\left(y_{2}-y_{4}\right)\right]\left[\left(u_{T C}\right)_{1}-\left(u_{T C}\right)_{3}\right] \\
& +\frac{1}{2}\left(r_{1}+r_{3}\right)\left[\pi_{x y}\left(x_{3}-x_{1}\right)\right. \\
& \left.-\pi_{x x}\left(y_{3}-y_{1}\right)\right]\left[\left(u_{T C}\right)_{2}-\left(u_{T C}\right)_{4}\right] \\
& -\frac{1}{2}\left(\pi_{\theta} A r e a\right)\left[\left(u_{T C}\right)_{1}+\left(u_{T C}\right)_{2}+\left(u_{T C}\right)_{3}+\left(u_{T C}\right)_{4}\right] \\
& +\frac{1}{2}\left(r_{2}+r_{4}\right)\left[\pi_{y y}\left(x_{2}-x_{4}\right)\right. \\
& \left.-\pi_{x y}\left(y_{2}-y_{4}\right)\right]\left[\left(v_{T C}\right)_{1}-\left(v_{T C}\right)_{3}\right] \\
& +\frac{1}{2}\left(r_{1}+r_{3}\right)\left[\pi_{y y}\left(x_{3}-x_{1}\right)\right. \\
& \left.-\pi_{x y}\left(y_{3}-y_{1}\right)\right]\left[\left(v_{T C}\right)_{2}-\left(v_{T C}\right)_{4}\right] .
\end{aligned}
$$

The four $\Pi$ terms were evaluated in the Phase 1 stress deviator calculation using Eq. (9) and stored for each cell for use here. In addition, the artificial viscous pressure $Q$ was saved from Phase 1, Eq. (4). 


\section{G. Phase 3 of the Calculation}

1. Rezone. When large fluid distortions are not expected, a purely Lagrangian approach will suffice, allowing the computing grid to follow the fluid motion exactly. In many cases, however, large fluid motions would create devastating effects, contorting cells to extreme aspect ratios or even turning cells inside out. It is often possible to ameliorate these effects by moving the mesh vertices with respect to the fluid so as to maintain a reasonable mesh structure. Whenever a vertex is moved relative to the fluid, however, there must be an exchange of material among the cells surrounding the vertex. SALE allows a broad spectrum of rezoning possibilities by treating this material exchange as an advective flux. The simplest case is that of a purely Eulerian flow, in which the vertices are moved back to their original positions every cycle. Between this extreme and the Lagrangian extreme lies whatever form of continuous or discrete rezoning the user wishes.

This latitude is made possible by defining a set of grid vertex velocities $\left(u_{G}, v_{G}\right)$ over the entire mesh. For a purely Lagrangian calculation, $\mathrm{u}_{\mathrm{G}} \equiv \mathrm{u}_{\mathrm{L}}$ and $\mathrm{v}_{\mathrm{G}} \equiv \mathrm{v}_{\mathrm{L}}$ everywhere. For a purely Eulerian calculation, $u_{G} \equiv 0$ and $\mathrm{v}_{\mathrm{G}} \equiv 0$. For a continuous rezone that approximates a Lagrangian calculation, but minimizes excessive grid distortions, grid velocities are chosen to lie somewhere between these two extremes. In particular, the vertices are moved according to some relaxation rate to place vertices at the average position of the neighboring vertices. This usually maintains cells of reasonable size and proportion throughout a run. Once a set of grid velocities $u_{G}$ and $v_{G}$ have been defined, it is a simple matter to construct the new grid and perform whatever advective flux calculations that may be required.

SALE could also be modified to have a discontinuous rezone capability in this Phase of a cycle. For example, grid quantities could be interpolated onto another grid whenever distortions are excessive.

2. Regrid. In this step, the vertices are moved to new locations as specified by $\left(\mathrm{u}_{\mathrm{G}}, \mathrm{v}_{\mathrm{G}}\right)$ :

$$
\begin{aligned}
& x_{i}^{j}=x_{i}^{j}+\delta t\left(u_{G}\right)_{i}^{j}, \\
& y_{i}^{j}=y_{i}^{j}+\delta t\left(v_{G}\right)_{i}^{j},
\end{aligned}
$$

and

$$
r_{i}^{j}=\left(x_{i}^{j}\right) C Y L+1-C Y L
$$

We next form a set of relative velocities $\left(u_{R E L}, v_{R E L}\right)$ to simplify the later task of calculating advective fluxes. For this purpose, the vertex velocities with respect to the fluid are

$$
\left(u_{R E L}\right)_{i}^{j}=\left(u_{G}\right)_{i}^{j}-\left(u_{L}\right)_{i}^{j}
$$

and

$\left(v_{R E L}\right)_{i}^{j}=\left(v_{G}\right)_{i}^{j}-\left(v_{L}\right)_{i}^{j}$

New cell volumes ${ }^{n+1} \mathrm{~V}$ are calculated from the new coordinates using Eq. (1), and replace the ${ }^{\mathrm{n}} \mathrm{V}$ values in storage.

3. Advective Flux of Mass, Energy, and Momentum. This step is bypassed completely for a purely Lagrangian calculation. In all other cases the relative velocities are not zero, and we must calculate the flux of mass, energy, and momentum between cells.

The flux calculation is performed on a cell-by-cell basis. For every cell, we calculate the volume swept out by each of the four faces relative to their Lagrangian positions.

a. To calculate these volumes, it is necessary to first form the Lagrangian coordinates $\left(x_{p}, x_{p}\right)$ given by

$$
\begin{aligned}
& \left(x_{p}\right)_{1}=x_{1}-\left(u_{R E L}\right)_{1} \delta t, \\
& \left(y_{p}\right)_{1}=y_{1}-\left(v_{R E L}\right)_{1} \delta t,
\end{aligned}
$$

and

$\left(r_{p}\right)_{1}=\left(x_{p}\right)_{1} C Y L+1-C Y L, \ldots$.

b. Then the four volumes for the right, top, left, and bottom sides are proportional to 


$$
\begin{aligned}
& F R=\frac{1}{12}\left[( r _ { 1 } + ( r _ { p } ) _ { 1 } + ( r _ { p } ) _ { 2 } ] \left\{x_{1}\left[\left(y_{p}\right)_{2}-\left(y_{p}\right)_{1}\right]\right.\right. \\
& +\left(x_{p}\right)_{1}\left[y_{1}-\left(y_{p}\right)_{2}\right] \\
& \left.+\left(x_{p}\right)_{2}\left[\left(y_{p}\right)_{1}-y_{1}\right]\right\} \\
& +\left[r_{1}+r_{2}+\left(r_{p}\right)_{2}\right]\left\{x_{1}\left[y_{2}-\left(y_{p}\right)_{2}\right]\right. \\
& +x_{2}\left[\left(y_{p}\right)_{2}-y_{1}\right] \\
& \left.\left.+\left(x_{p}\right)_{2}\left[y_{1}-y_{2}\right]\right\}\right), \\
& F T=\frac{1}{12}\left([ ( r _ { p } ) _ { 2 } + r _ { 3 } + ( r _ { p } ) _ { 3 } ] \left\{\left(x_{p}\right)_{2}\left[y_{3}-\left(y_{p}\right)_{3}\right]\right.\right. \\
& +x_{3}\left[\left(y_{p}\right)_{3}-\left(y_{p}\right)_{2}\right] \\
& \left.+\left(x_{p}\right)_{3}\left[\left(y_{p}\right)_{2}-y_{3}\right]\right\} \\
& +\left[r_{2}+\left(r_{p}\right)_{2}+r_{3}\right]\left\{x_{2}\left[y_{3}-\left(y_{p}\right)_{2}\right]\right. \\
& +\left(x_{p}\right)_{2}\left[y_{2}-y_{3}\right] \\
& \left.\left.+x_{3}\left[\left(y_{p}\right)_{2}-y_{2}\right]\right\}\right) \text {, } \\
& F L=\frac{1}{12}\left([ ( r _ { p } ) _ { 3 } + r _ { 4 } + ( r _ { p } ) _ { 4 } ] \left[\left(x_{p}\right)_{3}\left[y_{4}-\left(y_{p}\right)_{4}\right]\right.\right. \\
& +x_{4}\left[\left(y_{p}\right)_{4}-\left(y_{p}\right)_{3}\right] \\
& \left.+\left(x_{p}\right)_{4}\left[\left(y_{p}\right)_{3}-y_{4}\right]\right] \\
& +\left[r_{3}+\left(r_{p}\right)_{3}+r_{4}\right]\left\{x_{3}\left[y_{4}-\left(y_{p}\right)_{3}\right]\right. \\
& +\left(x_{p}\right)_{3}\left[y_{3}-y_{4}\right] \\
& \left.\left.+x_{4}\left[\left(y_{p}\right)_{3}-y_{3}\right]\right\}\right) \text {, }
\end{aligned}
$$

and

$$
F B=\frac{1}{12}\left(\left(x_{1}+\left(x_{p}\right)_{1}+\left(r_{p}\right)_{4}\right]\left\{x_{1}\left(y_{p}\right)_{1}-\left(y_{p}\right)_{4}\right]\right.
$$

$$
\begin{aligned}
& +\left(x_{p}\right)_{1}\left[\left(y_{p}\right)_{4}-y_{1}\right] \\
& \left.+\left(x_{p}\right)_{4}\left[y_{1}-\left(y_{p}\right)_{1}\right]\right\} \\
& +\left[r_{1}+r_{4}+\left(x_{p}\right)_{4}\right]\left\{x_{1}\left[\left(y_{p}\right)_{4}-y_{4}\right]\right. \\
& +x_{4}\left[y_{1}-\left(y_{p}\right)_{4}\right] \\
& \left.\left.+\left(x_{p}\right)_{4}\left[y_{4}-y_{1}\right]\right\}\right) .
\end{aligned}
$$

These represent one-half the volumes swept over by the sides moving from their Lagrangian positions to their rezoned positions, the factor of $1 / 2$ being included for convenience. Note also that FR for cell $(i+1 / 2, j+1 / 2)$ is equal to $-F L$ for cell $(i+3 / 2, j+1 / 2)$, and $F T$ for cell $(i+1 / 2, j+1 / 2)$ is equal to $-F B$ for cell $(i+1 / 2, j+3 / 2)$. This fact is used in the code to eliminate redundant calculations.

c. Associated with each fluid volume crossing a cell face there are corresponding values of mass, energy, and momentum. For example, the mass crossing the right face of cell $(i+1 / 2, j+1 / 2)$ might be computed as the product of the fluxing volume 2(FR) times the average fluid density of the cells $(i+1 / 2, j+1 / 2)$ and $(i+3 / 2, j+1 / 2)$ located on either side of the boundary. Unfortunately, this so-called 'centered differencing' leads to numerical instabilities. One way to circumvent this instability is to weight the quantity being fluxed more in favor of the upstream value. In the above example, this means the density associated with FR should be more nearly equal to the density in cell $(i+1 / 2, j+1 / 2)$ when the flux is leaving this cell (FR $<0$ ), or more nearly equal to the density in cell $(i+3 / 2, j+1 / 2)$ when the flux is leaving that cell (FR $>0$ ). In SALE, we incorporate the flux coefficients FR, FT, FL, and FB within expressions that allow various differencing forms determined from input constants $a_{0}$ and $b_{0}$ :

$$
\begin{aligned}
& a_{R}=a_{0} \operatorname{sign} F R+4 b_{0} F R /\left(v_{1+3 / 2}^{j+\frac{1}{2}}+v_{1+\frac{1}{2}}^{j+\frac{1}{2}}\right), \\
& a_{T}=a_{0} \operatorname{sign} F T+4 b_{0} F T /\left(v_{1+\frac{1}{2}}^{j+3 / 2}+v_{1+\frac{1}{2}}^{j+\frac{1}{2}}\right), \\
& a_{L}=a_{0} \operatorname{sign} F L+4 b_{0} F L /\left(v_{1-\frac{1}{2}}^{j+\frac{1}{2}}+v_{1+\frac{1}{2}}^{j+\frac{1}{2}}\right),
\end{aligned}
$$


and

$a_{B}=a_{0} \operatorname{sign} F B+4 b_{0} F B /\left(v_{i+\frac{1}{2}}^{j-\frac{1}{2}}+v_{i+\frac{1}{2}}^{j+\frac{3}{2}}\right)$,

where "sign FR," for example, equals +1 if $F R \geqslant 0$ and equals -1 if $F R<0$. Both $a_{0}$ and $b_{0}$ lie in the range 0 to 1 , and the limiting cases are

$a_{0}=0$ and $b_{0}=0 \rightarrow$ centered (unstable),

$a_{0}=1$ and $b_{0}=0 \rightarrow$ full donor cell or upstream differencing (stable, but diffusive),

$a_{0}=0$ and $b_{0}=1 \rightarrow$ interpolated donor cell (linearly stable, less diffusive),

and

$a_{0}=1$ and $b_{0}=1 \rightarrow$ (stable, but more diffusive).

Note that $\left(a_{0}+b_{0}\right)$ must be sufficiently positive for numerical stability (see Sec. III.D).

d. In terms of these weighting fractions, the new mass and specific internal energy for a cell $(i+1 / 2, j+1 / 2)$ are then given by

$$
\begin{aligned}
& { }^{n+1} M_{i+\frac{1}{2}}^{j+\frac{1}{2}}=n_{M_{i+\frac{1}{2}}^{j+\frac{1}{2}}}+F R\left(1+a_{R}\right) \rho_{L} \stackrel{j+\frac{1}{2}}{i+3 / 2} \\
& +F T\left(1+a_{T}\right) \rho_{L} \frac{j+3 / 2}{i+\frac{1}{2}} \\
& +F L\left(1+a_{L}\right) \rho_{L} \frac{j+\frac{1}{2}}{i-\frac{1}{2}}+F B\left(1+a_{B}\right) \rho_{L} i_{i+\frac{1}{2}}^{j-\frac{1}{2}} \\
& +\left[F R\left(1-a_{R}\right)+F T\left(1-a_{T}\right)+F L\left(1-a_{L}\right)\right. \\
& \left.+F B\left(1-a_{B}\right)\right] \rho_{L} \frac{j+\frac{1}{2}}{i+\frac{1}{2}}
\end{aligned}
$$

and

${ }^{n+1} I_{i}^{j}=\frac{1}{n+1 M_{i+\frac{1}{2}}^{j+\frac{1}{2}}}\left\{n(M I)_{i+\frac{1}{2}}^{j+\frac{1}{2}}+F R\left(1+a_{R}\right)\left(n_{I R_{L}}\right)_{i+3 / 2}^{j+\frac{1}{2}}\right.$

$$
\begin{aligned}
& +F T\left(1+a_{T}\right)\left(n_{I C_{L}}\right)_{1+\frac{1}{2}}^{j+3 / 2} \\
& +F L\left(1+a_{L}\right)\left(n_{I \rho_{L}}\right)_{1-\frac{1}{2}}^{j+\frac{1}{2}}+F B\left(1+a_{B}\right)\left(n_{I \rho_{L}}\right)_{i+T_{L}}^{j-\frac{3}{2}} \\
& +\left[F R\left(1-a_{R}\right)+F T\left(1-a_{T}\right)+F L\left(I-a_{L}\right)\right. \\
& \left.\left.+F B\left(1-a_{B}\right)\right]\left(n_{I C_{L}}\right)_{i+\frac{1}{2}}^{j+1}\right\} .
\end{aligned}
$$

e. The advection of momentum requires an extra step, because cell momenta are not carried throughout the cycle as primary field variables. Here we use the concept of a cell-centered momentum flux, which is a departure from that of a vertex-centered form previously used. ${ }^{3}$ The cell-centered flux form has the advantage that momentum is fluxed consistently with mass and energy. The approach is to compute average cell-centered momenta based on the vertex velocities. Changes in these cell momenta resulting from advection are computed in the same way as the other cell-centered quantities. These changes are then apportioned back to the vertices. Although this scheme requires the additional calculation of cell-centered averages and their average effect back on the vertex velocities, the entire process is simpler than using another set of control volumes, because it can be easily included in the advection calculation for mass and energy. Tests with this method have shown it to be superior to all momentum advection methods based on vertex-centered control volumes. In particular, it better preserves cylindrical or spherical symmetry and does not introduce diffusion across streamlines.

The first step in the momentum flux calculation is to form the cell-centered momenta. For every cell,

$\left.(\text { UMøM })_{L}\right)_{i+\frac{1}{2}}^{j+\frac{1}{2}}=\frac{\left(\rho_{L}\right)_{i}^{j}}{4}\left[\left(u_{L}\right)_{1}+\left(u_{L}\right)_{2}+\left(u_{L}\right)_{3}+\left(u_{L}\right)_{4}\right]$

and

$\left(V_{M \phi M}\right)_{i+\frac{1}{2}}^{j+\frac{1}{2}}=\frac{\left(\rho_{L}\right)_{i}^{j}}{4}\left[\left(v_{L}\right)_{1}+\left(v_{L}\right)_{2}+\left(v_{L}\right)_{3}+\left(v_{L}\right)_{4}\right]$. 
Then, using the flux coefficients formed in steps (b) and (c) above, the net advection changes in cell-centered momentum components are given by

$$
\begin{aligned}
& (\Delta U M)_{i+\frac{1}{2}}^{j+\frac{1}{2}}=F R\left(1+a_{R}\right)\left(U M D M M_{L}\right)_{i+3 / 2}^{j+\frac{1}{2}} \\
& +F T\left(1+a_{T}\right)\left(U M \phi M_{L}\right)_{i+\frac{1}{2}}^{j+3 / 2} \\
& \left.+F L\left(1+a_{L}\right)(U M \varnothing M)_{L}\right)_{i-\frac{1}{2}}^{j+\frac{1}{2}}+F B\left(1+a_{B}\right)\left(U M \emptyset M M_{L}\right)_{i+\frac{1}{2}}^{j-\frac{1}{2}} \\
& +\left[F R\left(1-a_{R}\right)+F T\left(1-a_{T}\right)+F L\left(1-a_{L}\right)\right. \\
& \left.+F B\left(1-a_{B}\right)\right]\left(U M \varnothing M_{L}\right)_{1+\frac{1}{2}}^{j+\frac{1}{2}}
\end{aligned}
$$

and

$$
\begin{aligned}
& (\Delta V M)_{i+\frac{1}{2}}^{j+\frac{1}{2}}=F R\left(1+a_{R}\right)(V M \phi M L){ }_{i+3 / 2}^{j+\frac{1}{2}} \\
& +F T\left(1+a_{T}\right)\left(V M \varnothing M_{L}\right)_{i+1 / 2}^{j+3 / 2} \\
& +F L\left(1+a_{L}\right)\left(V M \Phi M_{L}\right)_{i-\frac{1}{2}}^{j+\frac{1}{2}}+F B\left(1+a_{B}\right)\left(V M \varnothing M_{L}\right)_{i+\frac{1}{\varepsilon}}^{j-\frac{1}{2}} \\
& +\left[F R\left(1-a_{R}\right)+F T\left(1-a_{T}\right)+F L\left(1-a_{L}\right)\right. \\
& \left.\left.+F B\left(1-a_{B}\right)\right](V M \phi M L)\right)_{1+\frac{1}{2}}^{j+\frac{1}{2}} .
\end{aligned}
$$

The momenta changes are finally converted to vertex velocity changes in the next step.

\section{Updating the Vertex Quantities.}

a. We first calculate new vertex masses from averages of the new cell masses, using Eq. (3).

b. To adjust the velocities, we set initial values at all vertices, where the $\left({ }^{n} u,{ }^{n} v\right)$ values in storage are replaced by

$$
{ }^{n+1} u_{i}^{j}=\left(\frac{n_{M}}{n+1}\right)_{i}^{j}\left(u_{L}\right)_{i}^{j},
$$

and
${ }^{n+1} v_{i}^{j}=\left(\frac{n_{M}}{n+1}\right)_{i}^{j}\left(v_{L}\right)_{i}^{j}$

Because both the ${ }^{n+1} M$ and the ${ }^{n} M$ values are required, the replacement of ${ }^{n} \mathrm{M}$ values by ${ }^{\mathrm{n}+1} \mathrm{M}$ values is deferred until after completion of this step.

c. Finally, we distribute the cell-centered momentum changes to the four vertices of the cell, in the same manner that we calculate vertex masses, that is, giving equal fractions to each vertex,

$$
\begin{aligned}
& { }^{n+1} u_{1}={ }^{n+1} u_{1}+\left(\frac{0.25}{n+1}\right)\left(\Delta U M M_{1}\right)_{1+\frac{1}{2}}^{j+\frac{3}{2}}, \\
& { }^{n+1} u_{2}={ }^{n+1} u_{2}+\left(\frac{0.25}{n+1}\right)(\Delta U M)_{i+\frac{1}{2}}^{j+\frac{1}{2}} \text {, } \\
& \left.{ }^{n+1} u_{3}={ }^{n+1} u_{3}+\left(\frac{0.25}{n+1}\right)(\Delta U M)^{j+\frac{1}{2}}\right)_{i+\frac{1}{2}}^{j+} \\
& { }^{n+1} u_{4}={ }^{n+1} u_{4}+\left(\frac{0.25}{n+1}\right)\left(\Delta U M M_{4}\right)_{i+\frac{1}{2}}^{j+\frac{1}{2}}, \\
& { }^{n+1} v_{1}={ }^{n+1} v_{1}+\left(\frac{0.25}{n+1}\right)(\Delta V M)_{i+\frac{1}{12}}^{j+\frac{1}{2}}
\end{aligned}
$$

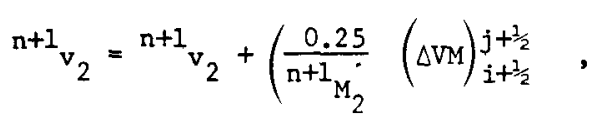

$$
\begin{aligned}
& { }^{n+1} v_{3}={ }^{n+1} v_{3}+\left(\frac{0.25}{n+1}\right)(\Delta V M)_{i+\frac{1}{M_{3}}}^{j+\frac{1}{2}}
\end{aligned}
$$

and

$$
{ }^{n+1} v_{4}={ }^{n+1} v_{4}+\left(\frac{0.25}{n+1}\right)(\Delta V M)_{i+\frac{1}{2}}^{j+\frac{1}{2}} .
$$

\section{H. Completion of the Cycle}

In a purely Lagrangian calculation, the advective flux is bypassed entirely, and the end-of-cycle ${ }^{n+1} u$ and ${ }^{n+1} v$ remain to be set. In the case of an explicit Lagrangian calculation, the Phase $1\left(\mathrm{u}_{\mathrm{L}}, \mathrm{v}_{\mathrm{L}}\right)$ values replace the $\left({ }^{n} u,{ }^{n} v\right)$ values. Similarly, for an implicit Lagrangian 
case, the Phase $2\left(u_{L}, v_{L}\right)$ values become the final values for the cycle.

\section{Summary of Solution Algorithm}

The above subsections complete the description of the basic finite-difference approximations to the dif- ferential equations of motion. Alternative approximations may be easily substituted for any one of the these sections, because they reside in independent subroutines. To complete the solution algorithm, it is necessary to specify suitable boundary conditions. SALE contains a variety of user options for boundary conditions, which are discussed in the next section, along with other code initialization and running instructions. 
-

- 


\section{THE SALE FORTRAN PROGRAM}

\section{A. General Structure}

The SALE computer program consists of a set of subroutines controlled by a short main program. The general structure is illustrated in Fig. 4, showing a topto-bottom flow encompassing the three phases described in Sec. II. Beside each box in the flow diagram appears the name(s) of the primary subroutine(s) responsible for the associated task. An examination of the main program listing lines SALE.170 through SALE.193 (App. A) reveals that the program closely follows the logic path of Fig. 4.

In addition to the primary subroutines, Fig. 4 also identifies a number of supporting subroutines that perform tasks for the primaries. These are concerned with boundary conditions, equation of state, and program output. Comment cards at the beginning of every subroutine in the listing describe its purpose.

The listing in App. A is for the FORTRAN Extended (FTN) compiler in use at the Los Alamos Scientific Laboratory (LASL) on the CDC-7600 computer, which operates under the Livermore Time-Sharing System (LTSS). The code is close to ANSI standard and is generally compatible with other compilers. The principal incompatibility with other systems lies in the calls that communicate with the operating system. Most of these concern the film-plotting routines. WRITE $(59,-)$ statements refer to the user's remote terminal at LASL. The functions of all calls to local routines in SALE are described in App. B to aid users at other installations.

The input quantities to set up a problem are described in the listing (lines SALE.11 through SALE.62), using the formats appearing in subroutine RINPUT. Provision is made for tape dump and subsequent restart. In this case, a modified input file is used, where $N_{x} \equiv 0$ and $\mathbf{N}_{\mathbf{y}}=$ the dump number.

\section{B. The Indexing Notation}

Figure 2 shows some variables centered at vertices and some at cell centers, typical of Lagrangian methods. In FORTRAN, one can reference $x_{i}^{\dagger}$ simply as $X(I, J)$, but $p_{i+1 / 2}^{j+1 / 2}$ cannot be referenced by a "halfinteger" index, so the convention is that $\mathrm{P}(\mathrm{I}, \mathrm{J})$ refers to this pressure. Thus, the indices $\mathrm{I}$ and $\mathrm{J}$ refer to a quantity lying at the lower left vertex of a cell, or at the cell center, depending upon where the quantity is defined. In SALE, (I,J) is replaced by (IJ), as only single subscripts are used for computer efficiency. In the SALE subscript notation, the letter $\mathbf{P}$ stands for + and $\mathbf{M}$ for - . Thus, we write

$$
\begin{aligned}
& \text { IMJ for }(i-1, j) \\
& \text { IPJ for }(i+1, j) \\
& \text { IJP for }(i, j+1) \\
& \text { IPJP for }(i+1, j+1), \ldots
\end{aligned}
$$

This notation allows programmed equations in the listing to be quickly comprehended.

As the number of vertices in either direction is one greater than the number of cells, it is apparent that the grid in computer storage must be $\left(\mathrm{N}_{\mathrm{x}}+1\right)$ by $\left.\mathrm{N}_{\mathrm{y}}+1\right)$ in size. Because our indexing refers to cell centers and lower left vertices, we must allow one extra column of storage on the right and one extra row across the top of the mesh.

\section{Boundary Conditions}

Seven types of boundary conditions are provided in the SALE listing of App. A, identified on lines BC.6BC.12. Except for special situations, as in the sample problem of Sec. IV.D, the user only needs to define the boundary types in the input data file and supply values for specified flow or applied pressure boundaries, and SALE will automatically do the rest. The input data flags indicating what conditions are to be applied along each edge of the mesh are WB, WL, WR, and WT, which correspond to the bottom, left, right, and top 


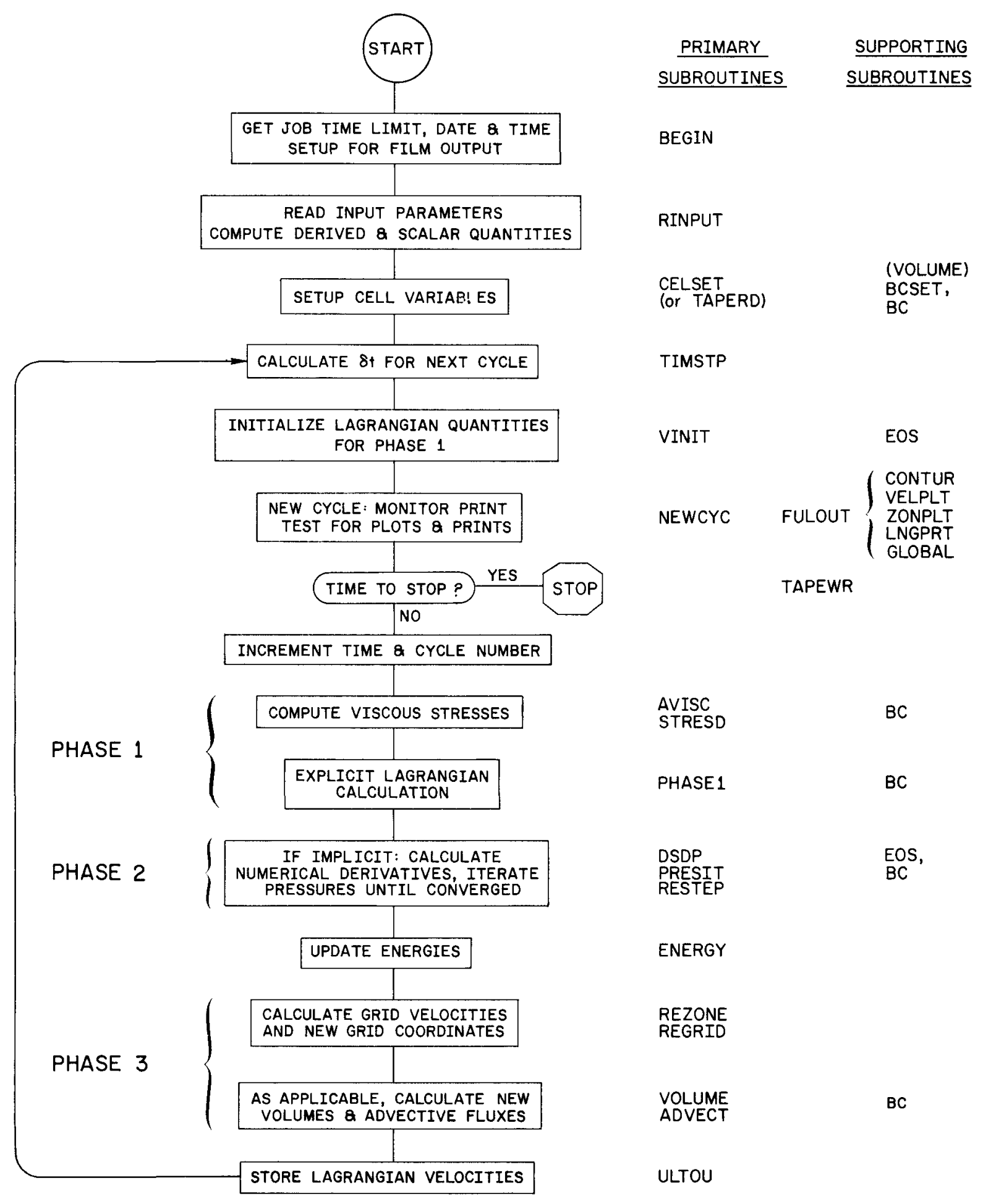

Fig. 4.

General flow diagram for the SALE program. 
boundaries. Integer values assigned to these flags range from zero to six and have the following meanings.

$0=a$ free Lagrangian surface,

$1=\mathrm{a}$ free-slip vertical or horizontal wall,

$2=$ a curved or tilted free-slip wall,

$3=$ a no-slip wall,

$4=$ a continuative outflow boundary,

$5=$ a specified inflow or outflow boundary, and

$6=$ a specified pressure boundary.

In general, application of a boundary condition implies some appropriate setting of the velocity components for boundary vertices. However, for a free Lagrangian surface, no adjustment is required, as the $u_{L}$ and $v_{L}$ from Phase 1 or 2 are the desired values, as in the sample calculation of Sec. IV.A.

For a symmetry boundary or a free-slip wall, the normal wall velocities must be kept at zero throughout the calculation. If such a boundary is parallel to the $x$ or $y$ axis, the $u$ is set to zero on a left or right boundary, or the $\mathrm{v}$ is set to zero on a bottom or top boundary. If the wall is slanted or curved (as in the sample calculation of Sec. IV.C), both velocity components must be adjusted to make the flow tangent to the local slope. This is done by first computing an average tangent at a boundary vertex from the neighboring vertices. Then the vertex velocity is changed in such a way that its component along this tangent remains unchanged, but its normal component is zero.

Currently, the general free-slip condition calculates the tangential direction in terms of the fluid-mesh coordinates. For this reason, the boundary keeps its original shape only when the vertices lying along it are treated as Eulerian grid points. It would be straightforward to modify the code to specify a fixed boundary, not tied to the calculational mesh, in terms of which the boundary condition would be applied. This would allow a fixed, curved boundary to be used with fully Lagrangian fluid motion.

It should be noted that general free-slip curved boundaries can cause difficulties in the limit of incompressible flow. The reason is that tangential motion at the curved boundary will not precisely conserve volume. If $\varepsilon$, the convergence parameter, is such that it requires total volume changes less than the error committed at the curved boundary, the pressure iteration will not converge. It is necessary, then, to decrease $\delta$ t, increase $\varepsilon$, or improve resolution along the curved boundary.
For a rigid no-slip wall, both velocity components are set to zero, regardless of wall orientation or curvature.

Inflow and outflow boundaries are more complex than those described above, as an inflow boundary requires not only specified velocity components (UIN, VIN), but also a density (ROIN) and energy (SIEIN). To have these cell quantities readily available for fluxing, SALE automatically makes the first column or row of cells at such a boundary into fictitious cells, and adjusts DO-loop limits accordingly so that the calculations bypass such cells.

The typical treatment of an outflow boundary is either to specify the outflow velocities or, if it is continuative, to set the velocity components equal to those located one vertex in. This generally works properly for high-speed flows, but for low-speed or incompressible flows, the prescription may require adjustment if it affects the upstream flow. Note also that an outflow boundary can only be used in a full-donor cell calculation $\left(a_{0}=1, b_{0}=0\right)$, because the flux expressions will refer to outside quantities for any other $a_{0}$ and $b_{0}$. SALE provides a warning message if the input specifies other than a full-donor cell treatment in combination with an outflow boundary. This can be dealt with, as we did in the sample calculation of Sec. IV.D, by storing the necessary values in outside cells. In such instances, it is simplest to choose the right or top boundaries for the outflow, as they provide true outside cells $\left(\mathrm{N}_{\mathrm{x}}+1\right.$ and $\mathrm{N}_{\mathrm{y}}+1$ ), and inside fictitious cells are not provided for continuative outflow boundaries. One should also be aware that a continuative outflow boundary could become an inflow boundary if the velocity field unexpectedly reverses during the calculation. Should this happen, the flux calculations will be incorrect at the boundary. Continuative boundaries, therefore, must be used with caution.

The final type of boundary condition we offer is a specified pressure boundary. It too uses inside fictitious cells for the pressure definition. Again, DO-loop limits are automatically adjusted to bypass such cells in the calculation, except in Phase 1, where these cells are included so that pressure accelerations are correctly calculated at the boundary. When a specified pressure boundary is used, the pressure must be defined in the input data list as the value of PAP.

The boundary conditions applied on the edges of the logical SALE mesh are set in the sequence of left, right, bottom, and top. A corner vertex, common to two edges, is therefore set to the condition of the edge that is treated second. 
The boundary conditions of both edges meeting at a corner are considered when the general free-slip condition is applied to either edge. If both edges are general free-slip, we 'wrap around' and reference the neighboring points on each side when calculating the slope at the corner. This is especially helpful for meshes with connected curved edges, as it maintains tangential flow.

\section{Numerical Stability and Accuracy}

Numerical stability and accuracy are essential factors to consider when assessing the application of numerical simulation models. Time and experience have proven that first-order methods such as SALE are perfectly adequate for many problems of interest. The researcher, however, should realistically evaluate his needs when he considers the suitability of any computing technique or program. It is no wiser to pay the expense for an overly sophisticated technique than it is to struggle with trying to apply a technique to a situation for which it is not suited.

The useful accuracy of a given numerical solution may be difficult to determine analytically. ${ }^{4}$ In such cases, it is sometimes possible to use a spectrum of computer runs with different meshes, time steps, donor-cell coefficients, artificial viscosities, convergence criteria, etc., to determine if a calculated effect is physical or simply a numerical artifice. Aside from this type of 'brute force' approach, there are several general rules one should follow in using the SALE program. For example, if a solution exhibits large variations over distances comparable to a cell width or over times comparable to the time step, it is probably not very reliable. Thus, when computing time or memory limitations preclude the use of a cell size and time step that are fine enough to resolve all spatial and temporal variations of interest in the dependent variables, then the results must be interpreted with care. In spite of such limitations, the investigator often has some choices. For example, a thin boundary layer in a large region may be resolved by employing much finer zoning at the wall and a no-slip boundary condition. If, however, its resolution is unimportant, then coarser zoning and a free-slip condition at the wall may be a valid approximation.

Numerical methods may give solutions that develop large, high-frequency oscillations in space or time. If the physical problem being modeled is known not to exhibit such behavior, the source may be numerical instability, caused by violation of one or more restrictions that should be used to limit the size of the time step.

Implicit methods have less stringent stability requirements than explicit methods, which typically require that the Courant condition on sound signal propagation,

$\max \left(\frac{c \delta t}{\delta x}, \frac{c \delta t}{\delta y}\right)<1$,

is not violated. When SALE is run implicitly, the Courant condition can be avoided because it uses timeadvanced quantities, which are determined by iteration. The resulting increase in running time per cycle can be more than compensated for by the reduction in number of time steps, but the time step must always be chosen to ensure that important short time-scale phenomena are resolved. When the Mach number of the flow exceeds the 0.1 range, an explicit solution is often more efficient, but below this range, the restriction on sound signal propagation would require a large number of time steps to move the fluid even one cell width, and the implicit solution becomes preferable.

Whether run implicitly or explicitly, the time step in SALE is always restricted by the well-verified condition that fluid cannot be moved more than approximately one cell width per time step, that is,

$\delta t<\min \left(\frac{\delta x}{|u|}, \frac{\delta y}{|v|}\right)$.

The minimum implies that every cell in the mesh must be considered to ensure that the $\delta$ t satisfies the most restrictive case. Our general advice is to start by choosing $\delta t$ equal to one-fifth of the minimum cell transit time (DTF $=0.2$ in the code), being more liberal if experience allows it for the application at hand. Although Lagrangian calculations do not have as restrictive a stability limit due to advection, we still recommend that the time step satisfy this requirement, primarily for reasons of accuracy, and secondarily for efficiency by avoiding negative cell volumes at the end of Phase 1 , as negative cell volumes automatically force the code to back up and restart the cycle with a smaller time step.

The donor cell or upstream component of the advection terms contributes numerical diffusion-like effects that influence the stability conditions. In particular, space-centered differencing $\left(a_{0}=b_{0}=0\right)$ leads to unstable results, ${ }^{2}$ whereas full donor-cell differencing $\left(a_{0}=\right.$ $1, b_{0}=0$ ) may be too diffusive for some circumstances. 
Our general recommendation is to use $a_{0}$ as small as possible without generating an instability.

Another numerical stability condition relates to the stress tensor. When viscous effects are included, the crucial condition to be satisfied is that

$\delta t<\left[\frac{2(\lambda+2 \mu)}{\rho}\left(\frac{1}{\delta x^{2}}+\frac{1}{\delta y^{2}}\right)\right]^{-1}$

is met in every cell, which roughly states that momentum must diffuse less than one cell width per time step. Also to be considered in Phase 1 is the related stability condition on the alternate node coupler, which can be shown to be $a_{n c}<1$.

In SALE, we automatically choose a new time step every cycle (subroutine TIMSTP) that must satisfy four requirements: (1) advective flux, (2) viscous effects of $\lambda$ and $\mu$, (3) no more than $5 \%$ increase from the time step of the previous cycle, for reasons of accuracy, and (4) no greater than the maximum time step for the calculation (DTMAX in the input file). We assume that the user has satisfied upstream $\left(a_{0}, b_{0}\right)$ and node coupling (ANC) requirements in the input data.

A final comment regarding the selection of the time step is that we specifically do not recommend tailoring the time step to precisely fit a specified output time. Occasionally, this may result in suddenly having, for an output cycle, a time step several orders of magnitude smaller than the problem has been running with. Experience has shown that such a discontinuous drop can adversely affect the results and cause some computing methods to blow up. It is better to let the four requirements above determine the time step, and do the output when the problem time equals or first exceeds the specified output time. 


\section{SAMPLE CALCULATIONS}

SALE is written in a very general fashion and is not geared to any specific type of calculation, as many codes are. It has an unusually wide range of capabilities, but as a result, most problems will require at least some code modification. Typically, this is either in the setup, boundary conditions, or the rezone. Techniques for mesh generation, boundary treatment, and rezoning are explored in the examples that follow. These include input data and code modifications, from which it is apparent that the necessary code changes for most problems are quite straightforward. In these examples, code changes are written in CDC UPDATE format. A line of the form *I, deckname.n means the FORTRAN statement(s) that appear between the *I line and the next line beginning with $\mathrm{a}^{*}$ are inserted following line deckname.n. The line ${ }^{*} \mathrm{D}$, deckname.m, deckname.n means to delete statements deckname.m through deckname.n and replace them with any lines between the ${ }^{*} \mathrm{D}$ and the next ${ }^{*}$ line.

The Central Processor Unit (CPU) times and the grind times are given for each example. The grind time, defined as the CPU time per cell per cycle, $\delta \mathrm{CPU} /$ $\left(\mathrm{N}_{\mathrm{x}}{ }^{*} \mathrm{~N}_{\mathrm{y}}\right)$, is a useful indicator of the computing efficiency of the code. It should be noted that CPU usage is influenced by the dynamic load on the resources in a timesharing environment.

\section{A. Broken Dam}

This problem can be solved by the SALE program exactly as listed in App. A. Because no code modifications are required, it has been selected as the test problem in App. C, which presents several pages of numerical output for verification of results at other installations. The setup consists of a 10-cell by 10-cell uniform mesh, in plane geometry, resting on a rigid freeslip surface. The left boundary is a rigid free-slip wall, representing a plane of symmetry. At time $t=0$, a dam at the right wall is removed, and the fluid is free to flow outward under the influence of gravity. The mesh is allowed to move in a purely Lagrangian fashion, and the top and right boundaries are treated as Lagrangian free surfaces. The calculation is run implicitly, in the incompressible limit (see Sec. II.E). Figure 5 shows the mesh configuration at three selected times: $t=2.0$ (cycle 20), $\mathrm{t}=5.0$ (cycle 71), and at the specified finish time, $t=10.0$ (cycle 207). The plots in the figure create the illusion of decreasing volume, solely because we scaled each plot to fit a specified maximum width on the film frame. The actual rightward progress of the flow can be determined from the numerical printout of cell data. The $\mathrm{x}$ coordinate of the lower right corner vertex $(11,1)$, which was at position $\mathrm{x}=10.00$ at $\mathrm{t}=0$, is located at $\mathrm{x}=14.40$ at $\mathrm{t}=2.0$, at $\mathrm{x}=28.94$ at $\mathrm{t}=5.0$, and at $\mathrm{x}=58.10$ at $\mathrm{t}=10.0$. The $\mathrm{y}$ coordinate of the upper left corner vertex $(1,11)$, which was at position $y$ $=10.00$ at $\mathrm{t}=0$, has dropped to $\mathrm{y}=9.127$ by $\mathrm{t}=2.0$, to $\mathrm{y}=6.782$ by $\mathrm{t}=5.0$, and down to $\mathrm{y}=3.379$ at $\mathrm{t}=$ 10.0 .

The calculation required $42.5 \mathrm{~s}$ of $\mathrm{CDC}-7600 \mathrm{CPU}$ time to run to completion, and created 110 frames of plots and printed information on microfiche. The input file had the following appearance.

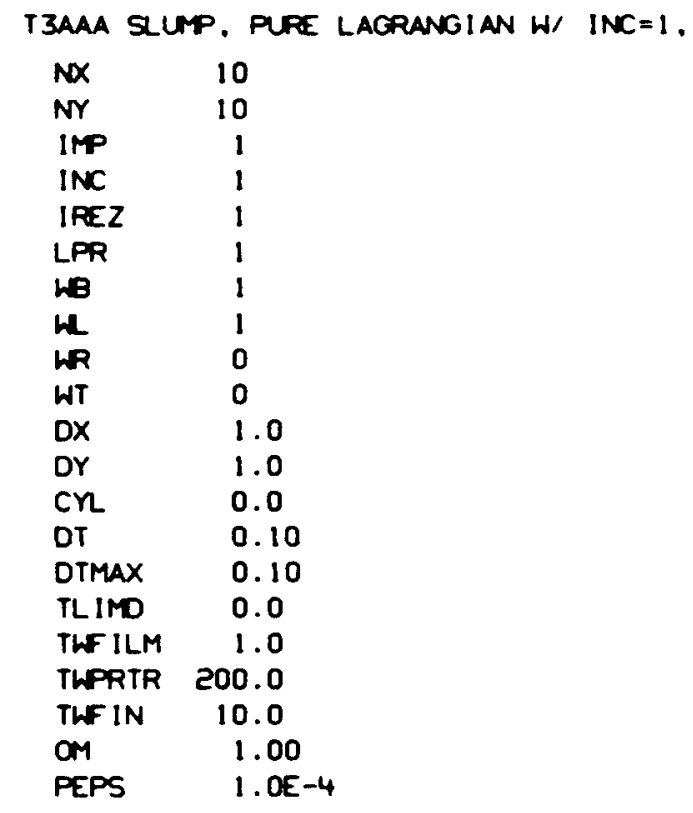




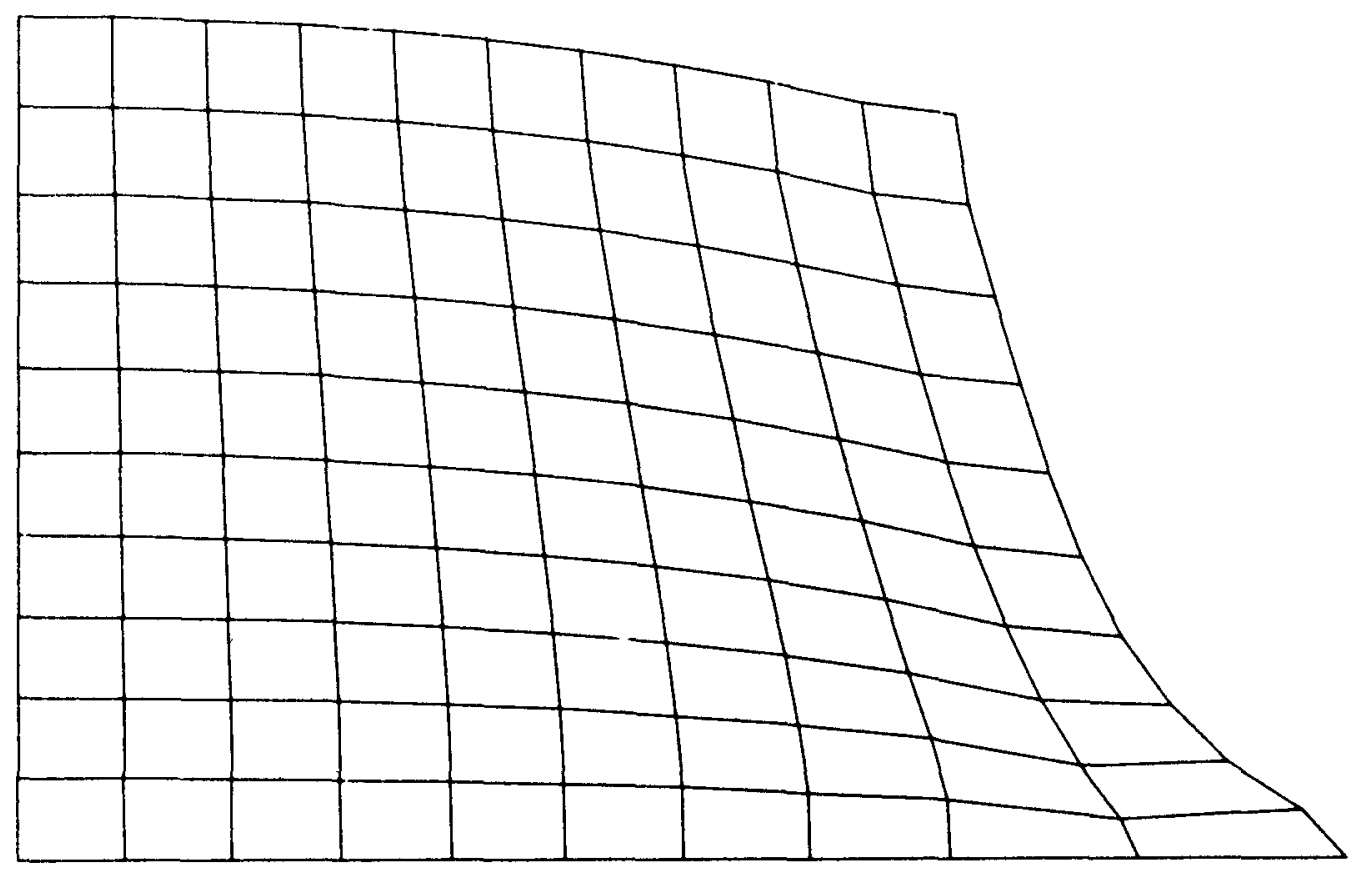

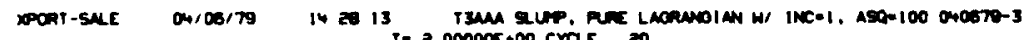

$T=2000000+00$ crae 20

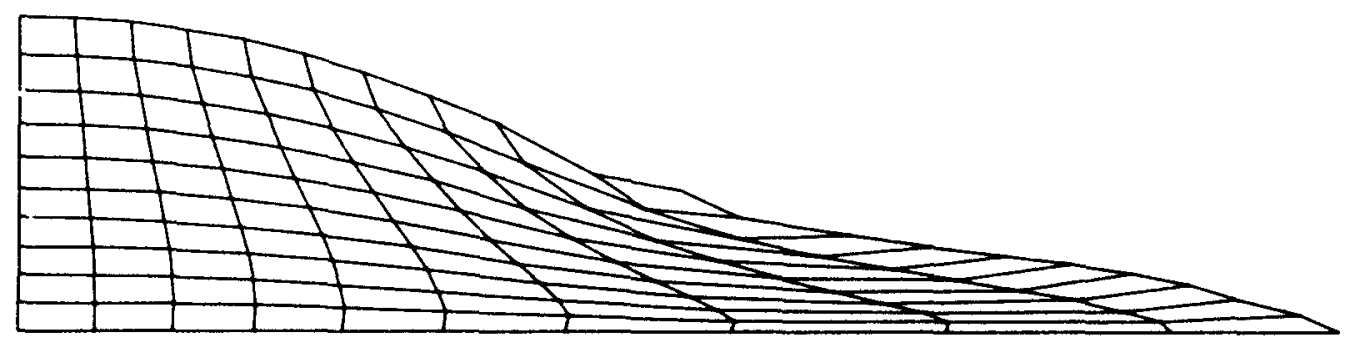

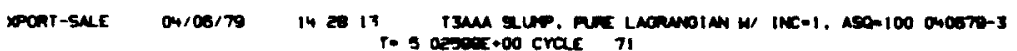

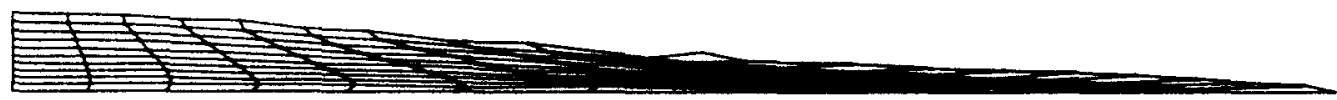

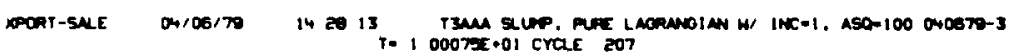

Fig. 5.

The broken dam calculation showing the configuration of the Lagrangian mesh at times $t=2.0, t=$ 5.0, and $t=10.0$. 


$\begin{array}{ll}\text { EPS } & 1.0 E-4 \\ \text { RF } & 0.05 \\ \text { ARTVIS } & 0.1 \\ \text { LAMBOA } & 0.0 \\ \text { MU } & 0.0 \\ \text { ANC } & 0.05 \\ \text { XI } & 1.0 \\ \text { GX } & 0.0 \\ \text { GY } & -1.0 \\ \text { AO } & 1.0 \\ \text { BO } & 0.0 \\ \text { ASO } & 1.0 E+2 \\ \text { RON } & 1.0 \\ \text { GMI } & 0.0 \\ \text { ROI } & 1.0 \\ \text { SIEI } & 0.0 \\ \text { UIN } & 0.0 \\ \text { VIN } & 0.0 \\ \text { ROIN } & 0.0 \\ \text { SIEIN } & 0.0 \\ \text { PAP } & 0.0\end{array}$

For further information on this calculation, refer to App. C.

\section{B. One-Dimensional Shock Tube}

The two graphs plotted in Fig. 6 illustrate density profiles from Lagrangian (upper profile) and Eulerian (lower profile) calculations of a 2:1 density-ratio shock tube. No attempt was made to obtain the best solutions ihat SALE can produce for this problem; rather, our intent is to illustrate that satisfactory solutions can be obtained in both limits. In Fig. 6, the SALE solutions are plotted with a heavy line and the theoretical solution ${ }^{5}$ is plotted with a light line.

The calculations were performed in a plane mesh 60 cells long by 1 cell high, allowing 30 cells for each fluid region. The initial density was 0.2 on the left and 0.1 on the right, and the initial specific internal energy was 0.18 . The gas was polytropic with $\gamma=5 / 3$. The initial cell size was $\delta x=\delta y=1 / 3$. Both calculations were completely inviscid $\left(\lambda_{0}=\lambda=\mu=a_{n c}=0\right)$, but were run with full donor-cell differencing $\left(a_{0}=1, b_{0}=0\right)$. The only difference between the two calculations is that the first is Lagrangian implicit (Phases 1 and 2 only), and the second is Eulerian explicit (Phases 1 and 3 only).

At $t=0$, the diaphragm separating the two fluid regions was instantaneously removed, causing a shock
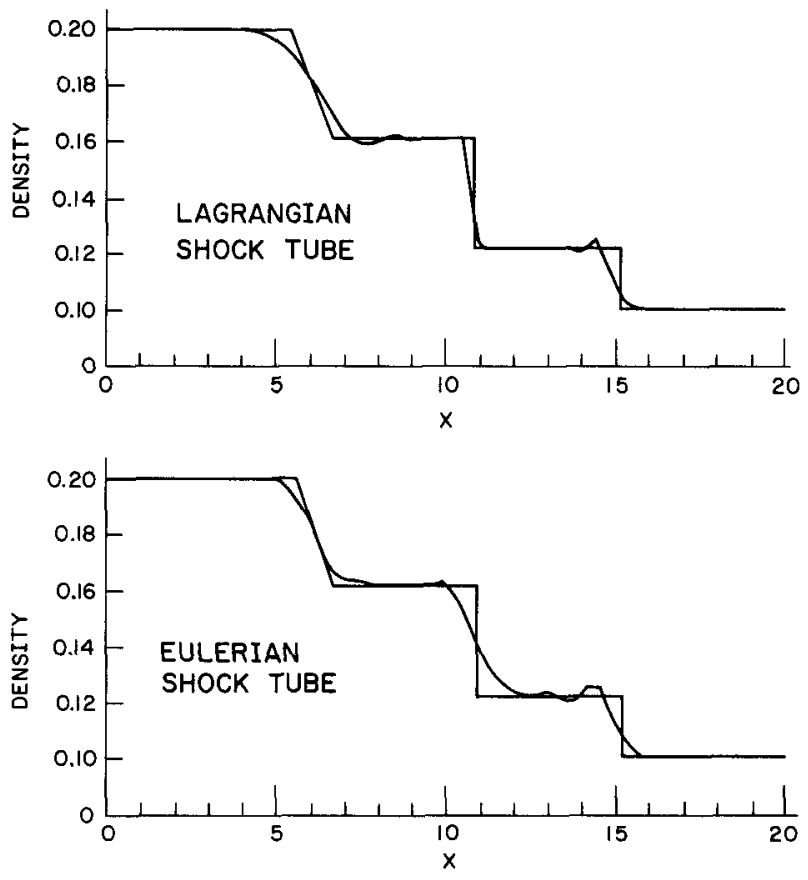

Fig. 6.

Density profiles at time $t=10.0$ from an implicit Lagrangian (upper) and an explicit Eulerian (lower) calculation of a shock tube with a 2:1 density ratio.

to advance into the lower density region and a rarefaction to propagate back from the contact surface into the 'higher density region. In both calculations, $\delta t$ was held constant at 0.1, and the profiles shown in Fig. 6 are at $t$ $=10.0$. The Lagrangian calculation required $8.6 \mathrm{~s}$ of $\mathrm{CDC}-7600 \mathrm{CPU}$ time to run to $\mathrm{t}=15.0$, running at 3 iterations per cycle, with a grind time around $0.315 \mathrm{~ms}$. The Eulerian calculation required $7.4 \mathrm{~s}$, with a grind time around $0.210 \mathrm{~ms}$. The one code modification required was to distinguish the two density regions in the setup:

- IDENT SOZ0279

-1 , CELSET.35

IF (I.GT.30) RO(IJ)=0.1 
The input file for the Lagrangian shock tube appeared as follows.

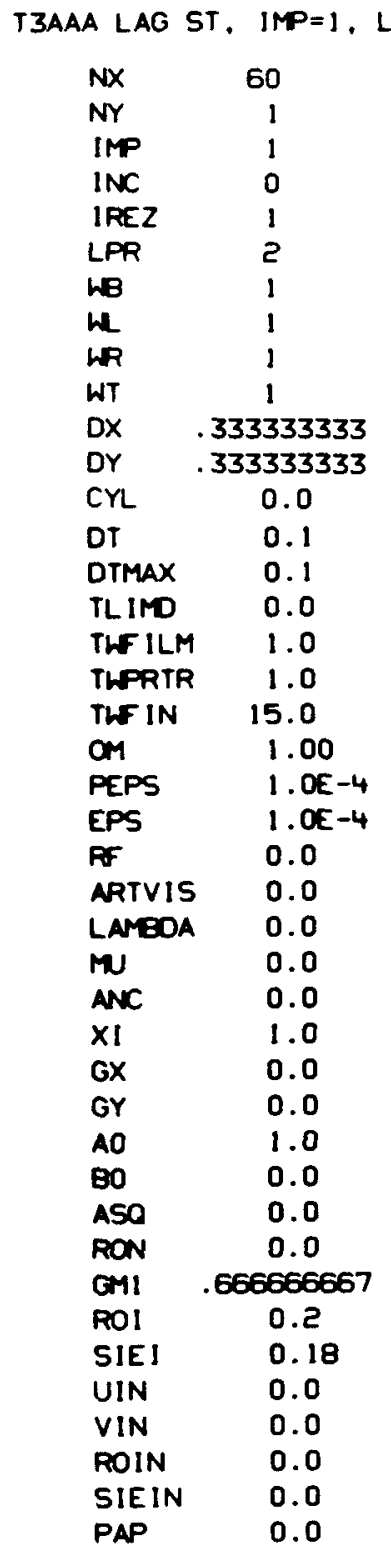

\section{Supersonic Flow Through a Curved Duct}

In this example we illustrate supersonic flow through a curved two-dimensional duct. Of interest here is the procedure for creating the mesh, and the usefulneess of the general free-slip boundary condition. The schematic for the mesh generation (Fig. 7) calls for a 35 -cell-long by 6 -cell-high Eulerian mesh, of which a 15 -cell portion of the central region is to be deformed into a $90^{\circ}$ curve, leaving a 10 -cell straight section at

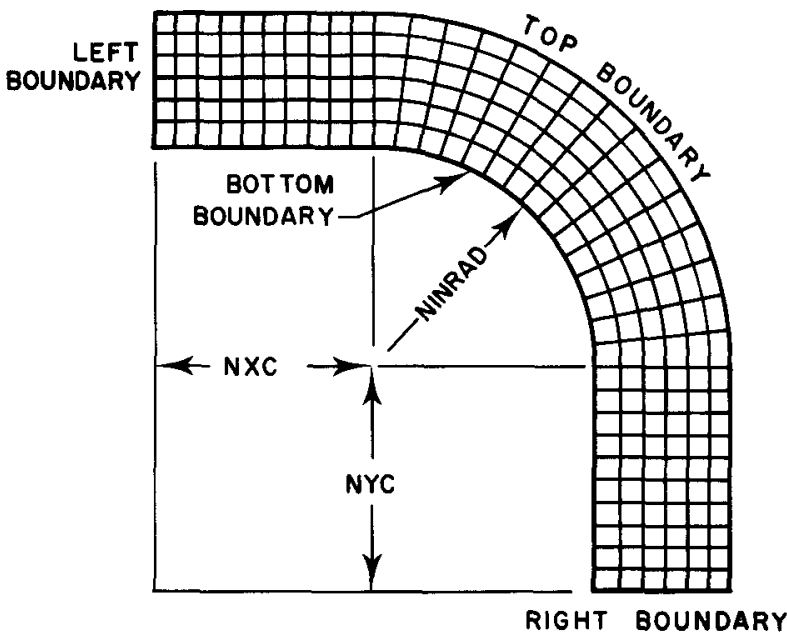

Fig. 7.

The curved-duct mesh. The three dimensions are defined in numbers of cells.

either end. The right mesh boundary, now visually appearing at the bottom, is the inflow boundary, and the left mesh boundary allows a continuative outflow. The top and bottom boundaries employ the general free-slip condition, which is intended for arbitrarily curved or straight regions.

The fluid is a polytropic gas with $\gamma=1.4$. Initial conditions state that the fluid in the mesh is at rest, with density and specific internal energy both equal to unity, and that at time $\mathrm{t}=0$, a shock with a Mach number $M$ $=10$ enters at the right boundary. The shock relations for a polytropic gas ${ }^{5}$ allow the required conditions to be calculated as functions of $M$ alone. In this case, the shock speed is 7.4833 , while behind the shock, the fluid speed is 6.1737 , the density is 5.7143 , and the specific internal energy is 20.3874 .

Figure 8 shows velocity vectors and isobars at three selected times in the calculation. The high and low contour values at the time of each contour plot are labeled with an $\mathrm{H}$ and $\mathrm{L}$. At the first time, $\mathrm{t}=0.25$ (cycle 33), the shock is midway through the curved portion of the duct, and a high-pressure region has developed where it has encountered the wall. By time 0.50 (cycle 71), in the second set of plots, the shock front is approaching the outflow boundary and shows a strong deformation as a result of having been turned $90^{\circ}$. At the last time shown, $t=3.00$ (cycle 445), well after the shock front has passed the outflow boundary, a nearly steady-state 


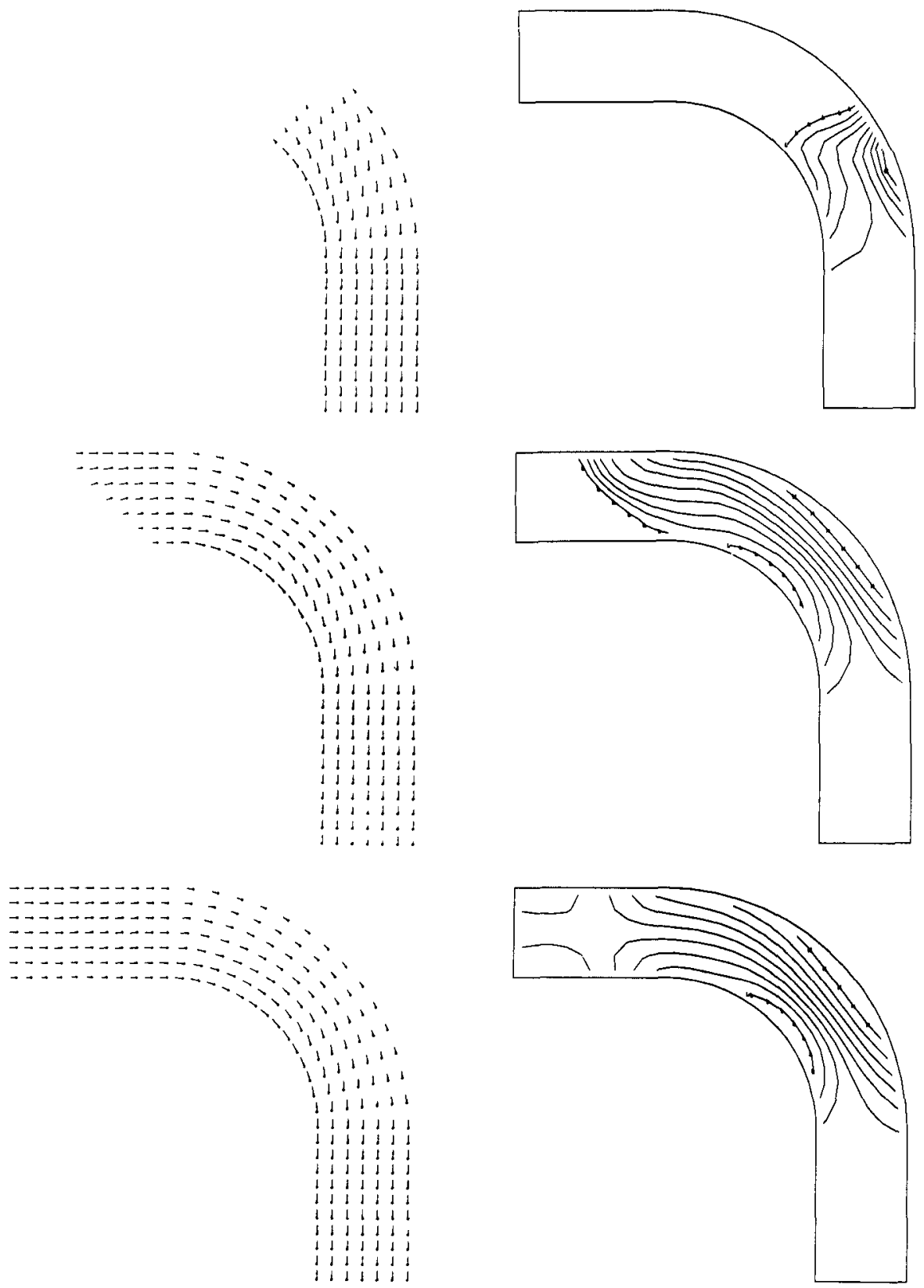

Fig. 8.

Velocity vectors (left) and isobars (right) for the supersonic duct calculation, at times $t=0.25$ (top), $t=0.50$ (middle), and $t=3.00$ (bottom).

configuration has been established. The pressures (and similarly the densities and specific internal energies) are highest at the outer radius of the bend where the fluid reflects off the wall in the turning process.

This calculation required $28.0 \mathrm{~s}$ of CDC-7600 CPU time to run to time $t=3.0$, with a grind time around $0.200 \mathrm{~ms}$. The code modifications and input file for this problem are listed below. The first change, to DTF, allows the use of a larger time step than the standard conservative value in the code. Although this is not possible for all problems, we did realize a substantial increase in computing efficiency for the duct problem. The remaining changes, in subroutine CELSET, create the mesh using the three dimensions NXC, NYC, and NINRAD identified in Fig. 7.

By simply varying the values of the five parameters (NX, NY, NXC, NYC, and NINRAD), one can alter the configuration considerably without having to revise the setup logic. In addition, it would be possible to create a mesh as shown here, then make another pass to 
further modify it, for example, necking the outflow end to a nozzle. Iterative or direct schemes for grid generation $^{6}$ are quite useful for such purposes.

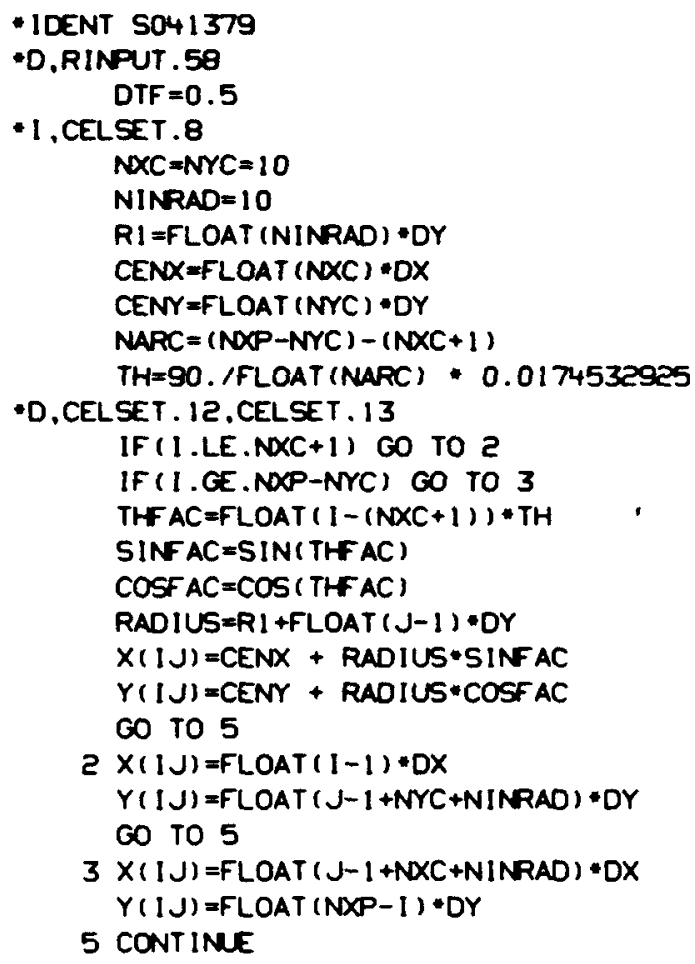

$\begin{array}{lc}\text { GX } & 0.0 \\ \text { GY } & 0.0 \\ \text { AO } & 1.0 \\ \text { BO } & 0.0 \\ \text { ASO } & 0.0 \\ \text { RON } & 0.0 \\ \text { GMI } & 0.4 \\ \text { ROI } & 1.0 \\ \text { SIEI } & 1.0 \\ \text { UIN } & 0.0 \\ \text { VIN } & 6.1737 \\ \text { ROIN } & 5.7143 \\ \text { SIEIN } & 20.3874 \\ \text { PAP } & 0.0\end{array}$

\section{D. von Karman Vortex Street}

The sequence of velocity vector plots in Fig. 9 show the development of a von Karman vortex street. This fluid-flow phenomenon represents a true physical instability that is seldom seen because of fluid transparency, but is a common occurrence when air or water flows past an object. If the Reynolds number $(\mathrm{Re})$ of the flow lies in a specific range, ${ }^{7}$ the wake will depart from uniform laminar flow, and vortices will be shed alternately from each corner of the object in a regular pattern.

In this example, the initial condition was a uniform upward flow of fluid past both sides of a rigid obstacle centered across the inflow boundary of a $16 \times 46$ cell mesh. The problem was run implicitly in the incompressible limit (see Sec. II.E).

After the laminar flow was well established, at time $t$ $=10$ (cycle 210 , Fig. 9a), we perturbed the flow by decreasing the incoming velocity on one side of the obstacle by $5 \%$, while increasing it by $5 \%$ on the other side. This perturbation was allowed to decay immediately as a function of time, and went to zero at $t=$ 30. Its effect is evident by $t=20$ (cycle 432, Fig. 9b), and by $t=30$ (cycle 654 , Fig. 9c) the flow is noticeably asymmetric. Figures $9 \mathrm{~d}-9 \mathrm{f}$ show the appearance at $\mathfrak{t}=$ 40 (cycle 925), $t=65$ (cycle 1585), and $t=70$ (cycle 1709). The frequency of shedding at each corner is about 10 units of time, thus the plots at $t=50$ and $t=$ 60 are similar to that at $t=70$, and those at $t=45$ and $t$ $=55$ to that at $\mathrm{t}=65$.

The mean flow velocity is about 0.5 , the fluid density is 1.0 , the effective obstacle width is 1.75 , and the shear viscosity $\mu=3.3 \times 10^{-3}$. This corresponds to $\operatorname{Re} \approx$ 260 , but the effective viscosity in the system is probably closer to $10^{-2}$, due to truncation error effects from donor-cell differencing. Although a truncation error 

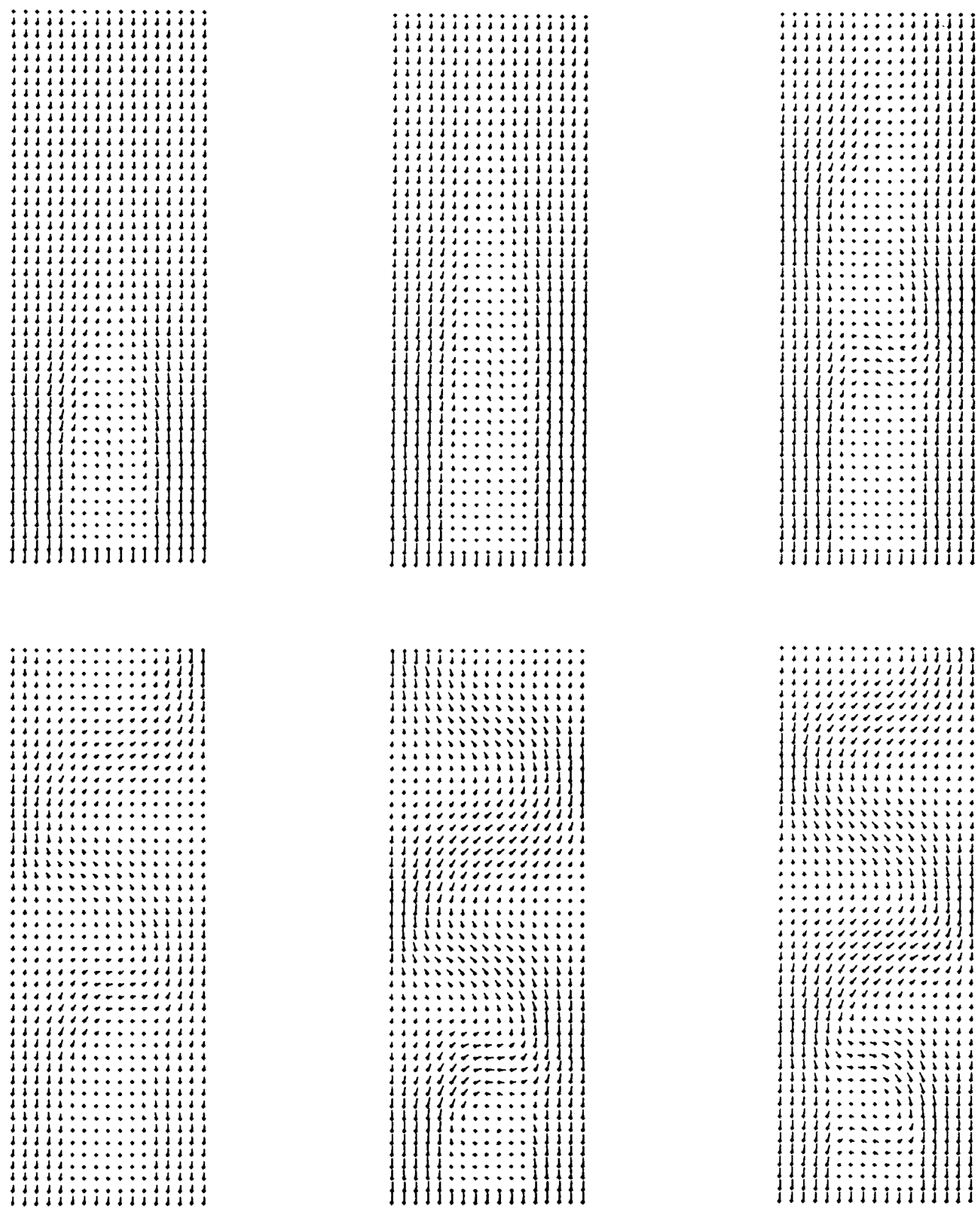

Fig. 9.

Velocity vectors for the von Karman vortex street calculation, at times $t=10, t=20, t=30, t=40$, $t=65$, and $t=70$. 
analysis ${ }^{4}$ has not been performed for SALE, it is safe to say the actual Reynolds number of the flow is closer to 100. Our results are also influenced by the narrow channel width and the placement of the obstacle at the inflow boundary, rather than up in the mesh where the flow could pass completely around it.

Of importance are the modifications required at the continuative outflow boundary. Outflow boundaries always pose a problem for low-speed flows, because whatever prescription is chosen has the potential to affect the entire flow field upstream. Our problem is compounded in the vortex street calculation, as the vortices significantly change the outflow velocity profile from one side of the channel to the other. The usual treatment for a continuative outflow boundary is to set both velocity components equal to those located one cell in from the boundary, except during the iteration, when they are allowed to vary with changes in pressure, as any interior velocity component. However, for the vortex street, the outflow velocities across the top must be continually scaled to the inflow to preserve the mass balance in the system. This must be repeated every iteration, because if the velocities are allowed to float, the number of iterations will double. Note also in this example that the open length across the inlet, required for the scaling, is $9 \delta \mathrm{x}$ rather than the $8 \delta \mathrm{x}$ it would appear to be, as two half-cells are effectively available for mass flux at the obstacle corners.

A small amount of fourth-order node coupling was required to prevent difficulty at the trailing edges of the obstacle. ${ }^{2}$ To minimize diffusion, we ran with only a small amount of donor-cell differencing, $a_{0}=0.1, b_{0}=$ 0 . For any departure from full donor-cell $\left(a_{0}=1, b_{0}=\right.$ 0 ), the density and energy must be set in the cells "outside" of the continuative boundary to prevent erroneous values from being computed in the flux calculation at the boundary.

The foregoing special considerations are dealt with in the UPDATE modifications listed below.

The calculation required $16.5 \mathrm{~min}$ of CDC-7600 CPU time to reach the completion time of $t=70$. At early times, the iteration number was typically 5 per cycle with a grind time of $0.46 \mathrm{~ms}$. By $t=30$, as the flow became unsteady, the iteration number was around 10 (0.66-ms grind). By t $=50,20$ iterations ( $1.00-\mathrm{ms}$ grind) were required. Thereafter, the iteration history oscillated, ranging as high as $27(1.30-\mathrm{ms}$ grinds), down to 13 (0.77-ms grind).

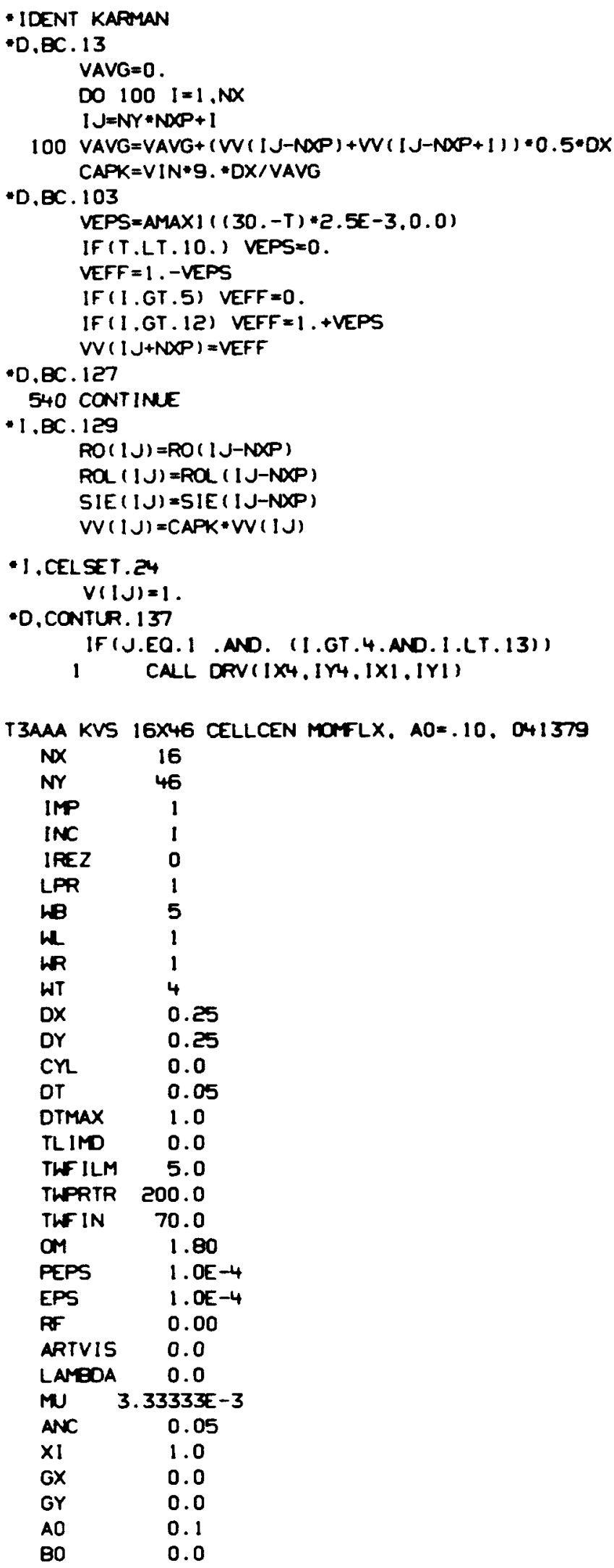




$\begin{array}{ll}\text { ASO } & 0.0 \\ \text { RON } & 0.0 \\ \text { GMI } & 0.4 \\ \text { ROI } & 1.0 \\ \text { SIEI } & 0.0 \\ \text { UIN } & 0.0 \\ \text { VIN } & 1.0 \\ \text { ROIN } & 1.0 \\ \text { SIEIN } & 0.0 \\ \text { PAP } & 0.0\end{array}$

\section{E. Strong Shock Passing Over a Mercury Drop in Water}

This final example concerns the calculation of a strong isothermal shock passing over a drop of mercury in water. It involves a more complex continuous rezone that illustrates what is sometimes required in order to obtain a solution, but it also illustrates the possibilities that can be realized in SALE with some imagination.

Figure 10 shows the initial configuration of the mesh. The drop has a $1-\mathrm{cm}$ radius and all units are in the CGS system. The incident shock, input at the lower mesh boundary, has speed $3.62 \times 10^{5}$, well into the supersonic regime, as the sound speed of water is $1.5 \times 10^{5}$. The solution of the isothermal shock relations ${ }^{5}$ gives the inflow conditions behind the shock - a water velocity of $3 \times 10^{5}$ and density of 5.83 . The mercury has density 13.5 and a slightly lower sound speed, $1.45 \times 10^{5}$.

Mesh configuration, velocity vectors, and pressure contours at selected times are shown in Fig. 11. In Fig. $11 \mathrm{a}$, at $\mathrm{t}=5 \times 10^{-6}$ (cycle 100), the shock has encountered the leading edge of the drop and a large pressure increase develops there because of the sudden increase in inertial resistance. By $t=7.5 \times 10^{-6}$ (cycle 150, Fig. 11b), significant deformation of the drop has already occurred when the shock has reached its back side. By $t$ $=1 \times 10^{-5}$ (cycle 200, Fig. 11c) the shock is noticeably diffracting, and at $t=1.25 \times 10^{-5}$ (cycle 250, Fig. 11d) it collapses on the symmetry axis behind the drop, and sends out a radial pressure wave evident in the $t=1.5 \times$ $10^{-5}$ plot (cycle 300, Fig. 11e). A Rayleigh-Taylor type of instability is to be expected at the leading surface of the drop. The instability may be developing in the $t=$ $1.5 \times 10^{-5}$ plot, but the numerical resolution is too coarse and the time too short to show this.

The UPDATE modifications to set up and run this calculation are listed below. The modifications to subroutine CELSET principally concern the creation of the initial grid, which required 158 iterations. ${ }^{6}$ The input file only allows for the definition of one material in our two- material problem. We defined the mercury in the input and supplied values for the water where needed (subroutines CELSET and VINIT). For efficiency, we bypassed the equation of state in the setup and the entire energy subroutine, taking advantage of the isothermal conditions.

A major portion of the UPDATE concerns the continuous rezone. The DATA statement identifies the vertices along the surface of the mercury drop, in singlesubscript code notation, where 81 and 241 are the vertices on the axis, at the leading and trailing edges, respectively. Except for the boundary of the mercury drop, continuous rezoning was employed to keep mesh distortions under control. A relaxation factor (RF) of 1.0 was required to keep the vertices sufficiently separated in the shock front. In an initial attempt, a value of $R F=0.05$ resulted in cells going to zero height across several rows.

Initially, we ran with the boundary of the mercury drop treated as purely Lagrangian (that is, moving with the fluid), but by a time of $5 \times 10^{-6}$, as the shock was encountering the drop, vertices $(6,6),(6,7),(6,8)$, and $(6,9)$ pinched together and crossed over. To counter this, we added a DO-loop at the end of the rezone to keep the interface vertices better distributed. Considering three vertices at a time, we passed a circular arc through them and rezoned the center vertex so that its new position would lie on the arc. The procedure involved determining the coordinates $\left(\mathrm{x}_{0}, \mathrm{y}_{0}\right)$ and radius $\left(\mathrm{r}_{0}\right)$ of the circular arc for use in a quadratic equation, whose correct root may be either the positive or the negative one, depending upon the circumstances. Choice of the wrong root would place the new position of the vertex on the opposite side of the circle, so care must be taken to select the root that places the new position closer to the original position.

The additional loop completely eliminated all problems of interface vertex spacing. Eventually, however, the shock deformed the drop so severely that at time $1.71 \times 10^{-5}$ (cycle 383), cell inversions took place in the folded region around vertex $(16,6)$ and we ended the run. To proceed further would require a slideline treatment and/or moving cells from one side of the interface to the other, but a project of this magnitude was beyond the scope of this study. The CPU time required for the run was $41.5 \mathrm{~s}$ on the CDC-7600, with a grind time of $0.174 \mathrm{~ms}$.

It can be noted in Fig. 11 that our rezone allowed the vertices along the inflow boundary (the $j=2$ line) to 

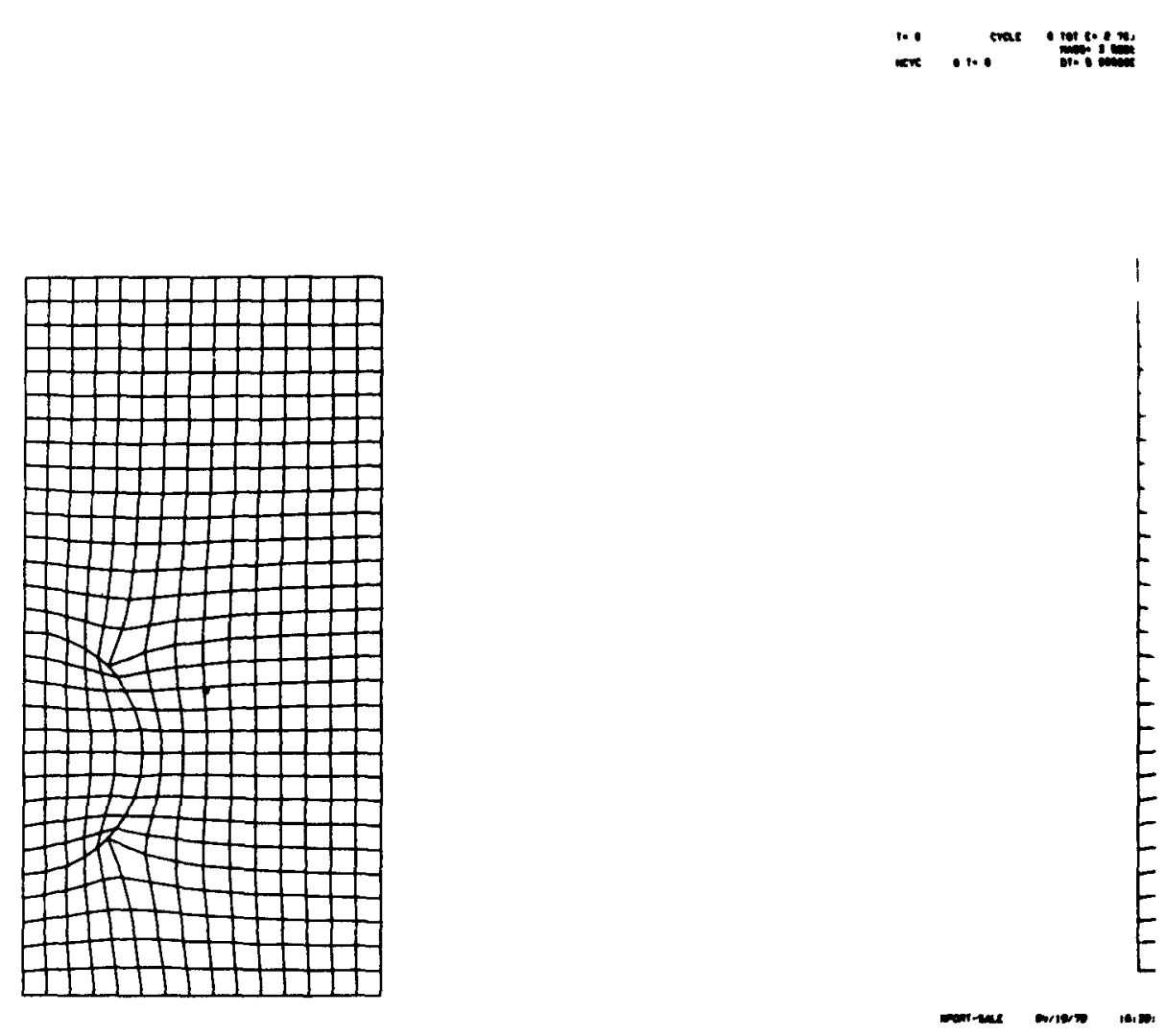

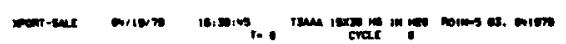

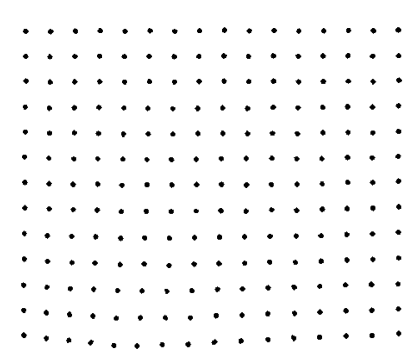

Fig. 10.

Initial mesh configuration for the mercury drop calculation. 

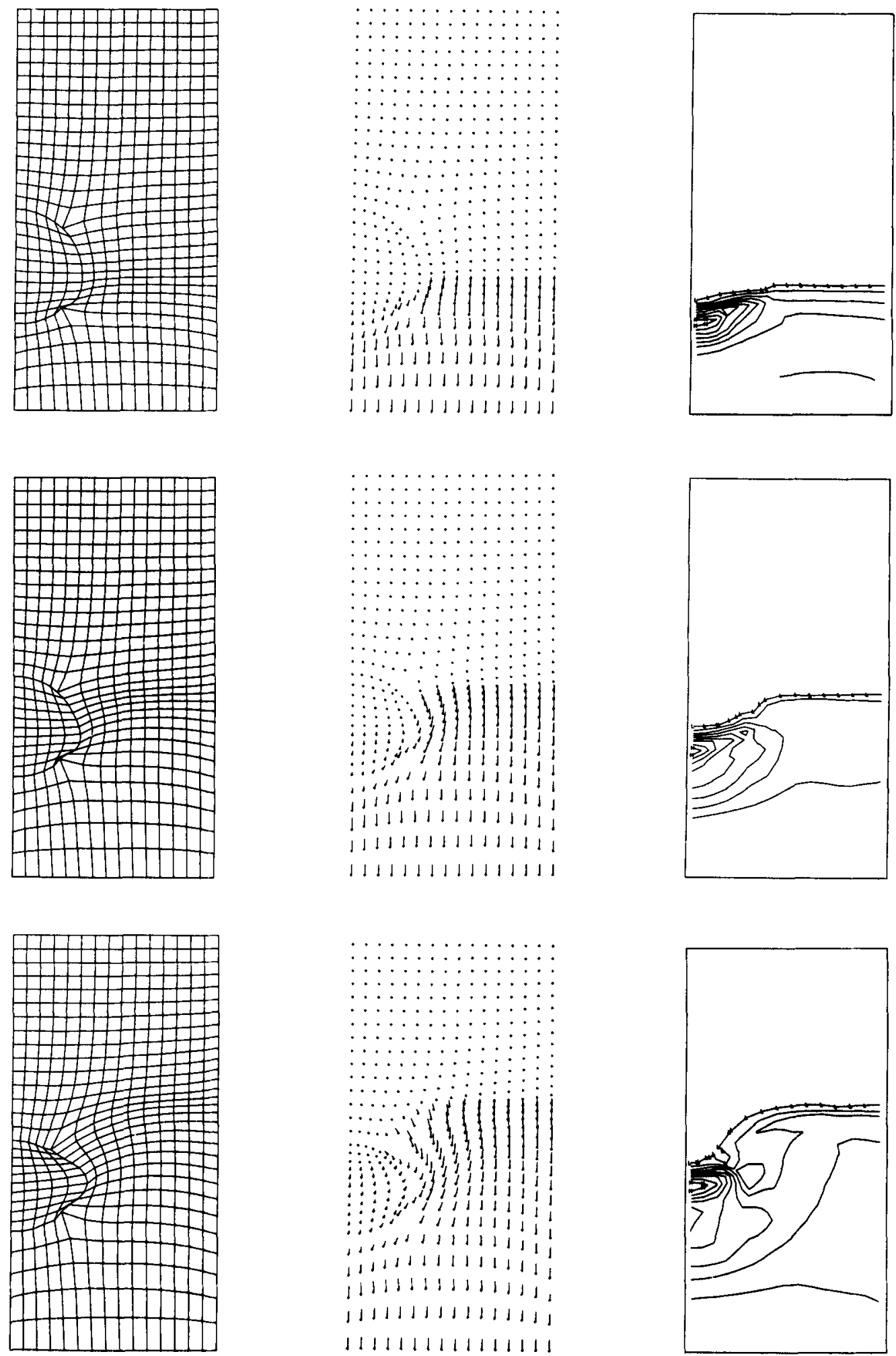

Fig. 11.

SALE calculation of a strong shock passing over a mercury drop in water. From left to right: the computing mesh, velocity vectors, and isobars. From top to bottom, the sequences are at times $5.0 \times$ $10^{-6}, 7.5 \times 10^{-6}$, and $1.0 \times 10^{-5}$. 

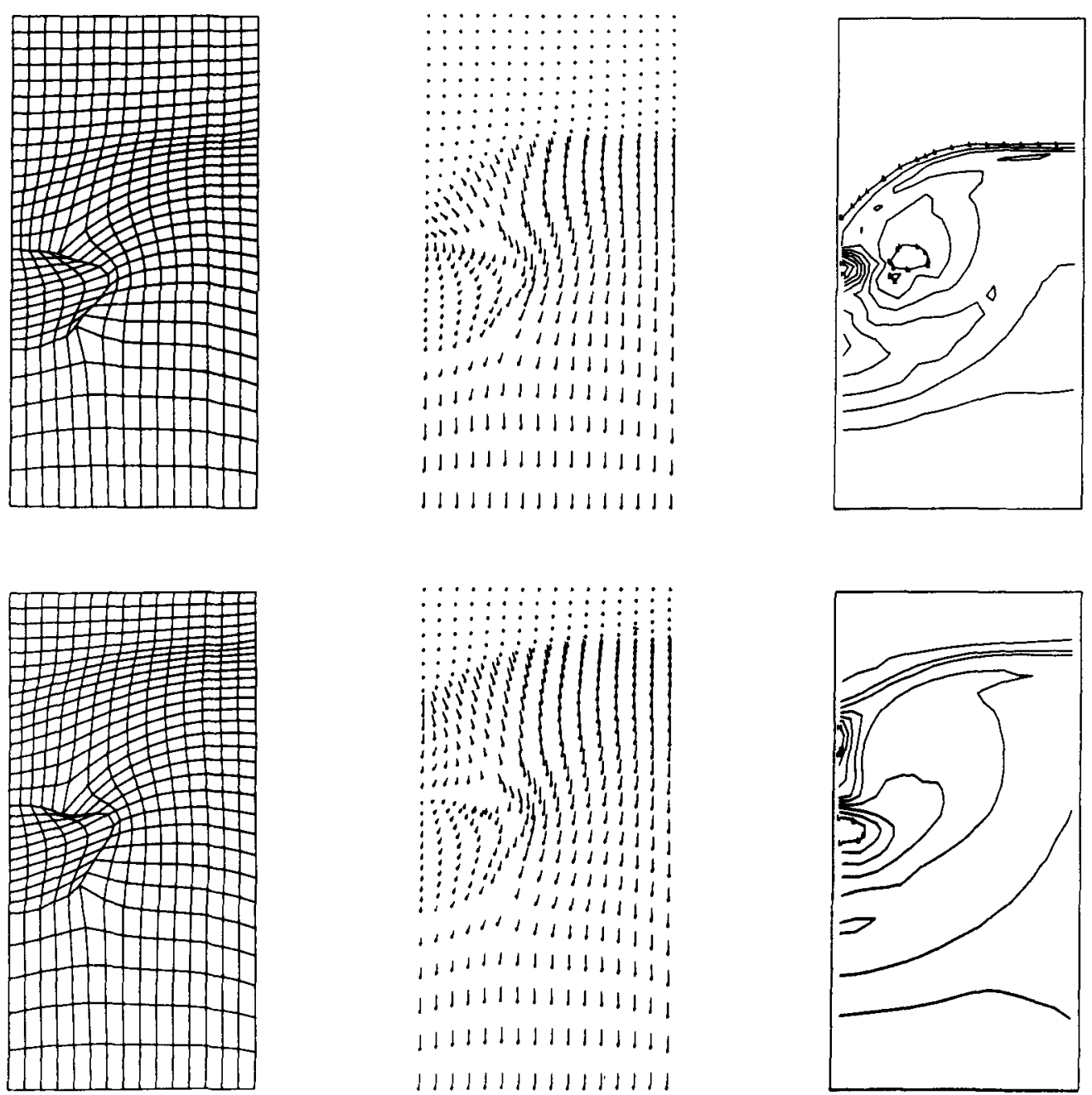

Fig. 11. (cont)

The times are $1.25 \times 10^{-5}$ and $1.50 \times 10^{-5}$.

move. As a result, the inflow conditions were not perfectly maintained. This particular calculation was not significantly affected, but as a general rule the vertices on a specified inflow boundary should not be allowed to move. A slight modification to the rezone logic to ensure zero grid velocities at these vertices can easily be made.

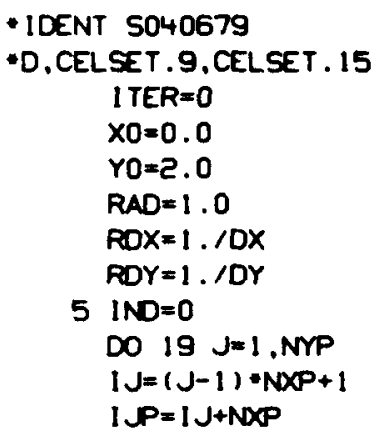

- IDENT 5040679

-D, CELSET . 9, CELSET . 15

ITER $=0$

$X O=0.0$

$Y O=2.0$

$R A D=1.0$

$\mathrm{ROX}=1.10 \mathrm{X}$

ROY $=1.10 Y$

5 INO=0

DO $19 \mathrm{~J}=1$. NYP

I $J=(J-1) \cdot N D P+1$

$I P=[J+N D P$ 


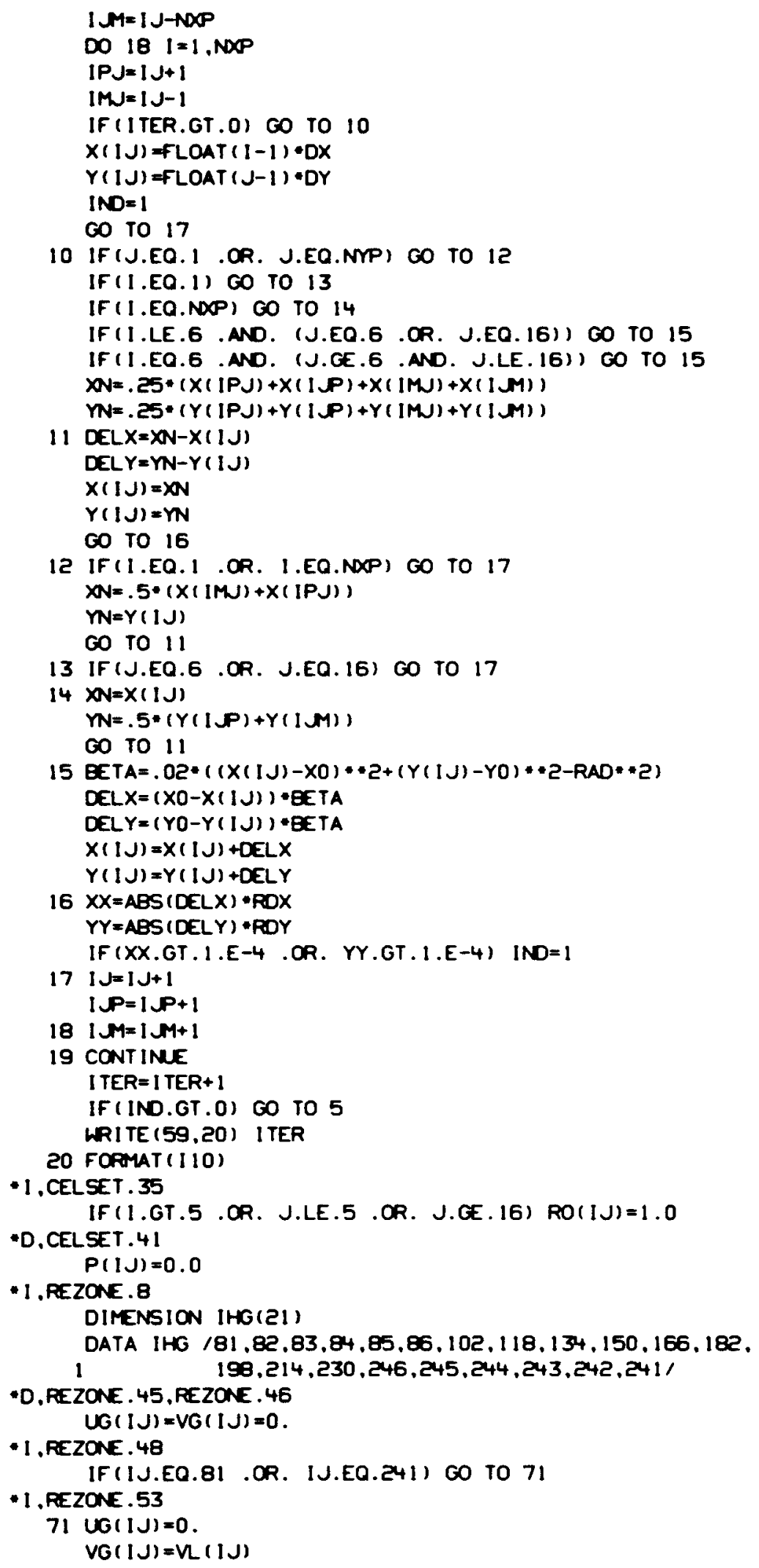




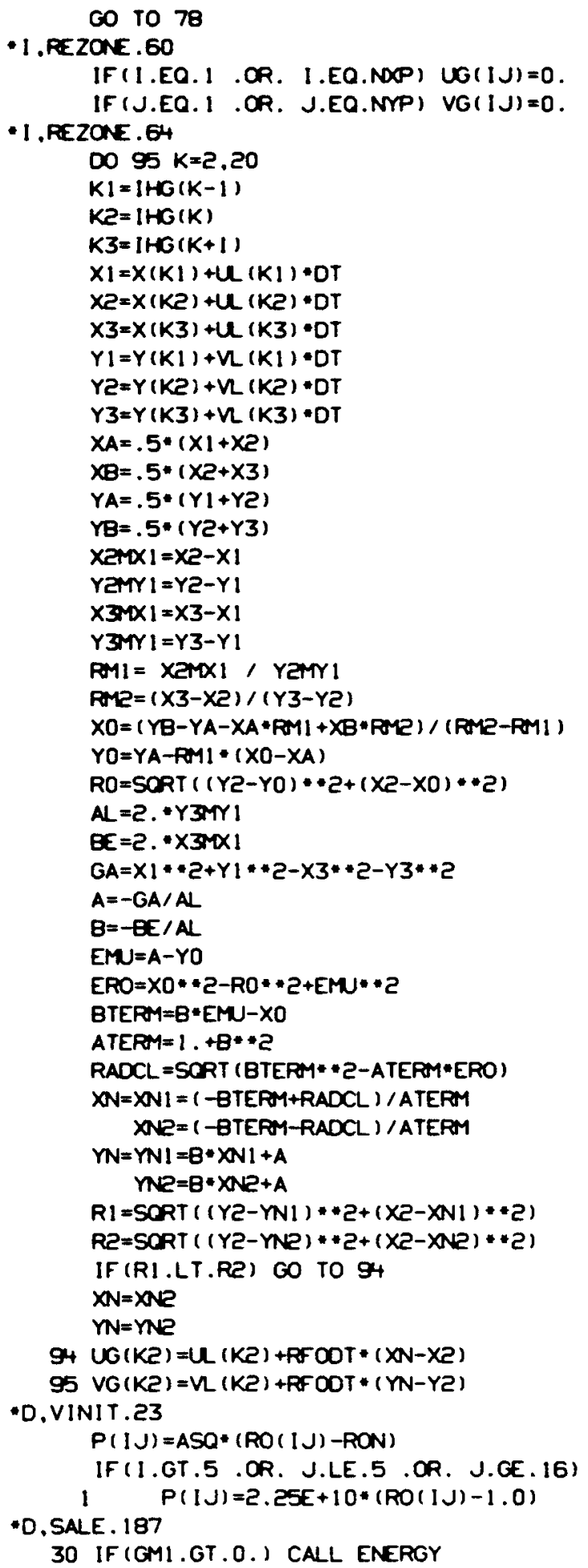

T3AAA $15 \times 30$ HO IN H2O, ROIN=5.83 VIN=3.0E5.

$\begin{array}{lr}\text { NX } & 15 \\ \text { NY } & 30 \\ \text { IMP } & 0 \\ \text { INC } & 0\end{array}$

\begin{tabular}{|c|c|}
\hline IREZ & 2 \\
\hline LPR & 1 \\
\hline WB & 5 \\
\hline WL & 1 \\
\hline WR & 1 \\
\hline WT & 4 \\
\hline$D X$ & 0.2 \\
\hline DY & 0.2 \\
\hline $\mathrm{cr}$ & 1.0 \\
\hline DT & 5. OE-B \\
\hline Dtmax & $5.0 \varepsilon-\theta$ \\
\hline TLIND & 0.0 \\
\hline TWF ILM & $5.0 E-6$ \\
\hline TWPRTR & 100.0 \\
\hline TWF IN & $4.0 E-5$ \\
\hline$O M$ & 0.0 \\
\hline PEPS & 0.0 \\
\hline EPS & 0.0 \\
\hline RF & 1.0 \\
\hline ARTVIS & 0.1 \\
\hline LAMBDA & 0.0 \\
\hline$M$ & 0.0 \\
\hline ANC & 0.05 \\
\hline$x \mid$ & 1.0 \\
\hline$G X$ & 0.0 \\
\hline GY & 0.0 \\
\hline$A O$ & 0.5 \\
\hline $\mathbf{B O}$ & 0.0 \\
\hline ASO & $2.1025 E+10$ \\
\hline RON & 13.5 \\
\hline GMI & 0.0 \\
\hline ROI & 13.5 \\
\hline SIEI & 0.0 \\
\hline UIN & 0.0 \\
\hline VIN & $3.0 E+5$ \\
\hline ROIN & 5.83 \\
\hline SIEIN & 0.0 \\
\hline PAP & 0.0 \\
\hline
\end{tabular}

\section{REFERENCES}

1. F. H. Harlow and A. A. Amsden, "A Numerical Fluid Dynamics Calculation Method for All Flow Speeds," J. Comput. Phys. 8, 197-213 (1971). Reprinted in AIAA Selected Reprints, Vol. XV, "Computer Fluid Dynamics-Recent Advances," 83-91 (1973).

2. C. W. Hirt, A. A. Amsden, and J. L. Cook, "An Arbitrary Lagrangian-Eulerian Computing Method for All Flow Speeds," J. Comput. Phys. 14, 227-253 (1974).

3. A. A. Amsden and C. W, Hirt, "YAQUI: An Arbitrary Lagrangian-Eulerian Computer Program for Fluid Flow at All Speeds," Los Alamos Scientific Laboratory report LA-5100 (March 1973). 
4. C. W. Hirt, "Heuristic Stability Theory for Finite Difference Equations," J. Comput. Phys. 2, 339 (1968).

5. F. H. Harlow and A. A. Amsden, "Fluid Dynamics," Los Alamos Scientific Laboratory report LA-4700 (June 1971).
6. A. A. Amsden and C. W. Hirt, "A Simple Scheme for Generating General Curvilinear Grids," J. Comput. Phys. 11, 348-359 (1973).

7. H. Schlichting, Boundary Layer Theory (McGrawHill Book Co., New York, 1960), pp. 16, 18. 


\section{APPENDIX A}

\section{FORTRAN LISTING OF THE SALE PROGRAM}

Note added in proof:

Line CELSET.53 should read: DO $180 \mathrm{~J}=$ JFIRST,JLAST

Line CELSET.54 should read: $\mathrm{IJ}=(\mathrm{J}-1)^{*} \mathrm{NXP}+\mathrm{IFIRST}$

Line CELSET.56 should read: DO 170 I=IFIRST,ILAST

Line CELSET.67 should read: DO $200 \mathrm{~J}=$ JFIRST,JLASTV

Line CELSET.68 should read: IJ $=(\mathrm{J}-1)^{*} \mathrm{NXP}+\mathrm{IFIRST}$

Line CELSET.69 should read: DO 190 I=IFIRST,ILASTV

Line TIMSTP. 9 should read: DO $40 \mathrm{~J}=\mathrm{JFIRST}$,JLAST

Line TIMSTP. 10 should read: $\quad \mathrm{IJ}=(\mathrm{J}-1)^{*} \mathrm{NXP}+$ IFIRST

Line TIMSTP.12 should read: DO 30 I=IFIRST,ILAST 
LASL Identification No. LP-2023

PROGRAM SALE (ITAPE. TAPE5=1 TAPE, TAPE6, TAPE7, TAPE8, TTY, TAPE59=TTY) SALE

$\mathrm{C}+4+$

C +t+ SALE 2D - A SIMPL IFIED ICED ALE PROGRAM IN 2 DIMENSIONS:

C +++ A.A.AMSOEN, LASL T-3. LA-8095 REPORT VERSION, $011780 / 1045$

SALE

SALE 4

$+++$

C

(1) INPUT QUANTITIES-

NAME PROBLEM IDENTIFICATION LINE

NX NO. OF CELLS IN X-DIRECTION (OR O IF TAPE RESTART)

SALE 5

SALE 6

SALE 7

SALE 8

SALE 9

SALE 10

SALE 11

NY NO. OF CELLS IN Y-DIRECTION IOR DUMP NO. IF TAPE RESTART) SALE 13

IMP $\quad=$ FOR IMPLICIT PRESSURE CALCULATION. SALE 14

$=0$ FOR PUPELY EXPLICIT CALCULATION

SALE 15

INC $=1$ FOR INCOMPPESSIBLE LIMIT VARIANT OF IMP=1 CALCULATION

IRE $Z$ REZONE FLAG- $0=E U$ ERIAN, $1=$ LAGRANGIAN, 2 OR GREATER

SALE 16

FOR SOME SPECIFIED CONTINUOUS REZONE

LPR LONG PRINT CONTRQL - $0=O M I T, \quad 1=F I L M, 2=F$ ILM AND PRINITER. 3=PRINTER

WB.WL.WR. WT INOICATORS FOR BOUNDARY CONDITION TO BE USED

SALE 17

SALE 18

SALE 19

SALE 20

SALE 21

ALONG THE BOTTOM,LEFT.RIGHT. AND TOP EDGES SALE 22

OF THE MESH ( $0=L A$ PANGIAN SURFACE, $1=$ SIMPLE FREESLIPSALE 23 $2=$ GENERAL FREESL IP FOR CURVILINEAR BOUNOARIES. $3=$ SALE 24 NOSL IP, $4=$ =ONT INUATIVE OUTFLOW, 5=SPECIFIED INFLOW SALE 25 OR OUTFLOW, 6=APPL IED PRESSURE )

DX CELL SIZE IN THE X-DIRECTION IF UNIFORM Y ZONED

SALE 26

SALE 27

DY CELL SIZE IN THE Y-DIRECTION IF UNIFORMYY ZONED

SALE 28

CYL $\quad=1.0$ FOR CYLINORICAL GEOMETRY, =0.0 FOR PLANE GEOMETRY SALE 29

DT TIME STEP, SUBECT TO AUTOMATIC RECALCULATION DURING RUN SALE 30

DTMAX MAXIMUM DT ALLONED

TLIMD $=1.0$ FORCES A TAPE DUMP EXIT BEFORE JOB TIME LIMIT

TWF ILM PROBLEM TIME INTERVAL BETWEEN FILM PLOTS

TWPRTR PROBLEM TIME INTERVAL BETWEEN LONG PRINTS

TWF IN PROBLEM TIME HEN TO TERMINATE THE CALCULATION

GM RELAXATION COEFF ICIENT USED IN PRESSURE ITERATION

PEPS PRESSURE FRACTION SCAL ING THE RELAXATION FACTOR RDSDP

SALE 31

SALE 32

SALE 33

SALE 34

SALE 35

SALE 36

SALE 37

EPS ALLONED RELATIVE ERROR IN THE PRESSURE ITERATION

SALE 38

RF RELAXATION FACTOR FOR CONT INUOUS GRID REZONING

ARTVIS ARTIFICIAL (BULK) VISCOSITY COEFFICIENT

LAMBOA BULK $V I S C O S I T Y$ COEFF ICIENT

$M$ SHEAR VISCOSITY COEFFICIENT

ANC ALTERNATE NOOE-COUPLER COEFF ICIENT

$X I \quad=1$. FOR 4 TH-ORDER NOOE COUPL ING,

$=0$. FOR ZND-OROER NOOE-COUPLING

GX BODY ACCELERATION IN X-DIRECTION. + OR -

GY BODY ACCELERATION IN Y-DIRECTION, + OR -

AO. BO FACTORS CONTROLLING CONVECTIVE FLUXING. LIMITING CASESCENTERED; UNSTABLE

$\begin{array}{lllll}1 & 0 & \text { FULL DONOR CELL; STABLE; DIFFUSIVE } & \text { SALE } & 50 \\ 0 & 1 & \text { INTERPOLATED DONOR CELL: LINEARLY STABLE; NON-DIFFIJSIVESALE } & 51\end{array}$

SALE 39

SALE 40

SALE 41

SALE 42

SALE 43

SALE 44

SALE 45

SALE 46

SALE 47

SALE 48

SALE 49

$\begin{array}{lllll}1 & 0 & \text { FULL DONOR CELL; STABLE; DIFFUSIVE } & \text { SALE } & 50 \\ 0 & 1 & \text { INTERPOLATED DONOR CELL: LINEARLY STABLE; NON-DIFFIJSIVESALE } & 51\end{array}$

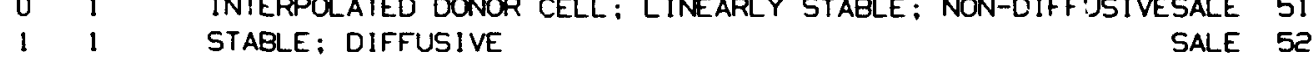

ASO, RON, GMI PARAMETERS FOR STIFFENED POLYTROPIC GAS EQUATION SALE 53 OF STATE- ASQ IS THE SQUARE OF THE ZERO-TEMPERA- SALE 54 TURE SOUND SPEED, RON IS THE FLUID NORMAL SALE 55 DENSITY. AND GMI IS GAMMA-1. IN WHICH GAMMA IS THESALE 56 RATIO OF SPECIFIC HEATS

ROI, SIEI INITIAL FLUID DENSITY AND SPECIFIC INTERNAL ENERGY SALE 58

UIN. VIN, ROIN. SIEIN DESCRIPTORS FOR A SPECIFIED FLOW BOUNDARY - SALE 59 $X$-DIRECTION VELOCITY, Y-DIRECTION VELOCITY, SALE 60 DENSITY, AND SPECIFIC INTERNAL ENERGY SALE 61 


\begin{tabular}{|c|c|c|c|c|}
\hline $\begin{array}{l}C \\
c\end{array}$ & PAP & APPL IED PRESSURE FOR PRESSURE BONDARY CONOITION & $\begin{array}{l}\text { SALE } \\
\text { SALE }\end{array}$ & $\begin{array}{l}62 \\
63\end{array}$ \\
\hline C & (2) DERIVED & QUANTITIES: & SALE & 64 \\
\hline $\mathbf{C}$ & & & SALE & 65 \\
\hline C & aMcrL & $1-\mathrm{CrL}$ & SALE & 66 \\
\hline C & ANCO & $\mathrm{ANC} / 4$ & SALE & 67 \\
\hline c & XICOF & $(1+x() / 2$ & SALE & 68 \\
\hline C & COLAM & LAMBDA+Z*MN & SALE & 69 \\
\hline C & DPCOF & PEPS*ROI/(2(1/(DX*DX)+1/(DY*DY))) & SALE & 70 \\
\hline C & GRF AC & $1 /(N X * N Y)$ & SALE & 71 \\
\hline C & TF ILM & PROQLEM TIME INTERVAL BETLEEN FILM PLOTS & SALE & 72 \\
\hline C & TPRTR & PROQLEM TIME INTERVAL BETLEEN LONG PRINTS & SALE & 73 \\
\hline C & NYP & $N Y+1$ & SALE & 74 \\
\hline C & NXP & $N X+1$ & SALE & 75 \\
\hline C & THE FOLOWI & ING 12 INDICES DEF INE DO-LOOP LIMITS, TO & SALE & 76 \\
\hline C & PROVIDE FIC & CTITIOUS CELLS FOR CERTAIN BOUNDARY TYPES: & SALE & 77 \\
\hline c & IF IRST & $=1$ IF $W L=1,2,3$ OR $4 ;=2$ IF $W L=5$ OR 6 & SALE & 78 \\
\hline c & FIRST & $=1$ IF $W B=1,2,3$ OR 4; $=2$ IF $W B=5$ OR 6 & SALE & 79 \\
\hline C & ILAST & $=N X$ If $W R=1,2,3$ OR 4; $=N X-1$ IF $W R=5$ OR 6 & SALE & 80 \\
\hline C & LAST & $=N Y \quad$ IF $W T=1,2,3$ OR 4: $=N Y-1$ IF $W T=5$ OR 6 & SALE & 81 \\
\hline c & IFPHI & $=1 \quad$ IF $\quad K L=1,2,3,4$ OR $6 ;=2 \quad$ IF $\quad K L=5$ & SALE & 82 \\
\hline c & JFPHI & $=1 \quad$ IF $W B=1,2,3,4$ OR $6 ;=2$ IF $W B=5$ & SALE & 83 \\
\hline C & ILPHI & $=N X$ IF $W R=1,2,3,4$ OR $6:=N X-1$ IF $W R=5$ & SALE & 84 \\
\hline C & LPHI & $=N Y$ IF $W T=1,2,3,4$ OR $6 ;=N Y-1$ IF $W T=5$ & SALE & 85 \\
\hline c & ILASTV & ILAST +1 & SALE & 86 \\
\hline C & LASTV & $\mathcal{L A S T}+1$ & SALE & 87 \\
\hline C & ILASTM & ILAST-I & SALE & 88 \\
\hline c & LASTM & lAST-1 & SALE & 89 \\
\hline C & & & SALE & 90 \\
\hline C & (3) SCALAR O & QUANTITIES: & SALE & 91 \\
\hline C & & & SALE & 92 \\
\hline C & $T$ & PROBLEM TIME & SALE & 93 \\
\hline C & NCYC & CYCLE COUNTER & SALE & 94 \\
\hline C & IPRES & $=1$ DURING ITERATION TO LET CONTINUATIVE BORY. U., VL FLOAT & SALE & 95 \\
\hline C & MAXIT & MAXIMM NO. OF ITERATIONS ALLOWED BEFORE DT CUT IN HALF & SALE & 96 \\
\hline C & NMMIT & NO. OF ITERATIONS RECO. FOR PRESSURE ITERATION CONVERGENCE & ESALE & 97 \\
\hline C & LOOPS & NO. OF DT CUTS FOR NON-CONVERGENCE PERFORMED & SALE & 98 \\
\hline C & & IN A GIVEN CYCLE & SALE & 99 \\
\hline C & LOOPMX & LIMITS NO. OF TIMES BEFORE ERROR STOP THAT DT CAN BE & SALE & 100 \\
\hline C & & CUT DUE TO NON-CONVERGENCE IN A GIVEN CYCLE & SALE & 101 \\
\hline C & THIRD & $1 / 3$ & SALE & 102 \\
\hline C & ThLF TH & $1 / 12$ & SALE & 103 \\
\hline C & PMAX & MAXIMM PRESSURE IN THE SYSTEM & SALE & 104 \\
\hline C & GRINO & CENTRAL PROCESSOR TIME PER CELL PER CYCLE, IN MSEC & SALE & 105 \\
\hline C & NDMP & TAPE DUMP COUNTER & SALE & 106 \\
\hline c & DROU & SCAL ING FACTOR FOR THE VELOCITY VECTOR PLOT & SALE & 107 \\
\hline C & VMAX & MAXIMUM VELOCITY IN THE SYSTEM & SALE & 108 \\
\hline C & DTF & TIME-STEP FACTOR FOR CONVECTIVE STABILITY AND ACCURACY & SALE & 109 \\
\hline C & $\mathrm{Cl}$ & WALL CLOCK HRS/MIN/SEC WHEN THE JOB BEGAN & SALE & 110 \\
\hline C & D1 & MONTH/DAY/YEAR WHEN THE JOB BEGAN & SALE & 111 \\
\hline C & $x \mathbf{L}$ & $X$-COORDINATE OF THE LEFTMOST VERTEX & SALE & 112 \\
\hline C & YB & Y-COORDINATE OF THE BOTTOMMOST VERTEX & SALE & 113 \\
\hline C & $F I X$ & FILM-FRAME COOROINATE ANALOG OF XL & SALE & 114 \\
\hline C & FIYB & FILM-FRAME COORDINATE ANALOG OF YB & SALE & 115 \\
\hline C & XCONV & FILM-FRAME CONVERSION COEFF ICIENT IN X-OIRECTION & SALE & 116 \\
\hline C & YCONV & FILM-FRAME CONVERSION COEFF ICIENT IN Y-DIRECTION & SALE & 117 \\
\hline C & TIMLMT & JOB TIME LIMIT, IN SECONDS & SALE & 118 \\
\hline C & DTMIN & MINIMM DT ALLOWED, = (DT OF CYCLE 1 )*E-10 & SALE & 119 \\
\hline C & IDOT & SYMBOL IDENTIFYINC. THE RESTRICTION CONTROLL ING THE & SALE & 120 \\
\hline c & & CURRENT TIME STEP, WHERE: G=105X OF PREVIOUS OT, & SALE & 121 \\
\hline
\end{tabular}




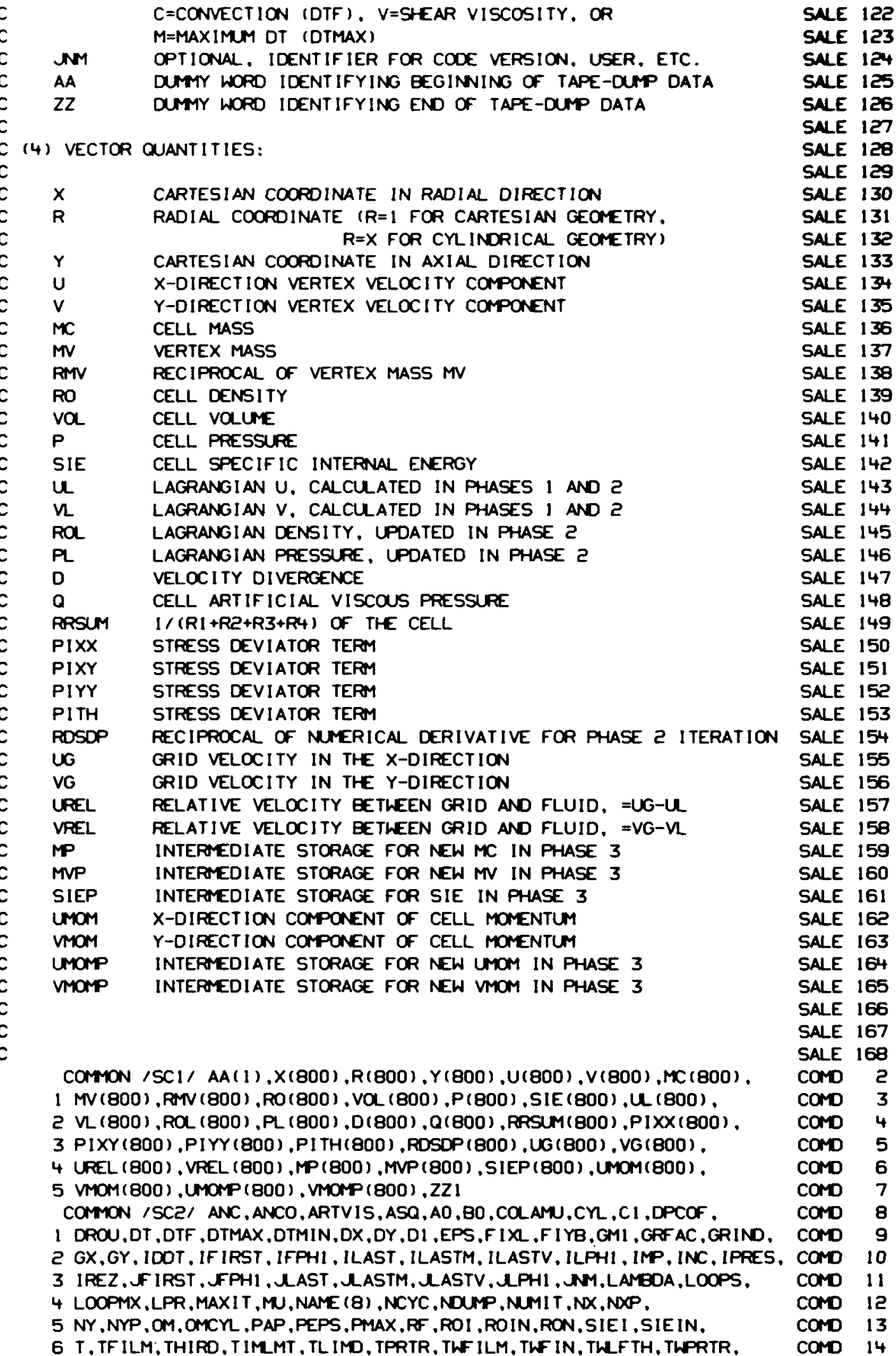




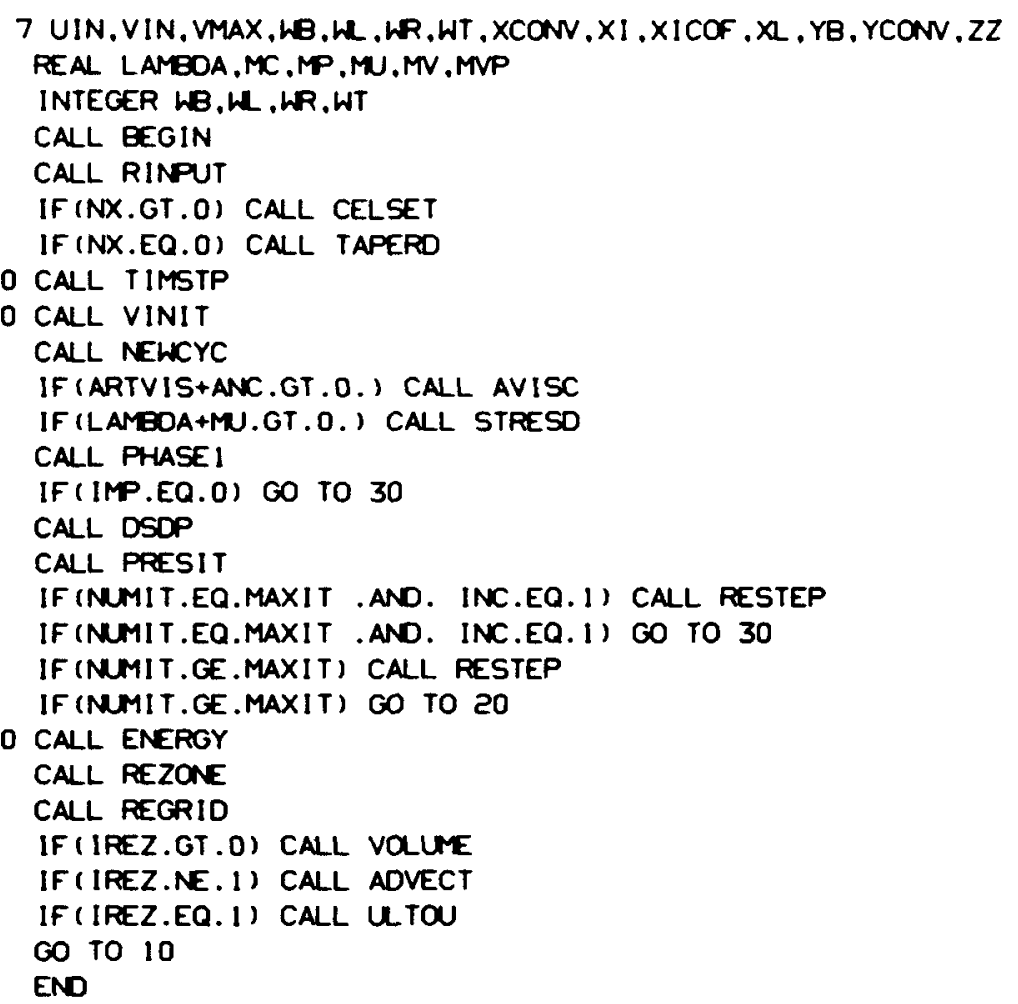

COMD 15

COMD 16

COMD 17

SALE 170

SALE 171

SALE 172

SALE 173

SALE 174

SALE 175

SALE 176

SALE 177

SALE 178

SALE 179

SALE 180

SALE 181

SALE 182

SALE 183

SALE 184

SALE 185

SALE 186

SALE 187

SALE 188

SALE 189

SALE 190

SALE 191

SALE 192

SALE 193

SALE 194 
SUBROUT INE ADVECT

COMMON /SCl/ AA (1),X(800),R(800), Y(B00),U(800),V(800),MC $(800)$.

$1 M V(800)$, RATV $(800), R O(800), V O(800), P(800), S I E(800), U(800)$.

$2 \mathrm{VL}(800), R O L(800), P L(800), D(800), Q(800), R R S U M(800), P I X X(800)$,

3 PIXY (800), PIYY (800), PITH(800), ROSOP $(800), U G(800), V G(800)$,

4 UREL $(800)$, VREL $(800), \operatorname{MP}(800)$, MVP $(800)$, SIEP $(800)$, UMOM $(800)$.

5 VMOM $(800)$, UMOMP $(800)$, VMOMP $(800), 2 Z 1$

COMHON /SC2/ ANC, ANCO, ARTVIS, ASQ, AO,BO,COLAM, CY, C1,DPCOF,

1 DROU,DT,DTF, DTMAX, DTMIN,DX,DY,DI, EPS, FIXL, FIYB, GMI ,GRF AC, GRINO,

2 GX,GY, IDOT, IF IRST, IFPHI, ILAST, ILASTM, ILASTV, ILPHI, IMP, INC, IPRES,

3 IREZ, IF IRST, JFPHI , LAST, LASTM, LASTV, LPHI , NM, LAMEDA , LOOPS,

4 LOOPMX, LPR, MAXIT , MU, NAME (8), NCYC, NOUMP, NUMI T, NX, NXP,

5 NY, NYP, OM, OMCY , PAP, PEPS, PMAX, RF, ROI, ROIN, RON, SIEI , SIEIN,

6 T, TFILM, THIRD, TIM MT, TL IMD, TPRTR, THF ILM, TWF IN, THLFTH, THPRTR,

7 UIN, VIN, VMAX, WB, WL, WR, WT , XCONV, XI , XICOF, XL, YB, YCONV, ZZ

REAL LAMBOA,MC,MP,MU,MV,MVP

INTEGER WB, WL, WR, WT

DIMENSION AT (100), FT (100)

C +++

C +++ PHASE 3. FLUXING OF CELL CENTERED QUANTITIES - MASS, ENERGY,

C +++ AND MOMENTUM. THEN CONVERT MOMENTA TO VELOCITIES.

C +++ CALLED ONLY IF EULERIAN (IREZ=0) OR OTHER REZONE (IREZ.GE.?)

$\mathrm{C}+++$

C +++ NOTE DO-LOOP LIMITS - INFLOW BOUNDARIES REOUIRE A MOMENTUM THAT

$\mathrm{C}+++$ CAN BE FLUXED IN . .

$\mathrm{C}+++$

DO $20 \mathrm{~J}=1$, NY

$I J=(J-1) * N \times P+1$

$1 \mathrm{P}=1 \mathrm{~J}+\mathrm{N} \times \mathrm{P}$

DO $10 \quad 1=1, \mathrm{NX}$

$[P J=1 \mathrm{~J}+1$

IPJP=I $P+1$

UMOM $(I J)=.25 * R O(I J) *(U(I P J)+U(I P P)+U(I J)+U(I J))$

$\operatorname{VMaM}(I J)=.25 * R O Q(I J) *(V(I P J)+h(I P J)+V(I P)+V(I J))$

$1 \mathrm{I}=I \mathrm{PJ}$

10 I $P=I P S$

20 CONTINUE

DO $60 \mathrm{~J}=J$ FIRST . LAST

$I J=(J-1) * N X P+I F I R S T$

$1 T P=1 J+N \times P$

$I M=I J-N X P$

DO 50 I = IF IRST, ILAST

IMJ $=1 J-1$

$[P J=1 J+1$

IPJ $\mathbf{P}=\mid \boldsymbol{P}+1$

$X]=X(I P J)$

$Y I=Y(I P J)$

$R !=R(I P J)$

$X Z=X(I P S P)$

$Y Z=Y(I P J P)$

$R 2=R(I P J)$ )

$X 3=X(I P P)$

$Y Z=Y(I P)$

$R 3=R(I P)$

$X 4=X(I J)$

$Y 4=Y(1 J)$

$R_{4}=R(I J)$

$X P 1=X 1-U R E L(I P J) * D T$

$X P 2=X 2-U R E L(I P J) * D T$

$X P 3=X 3-U R E L(I N P): D T$

$X P_{4}=X 4-U R E L(I J)$ "DT

$Y P I=Y 1-V R E L(I P J) * D T$

$Y P Z=Y Z-V R E L(I P J) * D T$

AOVECT 2

COMD 2

COND 3

COMD 4

COMD 5

COMD 6

COMD 7

COMD 8

COMD 9

COND 10

COMD 11

COMD 12

COMD 13

COMD 14

COMD 15

COMD 16

COMD 17

ADVECT 4

AOVECT 5

ADVECT 6

ADVECT 7

ADVECT 8

ADVECT 9

ADVECT 10

ADVECT!I

ADVECT 12

ADVECT 13

ADVECT 14

ADVECT 15

ADVECT 16

ADVECT 17

AOVECT 18

ADVECT 19

ADVECT2O

ADVECT2I

ADVECT2Z

AOVECT23

ADVECT24

AOVECT25

AOVECTZ6

ADVECT27

AOVECT28

AOVECTZ9

AOVECT30

ADVECT31

ADVECT32

ADVECT 33

ADVECT 34

ADVECT 35

ADVECT 36

ADVECT 37

ADVECT 38

ADVECT 39

ADVECT4O

ADVECT41

ADVECT42

ADVECT43

ADVECT44

ADVECT45

ADVECT46

AOVECT47

ADVECT48

ADVECT49 
YPZ $=Y 3-V R E L(I P) * D T$

$Y P_{4}=Y 4-V R E L(I J) * D T$

$R P 1=X P 1 * C Y+O M C Y$

$P P 2=X P 2 * C Y L+O M C Y$

$R P 3=X P 3 * C Y L+O M C n$

$R P_{4}=X P_{4} * C Y L+O M C Y$

VOLL $=V O L B=V O R=V O L T=V O L C=V O L(I J)$

IF (I.NE. I) VOLL $=V O L(I M)$

IF (J.NE. I ) VOLB=VOL (IM)

IF (I.NE.NX) VOR=VQ (IPJ)

IF (J.NE.NY) VOLT=VQL IIP)

$F L=-F R$

$A L=-A R$

IF (1.EQ. 1) $F L=A L=0$.

IF (WL.LT.4) GO TO 30

IF (I.GT. IF IRST) GO TO 30

$F L=\left(\left(R P 3+R 4+R P_{4}\right) *\left(X P 3 *\left(Y 4-Y P_{4}\right)+X 4 *\left(Y P_{4}-Y P_{3}\right)+X P_{4} *\left(Y P_{3}-Y_{4}\right)\right)\right.$

$1+(R 3+R P 3+R+) *(X 3 *(Y 4-Y P 3)+X P 3 *(Y 3-Y 4)+X 4 *(Y P 3-Y 3))) *$ ThLF TH

$A L=A O * \operatorname{SIGN}(1 ., F L)+B O * 4 . F L /(V O L L+V O L C)$

$30 \mathrm{FB}=-\mathrm{FT}(\mathrm{I})$

$A B=-A T(I)$

IF (J.EQ.1) $F B=A B=0$.

IF (WB.LT.4) GO TO 40

IF (J.GT.FIRST) GO TO 40

$F B=\left(\left(R 1+R P_{1}+R P_{4}\right) *\left(X_{1} *\left(Y P_{1}-Y P_{4}\right)+X P_{1} *\left(Y P_{4}-Y_{1}\right)+X P_{4} *\left(Y 1-Y P_{1}\right)\right)\right.$

$\left.1+\left(R 1+R_{4}+R^{\prime} P_{4}\right) *\left(X 1 *\left(Y P_{4}-Y_{4}\right)+X_{4} *\left(Y 1-Y P_{4}\right)+X P_{4} *\left(Y_{4}-Y_{1}\right)\right)\right) * T h L F T H$

$A B=A O * S I G N(1, F B)+B O * 4 . F B /(V O B+V O C)$

$40 F R=((R 1+R P 1+R P Z) *(X) *(Y P Z-Y P 1)+X P 1 *(Y 1-Y P Z)+X P Z *(Y P 1-Y 1))$

$1+(R 1+R 2+R P Z) *(X 1 *(Y Z-Y P Z)+X Z *(Y P Z-Y 1)+X P Z *(Y 1-Y Z))) * T h L F T H$

$A R=A O * S I G N(1 \ldots F R)+B O * 4$. *FR/ $(V O R+V O C)$

$F T(1)=((R P 2+R 3+R P 3) *(X P 2 *(Y 3-Y P 3)+X 3 *(Y P 3-Y P 2)+X P 3 *(Y P Z-Y 3))$

$1+(R Z+R P Z+R 3) *(X 2 *(Y 3-Y P Z)+X P Z *(Y Z-Y 3)+X 3 *(Y P Z-Y Z))) * T W L F T H$

$A T(1)=A 0 * S I G N(1 \ldots F T(1))+B O * 4$. *FT $(1) /(V O L T+V O L C)$

$S I=F R+(1 .-A R)$

$S 2=F R *(1,+A R)$

$S 3=F T(1) *(1 .-A T(1))$

$S 4=F T(1) \cdot(1 .+A T(1))$

$S 5=F L+(1,-A L)$

$S 6=F L *(1 .+A L)$

$S 7=F B *(1 .-A B)$

$S B=F B *(1 .+A B)$

$S 9=51+S 3+S 5+57$

$M P(I J)=M C(I J)+59 * R O R(I J)+5 S * R O L(I P J)+54 * R O L(I P)$

1 $+S 6 * R O L(I M)+S 8 * R O L(1 M)$

ADVECT5O

ADVECT5I

ADVECT52

ADVECT53

ADVECT54

ADVECT55

ADVECT56

ADVECT57

ADVECT58

ADVECT59

ADVECT6O

ADVECT61

AOVECTE2

ADVECT63

ADVECT64

AOVECT65

ADVECT66

ADVECT67

ADVECT 68

ADVECT69

ADVECT7O

ADVECT71

ADVECT72

AOVECT73

ADVECT74

ADVECT 75

ADVECT 76

ADVECT77

ADVECT78

ADVECT79

ADVECT 80

ADVECT 81

ADVECTE2

ADVECT83

ADVECT84

ADVECT85

ADVECTES

ADVECT87

ADVECT 88

ADVECT89

ADVECT 90

ADVECTOI

ADVECTS2

AOVECT93

$\operatorname{SIEP}(I J)=(M C(I J) * \operatorname{SIE}(I J)+S 9 * R O L(I J) * \operatorname{SIE}(I J)+S 2 * R O L(I P J) * S I E(I P J) A D V E C T 94$

1 +S4*RO (I P) *SIE (I P) +S6*ROL (IMJ) *SIE (IMJ) AOVECTSS

2 $+S 8 * R O L(I M) * S I E(I M)), M P(I J)$

AOVECTS6

UMOMP $(I J)=S 9$ "UMOM (IJ) +S2*UMOM(IPJ) +S4 *UMOM(IJP)

ADVECT97

1 +S6. UMOM (IMU) +SE* UMOM (IM)

$\operatorname{VMOMP}(I J)=S 9 * \operatorname{VMOM}(I J)+S 2 * \operatorname{VMOM}(I P J)+54 * \operatorname{VMOM}(I J)$

1

$I J=I P J$

I $P=$ IP $\boldsymbol{P}$

50 I $M M=1 \mathrm{~N} M+1$

$\mathrm{C}+++$

60 CONTINUE

$\mathrm{C}+++$ COMPUTE NEW VERTEX MASSES

$\mathrm{C}+++$

DO $80 \mathrm{~J}=$ F IRST, LAST

I $J=(J-1) * N X P+I F$ IRST

$1 \mathrm{in}=1 \mathrm{I}+\mathrm{N} X \mathrm{P}$

DO 70 I = IF IRST . ILAST

$I P J=I J+1$

ADVECT98

ADVECTS9

ADVEC 100

ADVEC 101

AOVEC 102

ADVEC 103

ADVEC 104

ADVEC 105

ADVEC 106

ADVEC 107

AOVEC 108

ADVEC 109

ADVEC 110

ADVEC 111

ADVEC 112 


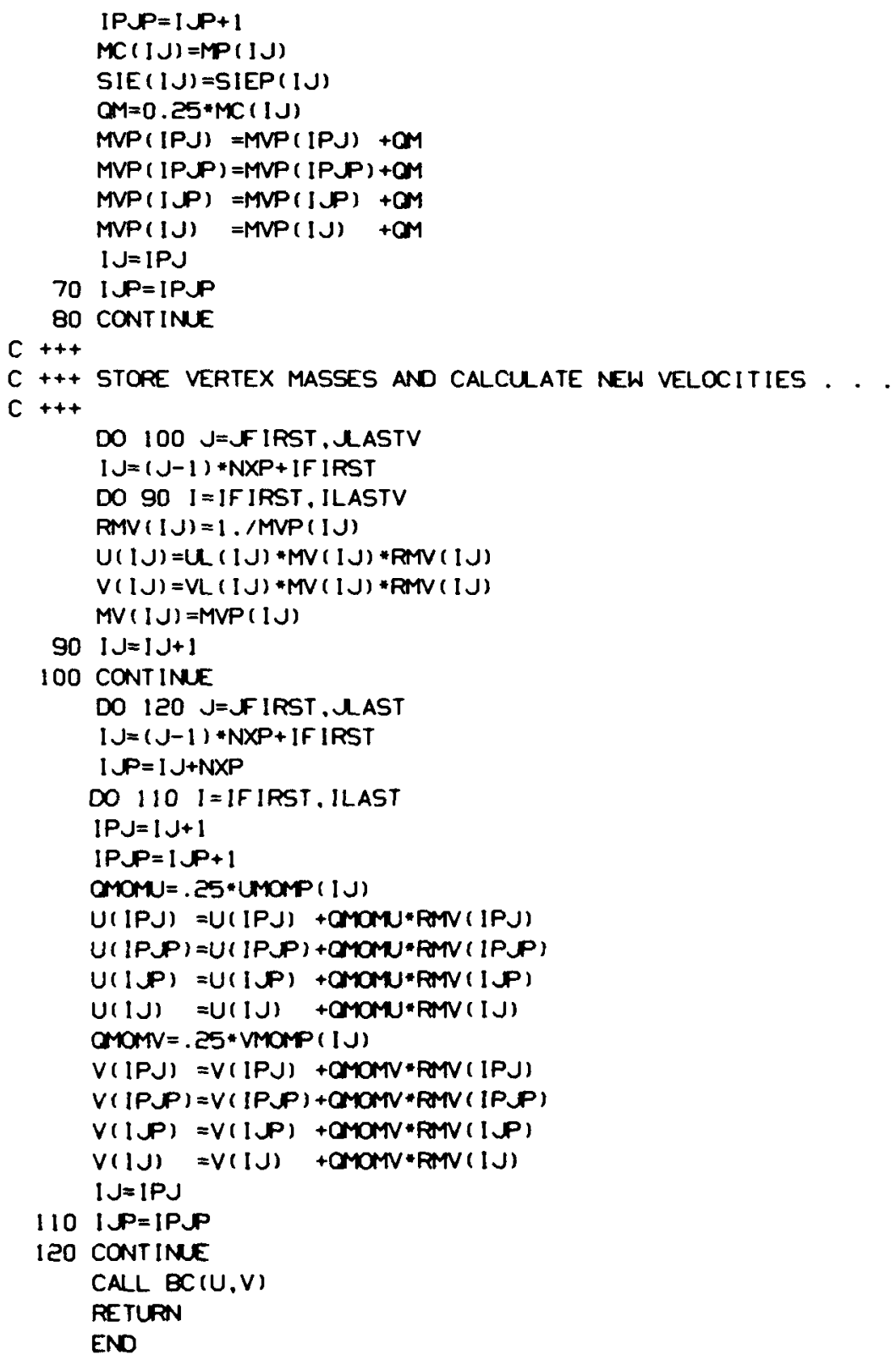

ADVEC 113

ADVEC114

ADVECI 15

ADVECI16

ADVEC 117

AOVEC 118

ADVEC 119

ADVEC 120

ADVEC 121

ADVEC122

AOVEC 123

ADVEC 124

ADVECI 25

ADVEC 126

ADVEC 127

ADVEC 128

ADVEC 129

ADVEC 130

ADVEC 131

ADVEC 132

ADVEC 133

ADVEC 134

ADVEC 135

ADVEC 136

ADVEC 137

ADVEC 138

ADVEC I 39

ADVEC 140

ADVEC 141

AOVEC 142

ADVEC 143

ADVEC 144

ADVEC 145

ADVEC 146

ADVEC 147

ADVEC 148

ADVEC 149

ADVEC 150

ADVEC 151

ADVEC 152

ADVEC 153

AOVEC 154

ADVEC 155

ADVEC 156

AOVEC 157 


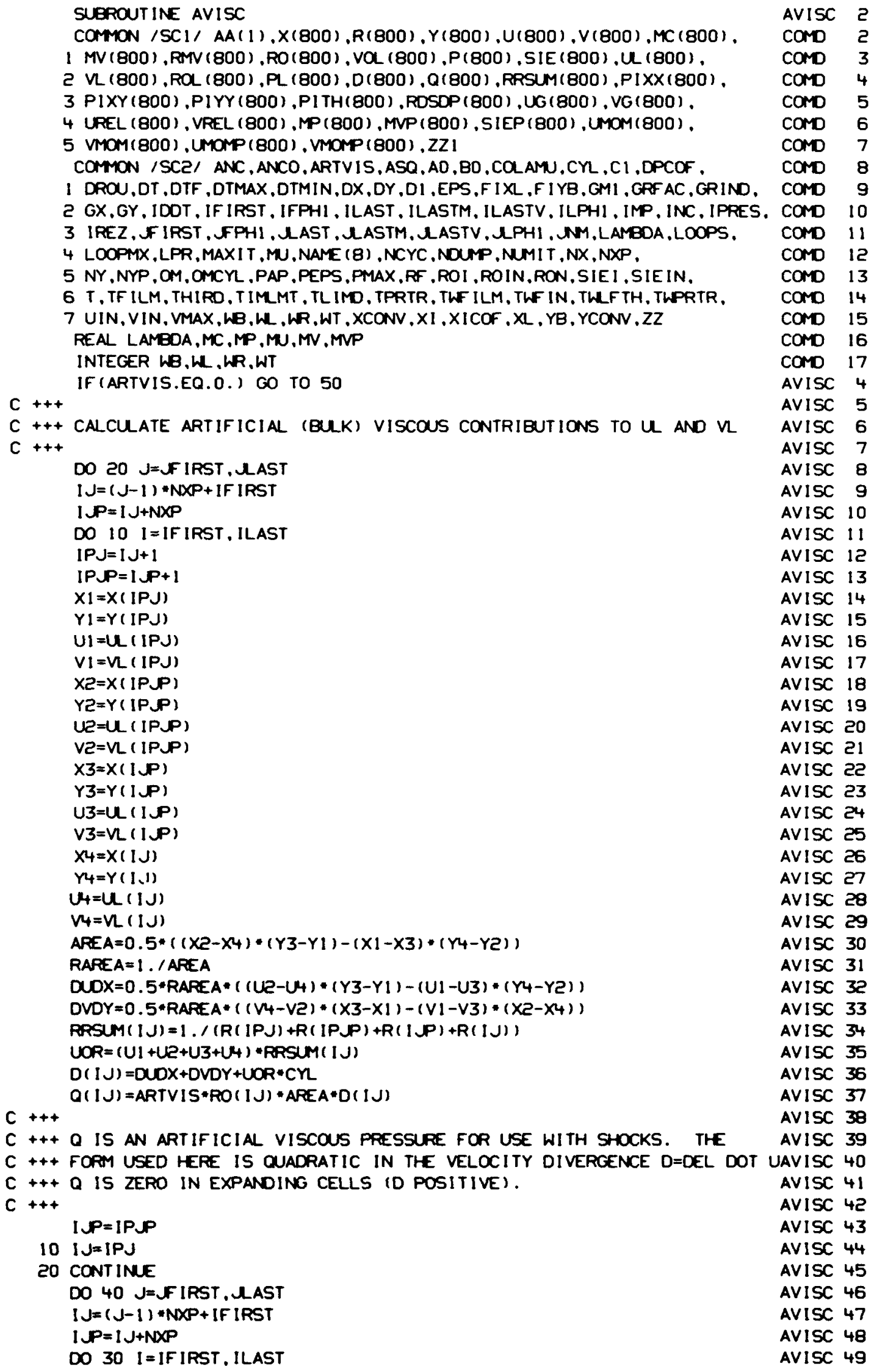




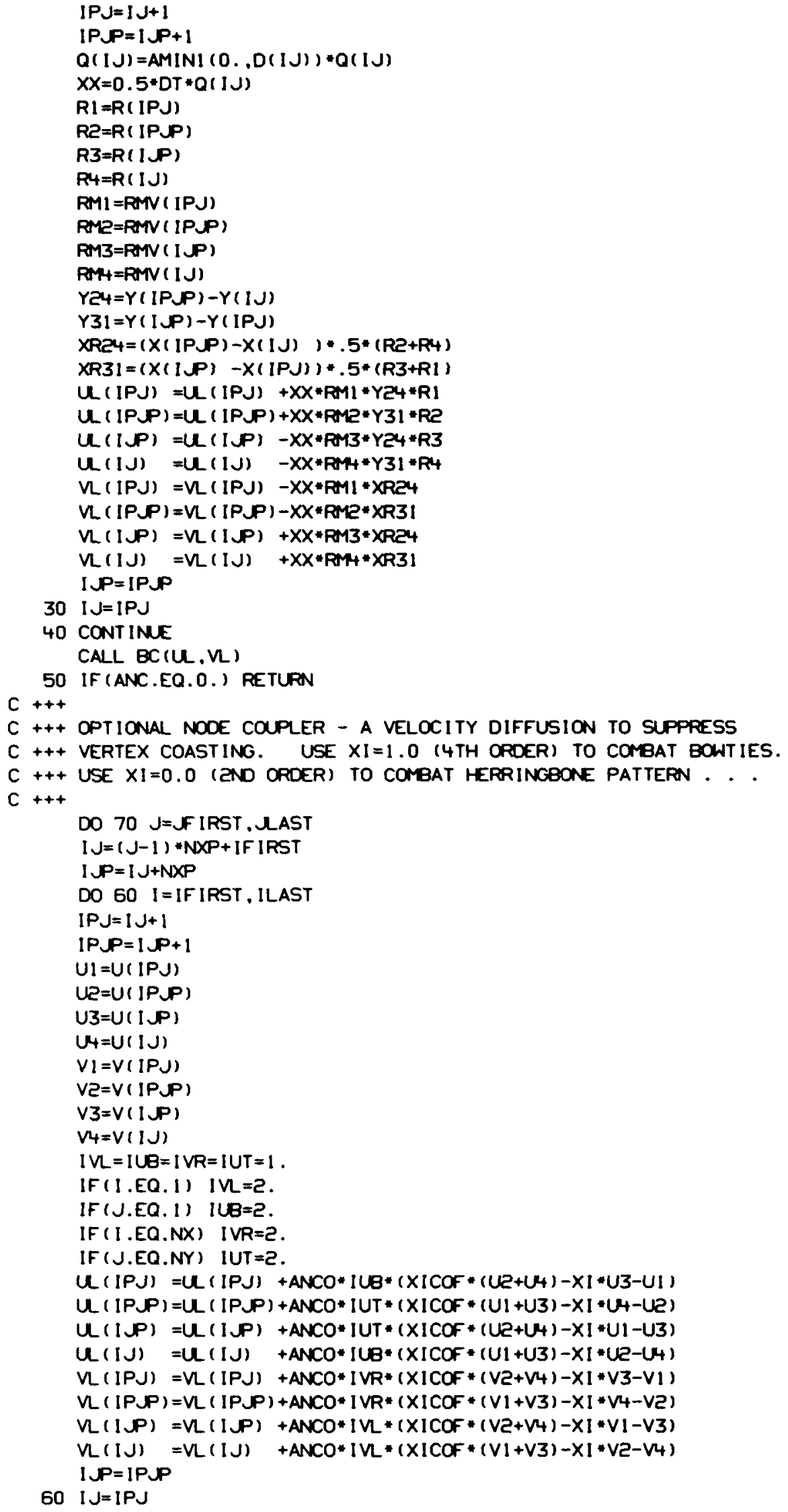

AVISC $\mathbf{5 0}$ AVISC 51 AVISC 52 AVISC 53 AVISC 54 AVISC 55 AVISC 56 AVISC 57 AVISC 58 AVISC 59 AVISC 60 AVISC 61 AVISC 62 AVISC 63 AVISC 64 AVISC 65 AVISC 66 AVISC 67 AVISC 68 AVISC 69 AVISC 70 AVISC 71 AVISC 72 AVISC 73 AVISC 74 AVISC 75 AVISC 76 AVISC 77 AVISC 78 AVISC 79 AVISC 80 AVISC 81 AVISC 82 AVISC 83 AVISC 84 AVISC 85 AVISC 86 AVISC 87 AVISC 88 AVISC 89 AVISC 90 AVISC 91 AVISC S2 AVISC 93 AVISC 94 AVISC 95 AVISC 96 AVISC 97 AVISC 98 AVISC 99 AVISC 100 AVISC 101 AVISC102 AVISCIO3 AVISC 104 AVISCI05 AVISC 106 AVISC 107 AVISC 108 AVISC 109 AVISC 110 AVISC111 AVISCII? 
70 CONTINUE

CALL BC(UL, VL)

AVISC 113

RETURN

AVISC1 14

END

AVISC1 15

AVISCI16

SUBROUTINE BC $(W, V V)$
COMMON /SCI/ AA(I),X(800),R(800),Y(800),U(800), V(800),MC $(800)$. $1 \operatorname{MV}(800)$, RTIV $(800), \operatorname{RO}(800)$, $\operatorname{VOL}(800), P(800)$, SIE $(800), U(800)$.

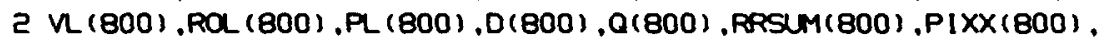
3 PIXY (800), PIYY (800), PITH(800), ROSDP $(800), \mathrm{UG}(800), V G(800)$. 4 UREL (BO0), VREL (BO0), MP (800), MVP (800), SIEP $(800)$, UMOM $(800)$, $5 \operatorname{VMOM}(800)$, UMOMP $(800), \operatorname{VMOMP}(800), Z Z 1$ COMMON /SC2/ ANC, ANCO, ARTVIS, ASO, AO,BO, COLAMN,CY , C1, OPCOF, 1 DROU,DT, OTF, DTMAX, DTMIN, DX,DY,DI, EPS, F IXI, FIYB, GMI, GRF AC, GRIND, 2 GX,GY, IDOT, IFIRST, IFPHI, ILAST, ILASTM, ILASTV, ILPHI, IMP, INC, IPRES, 3 IREZ, F IRST, FPHI, LAST, LASTM, LASTV. UPHI, NM, LAMBOA, LOOPS, 4 LOOPMX, LPR, MAXIT, MN, NAME (8), NCYC, NDUMP, NUMIT , NX, NXP,

5 NY, NYP, OM, OMCY , PAP, PEPS, PMAX, RF, ROI ,ROIN, RON, SIEI , SIE IN, 6 T, TF ILM, THIRO, TIMMT, TL IMD, TPRTR, TWF ILM, TWF IN, TLLF TH, TWPRTR, 7 UIN, VIN, VMAX, WB, WL, WR, WT , XCONV , XI, XICOF, XL, YB, YCONV, ZZ REAL LAMBOA,MC,MP,MU,MV,MVP INTEGER WB, WL, WR,WT DIMENSION WU(1), VV(1)

C +++

C +++ SET VELOCITY BOUNDARY CONDITIONS FOR ALL 4 SIDES, WHERE

C +++ Wh, WR, WB, AND WT ARE INPUT INTEGERS DEF INED AS FOLLOWS:

$C+++0=$ LAGRANGIAN SURFACE (NO VELOCITY ADUSTMENT WHATSOEVER),

$\mathrm{C}+++1=$ SIMPLE FREESLIP. 2 = GENERAL FREESL IP. $3=$ NOSL IP.

$C+++4$ = CONTINUATIVE OUTFLOW, 5 = SPECIFIED INFLOW OR OUTFLOW.

$c+++6=$ SPECIFIED PRESSURE. (NOTE - THE CONTINUATIVE QUTFLOW BONNARY BC

C +++ APPROXIMATION GIVEN HERE MAY NOT WORK FOR ALL APPLICATIONS.)

$\mathrm{C}+++$

DO $400 \mathrm{~J}=1$, NYP

C +++

$I J=(J-1) * N X P+1$

C +++ THE LEFT EDGE...

$\mathrm{C}+++$

IF (WL.EO.O) GO TO 300

gO TO $(210.220 .230 .240 .250 .240), h$

$210 \omega(1)=0$.

GO TO 300

520 I $M=1 \mathrm{I} P=1 \mathrm{~J}$

IF (J.GT.1) I $M=I J-N X P$

IF (J.LT.NYP) I $P=1 J+N D P$

IF (J.EQ. I .AND. WB.EQ.Z) I $M=1 J+1$

IF (J.EQ.NYP . AND. WT.EQ.2) I $P=1 J+1$

$E M=1 . E+20$

$X T E=X(I P)-X(I M)$

IF (XTE.NE.O.) EM $=(Y(\mid \mathcal{P})-Y(I M)) / X T E$

RDEN $=1.1(1 .+E M * E M)$

UOD $=W(I J)$

$W([J)=(E M * V V([J)+W O L D) * R O E N$

$V V(I J)=(E M * E M * V V(I J)+E M * U$ ULC $) * R D E N$

GO TO 300

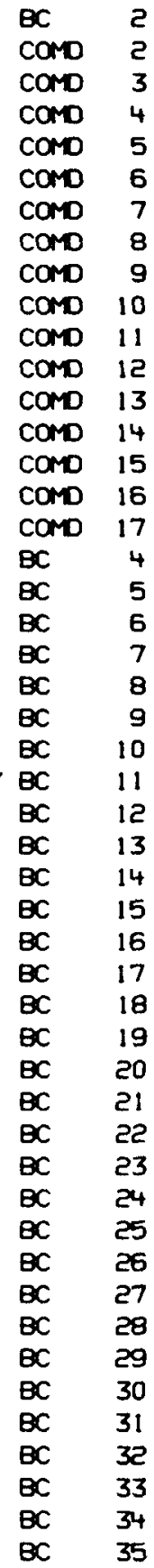




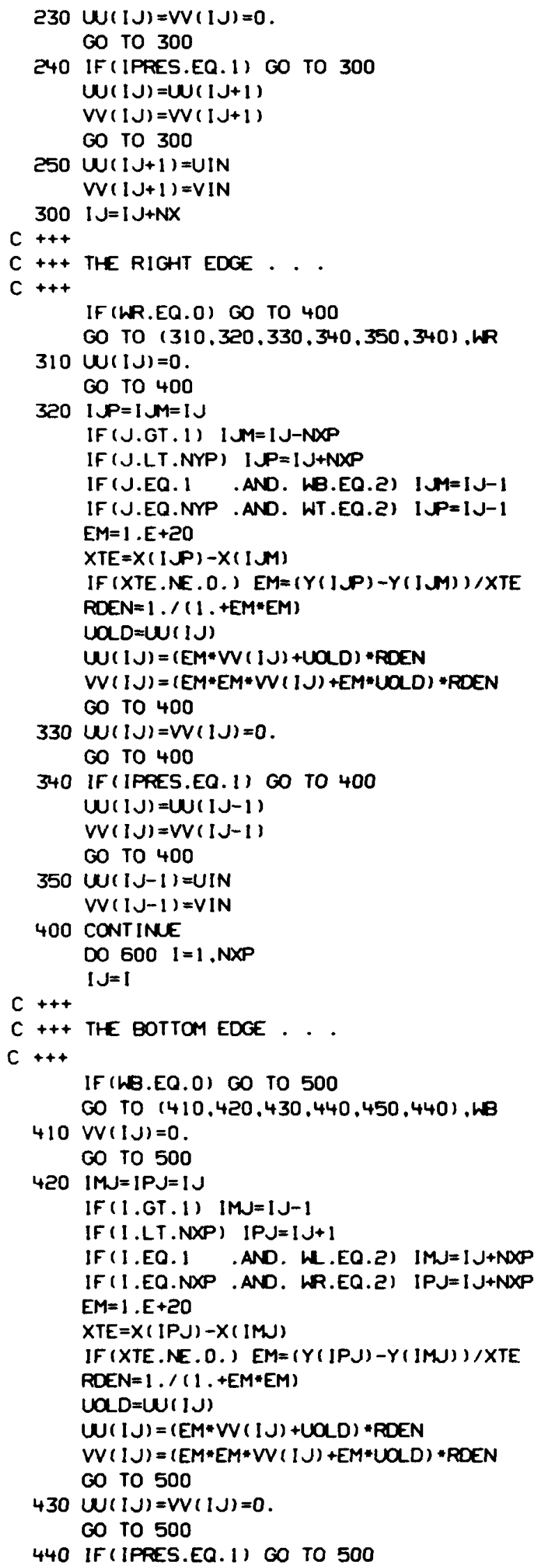




\begin{tabular}{|c|c|c|c|}
\hline & $W(I J)=U(I J+N \times P)$ & $B C$ & 99 \\
\hline & $V V(I J)=V V(I J+N X P)$ & $\mathbf{B C}$ & 100 \\
\hline & GO TO 500 & $\mathrm{BC}$ & 101 \\
\hline \multirow[t]{2}{*}{450} & $W(I J+N X P)=U I N$ & $\mathrm{BC}$ & 102 \\
\hline & $V V(I J+N X P)=V I N$ & $B C$ & 103 \\
\hline 500 & $I J=N Y * N X P+i$ & $B C$ & 104 \\
\hline++ & & $B C$ & 105 \\
\hline$+t+$ & THE TOP EDGE . . . & $\mathrm{BC}$ & 106 \\
\hline \multirow[t]{3}{*}{+++} & & $\mathrm{BC}$ & 107 \\
\hline & IF (WT.EQ.0) GO TO 500 & $B C$ & 108 \\
\hline & Go to $(510.520 .530 .540 .550 .540)$,WT & $\mathrm{BC}$ & 109 \\
\hline \multirow[t]{2}{*}{510} & $V V(I J)=0$ & $B C$ & 110 \\
\hline & GO TO 600 & $B C$ & 111 \\
\hline \multirow[t]{13}{*}{520} & $I M J=I P J=I J$ & $B C$ & 112 \\
\hline & IF $(I . G T .1) \quad$ IMU $=I J-1$ & $B C$ & 113 \\
\hline & IF $(I . L T . N X P) \quad I P J=I J+1$ & $B C$ & 114 \\
\hline & IF (I.EQ.I .AND. WL.EQ.2) IMJ IJ INXP & $B C$ & 115 \\
\hline & IF (I .EQ.NXP . AND. WR.EQ.2) IPJ $=I J-N X P$ & $B C$ & 116 \\
\hline & $E M=1 . E+20$ & $\mathrm{BC}$ & 117 \\
\hline & $X T E=X(I P J)-X(I M N)$ & $B C$ & 118 \\
\hline & IF (XTE.NE.O.) EM=(Y(IPJ) $-Y(I M J)) / X T E$ & $B C$ & 119 \\
\hline & ROEN $=1 . /(1 .+E M * E M)$ & BC & 120 \\
\hline & UaLD=UU(IJ) & $\mathrm{BC}$ & 121 \\
\hline & $W(I J)=(E M * V V(I J)+U O L D) * R O E N$ & $B C$ & 122 \\
\hline & $V V(I J)=(E M * E M * V V(I J)+E M *(Q \mathcal{}) * R D E N$ & $\mathrm{BC}$ & 123 \\
\hline & GO TO 600 & $B C$ & 124 \\
\hline \multirow[t]{2}{*}{530} & $W(1 J)=V V(I J)=0$ & $B C$ & 125 \\
\hline & GO TO 600 & $B C$ & 126 \\
\hline \multirow[t]{4}{*}{540} & IF (IPRES.EQ. 1) GO TO 600 & $B C$ & 127 \\
\hline & $W(1 J)=W(1 J-N X P)$ & $B C$ & 128 \\
\hline & $V V(I J)=V V(I J-N X P)$ & $B C$ & 129 \\
\hline & GO To 600 & $B C$ & 130 \\
\hline \multirow[t]{2}{*}{550} & $W(I J-N X P)=U I N$ & $B C$ & 131 \\
\hline & $V V(I J-N X P)=V I N$ & $B C$ & 132 \\
\hline \multirow[t]{3}{*}{600} & CONTINUE & $B C$ & 133 \\
\hline & RETURN & $B C$ & 134 \\
\hline & END & $B C$ & 135 \\
\hline
\end{tabular}

SUBROUT INE BCSET

BCSET 2

COMMON /SCI/ AA (1),X(800),R(800),Y(800),U(800),V(800),MC(800), COMD 2 $1 M V(800)$, RAT $(800), R O(800), V Q(800), P(800), S I E(800), U(800)$.

$2 \mathrm{~V}(800), R O L(800), P L(800), D(800), Q(800), R R S U M(800), P I X X(800)$.

$\operatorname{COMD} 3$

3 PIXY (800) ,PIYY (800), PITH(800), ROSDP $(800)$, UG $(800)$. VG $(800)$.

$\operatorname{COMD} 4$

4 UREL $(800)$. VREL $(800)$, MP (800). MMP $(800)$.SIEP $(800)$, UMOM $(800)$. COMD 6

5 VMOM (800), UMOMP $(800)$, VMOMP $(800), 2 Z 1 \quad$ COMD 7

COMMON /SC2/ ANC. ANCO,ARTVIS,ASO,AO,BO,CQLAM,CY, C1,DPCOF, COND 8

1 DROU,DT,DTF,DTMAX,DTMIN,DX,DY,DI, EPS, FIX, FIYB,GMI,GRFAC,GRINO, COMD 9

2 GX,GY, IDOT, IFIRST, IFPHI, ILAST, ILASTM, ILASTV, ILPHI, IMP, INC, IPRES, COMD 10

3 IREZ. F IRST, FPHI, LAST, LASTM, LASTV, LPHI, NM, LAMBOA,LOOPS, COMD 11

4 LOOPMX,LPR, MAXIT, MN,NAME (8),NCYC,NDUM,NUMIT,NX,NXP.

5 NY, NYP.OM, OMCY .PAP.PEPS, PMAX,RF, ROI,ROIN,RON.SIEI.SIEIN. OOMD 13

6 T. TFILM, THIRO, TIMLMT. TLIMD, TPRTR, TWFILM, TWF IN, TWF TH, TWPRTR, $\quad$ COMD 14

7 UIN.VIN, MMAX,WB.WL.WR,WT,XCONV,XI,XICOF,XI,YB,YCONV,ZZ

REAL LAMBDA,MC,MP.MU.MV,MVP $\quad$ COMD 16

INTEGER WB,WL, WR.WT $\quad$ COMD 17

C+++

BCSET 4 


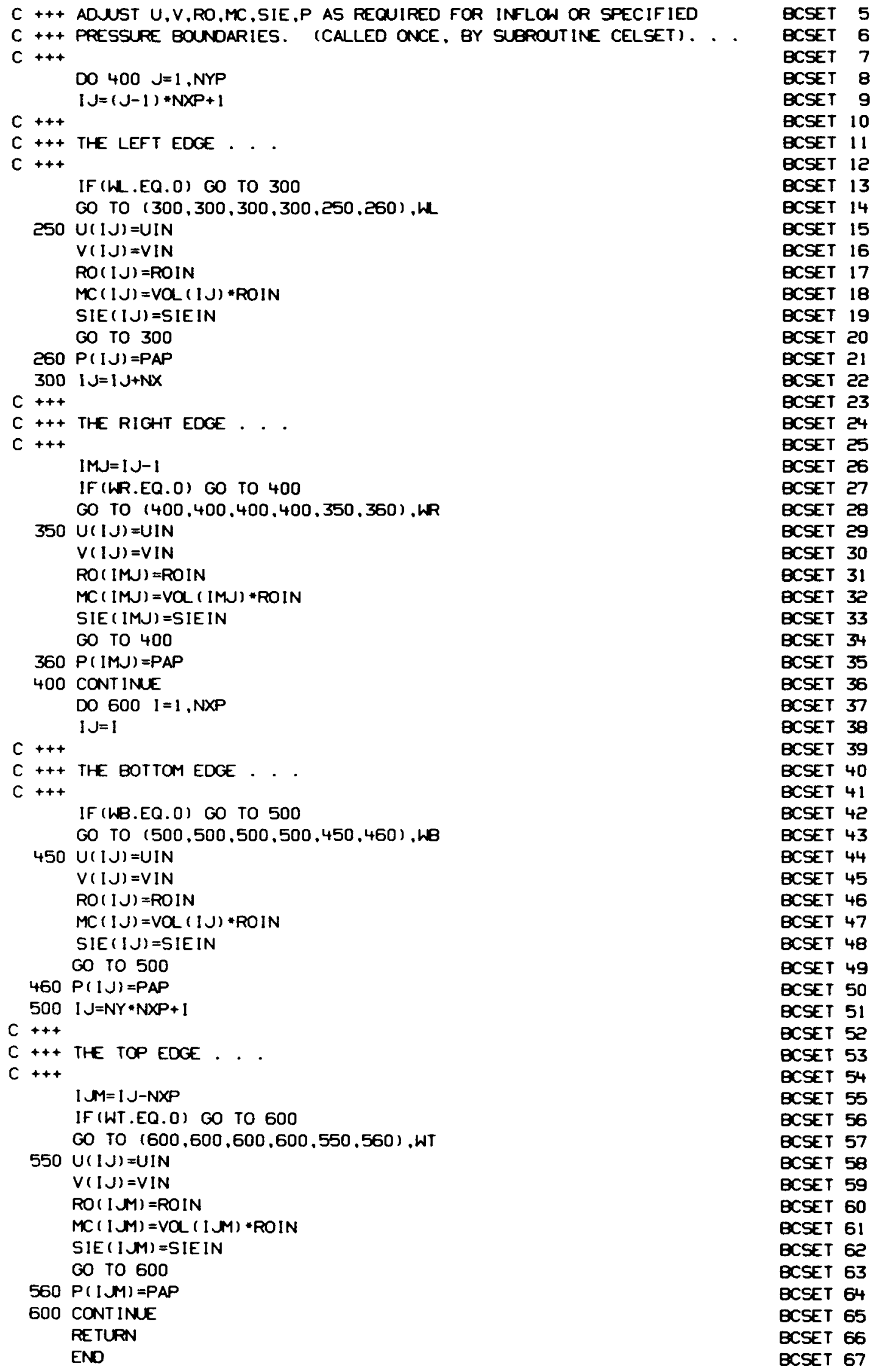




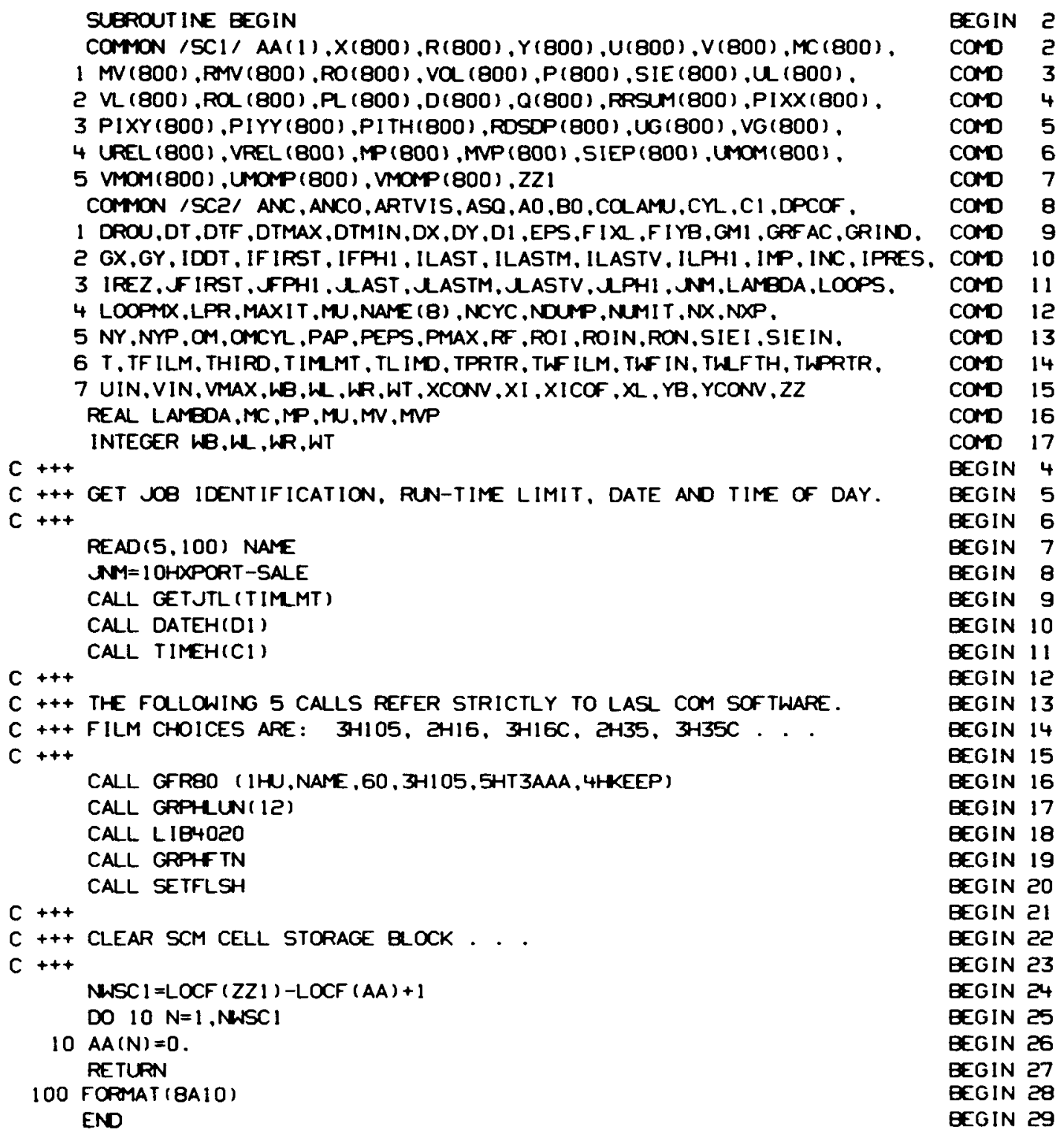




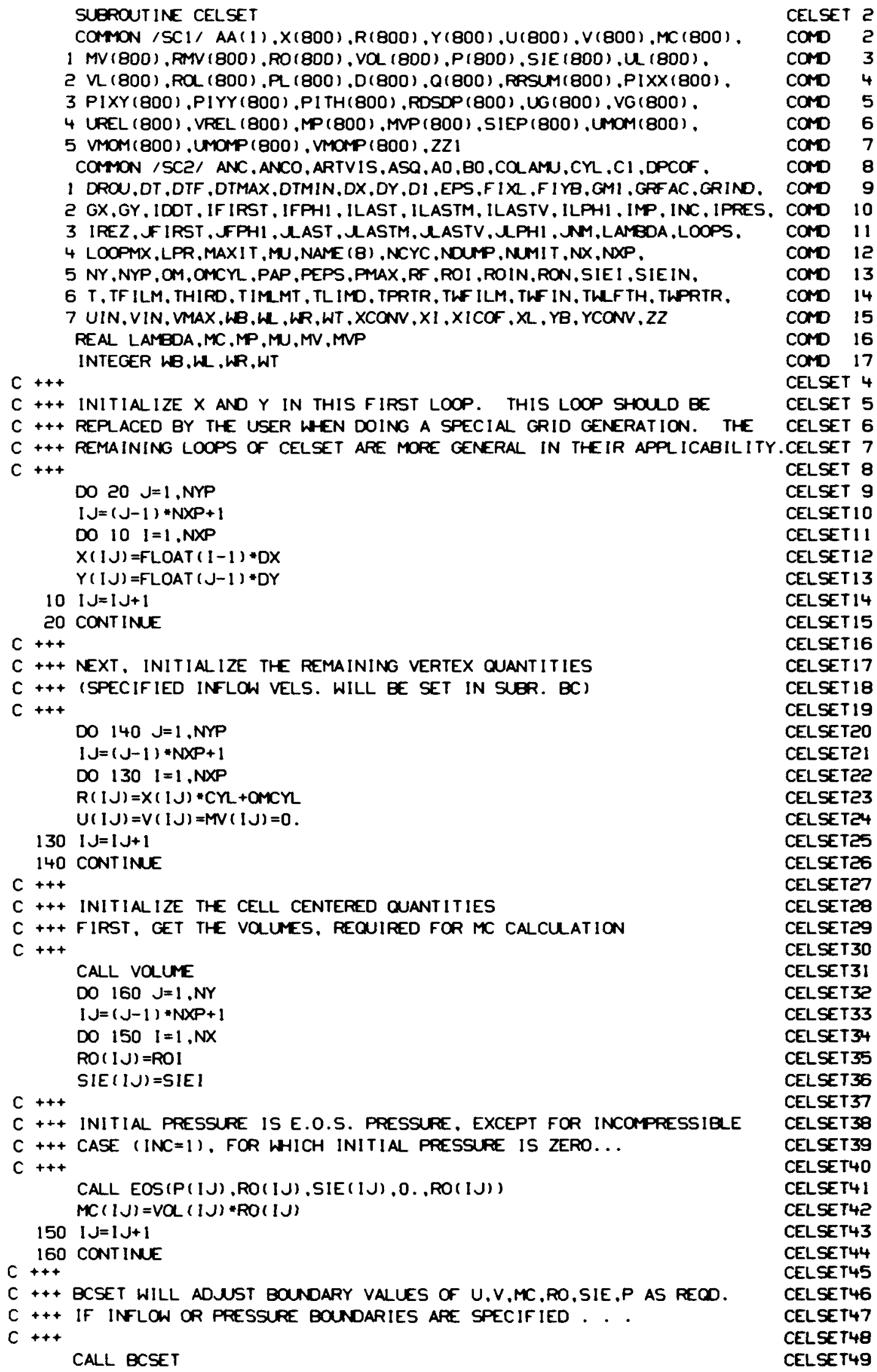




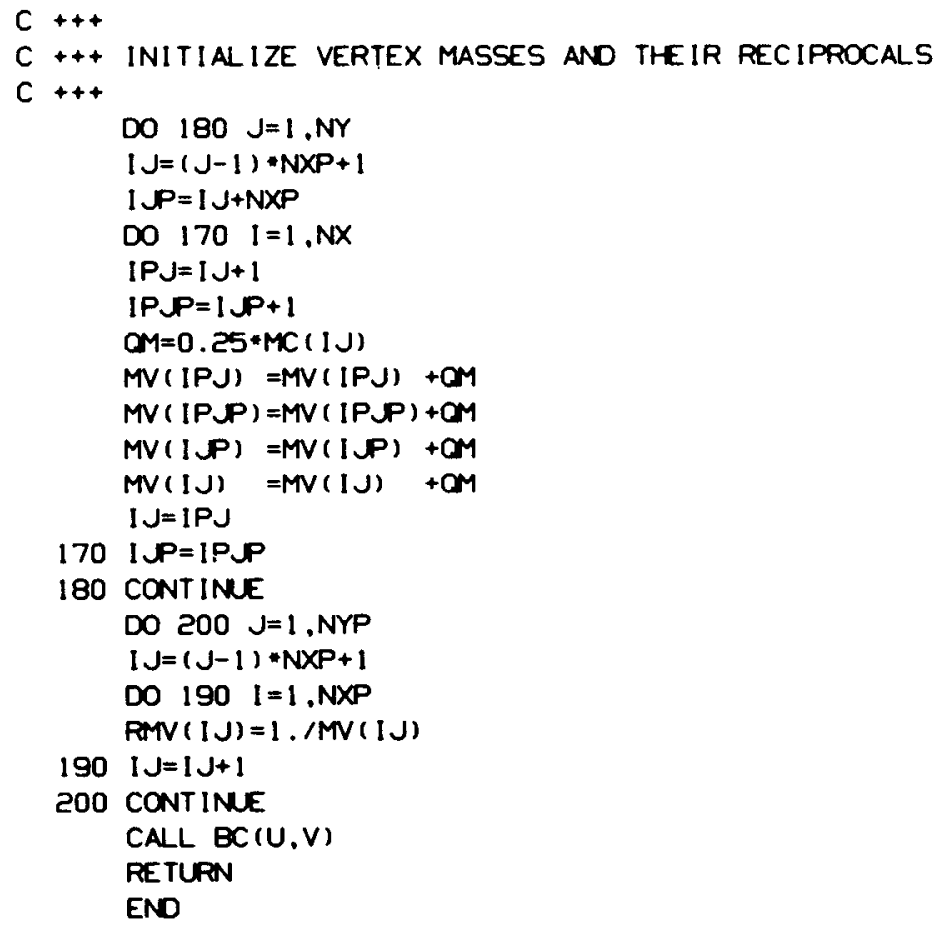

CELSET59

CELSET6O

CELSET61

CELSETG2

CELSET63

CELSET64

CELSET65

CELSET66

CELSET67

CELSET68

CELSET69

CELSET7O

CELSET7I

CELSET72

CELSET73

CELSET74

CELSET75 


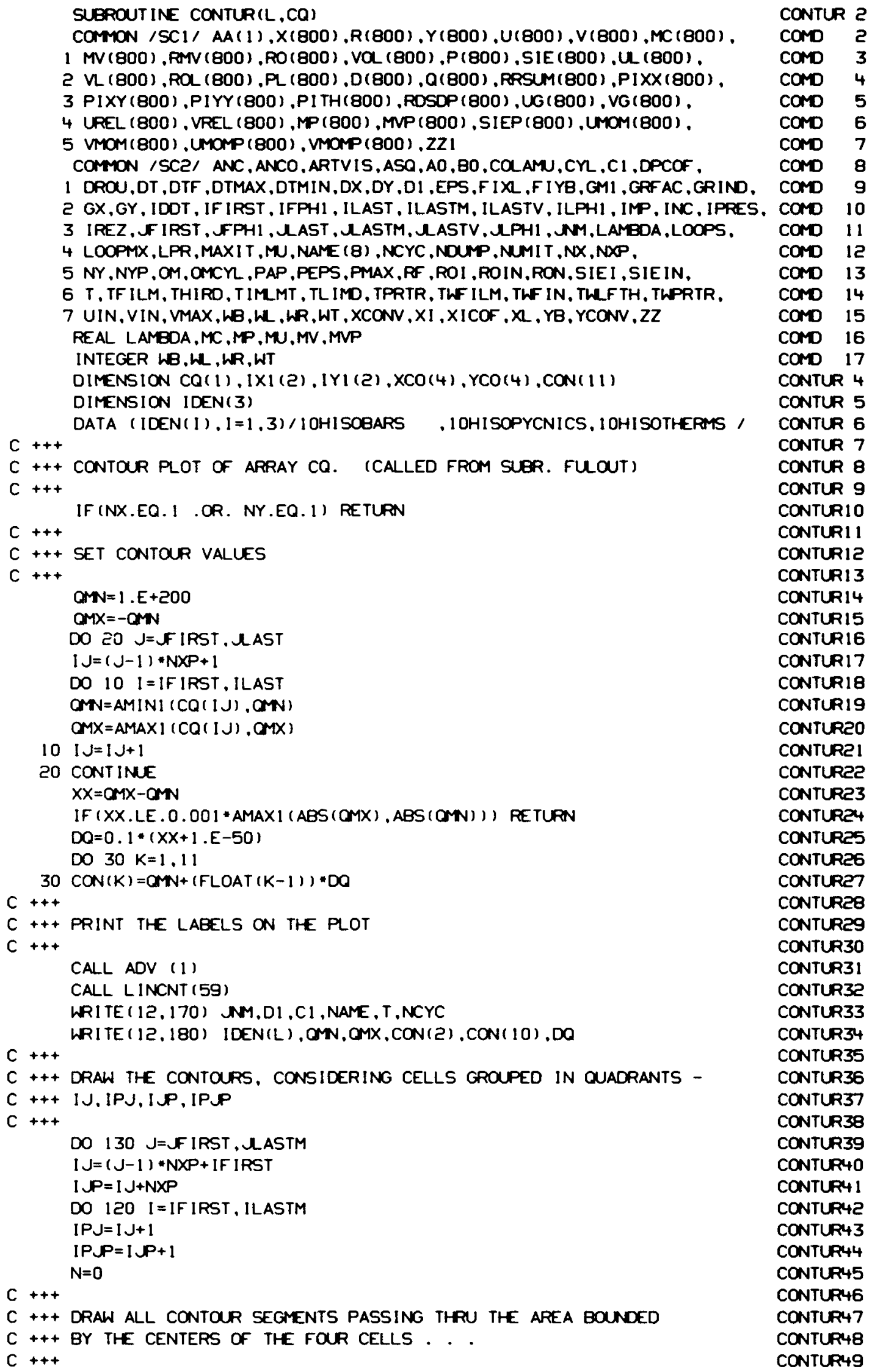
1 DROU,DT,DTF,DTMAX,DTMIN,DX,DY,DI ,EPS, F IX, ,F IYB,GMI, GRFAC, GRIND, COMD 9 3 IREZ, IF IRST, JFPHI, LAST, LASTM, LASTV, LPHI, NM, LAMBDA, LOOPS, COMD 11

CONTUR 2 $\operatorname{COMD} 2$ $\operatorname{com} 3$ $\operatorname{com} 4$ COMD 5 COMD 6 COMD 7 como 8 COMD 12 COMD 13 COMD 14 COMD 15 COMD 16 COMD 17 CONTUR 4 CONTUR 5 CONTUR 6 CONTUR 7 CONTUR 8 CONTUR 9 CONTURIO CONTUR1 1 CONTUR12 CONTUR 13 CONTUR14 CONTURI5 CONTURIG CONTURI7 CONTURIB CONTURIS CONTUREO CONTUR2I CONTURZ2 CONTURE3 CONTUREY CONTURZS CONTUREG CONTURET CONTURZB CONTURES CONTUR3O CONTUR31 CONTUR32 CONTUR33 CONTUR34 CONTUR35 CONTUR36 CONTUR37 CONTUR38 CONTUR39 CONTUR4O CONTUR4 1 CONTURYZ CONTUR43 CONTUR44 CONTUR45 CONTUR46 CONTUR47 CONTUR48 CONTURY9 


\begin{tabular}{|c|c|c|}
\hline & $\begin{array}{l}D 0110 \mathrm{~K}=2,11 \\
K 1=K 2=K 3=K 4=0\end{array}$ & CONTUR50 \\
\hline & & \\
\hline & IF $(\operatorname{CQ}(I J) \quad . L E . \operatorname{CON}(K)) \quad K 1=1$ & CONTUR52 \\
\hline & IF (CQ(IPJ). LE.CON(K)) $K 2=1$ & CONTUR53 \\
\hline & IF (CQ(IJP) .LE.CON(K)) K3=1 & CONTUR54 \\
\hline & IF (CQ(IPJP) , LE. CON(K)) K4=1 & CONTURSS \\
\hline $\mathrm{C}+++$ & & CONTUR56 \\
\hline$C+++$ & IF PROOUCT .NE. 0 , THEN ALL 4 ARE $=1$ & CONTUR57 \\
\hline$C+++$ & IF SUM. EQ. 0 . THEN ALL 4 ARE $=0$. FOR EITHER OF THESE, & CONTURSB \\
\hline $\mathrm{C}+++$ & THE CONTOUR DOES NOT PASS THRU, SO GO TO 110 TO TRY NEXT & CONTUR59 \\
\hline$C++$ & VALUE ON K LOOP . . & CONTUR6O \\
\hline$C+++$ & & CONTUR61 \\
\hline & IF $(K 1 * K 2 * K 3 * K 4 . N E .0 . O R \cdot K 1+K 2+K 3+K 4 . E Q .0)$ CO TO 110 & CONTUREC \\
\hline & IF (N.GT.O) GO TO 60 & CONTUR63 \\
\hline & $1 \mathrm{~B}=1 \mathrm{~J}$ & CONTUR64 \\
\hline & $I J A=I N P$ & CONTUR65 \\
\hline & $0050 \mu=1.2$ & CONTURE6 \\
\hline & $0040 \quad 11=1.2$ & CONTURE7 \\
\hline & $\mid P J B=1 \dot{B}+1$ & CONTUR68 \\
\hline & $I P J A=I J A+1$ & CONTUR69 \\
\hline & $N=N+1$ & CONTUR7O \\
\hline & 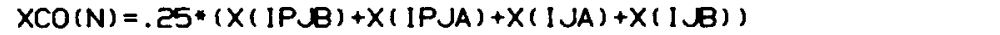 & CONTUR71 \\
\hline & $Y C O(N)=.25 *(Y(I P J B)+Y(I P J A)+Y(I J A)+Y(I J))$ & CONTUR72 \\
\hline & $I J A=I P J A$ & CONTUR73 \\
\hline 40 & 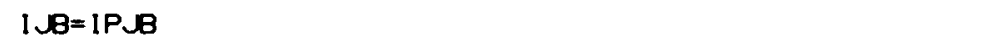 & CONTURT4 \\
\hline & $I J=I P$ & CONTUR75 \\
\hline 50 & $I J A=I J P+N X P$ & CONTURTE \\
\hline 60 & $L L=0$ & CONTUR77 \\
\hline & IF $(K \mid+K 3 . N E .1)$ Go To 70 & CONTUR78 \\
\hline & $|C|=1$ & CONTUR79 \\
\hline & $1 \mathrm{C} 2=3$ & CONTURBO \\
\hline & $|J|=\mid\rfloor$ & CONTURBI \\
\hline & $I J=I J P$ & CONTURBZ \\
\hline & $K R 1=1$ & CONTURB3 \\
\hline & Go To 100 & CONTURBY \\
\hline 70 & $\mid F(K \mid+K 2 . N E .1)$ GO TO 80 & CONTURBS \\
\hline & $|C|=1$ & CONTURBS \\
\hline & $1 C 2=5$ & CONTURB7 \\
\hline & $|J|=I J$ & CONTURBB \\
\hline & $I J E=I P J$ & CONTURBS \\
\hline & $K R 1=2$ & CONTUR9O \\
\hline & CO TO 100 & CONTUR91 \\
\hline 80 & IF (K2+K4.NE. 1) 60 TO 90 & CONTURSE \\
\hline & $|C|=5$ & CONTUR93 \\
\hline & $1 C 2=4$ & CONTURGY \\
\hline & $I J I=I P J$ & CONTURES \\
\hline & $I J=I P J P$ & CONTURSG \\
\hline & $K R 1=3$ & CONTUR97 \\
\hline & GO TO 100 & CONTURSB \\
\hline 90 & IF (K3+K4.NE.1) GO TO 110 & CONTUR99 \\
\hline & $|C|=3$ & CONTU10O \\
\hline & $1 C 2=4$ & CONTU101 \\
\hline & $|J|=I J P$ & CONTUIOZ \\
\hline & $I J=I P J P$ & CONTU103 \\
\hline & $K R 1=4$ & CONTUIO4 \\
\hline 100 & $L L=L L+1$ & CONTUI 05 \\
\hline & $x X=(\operatorname{CoN}(K)-\operatorname{CQ}(I J 1)) /(\operatorname{CQ}(\mid \pi)-\operatorname{CQ}(I J 1))$ & CONTU106 \\
\hline & $I X I(L L)=F I X L+(X C O(I C 1)+X X *(X C O(I C 2)-X C O(I C I))-X L) * X C O N V$ & CONTU107 \\
\hline & $I Y I(L L)=F(Y B-(Y C O(I C 1)+X X *(Y C O(I C 2)-Y C O(I C 1))-Y B) * Y C O N V$ & CONTUIO8 \\
\hline & IF (LL.LT.2) 60 TO $(70,80,90,110), K R 1$ & CONTU109 \\
\hline & CALL DRV $(I X I(1), I Y I(1), I X I(2), I Y I(2))$ & CONTU1 10 \\
\hline & IF (K.EQ.Z) CALL PLT $(I X I(1), I Y I(1), 35)$ & CONTU1 11 \\
\hline & IF (K.EQ.10) CALL PLT $(I X I(1), I Y I(1), 24)$ & CONTUI 12 \\
\hline
\end{tabular}




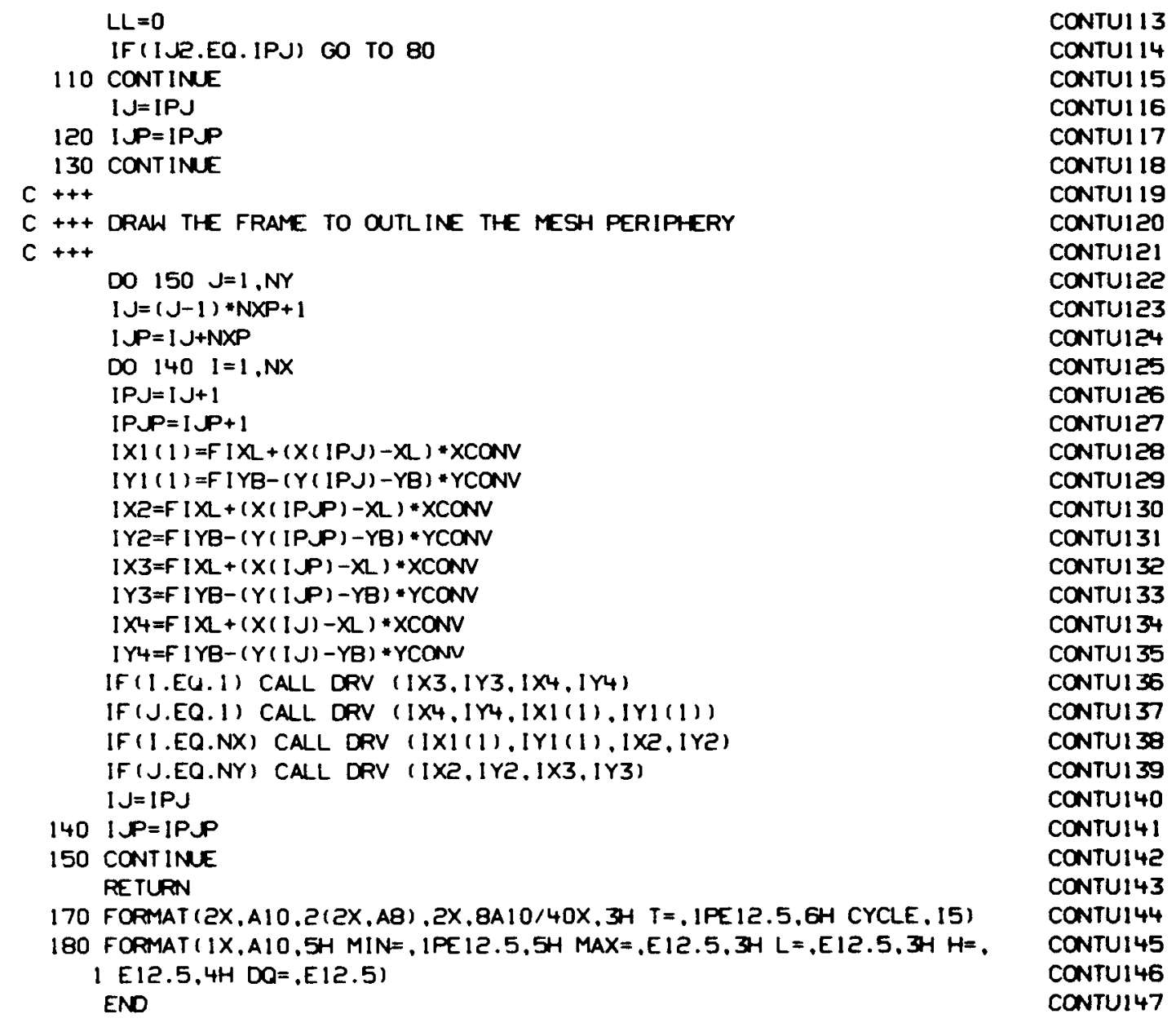


SUBROUTINE DSDP $\quad$ DSDP 2

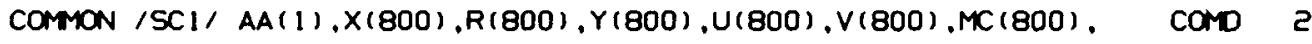

$1 \operatorname{MV}(800), \operatorname{RMV}(800)$, RO $(800), V Q(800), P(800)$, SIE $(800), U L(800), \quad$ COMO 3

$2 \mathrm{VL}(800), \mathrm{ROL}(800), \mathrm{PL}(800), \mathrm{D}(800), \mathrm{Q}(800), \mathrm{RRSUM}(800), \mathrm{PI} X X(800), \quad$ COMO 4

3 PIXY (800), PIYY (800), PITH(800), ROSDP $(800)$, UG $(800), V G(800), \quad$ COMD 5

4 UREL (800), VREL (800), MP(800), MVP (800), SIEP(800), UMOM(800), 6

5 VMOM(BO0), UMOMP $(800)$, VMOMP $(800), 2 Z 1 \quad$ COMO 7

COMMON ISC2/ ANC.ANCO.ARTVIS.ASQ,AO,BO,COLAM,CYL.CL,OPCOF. COMD 8

I DROU,DT,DTF,DTMAX,DTMIN,DX,DY,DI,EPS,FIXI,FIYB,GMI, GRFAC,GRIND, COMD 9

2 GX,GY, IDOT, IF IRST, IFPHI, ILAST, ILASTM, ILASTV, ILPHI, IMP, INC, IPRES, COMD 10

3 IREZ, JF IRST, JFPHI, LAST, JASTM, LASTV, LPHI, NM. LAMBDA .LOOPS, COMO 11

4 LOOPMX, LPR, MAXIT, MU, NAME (8), NCYC, NOUMP, NUMIT, NX, NXP,

5 NY,NYP,OM,OMCY, PAP,PEPS, PMAX,RF, ROI, ROIN,RON,SIEI,SIEIN, $\quad$ COMO 13

6 T, TF ILM, THIRD, TIMLMT, TLIMD. TPRTR. TWF ILM, TWF IN. THLFTH. TWPRTR, $\quad$ COMD 14

7 UIN,VIN, MMAX, WB,WL,WR,WT, XCONV,XI,XICOF, XL,YB,YCONV,ZZ COMD 15

REAL LAMBDA,MC,MP,MU,MV,MVP $\quad$ COMO 16

INTEGER WB,WL,WR,WT $\quad$ COMD 17

$\mathrm{C}+++$

C +++ PHASE 2. NUMERICAL EVALUATION OF RELAXATION FACTOR

$C+++$ TO BE USED IN THE PRESSURE ITERATION (SUBR. PRESIT) . . . $\quad$ DSDP 6

$\mathrm{C}+++$

$\mathrm{C}+++$

DATA PTEMP.PSTAR $10 ., 0.1$

$D P=D P C O F /(D T * D T)$

$D T P=0.5 * D T * D P$

DO $20 \mathrm{~J}=$ JFIRST. LAST

I $J=(J-1) * N X P+$ IF IRST

$1 \sim P=I J+N \times P$

DO $10 \quad I=I F I R S T$, ILAST

IPJ $=1 \mathrm{~J}+1$

$I P J=I P+1$

$X I=X(I P J)$

$x E=x($ IPJP $)$

$X 3=x(I P P)$

$X^{2}=X(I J)$

$R !=R(I P J)$

$R C=R(I P J P)$

$R 3=R(I P)$

$R_{4}=R(I J)$

$Y I=Y(I P J)$

$Y Z=Y(I P J)$

$Y Z=Y(I D)$

$Y 4=Y(I J)$

$U 1=U(I P J)$

$U E=U(I P J P)$

$U 3=U L(I P)$

$U_{4}=U(I J)$

$V I=V$ (IPJ)

$V Z=V(I P S)$

$V 3=V(I P)$

$V_{4}=V(I J)$

$X \mid P=X 1+U 1=0 T$

$Y|P=Y 1+V| \cdot D T$

$X E P=X F+U S \cdot D T$

$Y Z P=Y Z+V D=D T$

$X 3 P=X 3+U 3 * D T$

$Y 3 P=Y 3+V 3=0 T$

$X^{\prime} P=X^{4}+U 4=D T$

$Y 4 P=Y 4+V_{4}=D T$

$R I P=X I P=C Y+O M C n$

$R Z P=X Z P * C Y L+O M C Y$

$R 3 P=X 3 P * C Y L+O M C Y$

$R+P=X 4 P * C R+O M C Y$

DSOP 7

DSOP 8

DSDP 9

DSOP 10

OSOP 11

DSDP 12

DSDP 13

DSDP 14

DSDP 15

DSDP 16

DSDP 17

DSDP 18

DSDP 19

DSDP 20

DSDP 21

DSDP 22

DSDP 23

DSDP 24

DSDP 25

DSDP 26

DSDP 27

DSDP 28

DSDP 29

DSDP 30

DSOP 31

DSDP 32

DSDP 33

DSDP 34

OSDP 35

DSOP 36

DSDP 37

DSDP 38

DSOP 39

DSDP 40

DSOP 41

DSDP 42

DSDP 43

DSDP 44

DSDP 45

DSDP 46

DSDP 47

DSDP 48

DSDP 49 


\begin{tabular}{|c|c|c|}
\hline ATR $=.5 *((X 3 P-X Z P) *(Y 1 P-Y Z P)-(X 1 P-X Z P) *(Y 3 P-Y Z P))$ & DSOP & 50 \\
\hline$A B L=.5 *((X \mid P-X 4 P) *(Y 3 P-Y 4 P)-(X 3 P-X 4 P) *(Y 1 P-Y 4 P))$ & DSOP & 51 \\
\hline VQLLZ=THIRD*((RIP+RZP+R3P) $* A T R+(R 3 P+R 4 P+R I P) * A B C)$ & OSOP & 52 \\
\hline$X \mid T E M P=S I E(I J)+P(I J) *(1.0-V O L L Z / V O(I J)) / R O(I J)$ & DSOP & 53 \\
\hline ROTEMP=RO $(I J) * V Q R(I J) / V O L Z$ & DSDP & 54 \\
\hline CALL EOS(PTEMP,ROTEMP, XITEMP,P(IJ),RO(IJ)) & DSOP & 55 \\
\hline RMI = PRMV $(I P J)$ & DSOP & 56 \\
\hline RML=RMV (IPJP) & DSDP & 57 \\
\hline RMI3=RMV (I $P$ ) & DSOP & 58 \\
\hline RAMt=RAN $(I J)$ & DSDP & 59 \\
\hline$Y 24=Y 2-Y 4$ & DSDP & 60 \\
\hline$Y 31=Y 3-Y 1$ & DSOP & 61 \\
\hline$X R^{2}+=0.5 *(R 2+R+) *\left(X_{2}-x_{4}\right)$ & DSDP & 62 \\
\hline$X R 31=0.5 *(R 3+R 1) *(\times 3-X 1)$ & DSOP & 63 \\
\hline$U I P=U 1+D T P * P M I * Y Z 4 * R I$ & DSOP & 64 \\
\hline$U Z P=U Z+D T P * R M Z * Y 31 * R Z$ & DSOP & 65 \\
\hline$U 3 P=U 3-D T P * R M 3 * Y 24 * R 3$ & OSOP & 66 \\
\hline$U_{4} P=U_{4}-D T P * R M+* Y 31 * R_{4}$ & DSDP & 67 \\
\hline$V I P=V 1-D T P * P M I * X R 24$ & DSOP & 68 \\
\hline$V Z P=V Z-D T P * R M P * X R 31$ & DSOP & 69 \\
\hline$V 3 P=V 3+D T P * R M 3=X R 24$ & OSOP & 70 \\
\hline$V_{4} P=V 4+D T P * R M 4 * X R 31$ & DSOP & 71 \\
\hline$X 1 P=X 1+U 1 P * D T$ & DSOP & 72 \\
\hline$Y 1 P=Y 1+V 1 P=D T$ & DSDP & 73 \\
\hline$X Z P=X Z+U Z P * 0 T$ & DSDP & 74 \\
\hline$Y Z P=Y Z+V Z P * D T$ & DSOP & 75 \\
\hline$X 3 P=x 3+U 3 P * D T$ & DSDP & 76 \\
\hline$Y 3 P=Y 3+V 3 P * D T$ & OSOP & 77 \\
\hline$X_{4} P=X 4+U 4 P * D T$ & DSOP & 78 \\
\hline$Y 4 P=Y 4+V 4 P * D T$ & DSOP & 79 \\
\hline$R 1 P=X 1 P * C Y L+O M C Y L$ & OSDP & 80 \\
\hline$R Z P=X C P * C Y L+O M C Y L$ & DSOP & 81 \\
\hline$R 3 P=X 3 P * C Y L+O M C Y L$ & DSOP & 82 \\
\hline$R 4 P=X 4 P * C Y L+O M C Y L$ & DSDP & 83 \\
\hline$A T R=.5 *((X 3 P-X Z P) *(Y 1 P-Y Z P)-(X 1 P-X Z P) *(Y 3 P-Y Z P))$ & DSDP & 84 \\
\hline$A B L=.5 *((X 1 P-X 4 P) *(Y 3 P-Y 4 P)-(X 3 P-X 4 P) *(Y 1 P-Y 4 P))$ & DSDP & 85 \\
\hline$V O L L=T H I R D *((R I P+R Z P+R 3 P) * A T R+(R 3 P+R 4 P+R I P) * A B C)$ & DSDP & 86 \\
\hline$X I S T A R=X I T E M P+P T E M P *(1.0-V O L L / V O L L Z) / R O T E M P$ & DSDP & 87 \\
\hline ROSTAR=RO $(\mathrm{J}) * V O L(1) / V O L L$ & DSDP & 88 \\
\hline$P P D P=P(1))+D P$ & DSOP & 89 \\
\hline CALL EOS (PSTAR,ROSTAR, XISTAR,PPOP,RO $(1 J)$ ) & DSOP & 90 \\
\hline $\operatorname{RDSDP}(I J)=D P /(P T E M P+D P-P S T A R) * O M$ & DSDP & 91 \\
\hline$I J=I P J$ & DSDP & 92 \\
\hline$I P=I P J P$ & OSOP & 93 \\
\hline CONT INUE & DSDP & 94 \\
\hline RETLRN & DSOP & 95 \\
\hline END & DSDP & 96 \\
\hline
\end{tabular}




\section{SUEROUT INE ENERGY}

ENERGY 2

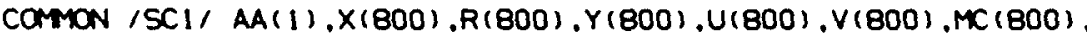

$1 M V(800)$, RMV $(800), R O(800), V O(800), P(800), S I E(800), U(800)$.

$2 V(800), F O(800), P L(800), 0(800), Q(800)$, RRSUM $(800), P I X X(800)$,

3 PIXY $(800), P I Y Y(800), P I T H(800), R O S O P(800), U G(800), V G(800)$,

4 UREL (800), VREL (800), MP( 800$)$, MVP $(800)$, SIEP $(800)$, UMOM $(800)$,

$5 \operatorname{VMOM}(800), \mathrm{UMOMP}(800), \operatorname{VMOMP}(800), 221$

COMMON ISC2/ ANC.ANCO.ARTVIS.ASO.AO,BO,COLAMU,CY, C1 .OPCOF.

COMD

COMD 3

$\operatorname{COMO} 4$

$\operatorname{COMD} 5$

$\operatorname{COMD} E$

$\operatorname{COMD} 7$

DROU,DT DTF DTMAX DIMIN,DX,DY,DI EPS,FIX ,FIYB,GMI GRFAC, GRIND, COMO

2 GX,GY, IDOT, IF IRST, IFPHI, ILAST, ILASTM, ILASTV, ILPHI, IMP, INC, IPRES, COMD 10

3 IREZ, JFIRST, JFPHI, LLAST, LASTM, LASTV, LPHI, NM, LAMBOA, LOOPS, COMO 11

4 LOOPMX, LPR, MAXIT, MU, NAME (8), NCYC, NOUMP, NUMIT, NX, NXP,

5 NY, NYP, OM, OMCYL, PAP, PEPS, PMAX, RF, ROI , ROIN, RON, SIE I, SIE IN,

$\operatorname{com} 12$

$\operatorname{com} 13$

6 T, TF ILM, THIRD, TIMLMT, TLIMD, TPRTR, TWF ILM, TWF IN, THLF TH, TWPRTR,

7 UIN, VIN, VMAX, WB, WL, WR, WT, XCONV, XI , XICOF, XL, YB, YCONV, ZZ

REAL LAMBOA,MC,MP,MU,MV,MVP

INTEGER WB,WL, WR, WT

$\mathrm{C}+++$

C +++ CALCULATE ENERGY CHANGES DUE TO PDV WORK AND VISCOUS STRESSES

$\mathrm{C}+++$

DO $20 \mathrm{~J}=$ JFIRST. LAST

$I J=(J-1) * N X P+I F$ IRST

$I J P=I J+N X P$

DO 10 I=IFIRST, ILAST

$I P J=I J+1$

IP $\boldsymbol{P}=\mid \mathcal{P}+1$

$X I=X(I P J)$

$Y I=Y(I P J)$

$R 1=R(I P J)$

UTCl $=U(I P J)+U($ IPJ)

$V T C l=V(I P J)+V(I P J)$

$X E=X(I P \perp P)$

$Y Z=Y(I P J P)$

$R Z=R(I P S)$

UTCE $=U(I P J P)+U($ IPSP $)$

$V T C 2=V(I P S)+V($ (IPSP)

$X Z=X(1] P)$

$Y 3=Y(1 J P)$

$R 3=R(I D)$

UTC $3=U(I P)+U(I D)$

COMD 14

COMO 15

COMD 16

COMD 17

ENERGY 4

ENERGY 5

ENERGY 6

ENERGY 7

ENERGY 8

ENERGY 9

ENERGY 10

ENERGY 11

ENERGY12

ENERGY 13

ENERGY 14

ENERGY 15

ENERGY16

ENERGY 17

ENERGY 18

ENERGY 19

ENERGYZO

ENERGY21

ENERGYZ2

ENERGY23

ENERGYZ4

ENERGY25

ENERGYZ6

ENERGY27

VTC $=V(I N P)+V L(I P)$

$X 4=X(I J)$

$Y 4=Y(I J)$

$R 4=R(I J)$

UTC4 $=U(I J)+U(I J)$

$V T C 4=V(I J)+V L(I J)$

$Y_{24}=Y 2-Y_{4}$

$Y 31=Y 3-Y 1$

$X^{2}+=X_{2}-X_{4}$

$x 31=x 3-x 1$

$H R Z^{4}=0.5 *(R 2+R 4)$

$H R 13=0.5 *(R 1+R 3)$

$X X 1=H R Z_{4} *\left(P I X Y(I J) * X Z_{4}-P I X X(I J) * Y Z_{4}\right)$

$X X 2=H R 13 *(P I X Y(1 J) * X 31-P I X X(1 J) * Y 31)$

$X X 3=1 R Z_{4} *\left(P I Y Y(I J) * X Z_{4}-P I X Y(I J) * Y Z_{4}\right)$

$X X 4=H R 13 *(P I Y Y(I J) * X 31-P I X Y(1 J) * Y 31)$

DV $=Y 24 *(U T C 1 * R 1-U T C 3 * R 3)+Y 31 *(U T C 2 * R 2-U T C 4 * R 4)$

ENERGYZ8

ENERGYZ9

ENERGY30

ENERGY31

ENERGY32

ENERGY33

ENERGY34

ENERGY 35

ENERGY36

ENERGY37

ENERGY38

ENERGY 39

ENERGY40

ENERGY41

ENERGY42

ENERGY43

ENERGY44

$1-H R Z_{4} * X Z_{4} *(V T C 1-V T C 3)-H R 13 * X 31 *(V T C 2-V T C 4)$

ENERGY45

DVIS $=X X 1 *($ UTC $1-$ UTC 3$)+X X 2 *$ (UTC2-UTC4)

$1-P(T H(I J) *(U T C 1+U T C 2+U T C 3+U T C 4) * 0.5 *$ AREA

$2+X X 3 *(V T C)-V T C 3)+X X X *(V T C 2-V T C 4)$

$S I E(I J)=S I E(I J)-((P(I J)+Q(I J)) * D V+D V I S) * 0.55 * D T / M C(I J)$

ENERGY46

ENERGY47

ENERGY48

ENERGY49 


\author{
I $P=I P J P$ \\ $10\lfloor\mathrm{I}=1 \mathrm{PJ}$ \\ 2O CONTINUE \\ RETURN \\ END
}

ENERGY50

ENERGYSI

ENERGY5?

ENERGY53

ENERGYSH

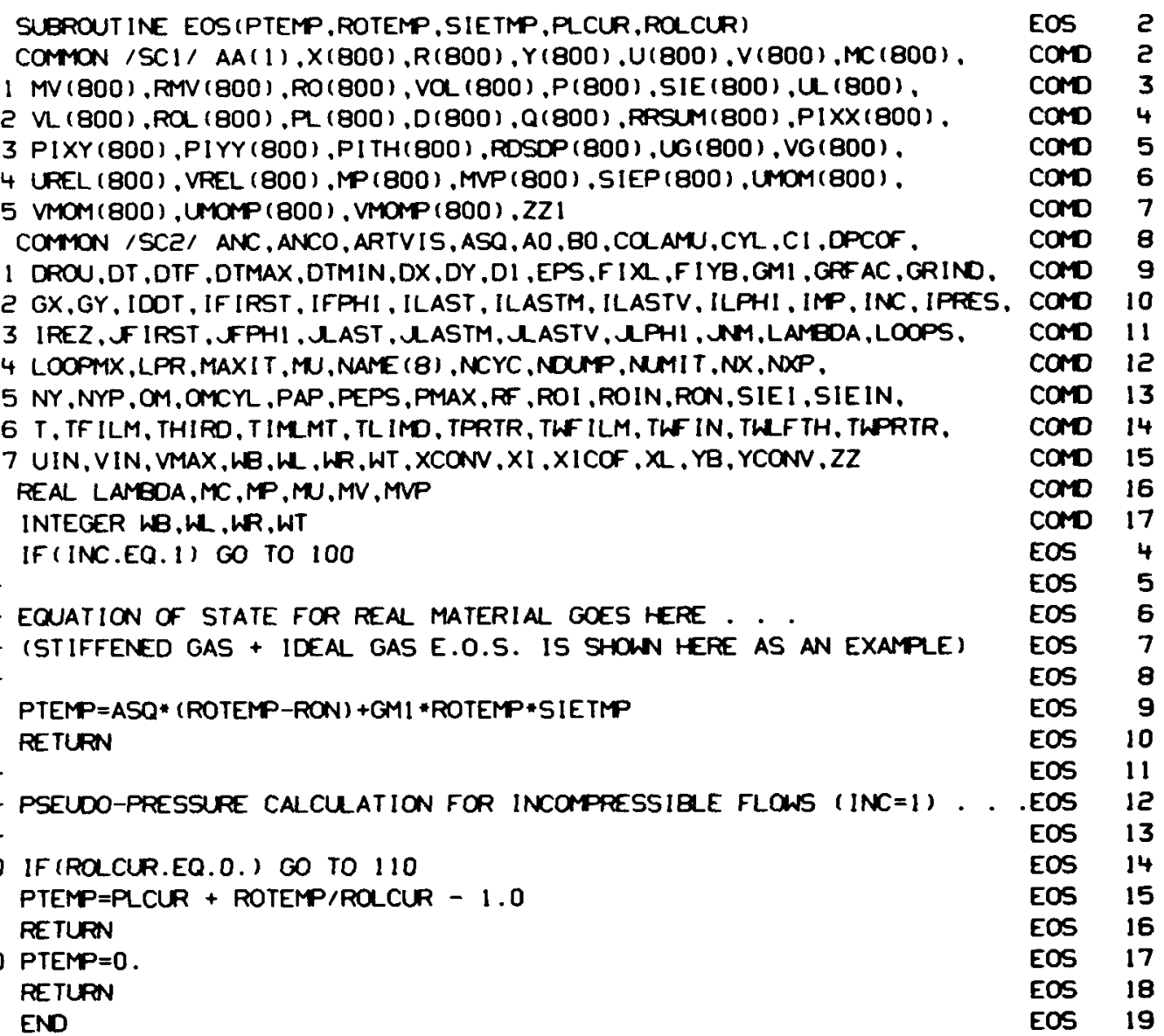


IF (LUN.EO.O) GO TO 10

FULOUT 4 IF (LUN.EQ.6) GO TO 40

FULOUT 5

TWF ILM=TWF ILM+TF ILM

C +++

C +++ SETUP PLOT SCAL ING AND CALL THE VARIOUS PLOT aNO PRINT SUBRS.

FULOUT 6

FULOUT 7

$\mathrm{C}+++$

$10 X Z=Y B=1 . E+100$

$X R=Y T=V M A X=-X L$

DO $30 \mathrm{~J}=1$, NYP

$I J=(J-1) * N X P+1$

DO $20 \quad 1=1$. NXP

$X L=A M I N I(X L, X(I J))$

$X R=A M A X I(X R, X(I J))$

$Y B=A M I N I(Y B, Y(I J))$

$Y T=A M A X I(Y T, Y(I J))$

VMAX $=A M A X 1(V M A X, A B S(U(I J)), A B S(V(I J)))$

FULOTT 8

FULOUT 9

FULOUT10

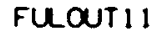

FULOTII

FULOTT 13

FULOTI 14

FULOIT15

FULOUT16

FULOUT 17

FULOUT18

FULOT 19

$50\lfloor J=I J+1$

30 CONT INUE

IF (VMAX.NE.0.) DROU $=0.9 * X R /(F L O A T(N X) *$ VMAX)

FULOUT20

FULOT21

FULOUT22

$F I Y B=900$.

$\mathrm{C}+++$

C +++ MAKE PLOTS SLIGHTLY UNOERSIZE TO ENSURE VELOCITY VECTORS

FULOT23

FULOUT24

Fulout25

FULOUT26

C +++ WILL BE PLOTTED PROPERLY AT MESH BOUNDARIES . . .

$\mathrm{C}+++$

$X T E=0.025 *(X R-X L)$

$Y T E=0.025 *(Y T-Y B)$

$X \mathrm{~L}=\mathrm{XL}-\mathrm{XTE}$

$X R=X R+X T E$

$Y B=Y B-Y T E$

$Y T=Y T+Y T E$

$X D=(X R-X L) /(Y T-Y B)$

$Y Y=0$.

IF (XD.LT.1.13556) $Y Y=1$.

$F I X L=A M A X I(0 \ldots,(511 .-450, * X D) * Y Y)$

$F I X R=(511 .+450 . * X D) * Y Y+1022 . *(1 .-Y Y)$

$F I Y T=(900 .-1022 . / X D) *(1 .-Y Y)$

$X C O N V=(F I X R-F I X L) /(X R-X L)$

$Y C O N V=(F I Y B-F I Y T) /(Y T-Y B)$

CALL ZONPLT

CALL VELPLT

CALL CONTUR (1,P)

CALL CONTUR(2,RO)

CALL CONTUR $(3$, SIE)

IF (LPR.EQ.1 .OR. LPR.EQ.2) CALL LNGPRT (12)

CALL GLOBAL (12)

IF (LUN.EQ.0) GO TO 50

RETURN

40 TWPRTR=TWPRTR+TPRTR

50 IF (LPR. GT. 1) CALL LNGPRT (6)

CALL GLOBAL (6)

RETURN

FULOUT27

FULOUT28

FULOUT29

FUOOT30

FULOT3!

FULOTI32

FULOUT33

FULOUT34

FULOUT35

FULOTI36

FULOUT37

FULOUT38

FULOTT39

FULOTT40

FULOUT4I

FULOTH2

FULOUT43

FULOUT44

FULOUT45

FULOUT46

FULOUT47

FULOTH8

FULOUT49

FULOUT50

FULOT51

FULOTS2

FULOUT53

FULOUT54

END

FULOUT55 


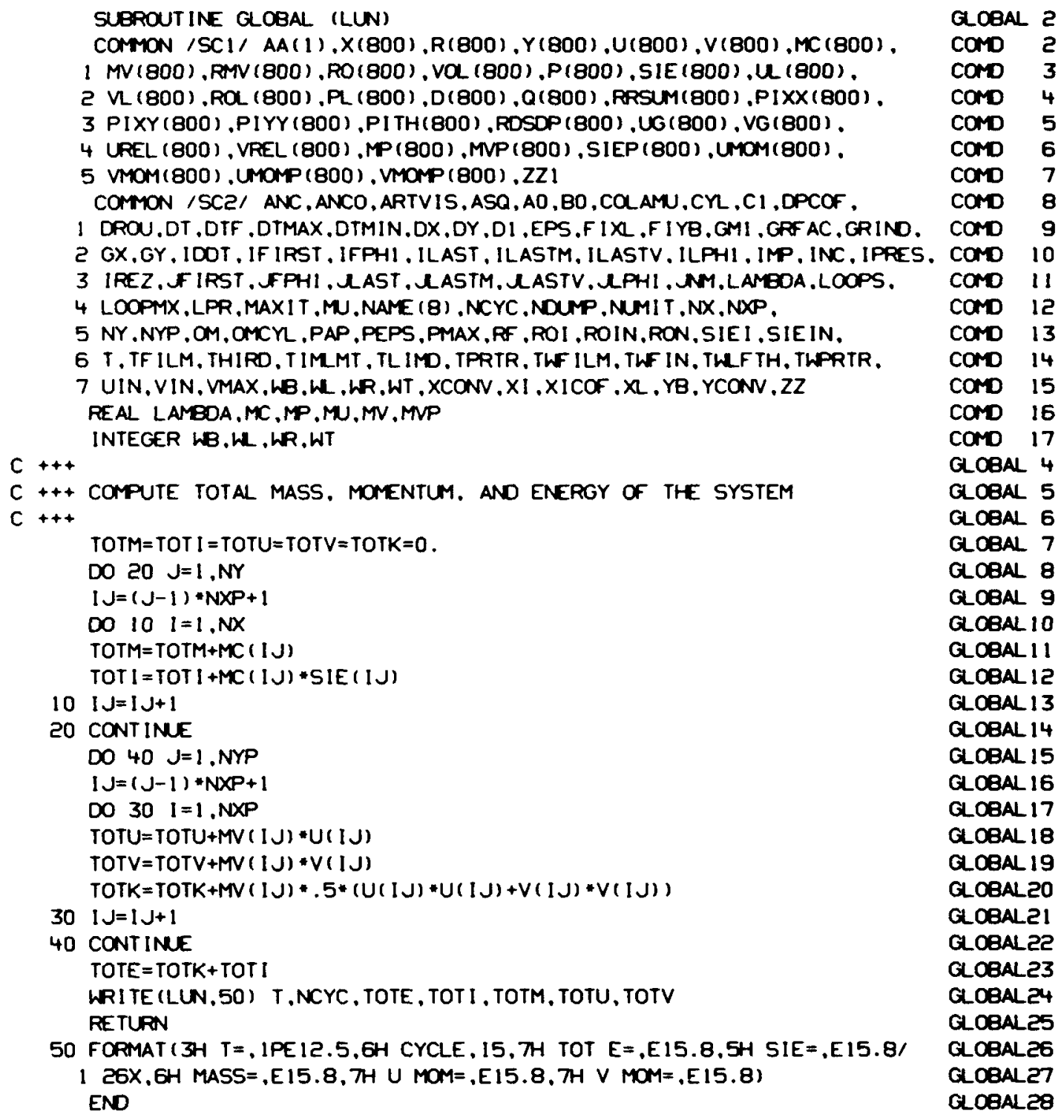


SUBROUTINE LNGPRT (LUN)

LNOPRT 2

COMMON /SC1/ AA 11$), X(800), R(800), Y(800), U(800), V(800), M C(800)$,

COMD

I MN $(800), \operatorname{RMN}(800), R O(800), V O(800), P(800), S 1 E(800), U(800)$.

$2 \mathrm{~V}(800), \mathrm{ROL}(800), \mathrm{PL}(800), \mathrm{D}(800), \mathrm{Q}(800), \mathrm{RRSUM}(800), \mathrm{PIXX}(800)$,

3 PIXY (800), PIYY (800), PITH(800), RDSOP (800), UG (800), VG $(800)$,

4 UREL (800), VREL (800), MP (800), MVP (800), SIEP (800), UMOM(800),

5 VMOM(800), UMOMP (BO0), VMOMP $(800), 2 Z 1$

COMMON ISC2/ ANC, ANCO, ARTVIS, ASO, AO,BO, COLAM, CY, Cl, DPCOF,

COMD 3

COMD 4

COMD 5

COMD 6

$\operatorname{COMD} 7$

COMD 8

1 DROU, DT,DTF, DTMAX,DTMIN, DX,DY,DI,EPS, FIXL,FIYB,GMI, GRFAC, GRINO, COMO 9

2 GX,GY, IDOT, IF IRST, IFPHI, ILAST, ILASTM, ILASTV, ILPHI, IMP, INC, IPRES, COMD 10

3 IREZ, JF IRST , JFPHI , LAST, LAASTM, LASTV, LPPHI , NM, LAMEDA , LOOPS,

4 LOOPMX,LPR, MAXIT, MU,NAME (8), NCYC, NOUMP, NUMIT, NX, NXP,

5 NY, NYP. OM.OMCY .PAP.PEPS, PMAX, RF, ROI .ROIN, RON, SIEI , SIEIN,

6 T, TF ILM. THIRD. TIMLMT , TLIMD. TPRTR, TWF ILM. THF IN, TWLFTH, TWPRTR,

7 UIN, VIN, VMAX, WB,WL,WR,WT, XCONV, XI .XICOF ,XL, YB, YCONV, ZZ

REAL LAMBOA,MC,MP,MU,MV,MVP

INTEGER WB.WL.WR.WT

$\mathrm{C}+++$

$C+++$ LONG PRINT OF X,Y,U,V,SIE,RO,MC,VO,P FOR ALL CELLS IN MESH.

$C+++$ DESTINATION IS FICHE (LUN=12), AND/OR LINE PRINTER (LUN=6)

$\mathrm{C}+++$

LPR $1=L P R 2=0$

IF (LPR.GT. I . AND. LUN.EQ.6) LPRI $=1$

IF (LPR.LT. 3 . AND. LUN.EQ.12) LPRE=1

LINES $=99$

DO $50 \mathrm{~J}=1$. NYP

$I J=(J-1) \cdot N X P+1$

DO $40 \quad l=1 . N \times P$

IF (LINES.LT.56) GO TO 10

LINES $=0$

IF (LPRI.GT.0) WRITE (6,100) NM,DI, CI .NAME, T, NCYC

IF (LPR2.GT.0) WRITE(12,100) NM,O1,CI.NAME,T,NCYC

$\mathrm{C}+++$

10 IF (LOOPS.LT.LOOPMX) GO TO 20

C +++ SPECIAL PRINT FOR RUN-ABORT CASE...

$\mathrm{C}+++$

IF(LPRI.GT.0) WRITE $(6,110) 1, J, X(I J), Y(I J) . U(I J) . V L(I J)$.

$\operatorname{CONO} 11$

$\operatorname{COMD} 12$

tom 13

COMD 14

COMD 15

COMD 16

COMD 17

LNGPRT 4

LNGPRT 5

LNGPRT 6

LNGPRT 7

LNGPRT 8

LNCPRT 9

LNGPRT 10

LNGPRT 11

LNGPRT 12

LNGPRT 13

LNGPRT 14

LNGPRT 15

LNGPRT 16

LNGPRT 17

LNGPRT 18

LNGPRT 19

LNGPRTZO

LNGPRT2I

LNGPRTZ2

LNGPRT23

I SIE (IJ), ROL (IJ),MC(IJ),VQ (IJ),PL(IJ)

IF (LPR2.GT.0) WRITE(12,I10) I,J,X(IJ),Y(IJ),UL(IJ),VL(IJ),

LNGPRT24

LNGPRT25

$1 \operatorname{SIE}(I J), R O(I J), M C(I J), V Q(1 J), P L(1 J)$

GO TO 30

$\mathrm{C}+++$

C +++ nORMAL OUTPUT CASE...

$\mathrm{C}+++$

20 IF (LPRI.GT.O) WRITE(6,110) I.J.X(1J), Y(1J).U(IJ).V(IJ).SIE (1J),

I RO(IJ),MC(IJ),VQ (IJ),P(IJ)

IF(LPR2.GT.0) WRITE(12,110) $1, J, X(1 J), Y(I J), U(I J), V(I J), S I E(I J)$,

1 RO (IJ), MC (IJ), VOL (IJ),P(IJ)

30 LINES $=$ L INES +1

$40[J=[J+1$

50 CONTINUE

IF (LPR2.GT.0) CALL ADV(1)

LNGPRT26

LNGPRT27

LNGPRT28

LNGPRT29

LNGPRT 30

LNGPRT 31

LNGPRT 32

LNGPRT 33

LNCPRT 34

LNGPRT 35

LNGPRT 36

LNGPRT 37 RETURN

LNGPRT 38

LNGPRT 39

100 FORMAT ( $1 \mathrm{H} 1,2 X, \mathrm{~A} 10,2(2 X, A B), 2 X, 8 \mathrm{~A} 10 / 40 \mathrm{X}, 3 \mathrm{H} \mathrm{T}=$, IPE $12.5,6 \mathrm{H}$ CYCLE, 15/ LNGPRT40

$1 \mathrm{HHO}, 7 \mathrm{H} 1 \mathrm{~J}, 6 \mathrm{X}, 1 \mathrm{HX}, 10 \mathrm{X}, 1 \mathrm{HY}, 10 \mathrm{X}, 1 \mathrm{HU}, 10 \mathrm{X}, 1 \mathrm{HV}$,

2 $10 X, 3$ HSIE, 8X, 3H RHO , 7X, 4HMASS, 8X, 3HVO, 8X, 1HPI

LNGPRT41

LNGPRT42

LNCPRT 43

END

LNGPRT44 


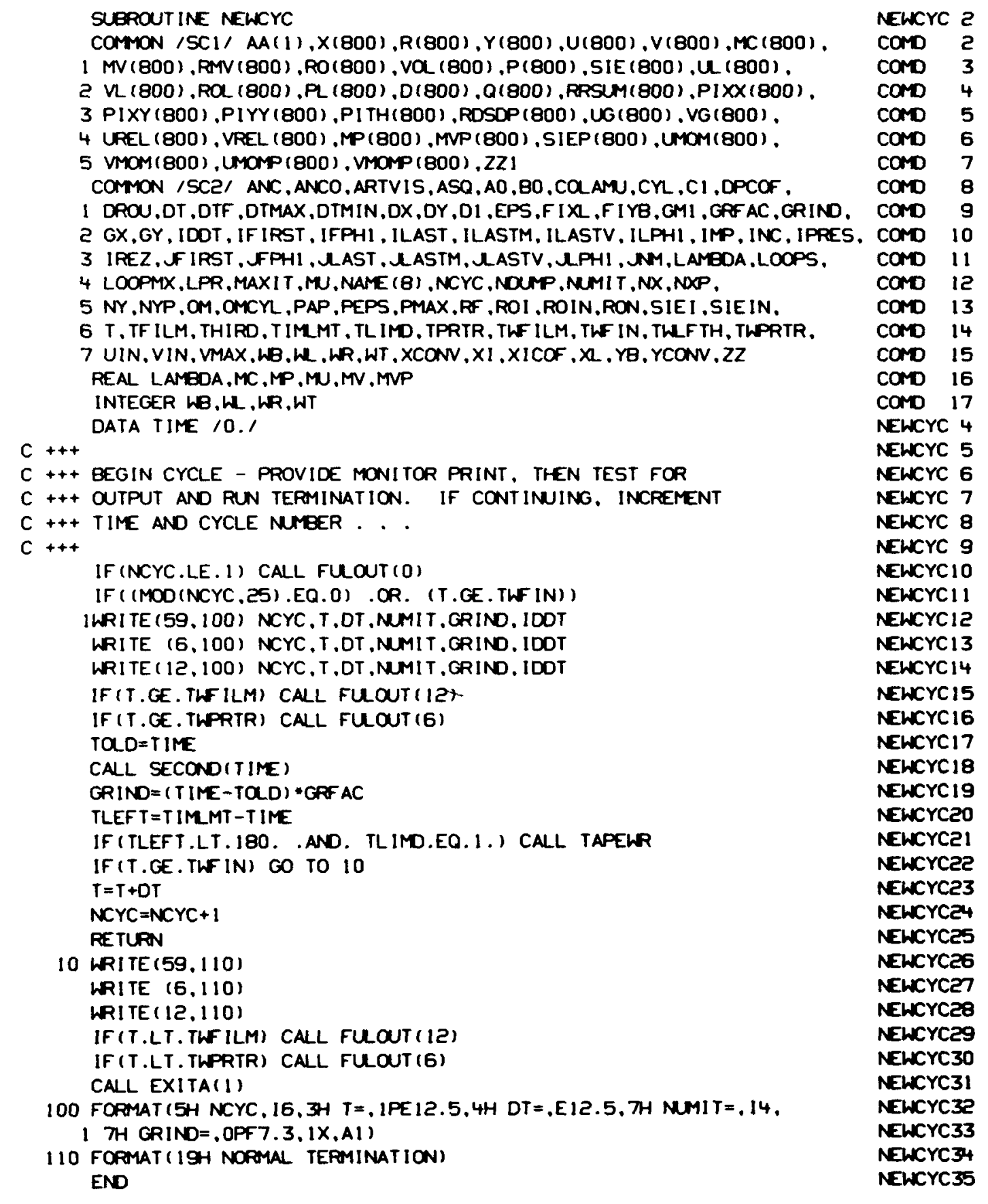




\section{SUBROUT INE PHASE 1}

COMMON /SC1/ AA (1), X(800), R(B00), Y (B00),U(800), V(800),MC $(800)$,

$1 M V(800), \operatorname{RMV}(800), R O(800), V Q(800), P(800)$, SIE $(800), U(800)$.

PHASE 12

$2 \mathrm{VL}(800), R O L(800), P L(800), D(800), Q(800), R R S U M(800), P I X X(800)$,

3 PIXY (800), PIYY (800), PITH(800), RDSOP $(800), \cup G(800), V G(800)$,

4 UREL (800), VREL (800), MP (800), MVP (800), SIEP (800), UMOM(800).

5 VMOM(800), UMOMP (800), VMOMP $(800), 221$

COMON /SCE/ ANC, ANCO, ARTVIS, ASO, AO,BO,COLAM, CY, Cl, DPCOF,

COMO 2

COMD 3

$\operatorname{COMD} 4$

$\operatorname{com} 5$

$\operatorname{com} 6$

$\operatorname{COMD} 7$

$\operatorname{COMD} 8$

1 DROU.DT,DTF, DTMAX,DTMIN,DX,DY,DI,EPS,FIX,.FIYB.GMI,GFAC,GRIND, COMD 9

2 GX,GY, IDOT, IF IRST, IFPHI, ILAST, ILASTM, ILASTV, ILPHI, IMP, INC, IPRES, COMD 10

3 IREZ, JFIRST, JFPHI, LAST, LASTM, LASTV, LPHI, NM, LAMBDA,LOOPS, COMD 11

4 LOOPMX, LPR, MAXIT,MN,NAME (8),NCYC,NDUM,NUMIT,NX,NXP, $\quad$ COMD 12

5 NY, NYP, OM, OMCY , PAP, PEPS, PMAX, RF, ROI , ROIN, RON, SIEI , SIE IN,

6 T, TF ILM, THIRO, TIM MT, TL IMO, TPRTR, TWFILM, TWF IN, THLF TH, TWPRTR,

7 UIN, VIN, VMAX, WB, WL, WR, WT , XCONV, XI , XICOF , XL, YB, YCONV, ZZ

REAL LAMBOA,MC,MP,MU,MV, MVP

$\mathrm{C}+++$

INTEGER WB,WL,WR,WT

C +++ PHASE 1. EXPL ICIT LAGRANGIAN CALCULATION, IN WHICH WE ADUST

C +++ THE LAGRANGIAN VELOCITIES BY PRESSURE GRADIENTS AND BODY FORCES.

C +++

C +++ THE PRESSURE ACCELERATIONS. .

$\mathrm{C}+++$

DO $20 \mathrm{~J}=\mathrm{JFPH1}, \mathbf{\mathrm { LPH } I}$

$I J=(J-1) * N \times P+I F P H I$

$I J P=I J+N X P$

DO $10 \mathrm{I}=$ IFPHI, ILPHI

$I P J=1 J+1$

IPJP=I $P+1$

$D T P=0.5 * D T * P(1 \mathrm{~J})$

RMI = RAN ( IPJ)

RMV=RMT (IPSP)

RM3 $=\operatorname{RMN}(I \boldsymbol{P})$

RMY = RAN (IJ)

$R I=R(I P J)$

$R P=R(I P P)$

$R 3=R(I P)$

$R_{4}=R(I J)$

$\left.\left.X R C_{4}=(X(I P J))-X(I J)\right) .5 *(R)^{2}+R 4\right)$

$X R 31=(X(I P)-X(I P J)) * .5 *(R 3+R 1)$

$Y Z_{4}=Y(I P J P)-Y(I J)$

$Y 3 I=Y(I P)-Y(I P J)$

$U(I P J)=U(I P J)+D T P * P M I+Y Z 4 * R I$

COND 13

COMD 14

COMD 15

COMD 16

COMD 17

PHASE 14

PHASE 15

PHASE 16

PHASE 17

PHASE 18

PHASE 19

PHASE 110

PHASE $1 ! 1$

PHASE IIL

PHASE 113

PHASE 114

PHASE 115

PHASE 116

PHASE 117

PHASE 118

PMASE 119

PHASE 120

PHASE 121

PHASE 122

PHASE 123

PHASE 124

PHASE 125

PHASE 126

PHASE 127

PHASE 128

PHASE 129

$U(I P J)=U(I P J)+D T P * R M P * Y 31$ - R2

$U(I P)=U(I P)-D T P * R M 3 * Y 24 * R 3$

$U(I J)=U(I J) \quad-D T P * R_{1}+Y 31 * R_{4}$

PHASE 130

PHASE 131

PHASE 132

$V(I P J)=V(I P J)-D T P * R M 1 * X R 24$

$V(I P J P)=V L(I P J P)-D T P * R M P * X R 31$

$V(I P)=V(I P)+D T P=R M 13 * X R 24$

$V(I J)=V(I J) \quad+D T P *$ PAT*XR31

IJ=IPJ

10 I P =IPJP

20 CONTINUE

IF (GX.EQ.O. .AND. GY.EQ.O.) GO TO 50

PHASE 133

PHASE 134

PHASE 135

PHASE 136

PHASE 137

PHASE 130

PHASE 139

PHASE 140

PHASE 141

C +++

C +++ THE BODY ACCELERATIONS . . .

C +++

$D T G X=0 T * G X$

$D T G Y=0 T * G Y$

DO $40 J=J F$ IRST, LASTV

I $J=N D P=(J-1)+$ IF IRST

DO 30 I = IF IRST. ILASTV

PHASE 142

PHASE 143

PHASE 144

PHASE 145

PHASE 146

PHASE 147

PHASE 148

$V(I J)=V L(I J)+D T G Y$

PHASE 149 
$U(I J)=U(I J)+D T G x$

$30\lfloor\mathrm{I}=I \mathrm{~J}+1$

40 CONT INUE

50 CALL BC(UL, VL)

RETURN

END
PHASE 150

PHASE151

PHASE 152

PHASE 153

PHASE 154

PHASE 155 


\begin{tabular}{|c|c|c|}
\hline & $\begin{array}{l}\text { SUEROUT INE PRESIT } \\
\text { COMON } / \text { SCI }\end{array}$ & PRESIT 2 \\
\hline & 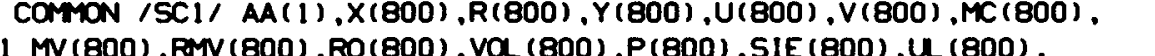 & COMD \\
\hline & & COMD \\
\hline & $2 n(800), R O L(800), P L(800), D(800), Q(800), \operatorname{RRSUM}(800), P I X X(800)$, & COMD \\
\hline & 3 PIXY (800), PIYY (800), PITH(800),RDSDP $(800)$, UG $(800)$, VG $(800)$ & COMD \\
\hline & 4 UREL $(800)$, VREL $(800), \operatorname{MP}(800), \operatorname{MPP}(800)$, SIEP $(800), \operatorname{UMOM}(800)$, & COMD \\
\hline & 5 VMOM $(800)$, UMOMP $(800)$, MOMP $(800), 2 Z 1$ & COMD \\
\hline & COMMON ISCE/ ANC, ANCO,ARTVIS,ASO,AO,BO,COLAM, CY, C1, DPCOF, & COMD \\
\hline & 1 DROU,DT,DTF,DTMAX,DTMIN,DX,DY,DI ,EPS,FIX, ,F IYB,GMI ,GFFAC,GRIND, & COMD \\
\hline & 2 GX,GY, IDOT, IF IRST, IFPHI , ILAST, ILASTM, ILASTV, ILPHI, IMP, INC, IPRES, & COMD \\
\hline & 3 IREZ, JF IRST, JFPHI, ULAST, LASTM, LASTV, LPHI, NM, LAMBOA, LOOPS, & $\operatorname{cond}$ \\
\hline & 4 LOOPMX, LPR, MAXIT, MU, NAME (8), NCYC, NOUMP, NMMIT , NX, NXP. & COMD \\
\hline & 5 NY, NYP, OM, OMCY, ,PAP, PEPS, PMAX, RF, ROI ,ROIN, RON, SIE I , SIEIN, & $\operatorname{COM}$ \\
\hline & 6 T, TF ILM, THIRD, TIMLMT, TL IMD, TPRTR, TWF ILM, THF IN, THLF TH, TWPRTR, & $\operatorname{com}$ \\
\hline & 7 UIN, VIN, VMAX, WB, WL, WR, WT, XCONV ,XI, XICOF, XI, YB, YCONV,ZZ & COMD \\
\hline & REAL LAMBOA,MC,MP,MN,MV,MVP & COMD \\
\hline & INTEGER WB,WL, WR,WT & COMD 17 \\
\hline+++ & & PRESIT 4 \\
\hline C +++ & PHASE 2. THE NEWTON-RAPHSON PRESSURE I TERATION . . . & PRESIT 5 \\
\hline+++ & 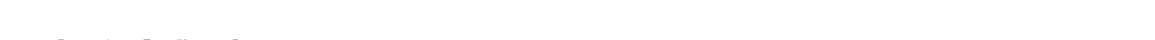 & PRESIT 6 \\
\hline & DATA PSTAR /0./ & PRESIT 7 \\
\hline & NUMIT =0 & PRESIT 8 \\
\hline 10 & NUMIT $=N U M I T+1$ & PRESIT 9 \\
\hline & MUSTIT $=0$ & PRESITIO \\
\hline & $P M A X N=0$ & PRESITII \\
\hline & DO $30 J=J$ IRST, LAST & PRESITIL \\
\hline & $I J=(J-1) * N X P+I F$ IRST & PRESIT13 \\
\hline & $I P=\mid J+N X P$ & PRESIT14 \\
\hline & DO $20 \quad$ I=IFIRST, ILAST & PRESIT15 \\
\hline & $I P J=I J+1$ & PRESIT16 \\
\hline & $I P \boldsymbol{P}=1 \boldsymbol{P}+1$ & PRESIT17 \\
\hline & $x \mid=x(\mid P J)$ & PRESITI8 \\
\hline & $R \mid=R(\mid P J)$ & PRESITIS \\
\hline & $Y I=Y(\mid P J)$ & PRESITZO \\
\hline & UI =UL(IPJ) & PRESITZI \\
\hline & $V I=V(I P J)$ & PRESI T22 \\
\hline & $x 2=x(I P J)$ & PRESI T23 \\
\hline & $R 2=R(I P J)$ & PRESI T24 \\
\hline & $Y Z=Y(I P D)$ & PRESITZ5 \\
\hline & $U R=U(I P J)$ & PRESITZ6 \\
\hline & $V 2=n(I P S)$ & PRESITE7 \\
\hline & $x 3=x(1 P)$ & PRESI TZO \\
\hline & $R 3=R(I / P)$ & PRESITZ9 \\
\hline & $Y 3=Y(I N)$ & PRESIT30 \\
\hline & $U 3=U(I D)$ & PRESIT3I \\
\hline & $V 3=V(I P)$ & PRESI T32 \\
\hline & $x_{4}=x(I J)$ & PRESI T33 \\
\hline & $R_{4}=R(1 J)$ & PRESI T34 \\
\hline & $Y 4=Y(I J)$ & PRESIT35 \\
\hline & $U_{4}=U(I J)$ & PRESIT36 \\
\hline & $v_{4}=V(I J)$ & PRESIT37 \\
\hline & $X(P=X I+U(I P J) * D T$ & PRESIT38 \\
\hline & $x E P=x E+U($ (IPJ) $* 0 T$ & PRESIT39 \\
\hline & $x 3 P=x 3+U L(I N)=D T$ & PRESI T40 \\
\hline & $x+P=x 4+U L(I J) * D T$ & PRESI T4I \\
\hline & $Y \mid P=Y I+V(I P J)=D T$ & PRESITH2 \\
\hline & $Y Z P=Y Z+Y L(I P J) * D T$ & PRESIT43 \\
\hline & $Y 3 P=Y 3+V(I N) * D T$ & PRESIT44 \\
\hline & $r_{4} P=r_{4}+V_{L}(I J)=O T$ & PRESI 145 \\
\hline & $R I P=X I P * C Y L+O M C Y$ & PRESI T46 \\
\hline & $R C P=x C P+C Y+O M C Y$ & PRESIT47 \\
\hline & $R 3 P=X 3 P=C Y+O M C n$ & PRESIT48 \\
\hline & $R+P=X 4 P * C Y+O M C Y$ & PRESIT49 \\
\hline
\end{tabular}




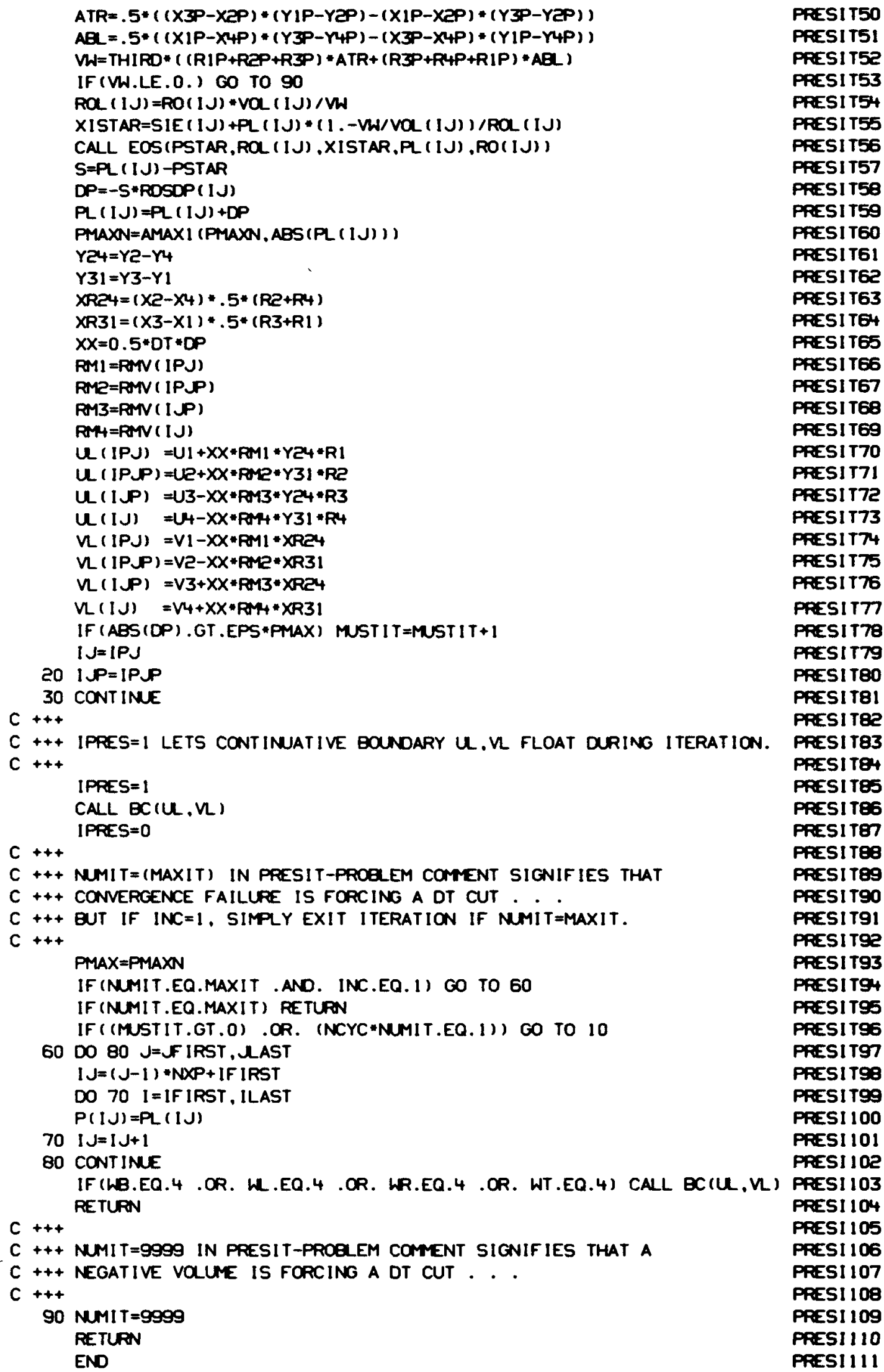




\begin{tabular}{|c|c|c|c|}
\hline & SUBROUTINE REGRID & REGRID & \\
\hline & COMHON /SC1/ AA(1), X(800), R(800), Y(800), U(800), V(800),MC(800), & COMD & 2 \\
\hline & $1 \operatorname{MV}(800), \operatorname{RMV}(800), R O(800), \operatorname{VO}(800), P(800), \operatorname{SIE}(800), \mathrm{U}(800)$ & COMD & 3 \\
\hline & a $\mathrm{VL}(800), \operatorname{RQ}(800), \mathrm{PL}(800), \mathrm{D}(800), \mathrm{Q}(800), \operatorname{RRSUM}(800), \mathrm{PI} X X(800)$, & COMD & 4 \\
\hline & 3 PIXY $(800), P I Y Y(800), P I T H(800)$, RDSDP $(800)$, UG $(800), V G(800)$ & como & 5 \\
\hline & $4 \operatorname{UREL}(800), \operatorname{VREL}(800), \operatorname{MP}(800), \operatorname{MNP}(800), \operatorname{SIEP}(800), \mathrm{UMOM}(800)$. & COMD & 6 \\
\hline & $5 \operatorname{VMOM}(800), \operatorname{UMOMP}(800), \operatorname{VMOMP}(800), Z Z 1$ & cono & 7 \\
\hline & COMMON /SC2I ANC, ANCO, ARTVIS, ASO,AO,BO,COLAMU,CY, C1,DPCOF. & COMD & 8 \\
\hline & 1 DROU,DT ,DTF, DTMAX,DTMIN,DX,DY,DI,EPS,FIXL,FIYB,GMI, GRFAC,GRIND, & COMD & 9 \\
\hline & 2 GX,GY, IDOT, IF IRST, IFPHI, ILAST, ILASTM, ILASTV, ILPHI, IMP, INC, IPRES, & COMD & 10 \\
\hline & 3 IREZ, IF IRST, JFPHI, LAST, LASTM, LASTV, LPHH, , MM, LAMBOA, LOOPS, & COMD & 11 \\
\hline & 4 LOOPMX, LPR,MAXIT,MU,NAME (8),NCYC,NDUMP,NUMIT, NX,NXP, & COMD & 12 \\
\hline & 5 NY, NYP, OM, OMCY , PAP, PEPS, PMAX, RF, ROI, ROIN, RON, SIEI , SIEIN, & COMD & 13 \\
\hline & 6 T. TF ILM, THIRO, TIMLMT, TLIMD, TPRTR, TWF ILM, THF IN, THLFTH, TWPRTR, & COMD & 14 \\
\hline & 7 UIN, VIN, VMAX, WB, WL, WR, WT ,XCONV, XI ,XICOF,X, YB, YCONV,ZZ & COMD & 15 \\
\hline & REAL LAMBOA,MC,MP,MU,MV,MMP & COMD & 16 \\
\hline & INTEGER WB,WL,WR,WT & $\operatorname{COMD} 1$ & 17 \\
\hline C +t+ & & REGRID & \\
\hline 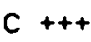 & MOVE VERTICES AND COMPUTE RELATIVE VELOCITY BETLEEN FLUID AND GRI & & \\
\hline 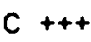 & & REGRID & \\
\hline & $D O 20 J=1, N Y P$ & REGRID & \\
\hline & $1 J=(J-1)=N X P+1$ & REGRID & \\
\hline & DO $10 \quad I=1, N X P$ & REGRID & \\
\hline & $x(I J)=x(I J)+D T * U G(I J)$ & REGRIDI & \\
\hline & $Y(I J)=Y(I J)+D T * V G(I J)$ & REGRID1 & \\
\hline & $R(I J)=x(I J) * C n+a r c n$ & RECRIDI & \\
\hline & UREL $(I J)=U G(I J)-U(I J)$ & RECRIDI & \\
\hline & $\operatorname{VREL}(\mid J)=\operatorname{VG}(I J)-\operatorname{VL}(I J)$ & EEGRIOI & \\
\hline & $\operatorname{MVP}(I J)=0$ & FEGRIDI & \\
\hline 10 & $1 J=1 J+1$ & FEGRIDI & \\
\hline 20 & CONT INUE & REGRIDI & \\
\hline & RETURN & REGRIDI & \\
\hline & END & REGRIDI & \\
\hline
\end{tabular}




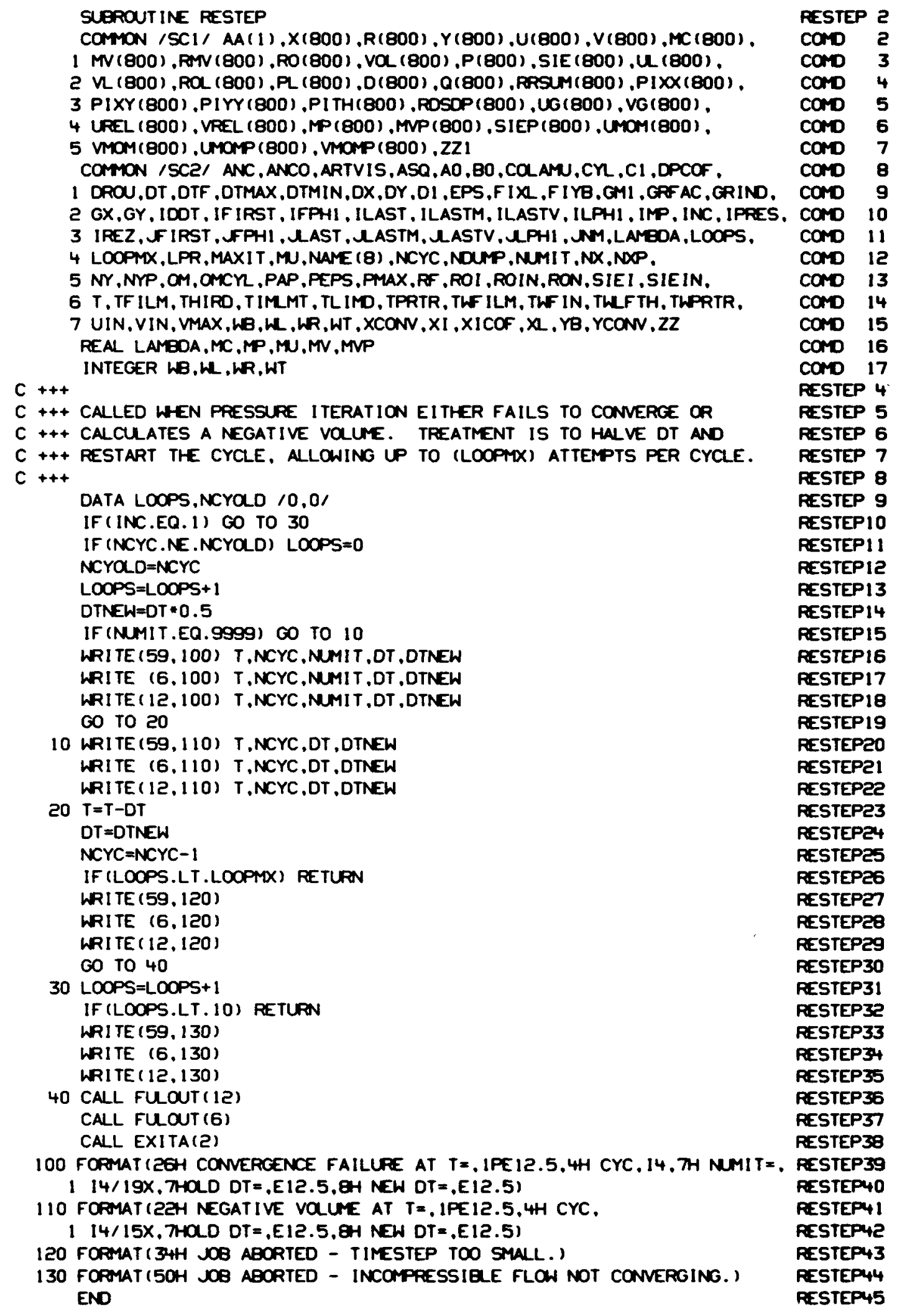


SUBROUT INE REZONE
COMMON /SCI/ AA $(1), X(800), R(800), Y(800), U(800), V(800), M C(800)$,

$1 M N(800), \operatorname{PN}(800), R O(800), V Q L(800), P(800), S I E(800), U(800)$,

$2 \mathrm{~V}(800), R Q(800), P L(800), D(800), Q(800)$, RRSUM $(800), P I X X(800)$,

3 PIXY $(800)$, PIYY $(800), P I T H(B 00)$, RDSOP $(800), U G(800), V G(800)$.

4 UPEL $(800)$, VEEL $(800), M P(800), M M P(800)$, SIEP $(800), U M O M(800)$,

$5 \operatorname{VMOM}(B 00)$, UMOMP $(800), \operatorname{MTOMP}(800), Z Z 1$

COMMON /SC2/ ANC, ANCO, ARTVIS, ASO, AO,BO, COLAMN,CY, Cl, DPCOF,

1 DROU,DT, DTF ,DTMAX, DTMIN, DX,DY, OI,EPS, F IX, F I YB, GMI, GPFAC, GRIND,

2 GX,GY, IDOT, IF IRST, IFPHI, ILAST, ILASTM, ILASTV, ILPHI, IMP, INC, IPRES,

3 IREZ, F IRST, JFPHI . LAST, LASTM, LASTV, LPHI , NM, LAMEDA, LOOPS.

4 LOOPTX, LPR, MAXIT, MU, NAME (B), NCYC, NDUP, NUMIT, NX, NDP.

5 NY, NYP, OM, OMCY, PAP, PEPS, PMAX, RF, ROI ,ROIN, RON, SIEI , SIEIN,

REZONE 2

COMD 2

con 3

COMD 4

COND 5

COMD 6

COND 7

COND 8

COMD 9

COND 10

COMD 11

GOMD 12

COMD 13

6 T, TF ILM, THIRD, TIMLMT, TLIMD, TPRTR, TWF ILM, TWF IN, TWLFTH, TWPRTR, $\quad$ COMD 14

7 UIN, VIN, VMAX, WB, WL,WR, WT, XCONV, XI, XICOF,XL, YB, YCONV,ZZ

cond 15

REAL LAMBOA,MC,MP,MU,MV,MNP

INTEGER WB.WL, WR,WT

C +++

C +++ COMPUTE GRID VELOCITIES UG AND VG FOR USE IN REGRID

$\operatorname{com} 16$

COMD 17

REZONE 4

REZONE 5

C +++ IREZ=0 IS EULERIAN. IREZ=1 IS LAGRANGIAN, IREZ=2 IS AVERAGING RE- REZONE 6

C +++ ZONE BY RELAXATION. IREZ $=3$ LEFT VACANT FOR SPECIF ICATION BY USER. REZONE 7

C +++

REZ = IREZ+ 1

GO TO $(10,40,70,100)$, JPEZ

C +t+

C +++ EULERIAN

$\mathrm{C}+++$

10 DO $30 \mathrm{~J}=1$.NYP

$I J=(J-1) * N \times P+1$

DO $20 \quad I=1$, NDP

$\operatorname{LG}(I J)=0$.

$\operatorname{VG}(I J)=0$.

REZONE 8

REZONE 9

REZONE 10

REZONE 11

REZONE1?

REZONE 13

REZONE14

REZONE15

REZONE16

REZONE17

$20 \quad I J=I J+1$

30 CONTINUE

RETURN

REZONE18

REZONE19

REZONEZO

REZONE2 1

$\mathrm{C}+++$

C +++ LAGRANGIAN

C +++

40 DO $60 \mathrm{~J}=1$, NYP

$[J=(J-1) * N X P+1$

REZONEZ2

REZONE23

REZONEZ4

REZONEZS

DO $50 \quad \mathrm{l}=1$, NXP

REZONEZ6

$U G(I J)=U(I J)$

REZONE27

$\operatorname{VG}(I J)=V L(I J)$

REZONEZ8

$50\lfloor J=1 J+1$

60 CONTINUE

REZONEZ9

REZONE30

REZONE31

RETUPN

REZONE32

REZONE33
C ++++ SAMPLE CONTINUOUS REZONE - RELAX ALL VERTICES EXCEPT THE 4 CORNERSREZONE34

C +++ TOWARD THE AVERAGE POSITION OF THE 4 OR 2 CLOSEST NEIGHORS... REZONE35

C +t+

70 RFOOT $=R F / D T$

DO $90 J=1$. NYP

REZONE36

REZONE37

REZONE38

I $J=(J-1) * N \times P+1$

REZONE39

$I P=1 J+N \times P$

$1 \mathrm{M}=1 \mathrm{~J}-\mathrm{NDP}$

REZONE40

DO $801=1$,NXP

REZONE41

$[P J=1 \mathrm{~J}+1$

REZONE42

IMU $=[J-1$

$U G(I J)=U(I J)$

$\operatorname{VG}(\mid J)=V(I J)$

IF IIJ.EQ.I .OR. IJ.EQ.NXP .OR. IJ.EQ.NXP*NY+1

1 .OR. IJ.EQ.NOP*NYPI $G O$ TO 78

IF ( I.EO. I .OR. I .EQ.NDP) GO TO 72

ONE43

REZONE44

REZONE45

PEZONE46

REZONE47

REZONE48

REZONE49 
IF (J.EQ. 1 .OR. J.EQ.NYP) GO TO 74

REZONESO

$X N=.25 *(X(I P J)+X(I P)+X(I M J)+X(I M))$

REZONES1

$\eta N=.25 *(Y(I P J)+Y(I P)+Y(I M N)+Y(I M))$

REZONE52

GO TO 76

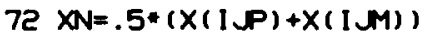

REZONE53

REZONE54

$Y N=.5 *(Y(I P)+Y(I M))$

REZONESS

GO TO 76

REZONE56

REZONE57

REZONESB

$W=.5 *(Y(I P J)+Y(I M U))$

76 UG $(I J)=U(I J)+R F O O T *(X N-X(I J))$

$\operatorname{VG}(I J)=V(I J)+R F O O T *(Y N-Y(I J))$

REZONE59

REZONE60

78 I $J=I J+1$

I $P=1 \mathrm{P}+1$

REZONE61

REZONE62

REZONE63

80 I $M=1 \mathrm{M} M+1$

REZONE64

RETURN

REZONE65

REZONE66

REZONE67

REZONEGB

C +++ GENERAL REZONE - ROLL-YOUR-OWN HERE . .

REZONE69

100 CONT INUE

RETURN

REZONE70

END

REZONE71 
COMMON /SC1/ AA(1),X(B00), R(800), Y(800),U(800),V(B00),MC (800),

$\operatorname{Comp} 2$

$1 \operatorname{MV}(800), \operatorname{RMV}(800), R O(800), V Q(800), P(800)$, SIE $(800), U(800)$.

$\operatorname{COMD} 3$

2 VL (800), ROL $(800), P L(800), D(800), Q(800), \operatorname{RPSUM}(800), P I X X(800)$,

$\operatorname{con} 4$

3 PIXY (800), PIYY $(800)$, PITH(800), ROSOP $(800), U G(800)$, VG $(800)$,

4 UREL (800), VREL $(800)$, MP (800), MVP $(800)$, SIEP $(800)$, UMOM $(800)$,

5 VMOM $(800)$, UMOMP $(800), \operatorname{VMOMP}(800), 2 Z 1$

COMMON /SC2/ ANC, ANCO, ARTVIS, ASO, AO,BO, COLAM, CY, C1, DPCOF,

COMD 5

COMD 6

$\operatorname{COND} 7$

1 DROU,DT,DTF, DTMAX,DTMIN,DX,DY,D1,EPS,FIX, ,FIYB,GMI, GRFAC,GRIND, COMD 9

2 GX, GY, IDOT, IF IRST, IFPHI, ILAST, ILASTM, ILASTV, ILPHI, IMP, INC, IPRES, COMD 10

3 IREZ, FIRST, FPHI, LAST, LASTM, LASTV, LPHI, NM,LAMBDA,LOOPS, COMD 11

4 LOOPMX, LPR.MAXIT,MU,NAME (8),NCYC,NDUMP.NUMIT, NX,NXP.

5 NY, NYP, OM, OMCY , PAP, PEPS, PMAX, RF, ROI ,ROIN, RON, SIEI , SIEIN,

6 T. TF ILM, THIRD, TIMLMT, TLIMD, TPRTR, TWFILM, TWF IN, TWLFTH, TWPRTR,

7 UIN,VIN, VMAX, WB,WL, WR, WT, XCONV , XI , XICOF, XL, YB, YCONV, ZZ

REAL LAMBOA,MC,MP,MU,MV,MVP

INTECER WB.WL,WR,WT

DIMENSION HOUT (42)

C +t+

C +++ READ DATA DECK, COMPUTE DERIVED AND SCALAR QuANTITIES

$\mathrm{C}+++$

READ (5.210) HOUT (1), NX, HOUT (2), NY, HOUT (3), IMP, HOUT (4), INC IF (NX.EQ.0) RETURN

READ (5.210) HOUT (5), IREZ, HOUT (6), LPR

READ (5,210) HOUT (7), WB. HOUT (8), WL, HOUT (9), WR, HOUT (10), WT

READ (5,220) HOUT (11), DX, HOUT (12), DY, HOUT (13),CYL

READ (5,220) HOUT (14), DT, HOUT (15), DTMAX, HOUT (16), TL IMD

READ (5,220) HOUT (17), TWF ILM, HOUT (18), TWPRTR, HOUT (19), TWF IN

READ (5,220) HOUT (20), OM, HOUT (21), PEPS, HOUT (22) , EPS, HOUT (23), RF

READ (5,220) HOUT (24), ARTVIS, HOUT (25), LAMBOA, HOUT (26), MN

REAO (5,220) HOUT (27), ANC, HOUT (28), XI , HOUT (29), GX

READ (5,220) HOUT ( 30 ), GY, HOUT ( 31 ), AO, HOUT ( 32 ), BO

READ (5,220) HOUT (33), ASO, HOUT (34), RON, HOUT (35) , GMI

READ (5,220) HOUT (36), ROI, HOUT (37), SIEI

READ (5, 220) HOUT (38), UIN, HOUT (39), VIN

READ (5,220) HOUT (40), ROIN,HOUT (41), SIEIN, HOUT (42), PAP

WRI TE (12,210) HOUT (1), NX, HOUT (2), NY, HOUT (3), IMP, HOUT (4) , INC

WRITE (12.210) HOUT (5), IREZ, HOUT (6), LPR

WRITE (12,210) HOUT (7), WB,HOUT (8), WL, HOUT (9), WR, HOUT (10), WT

WRITE (12,230) HOUT (11),DX,HOUT (12), DY,HOUT (13),CR

WRITE (12,230) HOUT (14), DT, HOUT (15), DTMAX, HOUT (16), TLIMD

WRITE (12,230) HOUT (17), TWFILM,HOUT (18), TWPRTR, HOUT (19), TWF IN

COMD 12

$\operatorname{COMD} 13$

COMD 14

$\operatorname{com} 15$

COMD 16

COMD 17

RINPUT 4

RINPUT 5

RINPUT 6

RINPUT 7

RINPUT 8

RINPUT 9

RINPUT 10

RINPUTII

RINPUTIE

RINPUT 13

RINPUT 14

RINPUT 15

RINPUTI6

RINPUTI7

RINPUT18

RINPUTIS

RINPUTZO

RINPUT21

RINPUT22

RINPUT23

RINPUT24

RINPUT25

RINPUTZ6

RINPUT27

RINPUTZ8

WRITE (12,230) HOUT (20), OM, HOUT (21), PEPS, HOUT (22) , EPS, HOUT (23), RF

WRITE (12,230) HOUT (24), ARTVIS, HOUT (25), LAMBOA, HOUT (26), MU

WRITE (12,230) HOUT (27), ANC.HOUT (28), XI , HOUT (29) , GX

WRITE (12,230) HOUT (30), GY,HOUT (31), AO,HOUT (32), BO

WRITE (12,230) HOUT (33), ASQ, HOUT (34), RON, HOUT (35), GMI

WRITE (12,230) HOUT (36), ROI ,HOUT (37), SIE I

WRITE (12,230) HOUT (38), UIN,HOUT (39), VIN

WRITE (12,230) HOUT (40), ROIN, HOUT (41), SIE IN, HOUT (42), PAP

WRITE (6,210) HOUT (1), NX, HOUT (2), NY, HOUT (3), IMP, HOUT (4), INC

WRITE (6,210) HOUT (5), IREZ, HOUT (6), LPR

WRITE (6,210) HOUT (7), WB, HOUT (8), WL, HOUT (9), WR, HOUT (10), WT

WRI TE (6,230) HOUT (11), DX, HOUT (12), OY, HOUT (13), CYL

WRITE (6,230) HOUT (14), DT, HOUT (15), DTMAX, HOUT (16), TLIMD

WRI TE (6,230) HOUT (17), TWF ILM, HOUT (18), TWPRTR, HOUT (19), TWF IN

WRITE (6,230) HOUT (20), OM, HOUT (21), PEPS, HOUT (22), EPS, HOUT (23), RF

WRI TE (6.230) HOUT (24), ARTVIS, HOUT (25), LAMBOA, HOUT (26), MU

WRITE (6,230) HOUT (27), ANC, HOUT (28), XI, HOUT (29), GX

WRITE (6.230) HOUT (30), GY, HOUT (31), AO, HOUT ( 32 ) , BO

WRI TE (6,230) HOUT (33), ASO, HOUT (34), RON, HOUT (35), GMI

WRITE (6,230) HOUT (36), ROI, HOUT (37), SIEI

WRITE (6,230) HOUT (38), UIN, HOUT (39), VIN

RINPUTZ9

RINPUT30

RINPUT31

RINPUT32

RINPUT 33

RINPUT34

RINPUT 35

RINPUT 36

RINPUT37

RINPUT 38

RINPUT39

RINPUT40

RINPUT4I

RINPUT4?

RINPUT43

RINPUT44

RINPUT45

RINPUT46

RINPUT47

RINPUT48

RINPUT49 
WRITE (6,230) HOUT (40), ROIN, HOUT (41), SIEIN, HOUT (42), PAP RINPUT5O

OMCY $=1 .-\mathrm{Cr}$

$T=G R I N D=D T M I N=0$.

$N C Y C=N U M I T=I P R E S=N O U M P=0$

$\mathrm{C}+++$

C +++ ENSURE E.0.S. WILL BE CALCULATED PROPERLY FOR EXPLICIT RUNS...

$C+++$

IF (IMP.EQ. O) INC=0

DTF $=0.2$

MAXIT $=1000+I N C=500$

LOOPMX $=6$

$T H I R D=1.13$.

TWLFTH $=.25 *$ THIRD

$A N C O=.25 * A N C$

$X I C O F=.5 *(1 .+X 1)$

COLAMU = LAMBOA+2. *MN

DPCOF $=P E P S * R O I /(2 . *(1 . /(D X * D X)+1 . /(D Y * D Y))$

GRF $A C=1000 . / F L O A T(N X * N Y)$

TF ILM $=$ TWF ILM

TPRTR $=$ TWPRTR

$N Y P=N Y+1$

$N X P=N X+1$

$\mathrm{C}+++$

C +++ ADUST LIMITS OF CALCULATIONAL DO-LOOPS FOR SPECIFIEO INFLOW (5)

$C+++$ OR APPL IED PRESSURE (6) BOUNDARY CONDITIONS

$\mathrm{C}+++$

IF IRST $=\sqrt{F}$ IRST $=\mid F P H I=\sqrt[F P H]{=1}=1$

ILAST $=I L P H I=N X$

$\Lambda A S T=\Lambda P H I=N Y$

IF (WL.GE.5) IF IRST $=$ ?

IF (WB.CE.5) FIRST $=$ ?

IF (WR.GE.5) ILAST $=N X-1$

IF (WT.GE.5) LAST $=N Y-1$

$\mathrm{C}+++$

C +++ PHASE I PRESSURE GRADIENTS INCLUOE APPL IED PRESSURE BONDARY

$C+++$ BUT EXCLUOE A SPECIFIED INFLOW BOUNDARY . .

$C+++$

IF (WL.EQ.5) IFPHI =2

IF (WB.EQ.5) FPHI $=2$

IF (WR.EQ.5) ILPHI $=\mathrm{NX}-1$

IF (WT.EQ.5) IPHI $=\mathrm{NY}-1$

ILASTV $=$ ILAST +1

LASTV $=\mathbf{L A S T}+1$

ILASTM $=$ ILAST -1

LASTM $=$ LAST -1

IF (AO.EQ.1.0 .AND. BO.EQ.0.0) GO TO 100

IF (WL.EQ.4 .OR. (WL.EQ.5.AND.UIN.LT.0.)) WRITE $(59,240)$

IF (WB.EQ.4 .OR. (WB.EQ.5.AND.VIN.LT.0.)) WRITE $(59,240)$

IF (WR.EQ.4 .OR. (WR.EQ.5.AND.UIN.GT.0.) ) WRITE (59.240)

IF (WT.EQ.4 .OR. (WT.EQ.5.AND.VIN.GT.0.1) WRITE (59.240)

100 RETUPN

210 FORMAT (A10, 15)

220 FORMAT (A10.F10.5)

230 FORMAT (A10, $2 X, 1$ PE 12.5 )

240 FORMAT (5EH WARNING - OUTFLOW BOUNDARY BUT NOT FULL DONOR CELL.'

1 4ZH ARE OUTSIDE DENSITY AND ENERGY SPECIFIED?!

END

RINPUT5!

RINPUTS2

RINPUT53

RINPUT54

RINPUT55

RINPUT56

RINPUT57

RINPUT58

RINPUT59

RINPUT60

RINPUT61

RINPUTE2

RINPUT63

RINPUTE4

RINPUTES

RINPUTE6

RINPUT67

RINPUT68

RINPUT69

RINPUT70

RINPUT71

RINPUT72

RINPUT73

RINPUT74

RINPUT75

RINPUT76

RINPUTT7

RINPUT79

RINPUT79

RINPUTEO

RINPUTBI

RINPUTE2

RINPUTB3

RINPUTE4

RINPUTES

RINPUTES

RINPUTE7

RINPUTE8

RINPUTB9

RINPUTSO

RINPUT9!

RINPUTS2

RINPUT93

RINPUTS4

RINPUT95

RINPUTSS

RINPUT97

RINPUTSO

RINPUTS9

RINPUI00

RINPUI01

RINPUI02

RINPUI 03

RINPUI04

RINPUI05

RINPU106 
$\begin{array}{ll}\text { SUBROUT INE STRESO } & \text { STRESD } 2\end{array}$

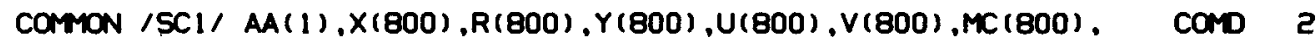

$1 M V(800), \operatorname{RMN}(800), R O(800), V O L(800), P(800), S I E(800), U L(800), \quad$ COMO 3

$2 \mathrm{~V}(800), R O(800), P L(800), D(800), Q(800), \operatorname{RRSUM}(800), P I X X(800), \quad$ COMO 4

3 PIXY $(800), P I Y Y(800), P I T H(800), R D S D P(800), U G(800), V G(800), \quad$ COMD 5

4 UREL $(800)$, VREL (800), MP (800), MVP $(800)$, SIEP $(800)$, UMOM $(800), \quad$ COMD 6

5 VMOM(800), UMOMP (800), VMOMP $(800), 2 Z 1 \quad$ COMD 7

COMMON ISC2/ ANC, ANCO,ARTVIS,ASQ,AO,BO,COLAM, CY, Cl,DPCOF, $\quad$ COMD 8

1 DROU,DT,DTF, DTMAX,DTMIN,DX,DY,DI,EPS,FIX, ,FIYB,GMI, GRFAC,GRIND, COMD 9

2 GX,GY, IDOT, IF IRST, IFPHI, ILAST, ILASTM, ILASTV, ILPHI . IMP. INC, IPRES, COMD 10

3 IREZ, JFIRST, JFPHI, LAST, LASTM. LASTV, LPHI, NM, LAMBOA.LOOPS. ' COMD 11

4 LOOPMX,LPR, MAXIT,MU,NAME (8),NCYC.NOUM,NUMIT,NX,NXP. COMD 12

5 NY,NYP,OM,OMCY, PAP.PEPS,PMAX,RF, ROI,ROIN,RON,SIEI.SIEIN, COMD 13

6 T, TFILM, THIRD, TIMLMT, TLIMD, TPRTR, TWF ILM, TWF IN, THLFTH, TWPRTR, $\quad$ COMD 14

7 UIN, VIN, VMAX,WB,WL,WR,WT,XCONV,XI,XICOF,XL,YB,YCONV,ZZ

REAL LAMBOA,MC,MP,MU,MV,MVP $\quad$ COMO 16

INTEGER WB,WL,WR,WT $\quad$ COMO 17

REAL LAMO $\quad$ STRESO 4

C +++ $\quad$ STRESO 5

C +++ THE STRESS DEVIATOR SUBROUTINE, IN WHICH WE CALCULATE THE STRESD 6

C +++ SHEAR (MN) AND BULK (LAMBDA) VISCOSITY CONTRIBUTIONS TO UL AND VL.STRESO 7

$C+++$ THE 4 STRESS TERMS ARE SAVED FOR LATER USE IN SUBR. ENERGY . . * STRESD 8

C +++ (MATERIAL STRENGTH EFFECTS COUD BE ADDED TO SUBR. STRESD.) STRESD 9

C +++

DTO2 $=.5 * D T$

DO $20 \mathrm{~J}=\mathrm{JF}$ IRST, LAST

I $J=(J-1) * N X P+I F$ IRST

I $P=1 J+N \times P$

DO $10 \quad I=$ IF IRST . ILAST

IPJ $=\lfloor J+1$

IPJP=I $\boldsymbol{P}+1$

$X I=X(I P J)$

$R I=R(I P J)$

$Y I=Y(I P J)$

$U I=U(I P J)$

$V I=V(I P J)$

$X 2=x(I P P)$

$R C=R(I P J P)$

$Y S=Y(I P J P)$

$U E=U(I P S P)$

$V Z=V(I P J P)$

$X 3=X(1 P)$

$R 3=R(I P)$

$Y Z=Y(I N P)$

$U 3=U(I P)$

$V 3=V(I P)$

$X^{4}=X(I J)$

$R+=R(I J)$

$r_{4}=Y(I J)$

$U_{4}=U(I J)$

$V_{4}=V(1 J)$

$X Z_{4}=X 2-X_{4}$

STRESOIO

STRESD 11

STRESD 12

STRESO 13

STRESO14

STRESO15

STRESOI6

STRESOI7

STRESO18

STRESO19

STRESOZO

STRESO21

STRESD2?

STRESD23

STRESO24

STRESO25

STRESDZ6

STRESOZ7

STRESDZ8

STRESDZ9

STRESO30

STRESO3!

STRESD32

STRESO33

STRESO34

STRESD 35

STRESD 36

STRESD37

$Y 24=Y 2-Y 4$

STRESO 38

$X 31=X 3-X 1$

STRESO39

$Y 31=Y 3-Y 1$

STRESD 40

$U O R=(U 1+U 2+U 3+U 4)$ *RRSUM $(I J) * C Y L$

STRESD +1

$H R 13=.5 *(R 1+R 3)$

$H R 24=.5 *(R 2+R 4)$

DTOZMI =DTOS*RMN (IPJ)

DTOEML=DTOE "RMV (IPJP)

STRESDH?

STRESD4 3

STRESD 4

STRESD+5

DTOZM3=DTOE *RMN ( I IP)

STRESOH6

DTOZM4 $=$ DTOZ $*$ RMN $(I \mathrm{~J})$

STRESD 7

AREA $=0.5 *\left(X_{2} 4 * Y 31-X 31 * Y Z_{4}\right)$

STRESD48 STRESD 49 
AREAC $=A R E A * 2.0$

STRESO50

RAREAC $=1.1$ AREAC

STRESOS1

$\mathrm{URY}_{4}=\mathrm{UR}-\mathrm{UH}_{4}$

$U 31=U 3-U 1$

$\mathrm{V} 24=\mathrm{V} 2-\mathrm{V} 4$

$V 31=V 3-V 1$

DUDX=RAREAZ* (UZ4*Y31-U31*YZ4)

STRESO52

STRESD53

STRESD54

STRESD55

DOOY=RAREA2*(U31*X24-UZ4*X31)

STRESO56

DVDX=RAREA2*(V24*Y31-V31*YZ4)

STRESD57

DVDY=RAREAC*(V3)*X24-V24*X31)

STRESDSO

STRESDS9

LAMD=LAMBDA * (DUDX+DVDY+UOR)

STRESDS0

$P I X X(I J)=2 . * M N * D U D X+L A M D$

$P I Y Y(I J)=2$. *MU*DVDY+LAMD

$P I X Y(I J)=M N *(D U D Y+D V D X)$

STRESDS1

STRESD62

STRESO63

STRESOO4

$P I T H(I J)=C Y *(2.0 * M N *$ UOR+LAMD)

STRESOS5

$Z Z=0.5 * A R E A * P I T H(I J)$

$X X=H R Z_{4} *\left(P I X Y(I J) * X Z_{4}-P I X X(I J) * Y Z^{4}\right)$

STRESO66

STRESD67

$U(I P J)=U L(I P J)+D T O Z M 1 *(X X-Z Z)$

$U(I J P)=U L(I P)-D T O Z M 3 *(X X+Z Z)$

$X X=H R 13 *(P I X Y(1 J) * X 31-P I X X(I J) * Y 31)$

STRESD68

STRESO69

U (IPJP) $=U(I P J P)+D T O Z M Z *(X X-Z Z)$

STRESO70

$U(I J)=U L(I J) \quad-D T O Z M H *(X X+Z Z)$

STRESO71

$X X=1 R Z_{4}$ *(PIYY (IJ) *XZ4-PIXY(IJ)*YZ4)

STRESD72

$\mathrm{VL}(I P J)=V L(I P J)+D T O Z M I * X X$

STRESO73

$\mathrm{VL}(I P)=\mathrm{VL}(I \mathcal{P})-\mathrm{DTOZM} 3 * \mathrm{XX}$

STRESO74

$X X=1 R 13 *(P \mid Y Y(I J) * X 31-P(X Y(I J) * Y 31)$

STRESO75

STRESOT6

V $(I P J)=V(I P J P)+D T O Z M 2 * X X$

$V L(I J)=V L(I J) \quad-D T O Z M 4 * x X$

STRESOT7

STRESOTB

STRESO79

I $P=I P J P$

20 CONTINUE

STRESDOO

CALL BC(U., $L)$

STRESOBI

RETURN

STRESDE2

END

STRESDO3 


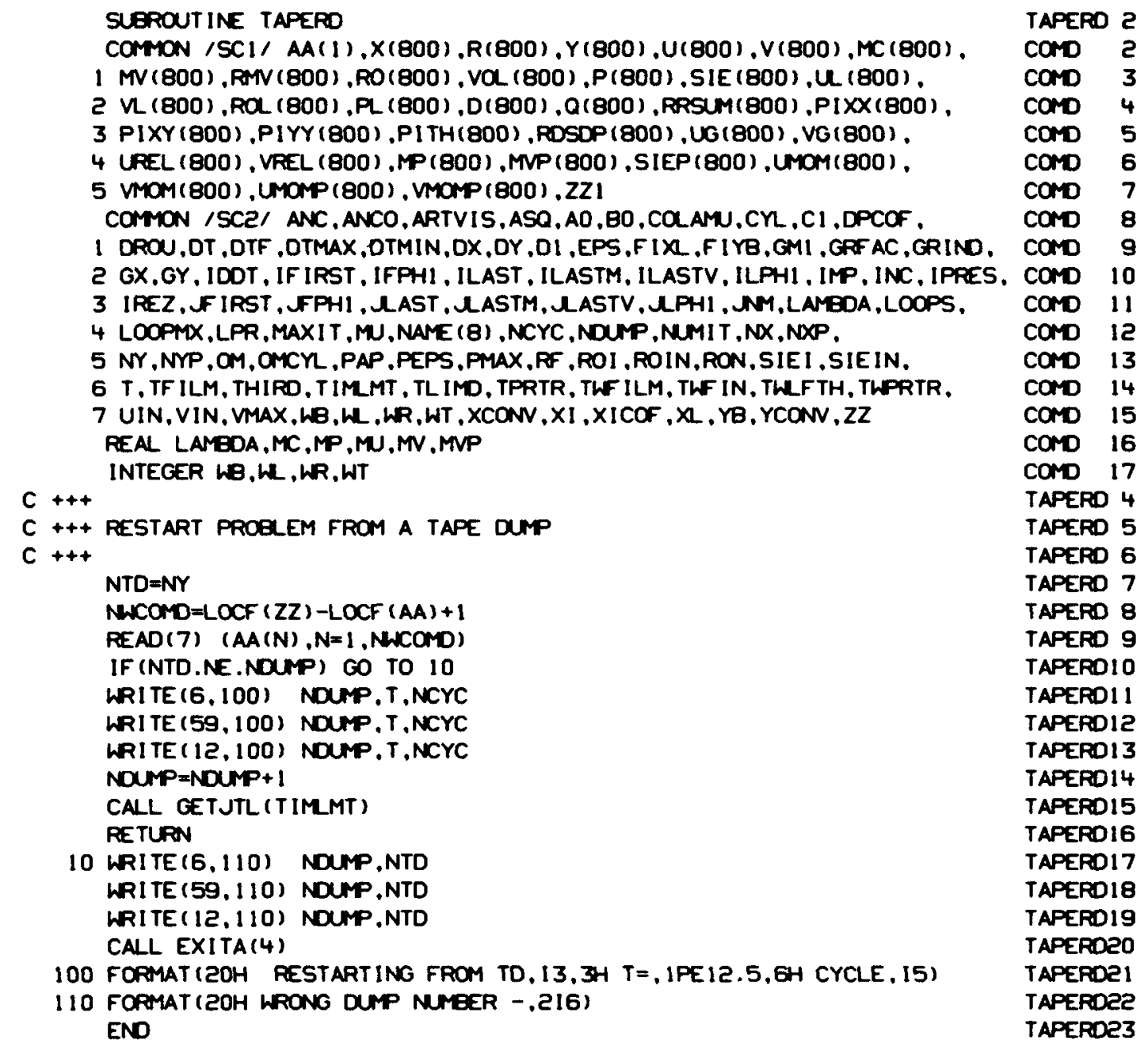


SUBROUTINE TAPEWR

TAPEWR 2

COMMON /SC1/ AA(1), X(BO0), R(800), Y(800),U(B00), V(800),MC (800),

COMD 2

$1 \mathrm{MV}(800), \operatorname{RMV}(800), \operatorname{RO}(B 00), \mathrm{VOL}(800), P(800), \operatorname{SIE}(800), \mathrm{U}(800)$,

$2, h(800), R O L(800), P L(800), D(800), Q(800), R R S U M(800), P I X X(800)$,

3 PIXY(800), PIYY $(800), P I T H(800), \operatorname{RDSDP}(800), \mathrm{UG}(800), \mathrm{VG}(800)$,

4 UREL (800), VREL (800), MP (800), MVP (800), SIEP (800), UMOM(800),

5 VMOM $(800)$, UMOMP $(800), \operatorname{VMOMP}(800), 2 Z 1$

COMMON ISCZ/ ANC, ANCO, ARTVIS, ASO, AO,BO, COLAMU, CY, C1, DPCOF,

1 OROU,OT,DTF,DTMAX,DTMIN,DX,DY,DI,EPS,FIXL,FIYB,GMI, GRF AC, GRIND,

Z GX,GY, IDOT, IF IRST, IFPHI, ILAST, ILASTM, ILASTV, ILPHI, IMP, INC, IPRES,

3 IREZ, F IRST, LFPHI, LAST, LASTM, LASTV, LPHI, NM, LAMEDA, LOOPS,

4 LOOPMX,LPR, MAXIT, MN,NAME (8), NCYC,NOUMP, NUMIT, NX, NXP.

5 NY, NYP, OM, OMCY, PAP, PEPS, PMAX, RF, ROI ,ROIN, RON, SIEI, SIEIN,

6 T. TF ILM, THIRD. TIMLMT , TLIMD, TPRTR, TWF ILM, THF IN, TWLFTH, TWPRTR,

7 UIN, VIN, VMAX, WB, WL, WR, WT, XCON, XI , XICOF, XR, YB, YCONV,ZZ

REAL LAMEOA.MC.MP.M.MV.MPP

INTECER WB.WL.WR.WT

DATA NOUMP/O/

$\mathrm{C}+++$

C +++ WRITE A DUMP TAPE AND EXIT

$\mathrm{C}+++$

NACOMD $=\operatorname{LOCF}(Z Z)-\operatorname{LOCF}(A A)+1$

WRITE (8) (AA (N), $N=1$, NWCOMD)

WRITE $(6,100)$ NDUM, T,NCYC

WRI TE (59, 100) NDUP, T,NCYC

WRITE $(12,100)$ NOUM, T,NCYC

CALL EXITA(3)

100 FORMAT (IIH TAPE DUP.13.6H AT T=.1PE12.5.GH CYCLE, 15)

$\operatorname{com} 3$

COMD 4

Comp 5

$\operatorname{com} 6$

Cond 7

COMD 8

COND 9

COND 10

COMD 11

COMD 12

Cond 13

COMD 14

coro 15

Cord 16

COMD 17

TAPERR 4

TAPELR 5

TAPEHR 6

TAPEWR 7

TAPELR $B$

TAPELR 9

TAPELRIO

TAPEWRII

TAPEWRIC

TAPELRI3

END

TAPEWR15 


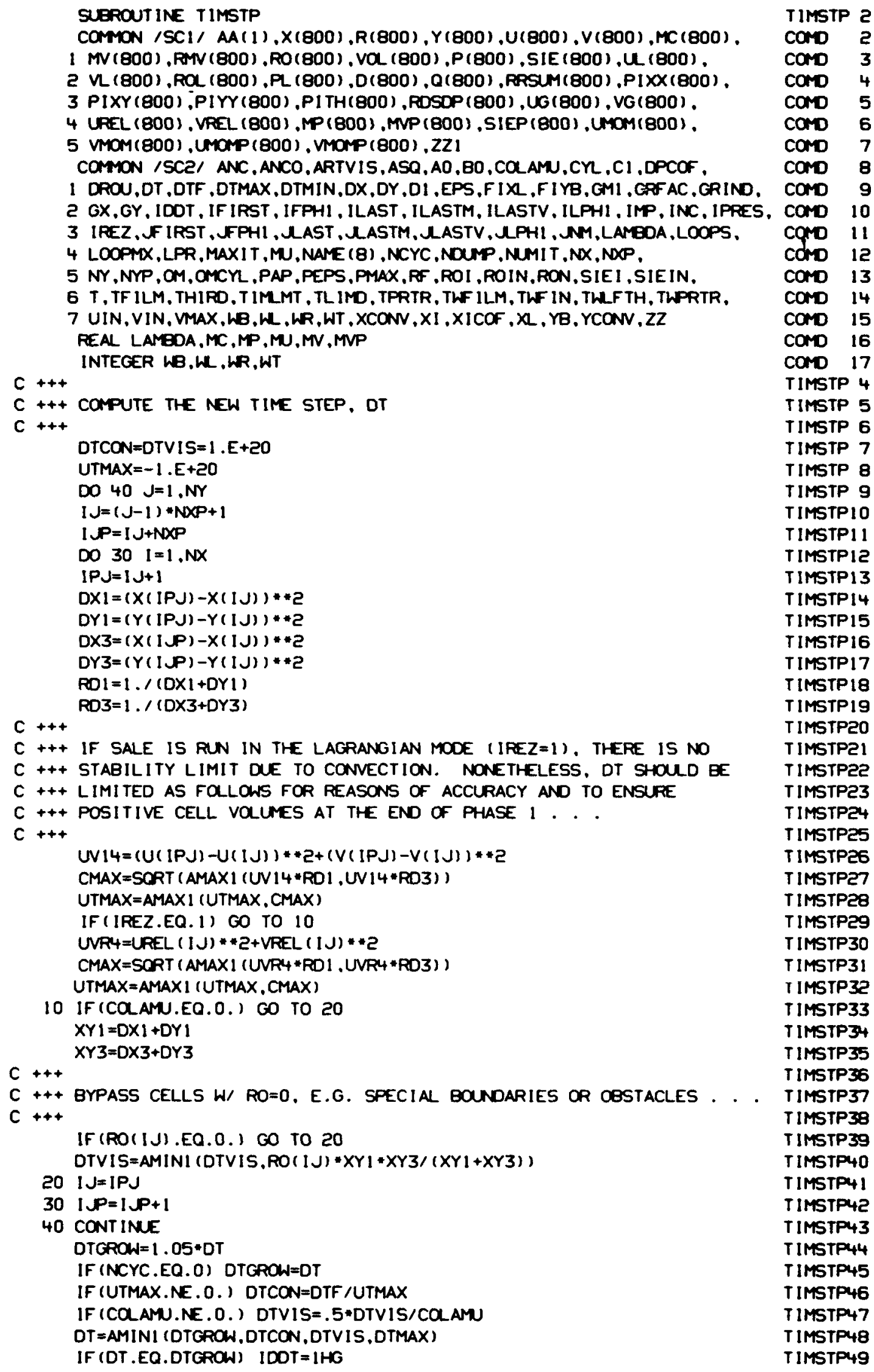


IF (DT.EQ.DTCON) IDOT $=I H C$

TIMSTP50

IF (DT.EQ.DTVIS) IDOT $=I H N$

TIMSTP5I

IF (DT.EQ.DTMAX) IDOT $=1 \mathrm{HM}$

TIMSTPS2

IF (NCYC.EQ. 1) DTMIN=DT *1 .E-10

TIMSTP53

IF (DT.GT.DTMIN) RETUPN

WRI TE (6, 100) DT, NCYC, IDOT

WRITE (59, 100) DT,NCYC, IDOT

TIMSTP54

TIMSTP55

WRITE(12,100) DT,NCYC, IDDT

CALL EXITA(6)

100 FORMAT (4H DT=, IPE I2.5,9H AT CYCLE, 15,11H, CAUSE IS . AI) END

TIMSTP56

TIMSTP57

TIMSTPSB

TIMSTPS9

TIMSTP60

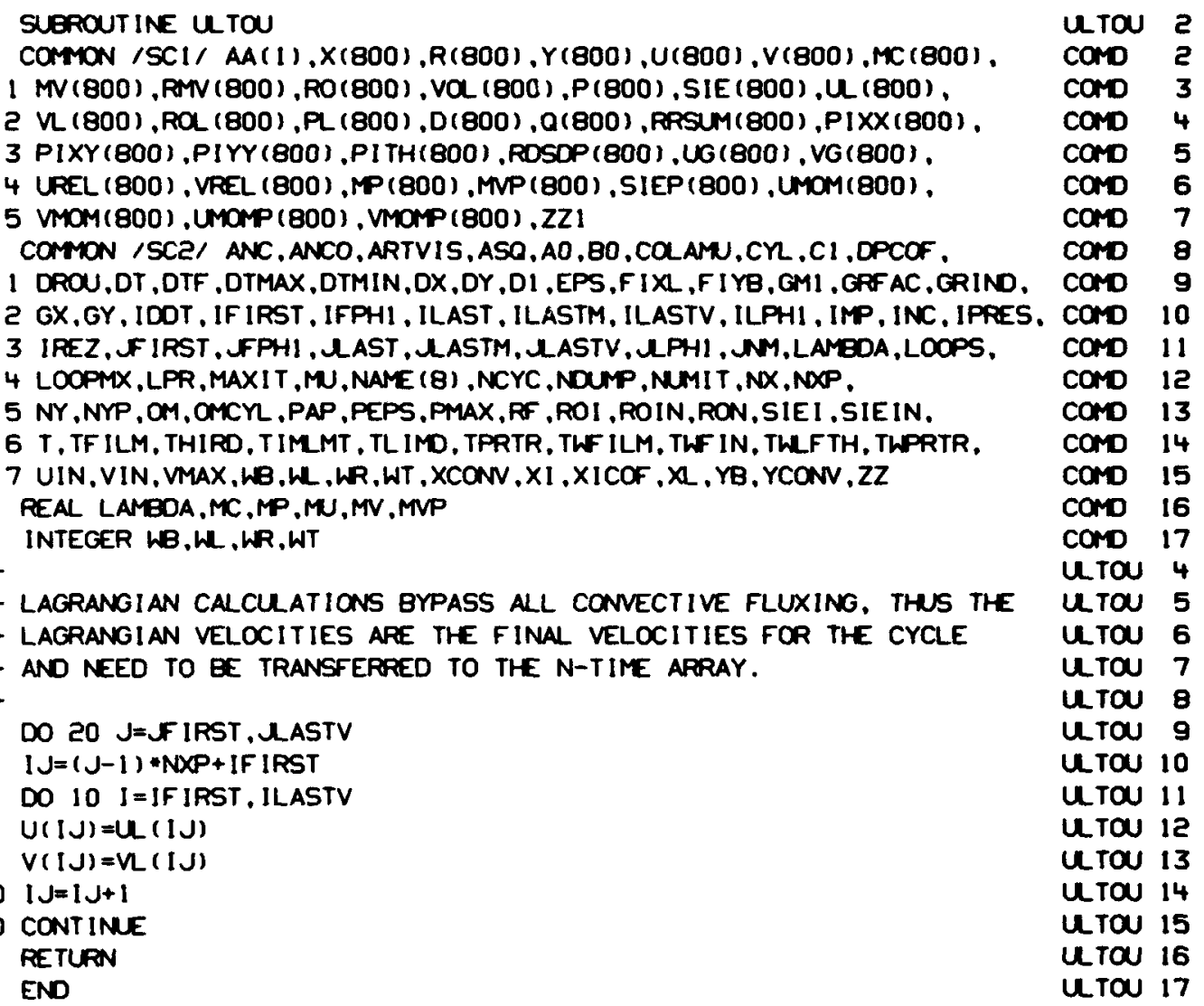




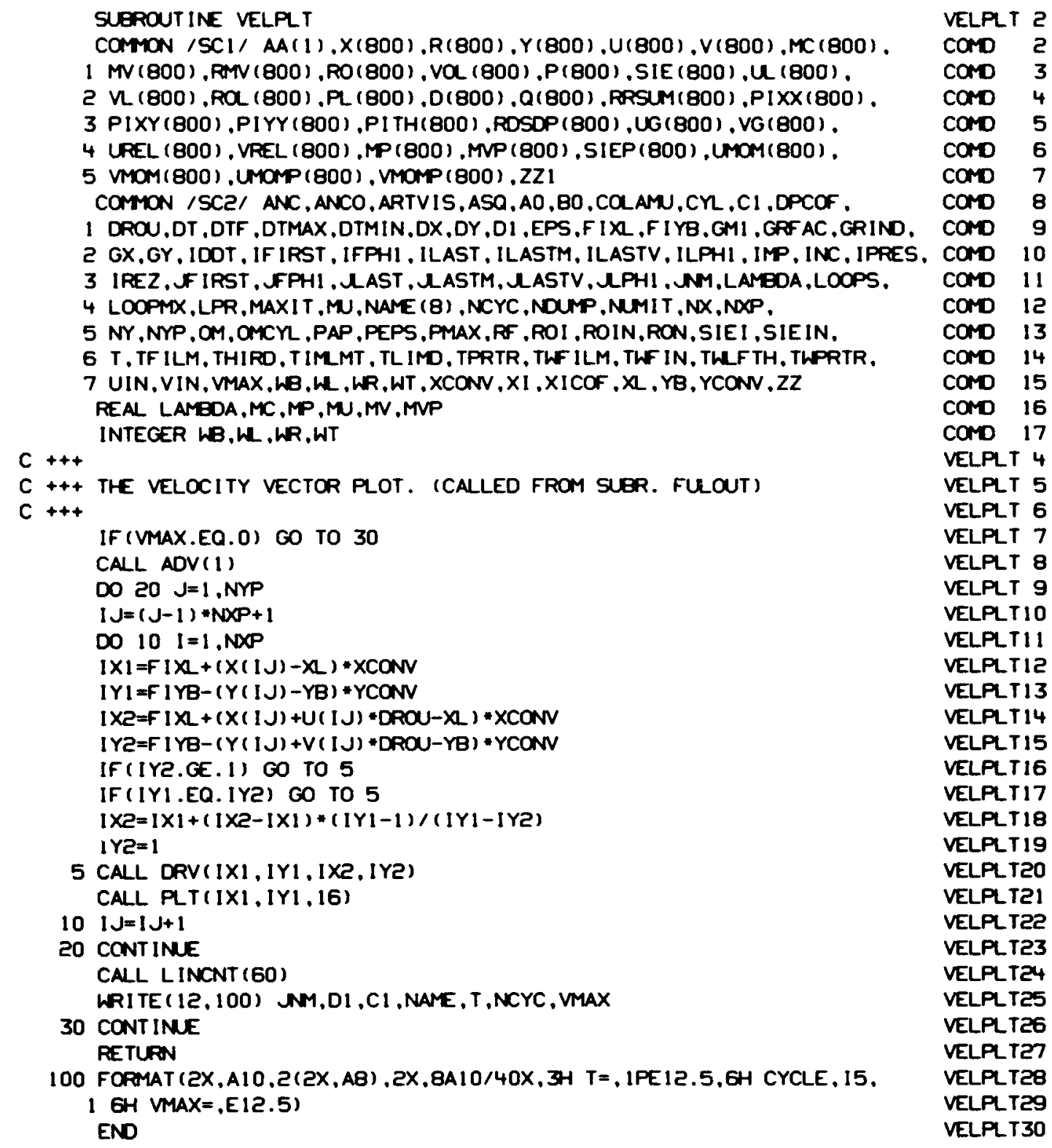




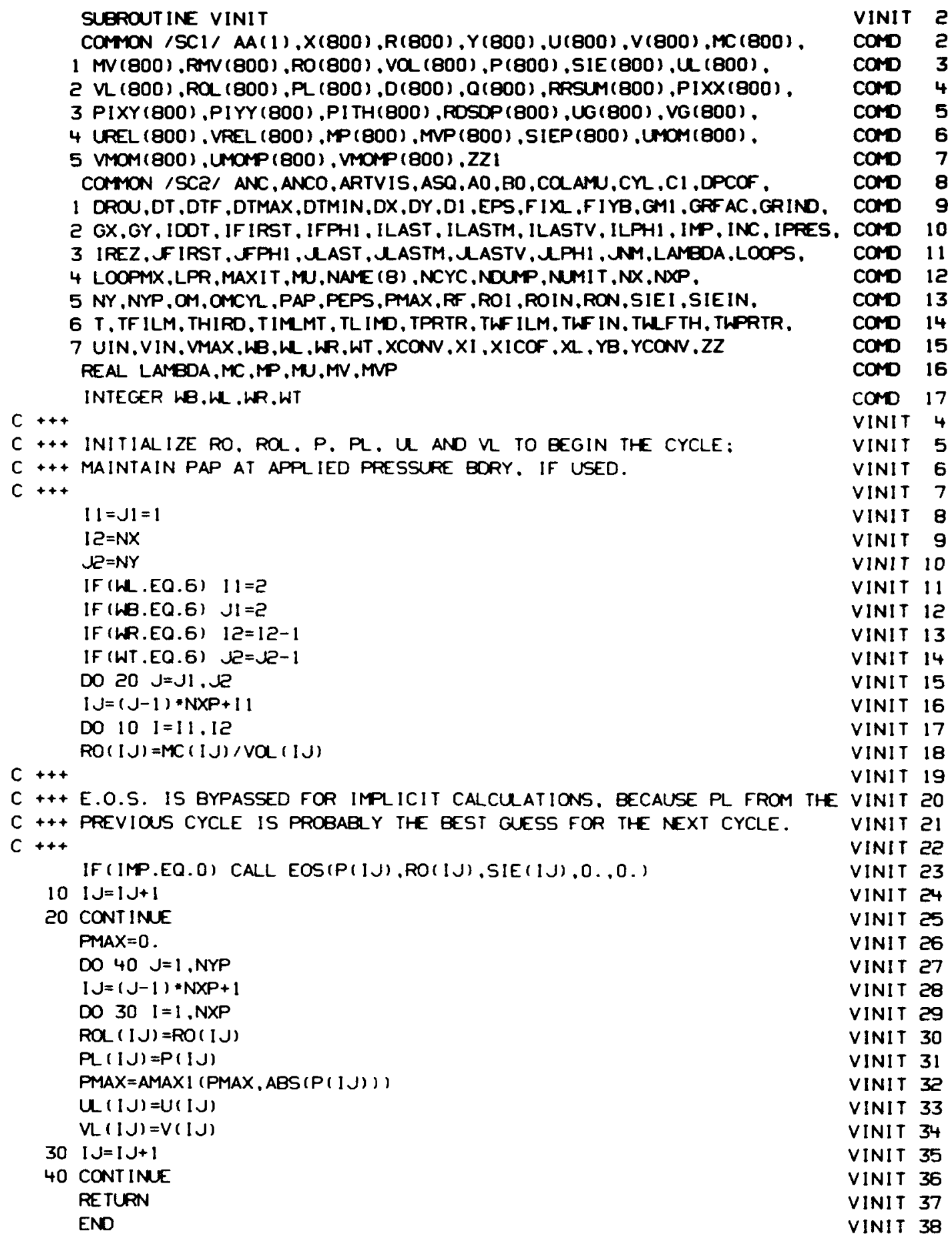

VINIT 38 


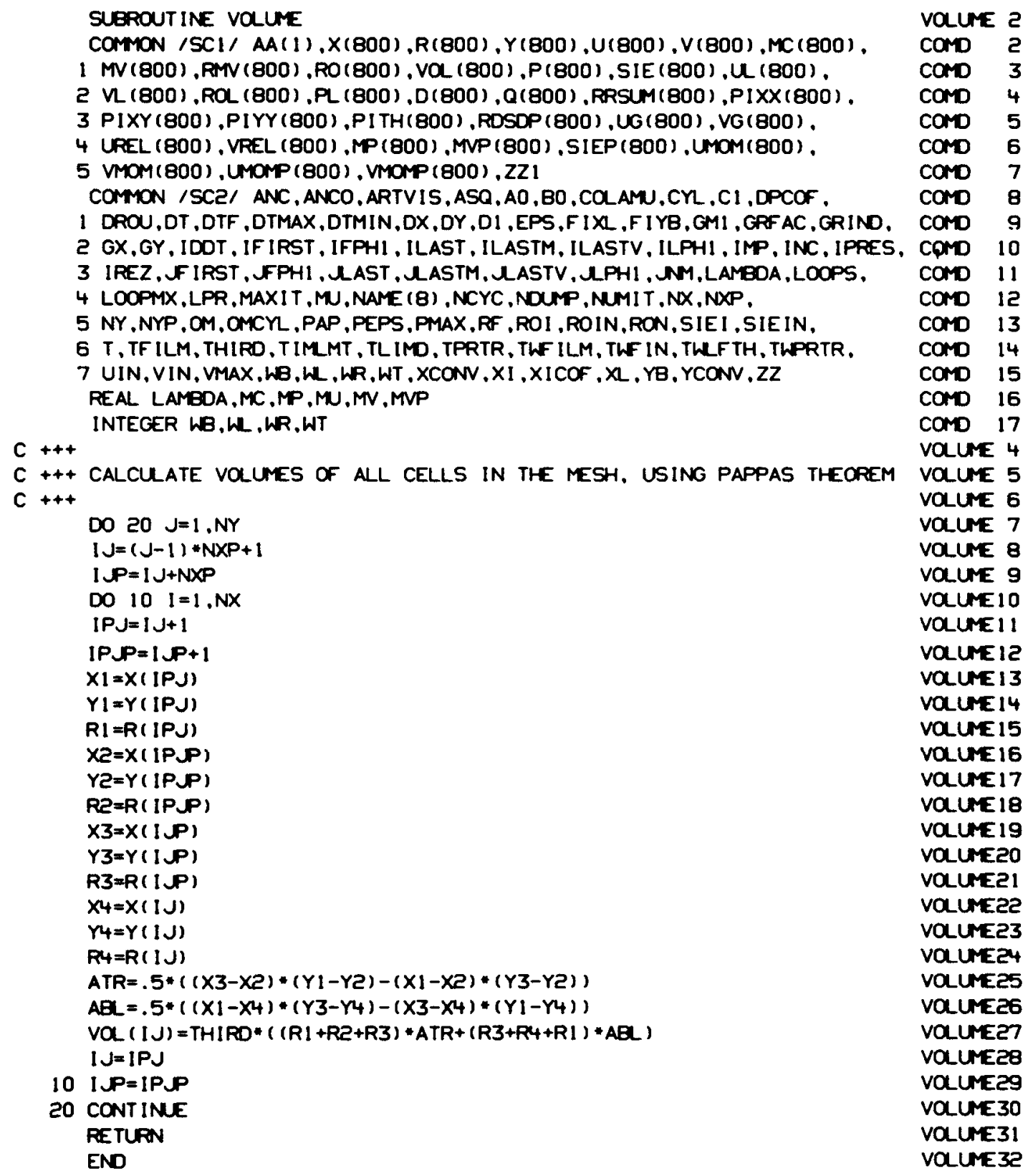


SUBROUT INE ZONPLT

ZONPLT 2

COMMON /SC1/ AA (1),X(800),R(800),Y(800),U(800),V(800),MC(800), COMD 2

$1 M V(800), \operatorname{RMV}(800), R O(800), V Q L(800), P(800), S I E(800), U(800)$.

$\operatorname{com} 3$

2 VL (800), ROL (800), PL (800),D(800),Q(800), RRSUM(800),PIXX(800), COMD 4

3 PIXY (800), PIYY (800), PITH(800), RDSDP $(800), U G(800), V G(800)$. $\quad$ COMD 5

4 UREL (800), VREL (800), MP (800), MNP (800), SIEP(800).UMOM(800). COMD 6

5 VMOM $(800)$, UMOMP (800), VMOMP $(800), Z Z 1 \quad$ COMD 7

COMMON ISC2/ ANC, ANCO,ARTVIS, ASO,AO,BO,CQAMN,CY,CI,DPCOF, COMD 8

1 DROU,DT,DTF, DTMAX,DTMIN,DX,DY,D1,EPS,FIXI,FIYB,GMI,GRFAC,GRIND, COMD 9

2 GX,GY, IDOT, IF IRST, IFPHI, ILAST, ILASTM, ILASTV, ILPHI, IMP, INC, IPRES, COMD 10

3 IREZ. FFIRST, JFPHI, LAST, LASTM, LASTV, LPHI, NM, LAMBDA, LOOPS, COMD 11

4 LOOPMX,LPR,MAXIT,MU,NAME (8),NCYC,NDUMP,NUMIT,NX,NDP, $\quad$ COMD 12

5 NY,NYP,OM,OMCY, , PAP, PEPS, PMAX, RF, ROI,ROIN, RON, SIEI, SIEIN, $\quad$ COMD 13

6 T, TF ILM, THIRD, TIMLMT, TLIMD, TPRTR, TWFILM, TWF IN, TWLFTH, TWPRTR, $\quad$ COMD 14

7 UIN, VIN, VMAX, WB, WL, WR, WT , XCONV, XI, XICOF, XL, YB, YCONV,ZZ

REAL LAMBDA,MC,MP,MU,MV,MYP $\quad$ COMD 16

INTEGER WB,WL,WR,WT $\quad$ COMD 17

$\mathrm{C}+++$

$C+++$ THE ZONE PLOT. (CALLED FROM SUER. FULOUT) ZONPLT 5

C +++

IF (IREZ.EQ.0 .AND. NCYC.GT.0) RETURN

CALL ADV (1)

DO $20 \mathrm{~J}=1$. NY

$17=(J-1) * n \times P+1$

I $P=I J+N X P$

DO $10 \quad I=1, N X$

$I P J=I J+1$

IPJ $=1 \boldsymbol{P}+1$

$I X I=F I X L+(X(I P J)-X L) * X C O N V$

$I X S=F \mid X L+(X(I P J P)-X L) * X C O N V$

$I X 3=F I X L+(X(I P)-X(L) * X C O N V$

$I X 4=F I X L+(X(I J)-X L) * X C O N V$

$I Y 1=F \mid Y B-(Y(I P J)-Y B) * Y C O N V$

$I Y Z=F I Y B-(Y(I P J P)-Y B) * Y C O N V$

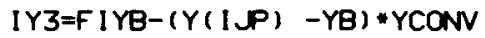

$I Y 4=F I Y B-(Y(I J)-Y B) * Y C O N V$

CALL DRV $(1 \times 4,1 Y 4,1 \times 3,1 Y 3)$

CALL DRV (IX4, IY4, IXI,IYI)

IF (I .EQ.NX) CALL DRV (IXI,IYI,IXZ, IYZ)

IF (J.EQ.NY) CALL DRV (IX2, IY2, IX3.IY3)

I $P=$ IPJP

10 IJ $J=I P J$

20 CONTINUE

CALL LINCNT (60)

WRITE(12,100) NM,DI.C1,NAME,T.NCYC

RETURN

100 FORMAT (2X,A10,2 (2X, AB), 2X,8A10/40X,3H T=,IPE12.5,6H CYCLE, 15)

END

ZONPLT 6

ZONPLT 7

ZONPLT 8

ZONPLT 9

ZONPLTIO

ZONPLTII

ZONPLTII

ZONPLT 13

ZONPLT14

ZONPLT15

ZONPLT16

ZONPLTI7

ZONPLTIB

ZONPLTIS

ZONPLTEO

ZONPLTE1

ZONPLTE2

ZONPLT23

ZONPLTZ4

ZONPLTES

zONRT T26

zONPLTET

ZONPLTEO

zONPLTe9

ZONPLT30

ZONPLT31

ZONPLT32

ZONPLT33

ZONPLTS4 


\section{APPENDIX B}

\section{SYSTEM SUBROUTINE CALLS IN SALE}

SALE calls a number ot system subroutınes to display graphic or numeric information on microfiche. The original microfilm recording CRT device at LASL was the SC-4020, and although it has been supplanted, the coordinate system in the particular software system we are using is that of the SC-4020. The CRT face has a matrix of $1024 \times 1024$ raster points, where $(0,0)$ is the coordinate of the upper left corner and $(1023,1023)$ that of the lower right corner. Because this coordinate system is different from that of SALE, our code must convert physical mesh coordinates to locate their positions on the 4020 frame. This scaling process is performed in SALE subroutine FULOUT. Numerical information is displayed in the typing mode, in which the film frame consists of 64 lines of 128 characters each. The system subroutines called by SALE are:

CALL ADV (nf) advances the film by nf frames.

CALL PLT (IX,IY,ch) plots the 4020 character identified by ch at frame coordinates (IX,IY).

CALL DRV (IX1,IY1,IX2,IY2) draws a straight line vector segment connecting the 4020 points (IX1,IY1) and (IX2,IY2).

CALL LINCNT (LN) locates the first column of line LN. Accessible lines range between 2 and 61. Frame advancement is automatic.
In addition to the above calls that are used continuously during program execution, initialization of the film file at the beginning of the run is handled by calls to GFR80, GRPHLUN, LIB4020, GRPHFTN and SETFLSH. These communicate with the graphics system at LASL and need not concern the outside user.

Other system calls not related to film usage appear in SALE:

CALL GETJTL (TL) returns the job CPU time limit in seconds.

CALL DATEH(D1) returns the date as a Hollerith constant of the form MM/DD/YY.

CALL TIMEH(T1) returns the wall clock time as a Hollerith constant of the form HH:MM:SS.

CALL SECOND(time) returns the CPU time used by the job up to this point.

CALL EXITA(n) terminates the code. Each call to EXITA in SALE has a different value for $n$, which is retained by the operating system and available for determining the cause of the exit, if necessary. 


\section{APPENDIX C \\ SAMPLE OUTPUT FROM BROKEN DAM CALCULATION}

The broken dam calculation described in Sec. IV.A is chosen as a sample calculation for aiding in code verification at other installations. It is solved using the SALE program exactly as listed in App. A and the input file listed in Sec. IV.A.

The frames on the following pages provide the cell data as created at time $t=0$, again after one cycle $(t=$ $0.1)$, and again much later at cycle $71(t=5.0)$. Also provided are two neighboring frames showing system totals of mass, momentum, and energy, and a sampling of cycle-by-cycle monitor prints of 'iteration number, grind time, and time step history.

Exact agreement with our calculated values may be impossible to attain because of different word lengths on other computers and differences in various FORTRAN compilers. 

T. 0 crace 0

\begin{tabular}{|c|c|c|c|}
\hline & 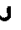 & $x$ & \\
\hline & $i$ & 0. & 0 . \\
\hline & I & $1.0005+00$ & 0. \\
\hline & 1 & $2000 x+00$ & 0 . \\
\hline & 1 & $3.000 E+00$ & 0. \\
\hline & 1 & $4.000 E+00$ & 0. \\
\hline & 1 & $5.000 \mathrm{C}+00$ & 0 . \\
\hline & 1 & $6.000 \varepsilon+00$ & 0 . \\
\hline & 1 & $7.000 \varepsilon+00$ & 0 . \\
\hline & 1 & B. 000E +00 & 0 . \\
\hline & $\mathbf{l}$ & $9.0005+00$ & o. \\
\hline & 1 & $9.000 E+01$ & 0. \\
\hline & 2 & 0 . & $1.000 E+00$ \\
\hline & 2 & $1.000 \varepsilon+00$ & $1.000 E+00$ \\
\hline & $\mathbf{z}$ & $2.000 x+\infty 0$ & $1.000 \varepsilon+00$ \\
\hline & 2 & $3.000 E \bullet 00$ & $1.000 E+00$ \\
\hline & 2 & $4.000 E+00$ & $1.000 \varepsilon+00$ \\
\hline & 2 & $5.000 \Sigma+00$ & $1.000=+00$ \\
\hline & 2 & $6.000<\div 00$ & $1.000<+00$ \\
\hline & 2 & $7.000<+00$ & $1.000 E+00$ \\
\hline & 2 & 0. $000 \Sigma \bullet 00$ & $1.000 \tau+00$ \\
\hline & 2 & $9.000<+00$ & $1.000 \Sigma+00$ \\
\hline & 2 & $1.000 z+01$ & $1.000 E+00$ \\
\hline & 3 & 0 . & $2.000 \Sigma+00$ \\
\hline & 3 & $1.000 c+00$ & $2.000 E+00$ \\
\hline & 3 & $2.000 \varepsilon+00$ & $2.000 \tau+00$ \\
\hline & 3 & $3.0005+00$ & $2.000 E+00$ \\
\hline & 3 & $4.000 E+00$ & $2.000 \leq+00$ \\
\hline & 3 & $5.000 \Sigma+00$ & $2.000 \Sigma+00$ \\
\hline & 3 & B. $000 E+00$ & $2.000 E+00$ \\
\hline & 3 & $7.0005+00$ & $2.0005+00$ \\
\hline & 3 & $8.000 E+00$ & $2.000 E+00$ \\
\hline & 3 & $9.000<+00$ & $2.000 E+\infty 0$ \\
\hline & 3 & $1.000 E+01$ & $2.0005+00$ \\
\hline & 4 & 0 . & $3.000 E+00$ \\
\hline & 4 & $1.000 E+00$ & $3.000 \Sigma+00$ \\
\hline & 4 & $2.000 E+00$ & $3.000 E+00$ \\
\hline & 4 & $3.000<+00$ & $3.000 E+00$ \\
\hline & 4 & $4.000 \Sigma+00$ & $3.000 E+00$ \\
\hline & 4 & $5.000 E+00$ & $3.000 E+00$ \\
\hline & 4 & $6.000 E+00$ & $3.000 E+00$ \\
\hline & 4 & $7.000 E+00$ & $3.000=+00$ \\
\hline & 4 & 0.000E+00 & $3.000 E+00$ \\
\hline & 4 & $9.000 E+00$ & $3.000 \varepsilon+00$ \\
\hline & 4 & $1.000 E+01$ & $3.000 E+00$ \\
\hline & 5 & D. & $4.000 E+00$ \\
\hline & 5 & $1.000 E=00$ & 4. $000 E+00$ \\
\hline & 5 & $2.000<+00$ & $4.000 E+00$ \\
\hline & 5 & $3.000=+00$ & $4.000 E+00$ \\
\hline & 5 & $4.000 E+00$ & $4.000 \varepsilon+00$ \\
\hline & 5 & $5.000 E+00$ & $4.000 E+00$ \\
\hline & 5 & 6. $000 E+00$ & $4.000 E+00$ \\
\hline & 5 & $7.000<+00$ & $4.000 E+00$ \\
\hline & 5 & $8.000 c+00$ & $4.000 \Sigma+00$ \\
\hline & 5 & $9.000 E+00$ & $4.000=+00$ \\
\hline & 5 & $1.000 E \cdot 01$ & $4.000 E+00$ \\
\hline & & 0. & $5.000 E+00$ \\
\hline
\end{tabular}

\begin{tabular}{|c|c|c|c|c|c|c|}
\hline 0 . & $\checkmark$ & SIE & $\begin{array}{c}\text { RNo } \\
1.000 E+00\end{array}$ & $\begin{array}{c}\text { Mass } \\
1.000 E+00\end{array}$ & $\underset{1.000 \varepsilon+00}{\mathrm{va}}$ & 0 . \\
\hline 0. & 0. & & $1.0005+00$ & $1.0005+00$ & $1.0005+\infty 0$ & 0 . \\
\hline 0. & 0 . & & $1.0002+00$ & $1.000<+00$ & $1.000 c+00$ & 0 . \\
\hline 0 . & 0 . & & $1.000<+00$ & $1.000 \mathrm{C}+00$ & $1.000=+00$ & 0 . \\
\hline 0. & 0 . & & $1.000 \leq+00$ & $1.000=-00$ & $1.000 \Sigma+00$ & 0 . \\
\hline 0. & 0 . & & $1.0005+00$ & $1.000=+00$ & $1.000 z+00$ & 0 . \\
\hline 0 . & D. & & $1.000 \varepsilon+00$ & $1.000 \leq \bullet 00$ & $1.000=\bullet 00$ & o. \\
\hline 0 & 0 . & & $1.0005+00$ & $1.000=000$ & $1.000=00$ & 0 . \\
\hline 0 . & o. & & $1.0005+00$ & $1.000 \varepsilon+00$ & $1.000 \leq+00$ & o. \\
\hline 0 . & 0 . & & $1.000 E+00$ & $1.000 z+\infty 0$ & $1.0005+00$ & 0 . \\
\hline 0. & 0 . & & o. & $\mathbf{0}$ & o. & 0 . \\
\hline 0 . & o. & & $1.000 \varepsilon+00$ & $1.0005+\infty 0$ & $1.0005+00$ & 0 . \\
\hline o. & o. & & $1.0005+00$ & $1.000 \tau+00$ & $1.000 \tau+00$ & o. \\
\hline 0 . & o. & & $1.0005+00$ & $1.000 E * 00$ & $1.000<+00$ & 0. \\
\hline 0 . & 0. & & $1.0002+00$ & $1.000 \varepsilon+00$ & $1.000 c \bullet 00$ & 0 . \\
\hline 0. & 0. & & $1.000 x+00$ & $1.000=+00$ & $1.000 c \cdot 00$ & 0. \\
\hline 0. & o. & & $1.000 \leq+\infty 0$ & $1.000 \Sigma+00$ & $1.000=+00$ & o. \\
\hline 0. & 0. & & $1.000 E+00$ & $1.000=+\infty 0$ & $1.000 \Sigma+00$ & 0 . \\
\hline 0. & 0. & & $1.000<+00$ & 1. $.000 E+\infty 0$ & $1.000 x+\infty 0$ & o. \\
\hline 0 & 0. & & $1.000=+00$ & $1.0005+00$ & $1.0005+00$ & o. \\
\hline 0. & 0. & & $1.000 z+00$ & $1.000<>00$ & $1.000<+00$ & o. \\
\hline 0. & 0 . & & o. & o. & 0 & $\mathbf{0}$. \\
\hline 0. & o. & & $1.000 \leq+00$ & $1.000 E+00$ & $1.000<+\infty 0$ & o. \\
\hline 0 . & 0. & & $1.000 \tau+00$ & $1.000 E+\infty 0$ & $1.000=000$ & o. \\
\hline 0 . & 0 . & & 1.000E+00 & $1.000 x+00$ & $1.000=+00$ & o. \\
\hline o. & 0. & & $1.000 \varepsilon+00$ & $1.000 E \bullet+\infty$ & $1.000 \Sigma+\infty 0$ & o. \\
\hline 0. & 0. & & $1.000<+00$ & $1.000<+00$ & $1.0005+00$ & o. \\
\hline 0. & 0. & & $1.000=+00$ & $1.000 x+00$ & $1.000=+00$ & 0 . \\
\hline 0. & 0. & & $1.000 z+\infty 0$ & $1.0002+\infty 0$ & $1.000<+00$ & 0 . \\
\hline 0 . & 0. & & $1.000 E+00$ & $1.000<+\infty 0$ & $1.000=+\infty 0$ & o. \\
\hline 0 & 0 . & & $1.000 x+00$ & $1.0005+00$ & $1.000 E+00$ & 0 . \\
\hline o. & 0. & & $1.000 x+00$ & $1.000=-\infty 0$ & $1.0002+00$ & o. \\
\hline 0. & $\mathbf{0}$ & & o. & o. & o. & 0 . \\
\hline 0. & 0. & & $1.000=000$ & $1.000=000$ & $1.000 \mathrm{E}+00$ & 0 . \\
\hline 0. & 0. & & $1.000=+\infty$ & $1.000=00$ & $1.000=+00$ & 0. \\
\hline 0. & 0 . & & $1.000=\$ 00$ & $1.000 x+00$ & $1.0005+00$ & o. \\
\hline 0. & 0. & & $1.000=+00$ & $1.000=00$ & $1.0005 \cdot 00$ & o. \\
\hline 0. & 0. & & $1.000 \tau+00$ & $1.000=\infty 00$ & $1.000<+00$ & o. \\
\hline 0. & o. & & $1.000 \leq+00$ & $1.000=+\infty 0$ & $1.000 \leq+\infty 0$ & o. \\
\hline 0. & 0. & & $1.000 \leq+00$ & $1.000 z+00$ & $1.000=00$ & o. \\
\hline 0 . & 0. & & 1. $.000=+00$ & $1.000 \leq+00$ & $1.000=+00$ & 0. \\
\hline 0 . & o. & & $1.000 \leq+00$ & $1.000=\bullet 00$ & $1.000 \leq+\infty 0$ & 0 . \\
\hline 0. & 0 . & & $1.000<+00$ & $1.000<=00$ & $1.000=00$ & 0. \\
\hline 0. & 0. & & o. & o. & o. & 0 . \\
\hline 0. & 0 & & $1.000=+00$ & $1.000 x+00$ & $1.000=00$ & 0. \\
\hline D. & o. & & $1.000=+00$ & $1.000<+00$ & $1.0005+00$ & o. \\
\hline 0. & 0. & & $1.000<+00$ & $1.0005 \div 00$ & $1.000=00$ & 0. \\
\hline 0. & 0. & & $1.000=+00$ & $1.000 \div \bullet 00$ & $1.000 \leq+00$ & o. \\
\hline 0. & 0. & & $1.0005+00$ & $1.000=00$ & $1.000=+00$ & 0 . \\
\hline o. & o. & & $1.000 \tau+00$ & $1.000=\$ 00$ & $1.0005+00$ & 0. \\
\hline 0. & 0. & & $1.000 E+00$ & $1.000 t+\infty 0$ & $1.000 \Sigma+\infty 0$ & 0 . \\
\hline 0. & 0. & & $1.000<>00$ & $1.000<+00$ & $1.0005+00$ & 0. \\
\hline 0 . & 0. & & $1.000=+00$ & $1.000 \leq * \infty 0$ & $1.000 x+00$ & 0 . \\
\hline 0 . & 0 . & & $1.000 \leq \bullet 00$ & $1.000=00$ & $1.000=00$ & 0. \\
\hline 0 . & 0. & & o. & o. & 0 & 0. \\
\hline 0. & 0. & & $1.000 E+00$ & $1.000 \Sigma+00$ & $1.000<+\infty 0$ & o. \\
\hline
\end{tabular}




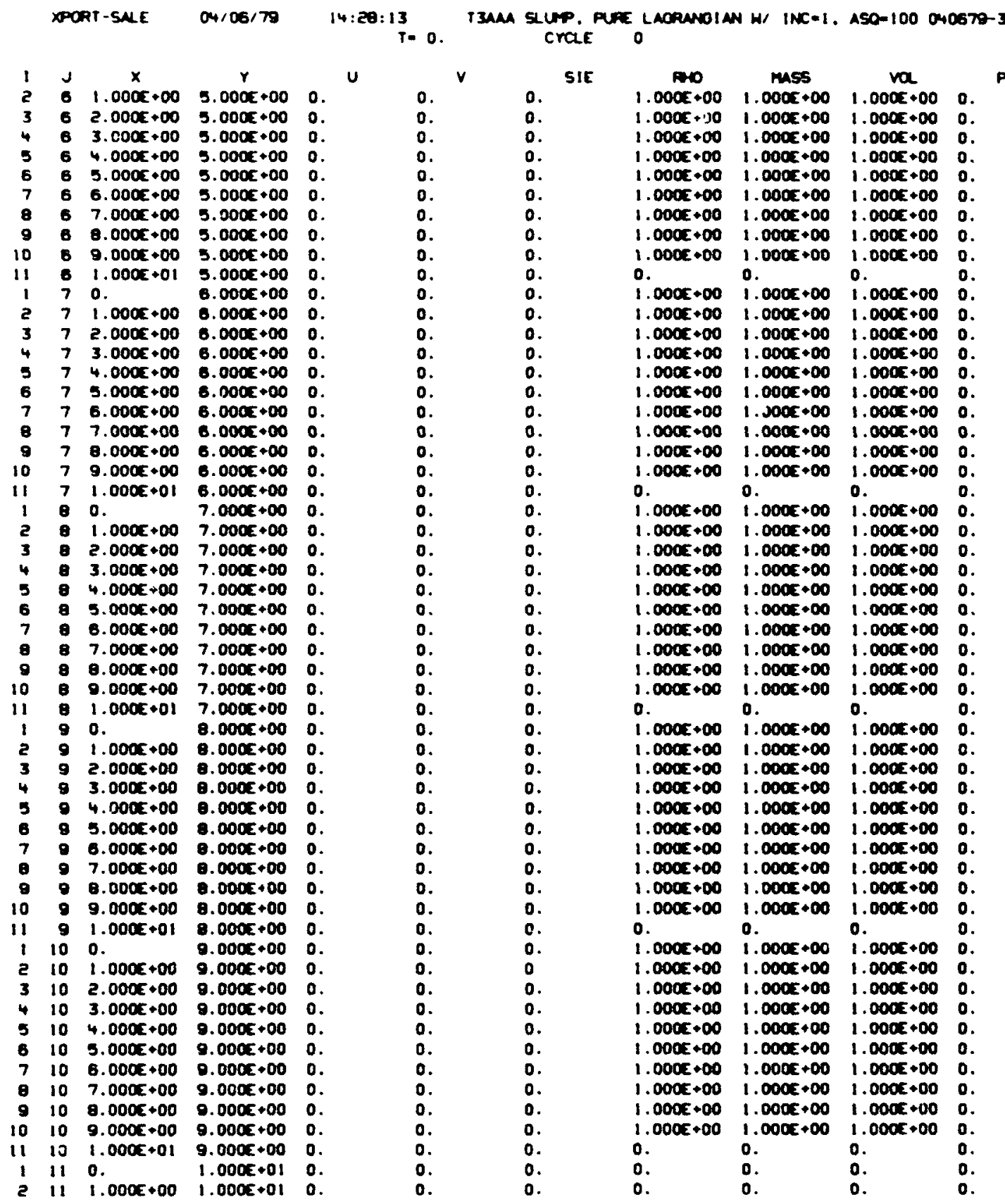



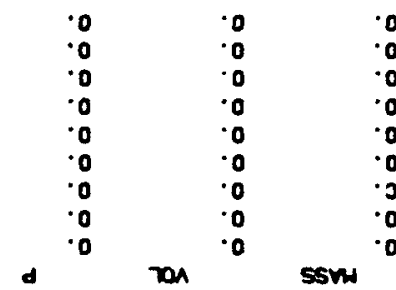

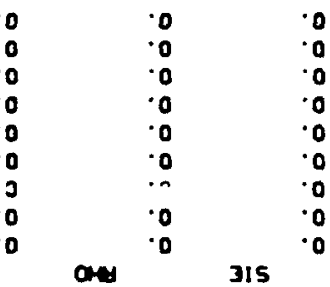

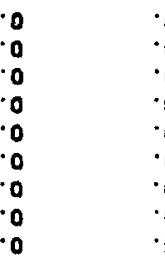

$\wedge$

. -1

E1:82:h1 BL/90/no 37ws-140-x 


\begin{tabular}{|c|c|c|c|c|c|c|c|c|c|}
\hline \multicolumn{2}{|c|}{ WORT-SALE } & \multirow{2}{*}{$\begin{array}{c}04 / 03 / 79 \\
Y\end{array}$} & $14: 28: 13$ & \multicolumn{2}{|c|}{ TMA SLUN. } & \multicolumn{2}{|c|}{ LACRANGINA H' INC=1. } & \multicolumn{2}{|c|}{$450=100 \quad 040579-3$} \\
\hline J & $x$ & & $u$ & $\mathbf{v}$ & SIE & مOD & mass & va & \\
\hline$i$ & 0. & 0 & 0. & o. & e. $305-05$ & $1.000 c+00$ & $1.000 E+00$ & $1.0005+00$ & $E \Sigma+00$ \\
\hline 1 & $1.001 E+00$ & 0. & $17 \theta=03$ & 0. & $5.0305-05$ & $1.0005 \bullet 00$ & $1.000 \varepsilon+\infty 0$ & $1.000 \leq+\infty 0$ & $x+\infty 0$ \\
\hline 1 & $2.00 z=00$ & 0. & $.67 \leq-02$ & 0 . & $4.4635-05$ & $1.000<+00$ & $1.000 \varepsilon+00$ & $1.0005 \div 00$ & $x=00$ \\
\hline 1 & $3.003 z+00$ & 0. & $.502 x-02$ & 0. & $3.7315-05$ & $1.000 \Sigma+\infty 0$ & $1.0005 \div 00$ & $1.0005+09$ & $1 E+\infty O$ \\
\hline 1 & $4.00 \times 5 \cdot 00$ & 0. & $3.6035-02$ & 0 & $2.900-05$ & $1.000 \mathrm{c}+00$ & $1.000 c+00$ & $1.000 \mathrm{C} \cdot 00$ & $E+\infty$ \\
\hline$i$ & $5.005=00$ & 0 & 4. $\pi \cos -02$ & 0 & $E-\infty$ & $1.000<+00$ & $1.000 \Sigma+00$ & $1.0005+00$ & $E+\infty$ \\
\hline$t$ & $6.000 x+00$ & 0. & $180 E-02$ & 0 . & $1.1225-05$ & $1.000<\bullet 00$ & $1.000<+00$ & $.0005+00$ & $E+\infty 0$ \\
\hline $\mathbf{1}$ & $7.0025+00$ & 0 & $7.9285-02$ & 0 & $1.035=-00$ & $1.0002+00$ & $1.0002+00$ & $.000 \varepsilon+00$ & $E+\infty$ \\
\hline$i$ & $0.010<+00$ & . & $1.0305-01$ & 0 . & $x=-05$ & $1.000=\cdot 00$ & $1.000<+00$ & $1.000 \varepsilon+00$ & $E+\infty$ \\
\hline$i$ & $1+5 E+00$ & & $.4302-01$ & 0 & E-os & $1.000 E+00$ & $1.000 E+00$ & $1.000=00$ & $E+00$ \\
\hline$i$ & $2=2+01$ & & $.0 \cos -0 i$ & & 0 & 0. & 0 & & \\
\hline 2 & 0. & $\varepsilon-01$ & . & $-0.311 E-03$ & $3.502 x-03$ & $x<+00$ & $1.000 \leq+00$ & $.000 \Sigma+00$ & $E+\infty$ \\
\hline 2 & $1.001 E+00$ & $=5-a 1$ & a. anes-03 & 4es -03 & $1.0025-\infty$ & $0 \Sigma+\infty$ & $1.000=+00$ & $1.000=-00$ & $E+00$ \\
\hline 2 & $1025+00$ & & 1. Gres-0? & $-0 . \operatorname{esc}-03$ & $9.25 \pi-03$ & $10 \Sigma+\infty$ & $1.0005+00$ & $1.000 E+00$ & $E \circ 00$ \\
\hline 2 & 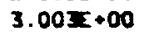 & & $2.5+4<-02$ & $-0 . \sec -03$ & $7.35:=-03$ & $\alpha=+\infty$ & $1.000 z+\infty 0$ & $100=00$ & $E+\infty$ \\
\hline 2 & $4.004 E+00$ & & $3.53 a 5-02$ & $-1.0735-02$ & $5.02 e x-03$ & $0<+\infty$ & $1.000 c+00$ & $00 E+\infty$ & $\Sigma+\infty$ \\
\hline 2 & $0=5+00$ & & $4.00-2-02$ & & 2. $30 \mathrm{e}-0$. & $E * 00$ & $1.000 E+00$ & $20 E+\infty$ & \\
\hline 2 & $6.000=+00$ & i & 6.00-5-02 & $-1.50 w 2-02$ & $-5.00-07$ & $E \bullet \mathbf{0}$ & $1.000=+00$ & $.000 \varepsilon+\infty 0$ & $E+\infty$ \\
\hline 2 & $E \Sigma+00$ & & $7.000-02$ & $1.027 E-02$ & $-4.00=c-00$ & $E+\infty$ & 1. $000 \mathrm{c}+00$ & $00 z+\infty 0$ & $E+00$ \\
\hline 2 & $\alpha \varepsilon+\infty$ & $c-0 i$ & 9. Eow - 02 & 2. enkt-oe & $-7.500=00$ & $1.000=+00$ & $1.000 \div-00$ & $000=>00$ & $E+\infty$ \\
\hline 2 & $E+\infty 0$ & $x-01$ & $1.20=-01$ & $11 E-02$ & $-3.0462-06$ & $\varepsilon+\infty$ & $1.000 c+00$ & $00 E+00$ & -01 \\
\hline 2 & $E+01$ & & $1.00=01$ & $30 c-02$ & & 0. & & & \\
\hline 3 & 0 & 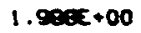 & 0 & $2 z=02$ & $2.6745-03$ & $J E \bullet 00$ & $1.0005+00$ & $0 \Sigma+\infty 0$ & $\Sigma+\infty$ \\
\hline 3 & $1.001 E+00$ & $2 E+00$ & $7.6025-03$ & $-1.0402-02$ & e. $114 E-03$ & $x=00$ & $000 \varepsilon+00$ & $00 E+\infty 0$ & $=+00$ \\
\hline 3 & $=+00$ & $2 x+0$ & 1. $50 \sqrt{2}-02$ & $-1.7 e E[-\infty e$ & $\varepsilon-\infty$ & $=00$ & $0005+00$ & $0 \Sigma+\infty$ & $=+\infty$ \\
\hline 3 & $E E \bullet 00$ & $0: 5+\infty 0$ & $2.4116-02$ & $-1,600 x-02$ & $E-\infty$ & $: 00$ & $005 \div 00$ & $0<+00$ & $\Sigma+00$ \\
\hline 3 & $= \pm 00$ & $0 x+00$ & $3.330 .-02$ & $-2.000-\infty 2$ & ce-os & $\rightarrow \infty 0$ & $000 c+00$ & $0=+00$ & $=\$ 00$ \\
\hline 3 & $t E \bullet 00$ & $x+\infty$ & $4.373=02$ & $-2.404 E-02$ & $=-0$. & $\varepsilon+\infty$ & $1.0005+\infty 0$ & $0 E+00$ & $:+0$ \\
\hline 3 & $\approx+00$ & $\pi+00$ & $5.504 c-02$ & $-2.0000-02$ & $-1.010-07$ & $+\infty$ & $1.0005+00$ & $0 E+00$ & $\$ 00$ \\
\hline 3 & $E+\infty$ & $E+00$ & 6. 8s:-02 & $-3.5002-02$ & $-2.07=5-\infty$ & $\$ \infty 0$ & $000 \varepsilon+\infty 0$ & $0 x+\infty$ & $\sum+\infty$ \\
\hline 3 & {$[+00$} & $E x+00$ & $.816 x-02$ & $-4.020 \mathrm{c}-02$ & $-2 \cdot \cos 5-\infty$ & $+\infty$ & $005+\infty$ & $E+\infty$ & {$[+\infty$} \\
\hline 3 & $E+\infty 0$ & $=0$ & $.01 \pi-01$ & $0.978:-02$ & -7. EN+E-07 & +00 & $1.0005+00$ & $x+00$ & \\
\hline 3 & $1.001 E+01$ & $E \mathbf{E}+\mathrm{C}$ & $1.11=E-01$ & $-8.3+[5-02$ & o. & 0 & & & \\
\hline 4 & & $a z+00$ & 0 & $-2.30 x i-02$ & $1.90 \pi-\cos$ & +00 & $1.0005+00$ & $0 E+\infty 0$ & \\
\hline & & 2 & 03 & DIE & & $\infty$ & $300 E+\infty 0$ & +00 & \\
\hline 4 & $E+00$ & $\pi+00$ & $1.4305-02$ & S1EL- & $5 \pi-0$ & $E+\infty 0$ & $1.0005+00$ & 0 & $\$+00$ \\
\hline & $3.002 x+00$ & $m \boldsymbol{m}+00$ & $2.2055-02$ & $-2.700 x-02$ & 3. $8:=2-08$ & $\varepsilon+\infty$ & $1.000 E+00$ & $20 E+0$ & $E+00$ \\
\hline 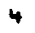 & $4.00 x x+00$ & $.907 k+00$ & $3.0305-02$ & $-3.00 z-02$ & e.eoge-06 & $I E+\infty$ & $1.000 c+00$ & $00 E+0$ & $=00$ \\
\hline 4 & $E+00$ & $\pi+c$ & $3.032 x-02$ & $-3.4202-02$ & 1. $3005-00$ & $+\infty$ & $E+\infty$ & $\varepsilon+0$ & $\$ 00$ \\
\hline 4 & & $\bar{F}$ & $01-$ & $137 \pi-02$ & & $+\infty 0$ & $E+\infty$ & & \\
\hline 4 & $\Sigma+\infty 0$ & $x+00$ & 6.001E-02 & $1 \pi-02$ & ME-07 & $E+\infty$ & $000 E+00$ & $x+\infty$ & $E+\infty$ \\
\hline 4 & $\varepsilon+\infty 0$ & $+E+00$ & 7.05:-02 & $-6.212 \varepsilon-02$ & $-1.000-\infty$ & $E+\infty 0$ & $1.000 \Sigma+00$ & $\alpha=+\infty$ & $E \star \infty 0$ \\
\hline 4 & $\varepsilon+00$ & $E+1$ & $7.600 \mathrm{cos}$ & $-7.020-02$ & $-2.4005-07$ & $E+\infty$ & $1.000<+00$ & $E+\infty 0$ & $=-01$ \\
\hline 4 & $1.001 E+01$ & $E+\infty 0$ & e. $371 E-02$ & $-8.8 T \pi /-02$ & 0 & 0. & 0. & & \\
\hline 5 & 0 & $E+00$ & 0 & $-3.038-02$ & $13 \pi /-05$ & & $00<+\infty 0$ & 0 & \\
\hline 5 & $1.001 E+0$ & 3 & 6.23.: -03 & $-3.001 E-$ & $397-2-05$ & $+\infty$ & $100 \Sigma+00$ & $E+\infty$ & \pm+00 \\
\hline 5 & $\sum+0$ & $=00$ & 1.E7IE-02 & $1=-02$ & 3. उTME-03 & $=\infty+\infty$ & $1.0005+00$ & $0 \varepsilon+\infty$ & $+\infty 0$ \\
\hline 5 & & & $1.9+2 E-02$ & & $2.85 \pi-03$ & $E+00$ & $000 \Sigma+00$ & & \\
\hline 5 & $x+00$ & $x+00$ & 2. Buge-02 & $-3.797 t-02$ & $1.91 \leq-08$ & $E+\infty 0$ & $000 E+00$ & $D C E+00$ & $2.4505+00$ \\
\hline 5 & $\Sigma+\infty$ & $x=00$ & 3. $\operatorname{xecc}-\infty 2$ & $-4.2005-02$ & $9.6-2-07$ & $=+\infty$ & $1.0005+00$ & $\alpha=+\infty$ & $.145 E+00$ \\
\hline 5 & $E+00$ & $C x+00$ & 4. $18 t E-02$ & $-4.900-02$ & $2.0795-07$ & 00 & $00=+00$ & $0 x+00$ & Tanc $5 \bullet 00$ \\
\hline 5 & $5+00$ & AE. & 4. $5002-02$ & $-5.6005-02$ & $-3.190<-07$ & $=00$ & $1.000=\bullet 00$ & $1002+00$ & $1.320 E+00$ \\
\hline 5 & $E+\infty 0$ & $E+00$ & 5. OHEE-02 & $-7.015:-02$ & $-4.914 E-07$ & $E+\infty$ & $1.000=+00$ & $100=+00$ & $0.18 x-01$ \\
\hline 5 & $9.000<+00$ & $E+\infty$ & $6.14 \pi-02$ & $-0.416 E-02$ & $-1.011 E-07$ & $1.000<+00$ & $1.0005+00$ & $1.000 E+00$ & $2.803 x-01$ \\
\hline 5 & $1.001 E+01$ & $31 E+00$ & $6.427 E-02$ & $-9.1795-02$ & 0 & & & & \\
\hline & & & & & & & & & \\
\hline
\end{tabular}




\begin{tabular}{|c|c|c|c|c|c|c|c|c|c|}
\hline \multicolumn{2}{|c|}{ XPORT-SNLL } & \multirow{2}{*}{$\begin{array}{c}04 / 06 / 79 \\
Y\end{array}$} & $14: 20: 13$ & \multicolumn{2}{|c|}{ T3AAA SLUNP. } & \multicolumn{2}{|c|}{ E LACRAMOIAN HI INCA-I. } & \multicolumn{2}{|c|}{$A S O=100 \quad 040679-3$} \\
\hline$J$ & $x$ & & $u$ & $\mathbf{v}$ & & RNO & MSS & & \\
\hline 6 & $1.0016 \cdot 00$ & $4.590 x+00$ & $5.3316-03$ & $-3.6725-02$ & & $1.000 \Sigma \div 00$ & $1.0005+00$ & $1.000 E+00$ & \\
\hline 6 & $2.001 E+00$ & $.9 \sec +00$ & $.00 x<-02$ & $-3.82 z \tau-02$ & $2.10 \pi-00$ & $1.000<=00$ & $1.000 c+00$ & $1.000 k+00$ & .00 \\
\hline 6 & $3.002 E+00$ & $.9905+00$ & 1. Gues - 02 & $-4.0785-02$ & $1.65 \pi-00$ & $1.0005+00$ & 1.000E +00 & $1.000 E+00$ & $=+\infty$ \\
\hline 6 & $4.002 x+00$ & $.9905+00$ & 2. 2 2as - 02 & $-4.45 \pi-02$ & $1.116<-00$ & $1.0005+00$ & $1.0005 * 00$ & $1.000 \tau+00$ & $: \circ 0 u$ \\
\hline 6 & $5.00 x+00$ & $.953 x+00$ & $.8165-02$ & $-4.975-02$ & $0.021 \varepsilon-07$ & $1.000[+00$ & $1.0005+00$ & $1.0005+00$ & +00 \\
\hline 6 & $6.00 \pi \varepsilon+00$ & $4.904 E+00$ & $3.41 \pi-02$ & $-5.040 \mathrm{C}-02$ & $1.55 \pi-07$ & $1.0005+00$ & $1.0005+00$ & $1.000 E+00$ & $\varepsilon+\infty$ \\
\hline 6 & $7.004 E+00$ & $4.9035 \cdot 00$ & $3.97 z-02$ & $-6.501 E-02$ & $-1.48:-07$ & $1,000 E+00$ & $1.000 z+00$ & $1.000 z+00$ & $5 * 00$ \\
\hline 6 & Q.004E +00 & 4. gaec +00 & $4.445=-02$ & $-7.535-02$ & -2.48 & $1.000 t+00$ & $1.0005+00$ & $1.0005+00$ & -01 \\
\hline 6 & $9.005 E+00$ & $.9916+00$ & $4.7005-02$ & & -4.80 & $1.0005+00$ & $1.000 \Sigma+00$ & $1.000=+00$ & \\
\hline 6 & $1.000 x+01$ & Saie +00 & $4.94 \leq x-02$ & $-0.3 x=-02$ & o. & 0. & o. & & \\
\hline 7 & 0 & $.908 x+00$ & 0 & $-4.112 x-02$ & $z-0$. & $1.000 \mathrm{x} * 00$ & $1.000 \Sigma+00$ & $.000 \varepsilon+00$ & \\
\hline 7 & $1.000 \varepsilon+00$ & $8 x+00$ & $4.3205-03$ & -4.18 & & $1.000<+00$ & $1.0005+00$ & $.000 \Sigma+00$ & +00 \\
\hline 7 & 2.001E $\bullet 00$ & $0 \tau+00$ & $0.731 E-03$ & -4.3 & $-\infty$ & $1.0005-00$ & $1.0005+00$ & $.000<+00$ & .00 \\
\hline 7 & $3.001 E+00$ & {$[x+00$} & 1. उRIE-02 & $-4.50 x-02$ & {$[-07$} & $1.000<+00$ & $1.000 x+00$ & $0 \Sigma+00$ & +00 \\
\hline 7 & $4.00 z E+00$ & $\operatorname{sos} 2+00$ & 1.The=-o2 & $-4.92=02$ & $5.70 \times[-07$ & $1.000 E+00$ & $1.0005+00$ & $1.000 \tau+00$ & $+\infty$ \\
\hline 7 & $2 x+00$ & $.00 \times E+00$ & $2.2305-02$ & $-5.5015-02$ & $2.93: 5-07$ & $1.000 t+00$ & $1.000<+00$ & $1.000 E+00$ & .00 \\
\hline 7 & $0 \leq x+00$ & $.90 \times 1+\infty 0$ & $2.600-02$ & $-0.15 a-02$ & $5.3 a 16-00$ & $0 E+00$ & $1.000 \tau+00$ & $000<\div 00$ & .00 \\
\hline 7 & $03 x+00$ & $.9032+00$ & $3.0025-02$ & & $-1.01=2-07$ & $0 E+00$ & $1.000 \tau+00$ & $0005+00$ & -01 \\
\hline 7 & $3 E+00$ & $.9025+00$ & $3.3005-02$ & & $-1.4508-07$ & $1.000 E \cdot 00$ & $1.000 \tau+00$ & $.000<+00$ & \\
\hline 7 & $9.00 \times E+00$ & $1 E \cdot 00$ & $3.60 \pi-02$ & -8.8 & $-2.7005-00$ & $1.0005+00$ & $1.000 x+00$ & $.0002+00$ & -01 \\
\hline 7 & $1.000 E+01$ & $1 E \bullet 00$ & 3.72 $=-02$ & $-0.44=5-02$ & 0 . & 0 & 0 & & D. \\
\hline 8 & 0. & $\sec +\infty$ & & $-4.40=5-02$ & $2.600 x-00$ & $1.000 E+00$ & $.000 x+\infty 0$ & $.000<+00$ & \\
\hline B & $1.000 \varepsilon+00$ & $.90 x+\infty$ & 3.201E-03 & $-4.948=-02$ & $5.71 \pi-07$ & $1.000 E+00$ & $1.000=+00$ & $000 E+00$ & $: \infty$ \\
\hline $\mathbf{B}$ & $2.001 E+00$ & $.905 E+00$ & $8.5 \pi=-03$ & $-4.712 x-02$ & 4. $\cos =-07$ & $0 E+00$ & $000=000$ & $000=\bullet 00$ & $: 00$ \\
\hline B & $1 E+00$ & $. \operatorname{sos} x+00$ & $9.9145-03$ & $-4.98 \pi-02$ & $3.3016-07$ & $0 E+\infty 0$ & $0002+\infty 0$ & $200=+00$ & $E+\infty$ \\
\hline$\theta$ & $4.001 E+00$ & $.00-2<00$ & 1. Jex-02 & $-5.370<-02$ & $2.01 \pi-07$ & $0 \tau+00$ & $.000 \Sigma \bullet+00$ & $000 E+00$ & {$[\bullet+\infty$} \\
\hline $\mathbf{8}$ & $5.002 E+00$ & SONE + & $1.60 x-02$ & $-5.600-02$ & $7.14 \pi-00$ & $1.000 \varepsilon+\infty 0$ & $1.0005 \cdot 00$ & $1.000=-00$ & -01 \\
\hline 8 & $x+00$ & $9035+00$ & 1. Saze-02 & $-6.516 x-02$ & $-3.20 \pi-00$ & $1.0005 \cdot 00$ & $1.0005+00$ & $.000 \approx+00$ & $E-01$ \\
\hline $\mathbf{B}$ & $x+00$ & $.9952+00$ & c.53ex-02 & $-7.2015-02$ & $-0.000-00$ & $0 E=+\infty$ & $1.000<+00$ & $.000<+00$ & $=-01$ \\
\hline 8 & 8. D02t +00 & $.90<+00$ & $2.455=02$ & $-0.100=-02$ & $-0.420 z-00$ & $\Sigma+00$ & $.0005 \cdot 00$ & $E+\infty$ & -01 \\
\hline B & $9.0035 \cdot 00$ & 991E+00 & 2.5cex-02 & $-9.0315-02$ & $-1.750 \mathrm{x}-00$ & $0 E+\infty 0$ & $1.000 \varepsilon \bullet 00$ & $t E+\infty 0$ & \\
\hline 8 & $1.00 x=01$ & $\sec c \cdot 00$ & $2.071 E-02$ & $-9.50 \pi-02$ & o. & o. & & & 0. \\
\hline 9 & & $905+00$ & & $-4.771 \varepsilon-02$ & e.ex & $0=\circ 00$ & $1.000 E+\infty 0$ & $.000 E+00$ & \\
\hline 9 & $1.000 E \cdot 00$ & $205+00$ & $2.170-03$ & $-4.0205-02$ & $-x-07$ & $1.0005 \cdot 00$ & $1.0005 \cdot 00$ & $.000 \varepsilon+00$ & \\
\hline 9 & 2. $000 E+00$ & $905 x+00$ & $4.3005-03$ & $-4.9005-02$ & $\Sigma-0$ & $1.000=+00$ & $1.0005+\infty 0$ & $.0005+00$ & 7.0 \\
\hline 9 & $E+\infty 0$ & 000 a +00 & & $-5.20 x-02$ & & $x=+\infty$ & $1.0005+00$ & $.000 E+00$ & \\
\hline 9 & $E \bullet 00$ & NE. & 0.705z-03 & & & $E+\infty$ & $0 \leq+\infty 0$ & $0 \Sigma+00$ & \\
\hline 9 & $E \circ 00$ & $2 \times E+\infty 0$ & 1.000:-02 & $-6.1535-02$ & $-4.504 \varepsilon-00$ & $x+\infty 0$ & $000:+\infty 0$ & $000 \leq+\infty 0$ & -01 \\
\hline 9 & $E+00$ & $903 x+00$ & 1. तET- DE & $-6.700 \mathrm{x}-02$ & $-7.0118-\infty$ & $1.000 E \bullet 00$ & $.0005 \cdot 00$ & DOCE +00 & -01 \\
\hline 9 & 7.00 & $90 x+00$ & $1.4505-02$ & $-7.46 \pi-02$ & $-7 . \operatorname{sen} \varepsilon-00$ & $1.000 \varepsilon+00$ & $.0005 \cdot 00$ & $00=+00$ & \\
\hline 9 & $E+00$ & $\sec x+0$ & 1. $.593 z-02$ & $-0.25 \pi-02$ & $-8.80 x-0$ & $0 E+\infty$ & $1.000 x+\infty 0$ & $1:+\infty$ & $=-01$ \\
\hline 9 & $E+\infty$ & $1 E+00$ & 1.e01E-02 & $-0.110<-02$ & $-1.074 \mathrm{E}-00$ & $1.0005+00$ & $1.000<-00$ & $1.0005+\infty 0$ & 8.3 \\
\hline 9 & $a c \circ 01$ & $.900 x+00$ & 1. $7205-02$ & $-0.540 z-02$ & o. & 0. & 0 & & o. \\
\hline 10 & 0 & $.805 x+00$ & 0 & $-4.93 \pi-02$ & $1.3-x-07$ & & & $c=00$ & \\
\hline 10 & 1.0 & 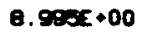 & $1.000=-03$ & & & $x+\infty$ & $000 x+00$ & $0=00$ & \\
\hline 10 & $2.0005+00$ & $\theta=00$ & $2.105 x-03$ & $-5.150-02$ & $-5.17+\varepsilon-\infty$ & $x=+\infty$ & $000:+\infty 0$ & $300=00$ & \\
\hline 10 & $3.000<+00$ & $\cos +\infty$ & $3.2916-03$ & $-5.4316-02$ & $-8 \cdot 0 \cdot x-\infty$ & $E \bullet \infty 0$ & $0005 \cdot 00$ & $000 E+\infty 0$ & -01 \\
\hline 10 & +.00 & $. \operatorname{sant}+00$ & $4.371 E-03$ & $-5.015[-02$ & $-1.2 x+5-00$ & $\Sigma=00$ & $1.0005+\infty$ & $0005+00$ & \\
\hline 10 & 5.0 & 0,4600 & $5.4005-03$ & $-6.3002-02$ & $-1.50=0$ & $c \varepsilon+\infty$ & $1.000<=00$ & $1.000=00$ & \\
\hline 10 & 6.00 & $93 E+00$ & $0.335-03$ & & $-1.500-\infty$ & $1.0005+00$ & $1.0005 \cdot 00$ & $1.000=00$ & \\
\hline 10 & $7.001 E+00$ & $.802+00$ & 7. $18: 5-03$ & -7. & $-1.441 E-09$ & $1.000[+00$ & $1.000 \leqslant \cdot 00$ & $1.0005+00$ & $1.003=-01$ \\
\hline 10 & 0.001E $\bullet 00$ & $.908+00$ & $7.83 \times[-03$ & $-0.3+1 E-02$ & $-1.010 z-08$ & $1.000 \Sigma+00$ & $1.0005 \times \infty 0$ & $1.000=00$ & 6. 1exz-02 \\
\hline 10 & $9.00 t E+00$ & $.901 E+00$ & 0.246:-03 & $-9.15 \times E-02$ & $-1 . e z 45-\infty$ & $1.000 E+00$ & $1.0005 \cdot 00$ & $c \Sigma+0 n$ & 2.0 \\
\hline 10 & $1.000 E+01$ & $.9005+00$ & e. Howe -03 & $-0.571 E-02$ & 0 & o. & 0 & 0 & o. \\
\hline 11 & & a. $\cos 2 \cdot 00$ & 0 & $-5.0205-02$ & 0 . & 0. & 0 & 0 & 0 . \\
\hline 11 & $1.000 E+00$ & $.9955+00$ & 5. $44 E=-04$ & $-5.07-02$ & 0 . & 0 . & 0 & & o. \\
\hline
\end{tabular}




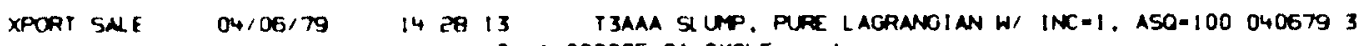
T* I OOOOOE OI CYCLE I

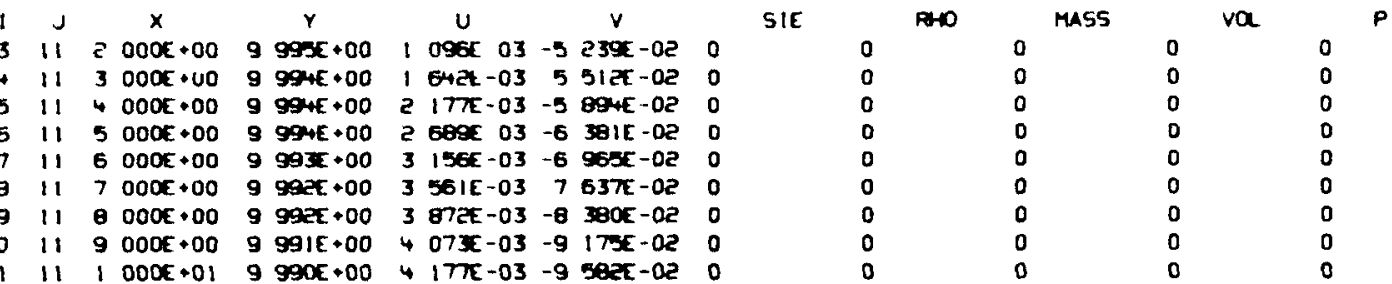

$T=1$ Do000E-01 CYCLE 1 TOT $E=245400442 E-0151 E-445181003 E-04$

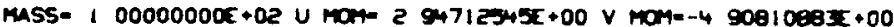

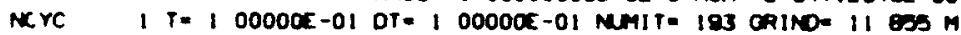

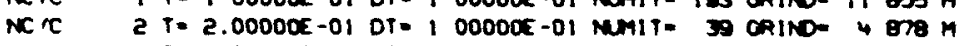

NCYC $3 T=3$ DOOOOE-0I DT= 1 O0000E-01 MHIT- II CRINO $1600 \mathrm{M}$

NCYC $4 T=400000 E-01$ OT= $100000 E-01$ MMIT- 51 CAINO- $2210 \mathrm{M}$

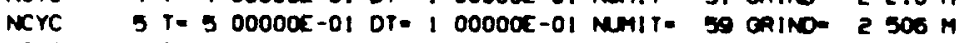

NCYC 6 T 6 O0000E-01 DT 1 00000E-01 NEIT= OH CRINDE $2703 \mathrm{M}$

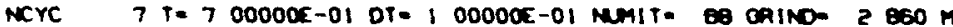

NCYC 8 T. 8 00000E-DI DT- 1 00000E-01 MMIT- 72 CRINDE 3 O3H M

NCYC 9 T. 9 OOOOOE-OI DI- 1 ODOOOE-0I MMITE 74 GAINO- $3110 \mathrm{M}$ 


\begin{tabular}{|c|c|c|c|c|c|c|c|c|c|}
\hline & & $4 / 06 / 79$ & . & $\begin{array}{r}134 \\
2599\end{array}$ & Prase & LACRAK & $\omega / \mid N C-1$, & 00 & \\
\hline J & $x$ & $Y$ & $u$ & $v$ & SIE & mo & Mass & & \\
\hline 1 & 0 & 0. & 0 & D. & $2.70 \pi-03$ & $1.000<+00$ & $1.000<+00$ & & $E+\infty$ \\
\hline 1 & $1.672 E+00$ & & 2. $165 x-01$ & 0 . & $1.3+\pi-03$ & $1.000<+00$ & $1.000 E+00$ & & $E+00$ \\
\hline 1 & 3. $578 x \cdot 00$ & & $4.440 E-01$ & 0 & 1. Osex -03 & $1.000 x+00$ & $.000 E+00$ & & $\bullet \infty$ \\
\hline 1 & $5.1602 \cdot 00$ & 0 & $7.0305-01$ & 0. & $6.18-x-\infty$ & $1.0005-00$ & $.000<\cdot 00$ & & .00 \\
\hline 1 & $7.095 x+00$ & 0 & $1.00 x E+00$ & 0 . & $-1.211 \varepsilon-\infty$ & $1.0005-00$ & $1.000<-00$ & & $+\infty$ \\
\hline 1 & $\exists .300 E \bullet 00$ & 0 . & $1.416 E+00$ & 0. & $-1.20:=03$ & $9.9=2-01$ & $1.000=00$ & &.$+\infty$ \\
\hline i & $1.19 \pi+01$ & 0 & $2.043 x+00$ & 0. & $-3.620=-03$ & & $.000 c+00$ & $=+\infty$ & $+\infty$ \\
\hline 1 & $1.580 c-01$ & 0 & $3.00 \mathrm{coc}+00$ & 0. & $-5.82 w E-03$ & & $000 x \cdot 00$ & $=00$ & $=00$ \\
\hline i & $2.032 x+01$ & & 4. $220<+00$ & 0. & $-3.0205-03$ & $9.9-01$ & $.0005+00$ & $+\infty 0$ & $+\infty 0$ \\
\hline$i$ & 2. $52 \times E+01$ & & $.905 z+00$ & 0 . & $-5.603 \Sigma-04$ & $9 . \cos x-01$ & $1.000 E+00$ & & -01 \\
\hline I & $2.69 \times E+01$ & & 5. $5 \sec x+\infty$ & 0 & o. & o. & o. & & 0. \\
\hline 2 & 0 & Sg0e-01 & & $-7.0+1 \varepsilon-02$ & $1.30=-0]-03$ & $1.000 c+00$ & $1.000 \Sigma+00$ & -01 & $+\infty$ \\
\hline द & 1. $60 \mathrm{AN}+00$ & $+\varepsilon-01$ & 2. $200 x-01$ & $-7 . \sec =-02$ & 1. $916 x-04$ & $1.000<-00$ & $000 E+00$ & & $+\infty$ \\
\hline 3 & $3.40=x+00$ & $0 \varepsilon-01$ & 4. $\operatorname{cec}:-01$ & $-0.0 \geq 4 \varepsilon-0$ & $9.3 x z-\infty$ & $1.000 \leq+00$ & $000 E+\infty 0$ & & \\
\hline z & $5.208 \Sigma+00$ & $.307 t-01$ & 7. $\sec =01$ & $-0.4835-02$ & $-6.545 x-05$ & $5+\infty$ & $1.000<+00$ & & \\
\hline 2 & $7.154 E+00$ & gese-01 & $1.05 x+00$ & $-0.11 \leq-02$ & $-3.035=-04$ & $1.000<+00$ & 1. .000E +00 & & $E .00$ \\
\hline 5 & $9.360 x+00$ & & $1.471 E \bullet 00$ & $-9.20 e x-02$ & $-7.00 \pi-04$ & $1.0005+00$ & $.000 \varepsilon+\infty 0$ & $=\infty 0$ & \\
\hline 2 & $1.200 x+01$ & $e=01$ & 2. $1035=00$ & $-0.37 c-02$ & $-1.30 \mathrm{~s}-03$ & $1.000 c+00$ & $0002+00$ & & $E+\infty$ \\
\hline 2 & $1.56 \pi+01$ & $\pi \varepsilon-01$ & $3.131 E+00$ & $-7.6305-02$ & $-2.19=5-03$ & o. cosis-01 & $000 x+\infty 0$ & $+\infty$ & $E+\infty$ \\
\hline 2 & $2.0345 \circ 01$ & $E-1$ & $4.2345+00$ & $-2,5005-02$ & $-1.434[-03$ & $9.90 \pi$ & $1.000=\bullet 00$ & $+\infty$ & $=+\infty$ \\
\hline 2 & $2.50 x=01$ & & $4.950 \mathrm{c}+00$ & $-3.70=5-02$ & 1. $2005-\infty$ & 9.900 & $1.000 E+00$ & $+\infty$ & $E-01$ \\
\hline 2 & $2 . \cos x+01$ & -1 & 3. $2045+00$ & $-2.67 z E-02$ & 0 & o. & 0 & & \\
\hline 3 & 0 & $x=0$ & 0 & $-1.590 x-01$ & $1.019-03$ & $1.000 E+00$ & $1.000<+00$ & & $\bullet 00$ \\
\hline 3 & 1. $68 \mathrm{ex}+00$ & $\pi \circ 0$ & 2. $22 \mid \varepsilon-01$ & $-1.50=-01$ & 1. $] x=2-0_{4}$ & oot. & $.0002 \cdot 00$ & & .00 \\
\hline 3 & $3.360 \mathrm{x}+00$ & $0 E+0$ & $4.97 \pm E-01$ & $-1.8325-01$ & $5.19 \pi-\infty$ & $1.000 x+00$ & $.0005+\infty 0$ & & $-\infty$ \\
\hline 3 & $5.135 E+00$ & $60 x \cdot 00$ & 7. $191 E-01$ & $-1.0018-01$ & $-7.140 t-05$ & $1.0005+00$ & $.000 r+00$ & 01 & $+\infty$ \\
\hline 3 & $7.045 t+00$ & $00<-0$ & $1.0315 \bullet 00$ & $-1.67 \pi-01$ & $-2.5905-04$ & $E+\infty$ & $.000<+00$ & $+\infty$ & $-\infty$ \\
\hline 3 & $9.1932+00$ & $E-c$ & $1.4205 \cdot 00$ & $-1.7725-01$ & $-5.97 \pi-04$ & $E+\infty$ & $100:+\infty 0$ & $+\infty$ & $\bullet \infty$ \\
\hline 3 & $1.182 E+01$ & $M E-0$ & $.0+4 E+00$ & $-1.7758-01$ & $-1.140 x-03$ & 1.00 & $0 t: 00$ & & 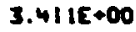 \\
\hline 3 & $1.525+01$ & $4 \pi-0$ & 3. O4ET+00 & $-1 . \cos 2-01$ & $-1.64=5-03$ & & $0 x \bullet \infty 0$ & $E+\infty$ & $=\infty \infty$ \\
\hline 3 & $1.978 x+01$ & $2 a t-0$ & $4.1202+00$ & $-7.09 \pi-02$ & $-1.2725-03$ & o.er: & $00 t+\infty$ & $x+\infty$ & .00 \\
\hline 3 & $2.41 \pi+01$ & $11 \varepsilon-0$ & $4.0+1 E+00$ & $-6.17 M E-02$ & $2.70 \pi-05$ & 1.000 & $00 t+00$ & & -01 \\
\hline 3 & $2.671 E+01$ & $0<-0$ & $5.13 \times E+00$ & $-8.0525-02$ & 0 & 0 & & & 0. \\
\hline 4 & 0 & $05+0$ & & $-2.4005-01$ & $7.6205-04$ & & & & \\
\hline 4 & $1.62 \pi+00$ & E & $15+2-01$ & $-2.41 c c-01$ & B. $0005-0 s$ & 0 & $\Sigma+00$ & & \\
\hline 4 & $3.2605+00$ & $x+0$ & $4.412 \varepsilon-01$ & $-2.402=-01$ & 2.e10r-os & 1.0 & $x+\infty$ & & \\
\hline 4 & $E E+\infty 0$ & $+6 x+0$ & $6.955-01$ & $-2.5335-01$ & $-7.3315-\infty 0$ & $E+\infty$ & $x+\infty$ & $\infty$ &.$\infty 0$ \\
\hline 4 & $a c+00$ & $x+0$ & $9.907 E-01$ & $-2.500 .-01$ & $-2.00 \pi /-04$ & & $E+\infty$ & $\boldsymbol{x}$ &.$\infty$ \\
\hline 4 & $0.933 E+00$ & $E+0$ & $1.300 \div+00$ & $-2.815-U 1$ & -4. Troc $-\mathrm{O}_{4}$ & $E+\infty$ & $x=00$ & $00+\infty$ & .00 \\
\hline 4 & $1.1435+01$ & $E E+0$ & $1.94 x+00$ & $-2.73 \times 5-01$ & $-9.330 \mathrm{c}-04$ & 1.0 & $\sum+\infty$ & $x=00$ & $=\infty$ \\
\hline 4 & $1 E+01$ & or. 0 & $2.68 \pi+00$ & $-2.37 \times 6-01$ & $-1.4795-03$ & & $\Sigma \cdot 00$ & $\Sigma+00$ & $: 00$ \\
\hline 4 & $E+01$ & $x-0$ & $3 . \sec 5+\infty 0$ & $-1.31 t E-0 \mid$ & $-1.042 x-03$ & -01 & {$[+\infty$} & $E+\infty$ & $5 . \infty$ \\
\hline 4 & 2.3 & -1 & $4.701 E+00$ & $-9.1292-02$ & $-2.245 x-0 r$ & & & & \\
\hline 4 & $2.560 x+01$ & $=-$ & $4.95=x+00$ & $-1 . \cos 0 x-01$ & 0 & 0 & & 0 . & \\
\hline 5 & 0 & & & -3. 2E2E - 01 & $53005-0_{4}$ & & & & \\
\hline 5 & $1.581 E+00$ & स & $2.0598-01$ & $-3.245 x-01$ & 4. oser-os & 1.0 & $\varepsilon+\infty$ & $\cdots E-$ & $E \cdot \infty$ \\
\hline 5 & 3. $180 E+00$ & $8 F+0$ & $4.2135-01$ & -3.20त-01 & $1.101 \varepsilon-05$ & $E+\infty$ & $100<+00$ & $00<+\infty 0$ & $E+\infty$ \\
\hline 5 & $4.850 E+00$ & $0 x+5$ & $5.61]=-01$ & $-3.400 E-1$ & $-7.405=-\infty$ & & $005+00$ & $00 \leq-00$ & $: \infty 0$ \\
\hline 5 & 6.64 & $0 E+0$ & $9.4095-01$ & $-3.45 \pi-01$ & $-1 \cdot \operatorname{cosec}-0_{4}$ & & $x \cdot \infty$ & $x+\infty$ & .00 \\
\hline 5 & 0. $59 x=+00$ & & $1.293 E+00$ & $-3.488 z-01$ & $-3.462 x-04$ & & $00 E+00$ & $E+\infty$ & \\
\hline 5 & $1.092 x+01$ & ond & 1. EOUE +00 & $-3.878 x-01$ & $-7.2935-04$ & $1.000=+\infty 0$ & $1.0005 \bullet+0$ & $1.000 \leq+\infty 0$ & $2.000 x+\infty$ \\
\hline 5 & $1.305 E+01$ & $g+E+0$ & $2.608 x+00$ & $-3.397-01$ & $-1.142 x-03$ & 9. $\operatorname{exc}-01$ & $1.000<+00$ & $1.000=+\infty 0$ & $2.005 \cdot 00$ \\
\hline 5 & 1. 7EaE+01 & & $3.7 E \leq E+00$ & $-2.13 \times E-1$ & $-8.60 \pi-04$ & 9.990:- & $1.000=+\infty 0$ & $1.000 \div+00$ & $1.13=00+\infty$ \\
\hline 5 & 2. $18 \pi+01$ & B. esce-0 & $4.501 E+00$ & $-1.335 \mathrm{x}-01$ & $-3.380 \mathrm{cos}$ & $1.000 E+00$ & $1.0005+00$ & $1.000 E+\infty 0$ & $3.6105-01$ \\
\hline 5 & $2.437 \mathrm{E}+01$ & & 4. 74EE + 00 & $-1.589 \varepsilon-\mathrm{C}_{1}$ & 0 & o. & & o. & o. \\
\hline 6 & & $3.095=0$ & & $-4.0495-01$ & & $E+\infty 0$ & $00=+00$ & {$[-01$} & $=00$ \\
\hline
\end{tabular}




\begin{tabular}{|c|c|c|c|c|c|c|c|c|c|c|c|c|c|c|c|c|c|c|c|}
\hline & $x+0$ & & SALE & & $405 / 79$ & & 1428 & & $13 \mu 4$ & & rate & & & & & & $=100$ & & \\
\hline I & $J$ & & $x$ & & $Y$ & & $u$ & & $v$ & & SIE & & AMO & & MSs & & & & \\
\hline 2 & 6 & 1 & $5 \times+4+00$ & 3 & $056 c+00$ & & $935 x-01$ & 4 & OQIE-OI & 1 & $5+5 x-05$ & 1 & $000<+00$ & 10 & $000<+00$ & 1 & $000 \varepsilon+00$ & 3 & $372 E+00$ \\
\hline 3 & 6 & 3 & $3 x+00$ & 2 & $900 \mathrm{C}+00$ & 3 & $\sec -01$ & 4 & $|3+E-0|$ & -1 & $4 I I E-O S$ & 1 & $000<+00$ & 1 & $000<+00$ & 1 & $000 c \bullet 00$ & 3 & $32 E E+00$ \\
\hline 4 & 6 & 4 & $670 \mathrm{x}+00$ & & $\theta+5 \times 00$ & 6 & $190 \mathrm{E} 01$ & 4 & $2506-01$ & -6 & $5925-05$ & 1 & $00 E+00$ & 1 & $1005+00$ & 1 & $000 c \vdash 00$ & 3 & $278 E+00$ \\
\hline 5 & 6 & 6 & $70 c \cdot 00$ & & $645=00$ & $\mathbf{B}$ & BOAE 01 & -4 & $40 \bar{x}-01$ & -1 & $34 \leq=04$ & 1 & $00 r+00$ & 1 & $100 E+00$ & & $000 \div+00$ & 3 & $151 E+00$ \\
\hline 6 & 6 & 8 & $205 E \cdot 00$ & $\boldsymbol{z}$ & $\pi g=00$ & 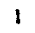 & 21 $2 E+00$ & -4 & $364 E-01$ & -2 & $2995-\infty$ & 1 & $000<\bullet 00$ & 10 & $000 E+00$ & 1 & $000 \Sigma+00$ & & $\therefore=\Sigma+00$ \\
\hline 7 & 6 & 1 & $0325+01$ & & 97SE +00 & & Guer +00 & 4 & $5785-01$ & -5 & $19 e x-04$ & 1 & $000 E+00$ & 1 & $000 c+00$ & $\mathbf{I}$ & $000 c+00$ & & $6005+00$ \\
\hline 8 & 6 & 1 & $3085+01$ & 1 & $4905+00$ & $?$ & $410 \mathrm{C}+00$ & -4 & $5395-01$ & $-\theta$ & $4005-04$ & 1 & $000 \varepsilon+00$ & 1 & $000 \leq+00$ & 1 & $000<+00$ & 2 & $0205+00$ \\
\hline 9 & 6 & 1 & $\operatorname{esec}+01$ & 1 & $152 x+00$ & 3 & $42 \pi[+00$ & -3 & 220E-01 & -7 & $175=04$ & 9 & $\operatorname{gsc}[-01$ & 1 & $100 c+00$ & 1 & $00 E+00$ & $t$ & $13 \times E+00$ \\
\hline 10 & 6 & 2 & $055 x+01$ & 1 & $105 E+00$ & 4 & 27IE+00 & -1 & SSHE-01 & -3 & $3305-05$ & 1 & $00 \varepsilon+00$ & & $00 E+00$ & 1 & & & \\
\hline & 6 & 2 & ose +01 & 1 & $45 \pi+00$ & & $53 \pi+00$ & -1 & $916 x-01$ & 0 & & 0 & & 0 & & 0 & & 0 & \\
\hline 1 & 7 & 0 & & 3 & $753 \mathbf{E} \cdot 00$ & 0 & & 4 & soes -01 & 2 & DOEE-O4 & 1 & $00 \tau+00$ & & ODOE +00 & & $x=01$ & & Q1E+00 \\
\hline 2 & 7 & 1 & $461 E+00$ & 3 & $72 \pi \cdot 00$ & 1 & $\operatorname{eos} \varepsilon-01$ & -4 & $9 \mid E E-01$ & -4 & $500 x-08$ & 1 & $000 \mathrm{0}+00$ & 1 & $000 E+00$ & 1 & $000<+00$ & & Tex +00 \\
\hline 3 & 7 & 2 & $S+1 E+00$ & 3 & $640 E+00$ & 3 & $6095-01$ & -5 & $010 \varepsilon-01$ & -2 & $4805-\cos$ & 1 & $000<\bullet 00$ & 1 & $000 E+00$ & $i$ & $000 \tau+00$ & & $0 x=00$ \\
\hline 4 & 7 & 4 & W6UE +00 & & $490 x+00$ & 5 & $777 \mathbf{E}-01$ & -5 & $101 E-01$ & -3 & $176 x-05$ & 1 & $0<\cdot 00$ & & $000 c+00$ & & $000 t+00$ & & $50=5+00$ \\
\hline 5 & 7 & 6 & $565+00$ & & 27EE $• 00$ & $\mathbf{0}$ & $|5| E-01$ & -5 & $3 e 8=01$ & -1 & $02{ }_{2}-\alpha_{4}$ & 1 & $000 \mathrm{C}+00$ & 1 & $000 \leq+00$ & & $100 E+00$ & & $38+c+00$ \\
\hline 6 & 7 & 7 & $787 E+00$ & & $900 x+00$ & 1 & 1ZZE+00 & -5 & $300 c-01$ & -1 & $481 E-\alpha_{4}$ & 1 & DOOE +00 & 1 & $000 E+00$ & 1 & $000 E \cdot 00$ & & $4005+00$ \\
\hline 7 & 7 & 9 & EEAE +00 & & Seit+00 & 1 & $480 x+00$ & -5 & $429 E-01$ & -3 & $012 \varepsilon-04$ & 1 & $00 x+00$ & 1 & $000 E+00$ & I & $000 \varepsilon+00$ & & $200 x+00$ \\
\hline 8 & 7 & 1 & $210 E+01$ & 1 & $\operatorname{cosc}+00$ & 2 & $120 E+00$ & -5 & Ge:E-01 & -5 & G72E-04 & 1 & $\alpha \varepsilon+00$ & 1 & $00 E+00$ & I & $00=+00$ & 1 & EOIE+00 \\
\hline 9 & 7 & 1 & $c+01$ & 1 & $513 \mathbf{x}+00$ & 3 & OBZE+00 & -4 & $578 x-01$ & -5 & $5+\pi-04$ & 1 & & 1 & $00 x+00$ & & & $i$ & $12 \pi=00$ \\
\hline 10 & 7 & 1 & $911 E+01$ & 1 & $3+4 E+00$ & 3 & $97 e=+00$ & -2 & OIE-OI & -1 & ecest-os & 1 & $\varepsilon+00$ & 1 & $005+00$ & 1 & $x=00$ & 3 & $4005-01$ \\
\hline 1 & 7 & 2 & $9 \varepsilon+01$ & 1 & $0+3 x+00$ & 4 & $285 x+00$ & -2 & $4635-01$ & 0 & & & & & & 0 & & & \\
\hline 1 & 8 & 0 & & 4 & $45 \pi=+00$ & 0 & & -5 & $7+65-01$ & 9 & $15=-05$ & 1 & $x=00$ & & $00 c+00$ & & $x=-01$ & & $30 \mathrm{E}+00$ \\
\hline 2 & $\mathbf{8}$ & 1 & $3932+00$ & & $4285+00$ & 1 & $68 c 5-01$ & 5 & 78+E-01 & -1 & sect-os & 1 & $E+00$ & & $005+00$ & 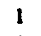 & $0 \Sigma \mapsto 00$ & 1 & $2025+00$ \\
\hline 3 & $\mathbf{\theta}$ & 2 & $E+\infty 0$ & & $3398+00$ & 3 & $393 E-01$ & -5 & Gase-01 & -2 & soce-os & 1 & $c+00$ & & $000 E+00$ & 1 & $x=00$ & 1 & $B+4 E+00$ \\
\hline 4 & $\mathbf{8}$ & 4 & $E+00$ & & $18 x=00$ & 5 & $29 x-01$ & -6 & $0135-01$ & -4 & $\cos 3 x-\cos$ & 1 & $c+\infty 0$ & 1 & $0005+00$ & I & $E+\infty$ & 1 & $33 \Omega+00$ \\
\hline 5 & $\mathbf{8}$ & 5 & $5+00$ & & $9595+00$ & 7 & $419 \Sigma-01$ & -6 & $18 N E-01$ & -6 & $414 E-05$ & 1 & $\varepsilon+\infty$ & & $0 E+00$ & & $c+00$ & & $30=5+00$ \\
\hline 6 & 8 & 7 & $E+D$ & 3 & $\theta+\varepsilon \varepsilon+00$ & 1 & $010 E+00$ & -6 & $45+E-01$ & -9 & 680E-0s & $i$ & & 1 & .00 & & $E+00$ & & $65 \pi+00$ \\
\hline 7 & $\boldsymbol{\theta}$ & 9 & $E+00$ & 3 & $2565+00$ & 1 & $3+\pi \cdot 00$ & -6 & $3905-01$ & -1 & 4eas- $-O_{4}$ & 1 & $: 00$ & & $E+\infty$ & & $E \nrightarrow 00$ & & $6845+00$ \\
\hline B & B & 1 & $9 \varepsilon+01$ & 2 & 6rose + 00 & 1 & $\operatorname{cecc} \cdot 00$ & -6 & $706 E-01$ & -3 & $05 e x-04$ & 1 & $E+\infty 0$ & & $100<+00$ & & $\varepsilon+00$ & 1 & $\sec \varepsilon+00$ \\
\hline 9 & 8 & 1 & $3 z=01$ & 1 & $978 E+00$ & 2 & GHEE+00 & -6 & ISIE-DI & -3 & Sesec-04 & 1 & $E+\infty 0$ & 1 & $000 E+00$ & & $x+\infty 0$ & 1 & $09 \pi+00$ \\
\hline 10 & 8 & 1 & $x+01$ & 1 & 63 & 3 & BOEE +00 & -4 & $181 E-01$ & -5 & elge-06 & & & & & & & 3 & -01 \\
\hline 11 & $\mathbf{a}$ & 1 & $\Sigma+01$ & 1 & $93 x=00$ & 3 & $4 \pi+00$ & -3 & $33 a x-01$ & 0 & & & & & & & & & \\
\hline 1 & 9 & 0 & & 5 & $19 x x+$ & 0 & & -6 & BIsE-01 & 2 & प2ZE-OS & 1 & & & 10 & 1 & 0 & 1 & {$[+\infty 0$} \\
\hline 2 & 9 & 1 & 32Cx+00 & & $10 \times E+0$ & 1 & $x=01$ & -6 & $6+2 E-01$ & -1 & $679 x-05$ & 1 & & & & & & & $\Sigma \bullet 00$ \\
\hline 3 & $\mathbf{g}$ & e & $\pi+00$ & & $07 \overline{x+00}$ & 3 & DENE-01 & -6 & $7385-01$ & -2 & $04+1 E-0 s$ & 1 & $\$ 00$ & & & I & 0 & & $2 z+00$ \\
\hline 4 & 9 & 4 & 2.00 & 4 & $919 x+00$ & 4 & $\pi \mid E-01$ & -6 & $\cos 5-01$ & -2 & $6295-05$ & $i$ & & & & 1 & & 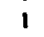 & $1 E+00$ \\
\hline 5 & 9 & 5 & $x+00$ & 4 & OeEs + 00 & 6 & $697 \varepsilon-01$ & -7 & $10 z E-01$ & -3 & $302 x-05$ & 1 & +00 & 1 & $E+00$ & 1 & $000 x+00$ & 1 & $17 \pi \varepsilon+00$ \\
\hline 6 & 9 & 6 & EnIE +00 & 4 & $391 E+00$ & $\mathbf{B}$ & $940 E-01$ & -7 & $30=5-01$ & -4 & $60=0,05$ & 1 & $=\infty 00$ & r & $E+\infty$ & $\mathbf{I}$ & $E+\infty$ & 1 & $171 E+00$ \\
\hline 7 & 9 & $\mathbf{8}$ & 4 & 3 & $9 \pi$ & 1 & $193 x+00$ & -7 & sect -01 & -6 & ssst-os & 1 & 00 & r & & 1 & 10 & 1 & $E+00$ \\
\hline 8 & 9 & $i$ & $x+01$ & 3 & 446 & 1 & $507 E+00$ & -7 & $701 E-01$ & -9 & $30 E-05$ & & & & & & $\therefore+\infty 0$ & 1 & $00=c+00$ \\
\hline 9 & $\mathbf{9}$ & 1 & $2+4 E+01$ & $e$ & $660 c \cdot 00$ & 2 & $205 E+00$ & -7 & $7 E x-01$ & -1 & $\sec =\alpha_{4}$ & . & .00 & & $=00$ & & $:+\infty$ & 9 & $3::=-01$ \\
\hline 10 & 9 & 1 & $577 E+01$ & 1 & 999 & 3 & $171 E+00$ & -6 & $015=-01$ & 5 & $473 x-00$ & 1 & $:+0$ & 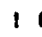 & $\varepsilon \cdot 00$ & 1 & $E+00$ & 3 & e87t-01 \\
\hline 11 & 9 & 1 & $\Sigma+01$ & 2 & $08 N E+00$ & 3 & $x+00$ & -4 & $371 E-01$ & 0 & & 0 & & & & 0 & & 0 & \\
\hline 1 & 10 & 0 & & 5 & GIE +00 & 0 & & -7 & $47 E E-01$ & $\mathbf{B}$ & $7035-$ & 1 & & & & & $\Sigma+00$ & 4 & \\
\hline 2 & 10 & 1 & & 5 & 94 & 1 & -01 & -7 & $510 c-01$ & -6 & $4805-08$ & 1 & & & & & $E+00$ & 4 & $0425-01$ \\
\hline 3 & 10 & 2 & $E+\infty 0$ & 5 & $85 z E+00$ & 2 & $7485-01$ & -7 & BIIE-01 & -7 & $310<-\infty$ & 1 & & & & & $E+\infty 0$ & 4 & $045 c-01$ \\
\hline 4 & 10 & 3 & $78 \pi+00$ & 5 & TOEE $\cdot 00$ & 4 & 245E-01 & -7 & $T$ Thes-01 & $-\theta$ & $5 \cos -\infty$ & 1 & $+\infty$ & 1 & & & $E+\infty 0$ & 4 & 021E-01 \\
\hline 5 & 10 & 5 & $\operatorname{eac}+00$ & 5 & $481 E \cdot 00$ & 5 & $9035-01$ & $-\mathbf{8}$ & ||$E-0 \mid$ & -1 & $000 x-00$ & 1 & & & & & $E+00$ & 4 & OBEc-01 \\
\hline 6 & 10 & 6 & $E+00$ & 5 & 18 NE + C & 7 & 63.0E- & -6 & $z g e x-01$ & -1 & $323-05$ & 1 & 00 & & & 1 & $=00$ & 3 & $0005-01$ \\
\hline 7 & 10 & 7 & $E \cdot 00$ & 4 & $79 \geq \leq 00$ & 1 & $014 E+00$ & -8 & GIEE-01 & -2 & $314 \varepsilon-\infty 5$ & 1 & $E+00$ & 1 & 00 & I & $E+00$ & 4 & $2325-0$ \\
\hline 8 & 10 & 9 & & 4 & $29 \pi+00$ & 1 & $3+6 x+00$ & -8 & eazt-01 & -2 & $1 \pi \pi-0 s$ & & & & & & $\varepsilon+00$ & 3 & $25 \pi-01$ \\
\hline 9 & 10 & 1 & $1008+01$ & 3 & $6+3 E+00$ & 1 & $73: 5+00$ & $-\mathbf{B}$ & $731 E-01$ & -8 & $\sec x-\cos$ & 1 & $E+\infty 0$ & 1 & $E+00$ & 1 & $E+\infty$ & 3 & $E:-01$ \\
\hline 10 & 10 & 1 & $3052+01$ & 2 & Guse $\circ 00$ & 2 & $500 c+00$ & $-\mathbf{8}$ & $245 x-01$ & 9 & $235 t-06$ & 1 & $\varepsilon+00$ & 1 & $000 \varepsilon+00$ & 1 & $x=+00$ & 2 & $5116-01$ \\
\hline 11 & 10 & 1 & $5 \times 98+01$ & 2 & $442 E+00$ & 2 & esecto0 & -6 & GOEE OI & 0 & & & & 0 & & 0 & & 0 & \\
\hline 1 & 11 & 0 & & 6 & $70 z e+00$ & 0 & & $-\theta$ & $335 x-01$ & 0 & & & & 0 & & 0 & & 0 & \\
\hline 2 & 11 & 1 & $216 E+00$ & 6 & $7532+00$ & 1 & $2705-01$ & -8 & $3705-01$ & 0 & & & & 0 & & 0 & & 0 & \\
\hline
\end{tabular}




\begin{tabular}{|c|c|c|c|c|c|c|c|c|c|c|}
\hline & 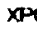 & RT - SALE & $04 / 06 / 79$ & $14 \cdot 29: 1$ & T3AA & SLUP. & E LACRAM & $N W^{\prime}$ INC=1 & $450-100$ & $040879-3$ \\
\hline 1 & $J$ & $x$ & $r$ & $\mathrm{u}$ & V & SIE & Fito & mass & va & $\mathbf{P}$ \\
\hline 3 & 11 & $2.43 \pi+00$ & $6.65 \pi 5+00$ & $2.5795-01$ & $-0.4935-01$ & o. & 0 . & D. & 0. & 0 . \\
\hline 4 & 11 & $3.671 E+00$ & $6.510 E+00$ & $3.978 x-01$ & $-8 \cdot \sec :-01$ & 0. & 0. & 0. & 0. & 0. \\
\hline 5 & 11 & 4.923K $\bullet 00$ & $6.200 \varepsilon+00$ & $3.501 E-01$ & $-8.9 S \mid E-01$ & 0. & 0 . & 0. & 0. & 0 . \\
\hline 6 & 11 & $6.20 \pi+00$ & $5.92 a c+00$ & 7. $28 \pi-01$ & $-9.3358-01$ & 0. & 0. & 0. & 0. & 0. \\
\hline 7 & 11 & $7.530 \mathrm{~F} \bullet 00$ & $5.605 x+00$ & 9.2sec-01 & $-9.63+6-01$ & 0. & 0 . & D. & 0. & 0 . \\
\hline $\boldsymbol{B}$ & 11 & $0.551 E \cdot 00$ & $5070 x+00$ & $1.230 t+00$ & $-1.035 x+00$ & 0. & 0. & 0. & 0. & 0 \\
\hline 9 & 11 & $1.044 E+01$ & 4. $326 x+00$ & $1.5532+00$ & $-1.00 \pi+00$ & 0. & 0. & 0 . & 0. & 0. \\
\hline 10 & 11 & $1.2582+01$ & $3.373 x+00$ & 2. 32EE+00 & $-1.04 z E+00$ & 0. & 0. & 0. & 0. & 0. \\
\hline 11 & 11 & $1.450 \%+01$ & $3.0395+00$ & 2.635x+00 & $-8.142 E-01$ & 0. & 0 & o. & 0. & 0 . \\
\hline
\end{tabular}

T= 5.02599E.00 crCLE 71 ior E- 2.5729452\%+02 SIE--2.93271763E-02

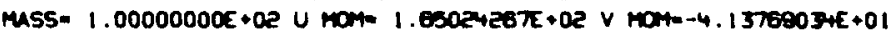

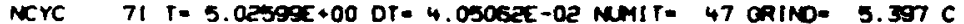

NCYC $72 T=5.060495+00$ DT $=4.03400 \mathrm{C}-02$ MMIT $=47$ GRINO= $2.063 \mathrm{C}$

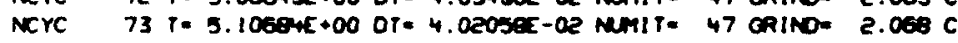

NCYC 74 T $=5.14705 E+00$ OT $=4.0070$ E-02 MMIT = 46 CAINO- $2.016 \mathrm{C}$

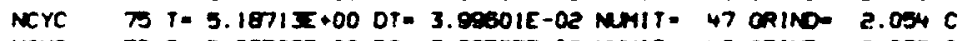

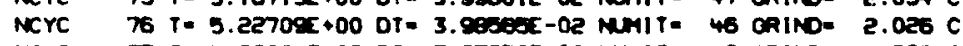

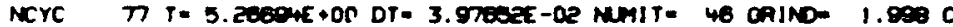

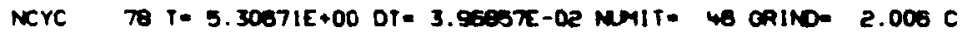

NCYC 79 T- $5.346392+00$ DT- 3.5E17EE-02 MUIT- 45 CAIND- $1.980 \mathrm{C}$

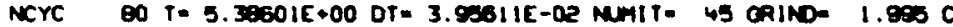

NCYC $\quad 1 T=5.4255 \pi+00$ DT $=3.95152 E-02$ MEMIT- 45 CAIND $1.977 \mathrm{C}$

NCYC Q2 To $5.465005-00$ DT- 3.94600E-02 NMIT= 44 CAIND $1.828 \mathrm{C}$

NCYC $83 \mathrm{~T}=5.5045 \pi+00$ OT= 3.945JIE-02 NMIT = 44 CAIND= 1.922

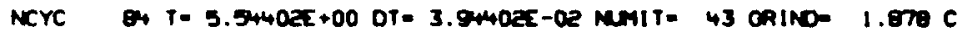

NCYC ES T- $5.503465+00$ DT - 3.9435IE-02 MMIT- 43 CAIND $1.677 \mathrm{C}$

NCYC $83 T=5.622905+00$ OT $=3.943805-02$ NMIT 42 GRINO- $1.843 \mathrm{C}$

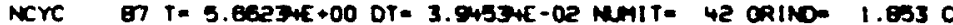

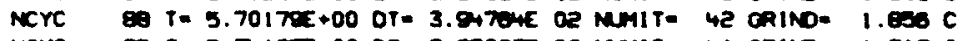

NCYC $69 T=5.74127=00$ DT- 3.950035-02 MMIT- 41 CRIND $1.613 \mathrm{C}$

NCYC 90 T. $5.7007 \pi+00$ OT $3.99490 \mathrm{~L}-02$ MMIT 40 GRIND $1.770 \mathrm{C}$

NCYC 91 T $=5.8203 E E+00$ OT- 3.959azE-02 MMIT = 41 CRINO $1.819 \mathrm{C}$

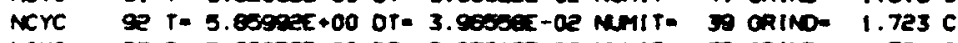

NCYC 93 T $5.899085+00$ DT $3.972165-02$ MMIT. 39 CRINO $1.724 C$

NCYC S4 T= $5.939302+00$ OT $=3.97908-02$ NMIT- 39 CRIND= $1.729 \mathrm{C}$

NCYC SS $T=5.97910 E+00$ DT $=3.9979 E-02$ MMIT $=37$ CAIND- $1.630 \mathrm{C}$ 